\title{
MITIGATION TRANSLOCATION FOR CONSERVATION OF NEW ZEALAND SKINKS
}

\section{OX LENNON}

\author{
A thesis \\ submitted to the Victoria University of Wellington \\ in fulfilment of the requirements for the degree of \\ Doctor of Philosophy
}

Victoria University of Wellington 2019 





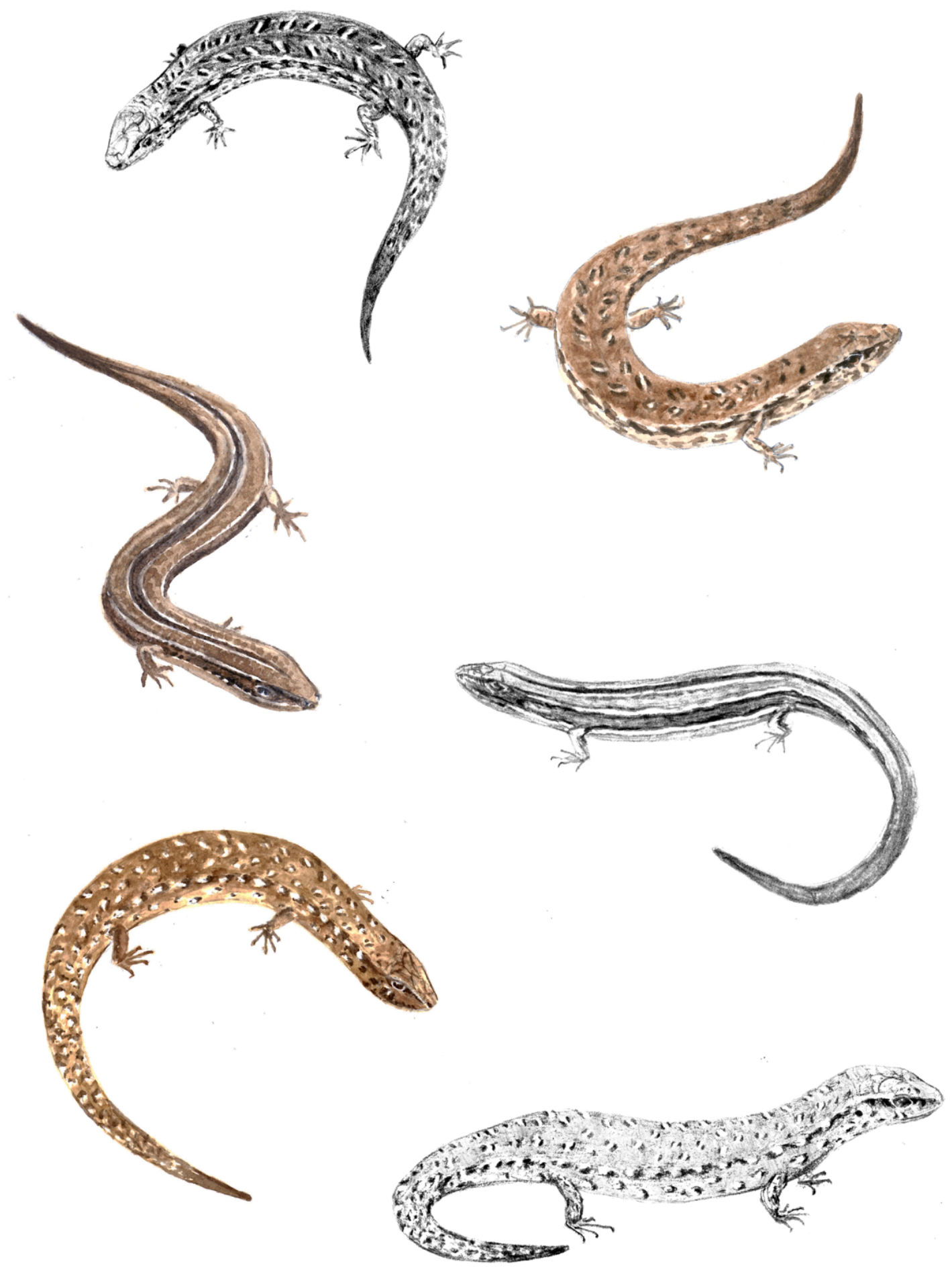

Three endemic New Zealand skink species. Top row: copper skinks, Oligosoma aeneum. Middle row: northern grass skinks, O. polychroma. Bottom row: ornate skinks, O. ornatum. (C) Kezia Fairbrother. 


\section{ACKNOWLEDGEMENTS}

This $\mathrm{PhD}$ wouldn't have been possible without the support of many people who helped me along the way. Firstly, my supervisors, Nicky Nelson and Heiko Wittmer. I think the best thing a student can hope for from a supervisor is that they feel less stressed after talking to them than they did before, and you've both given me that.

Thanks to those who helped me with data, photos, discussed concepts with me, or taught me field skills: Marieke Lettink, Hermann Frank, Rod Hitchmough, Carrol Bannock, Lynn Adams, Andre Geldenhuis, Richard Romijn, and Laurence Barea. Also to Riley Edwards and Andrea Wilson, who helped me check pitfall traps every day even when there were no lizards in sight. Thanks to Aimee Culverhouse and Stacey Parbhu for your lab expertise, and Rhiannon Leddra for your help with field work. Thank you to Jen Germano, Phil Lester, and Richard Griffiths for reading my thesis and for your helpful feedback.

To Boffa Miskell and CPB/HEB who allowed me to experiment with their translocation and made this thesis possible. To those from both organisations who supported me, taught me, drove me around, and helped me with field work: Reuben Mills, Tony Payne, Arianna Jones, and Kory Wright from Transmission Gully; and Karin Sievwright, Kat Muchna, Linda Kerkmeester, Mel Brown, and Stephen Fuller from Boffa Miskell. To the staff from Ngā Manu who let me work with the animals they stewarded: Matu Booth, Rhys Ward, and Scott Pearson. I'm especially grateful to the labourers who tipped out 64 piles of rocks and dug 200 holes.

Thanks to Chris Wedding, Simon Chapman, and Dave Craddock for being so generous with your data and allowing me to revisit your translocations, and for your input into the long-term chapter. Thanks to those landowners and residents who let me dig holes in their properties, and to Shakespear Open Sanctuary Incorporated for allowing me access. Thanks to Ngāti Toa, Te Ati Awa ki Whakarongotai and Ngāti Manuhiri for trusting me with their tipuna.

Thanks to my office mates and colleagues; Patty Ramírez, Vaughn Stenhouse, Ellen Irwin, Steph Price, Anna Carter, Chris Woolley, Sarah Herbert, Brittany Florence- 
Bennett, Linlin Liu, Sydney Dean, Douglas Rands, and Florence Kelly. And to Jana Dobelmann, Evan Brenton-Rule, and Jess Russell; it was great sharing an office with you (while we still had one). Thanks to Sue Keall for your help and support and for your ability to spot the tiniest of typos. Thanks to Phil Lennon, Finn Teppett, Freya Daly Sadgrove, Tom Wilson, and Frank Wills for their proofreading help.

Thanks to my family: Yvonne, Phil, Rosemary and Josephine. I wouldn't be where I am today without your love and support over the past 27 years. Also thanks to the two new brothers-in-law I gained over the course of this PhD, Asad and Shane. Thanks to Eddie Crawshaw for being such a kind, generous, and supportive partner and for digging so many holes. Thanks to Frank Wills for your friendship and support. Thanks to Mike Crawshaw for giving me a place to stay and company while I hunted skinks in Auckland. Thanks to Kezia Fairbrother for drawing such an excellent diagram and beautiful skinks. 
ABSTRACT

Worldwide, human development is leading to the expansion and intensification of land use, with increasing encroachment on natural habitats. A rising awareness of the deleterious effects of habitat destruction on species and ecosystems has increased the use of strategies intended to mitigate these negative impacts. One increasingly common strategy is mitigation translocation, the movement of living organisms from a future development site to another location in an effort to mitigate damage caused. Mitigation translocations may be implemented due to legislation or regulations in many jurisdictions, and in many instances command more resources than purely conservation-motivated translocations. Although they are intended to reduce or offset harm, the effectiveness of mitigation translocations as a conservation strategy has been questioned.

I investigated the effectiveness of mitigation translocations for achieving conservation outcomes, using the study system of endemic New Zealand skinks. New Zealand's skinks show a high level of endemism, are threatened by habitat loss and predation by introduced mammals, and are increasingly subject to mitigation translocations, making them an ideal study system for investigating mitigation outcomes. I investigated: whether mitigation translocations are meeting conservation goals; how the implementation and legal requirements of mitigation translocation relate to conservation goals; and how mitigation translocation practices might be improved to achieve better conservation outcomes.

A technique used in mitigation translocations of lizards in New Zealand is the construction of rock piles as habitat enhancement at the receiving site. I developed a novel use of computer game physics software to model the three-dimensional interstitial spaces within such rock piles, and used this model to design rock piles with the aim of protecting translocated skinks from mice (Mus musculus), New Zealand's smallest introduced mammalian predator. The protection is achieved by selecting rocks to optimise the size of interstitial spaces to be accessible to skinks but not to the larger mice (or other larger predators). This rock pile design could be used to improve survival of skinks both in translocations and other situations such as backyard conservation or 
restoration. The modelling technique I developed could be used for investigation of refuge space more widely, for instance in other terrestrial systems or aquatic systems. I also took part in a mitigation translocation of lizards at Transmission Gully near Wellington, New Zealand. I used this translocation to test my rock pile design, and as a case study of the challenges facing mitigation translocations and the barriers to conservation success. In addition, I revisited nine historical mitigation translocations of skinks (7-14 years post translocation), took surveys of current populations to assess their success at meeting conservation goals, and found a success rate of $22 \%$, considerably lower than conservation translocations of New Zealand skinks (success rate of $88.9 \%$ ). Despite this, all but one met their goals of fulfilling legislative requirements.

Mitigation translocations fail to result in conservation benefit due to their implementation and goals. The goals of mitigation translocations are rooted in legislation, and vary due to inconsistent application of relevant laws (in New Zealand, the Wildlife Act 1953 and the Resource Management Act 1991), and the fact that the requirements under these laws do not necessarily reflect conservation goals. Additionally, mitigation translocations may be undertaken even when evidence indicates that meaningful conservation outcomes are unlikely (as in the case of the translocation at Transmission Gully). Failure may also be due to poor implementation; examples from case studies here include failure to control predators, low standards of planting at receptor sites, and small founder populations. To improve conservation outcomes, legal requirements for mitigation translocations should be implemented to require biologically-relevant goals (including a no net loss of biodiversity standard) and management techniques, and alternative methods of meeting conservation goals should be considered where appropriate. 


\section{TABLE OF CONTENTS}

ACKNOWLEDGEMENTS..............................................................................................................................II

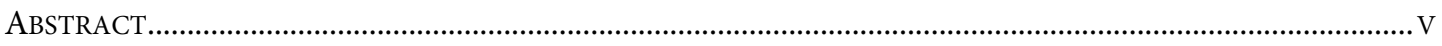

CHAPTER 1. MITIGATION TRANSLOCATIONS AND THEIR CONSERVATION CONTEXT ......................................

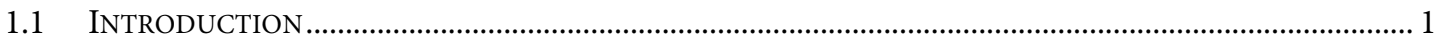

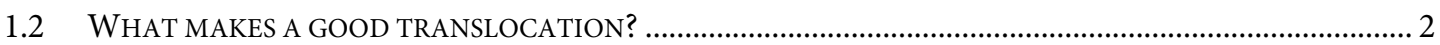

1.2.1 Different kinds of translocations have different goals ..............................................................

1.2.2 Translocation best practices ...................................................................................................

1.2.3 Evaluating translocation success, monitoring, and reporting ................................................

1.3 THE SCOPE OF TRANSLOCATIONS WORLDWIDE ...............................................................................

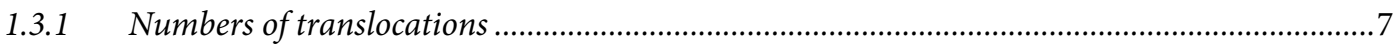

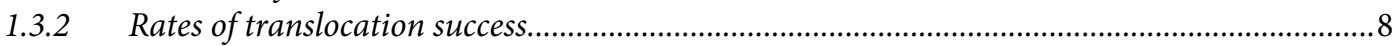

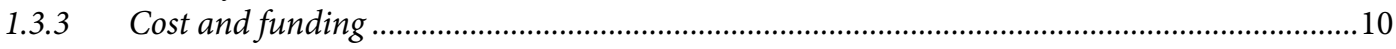

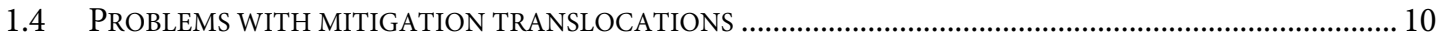

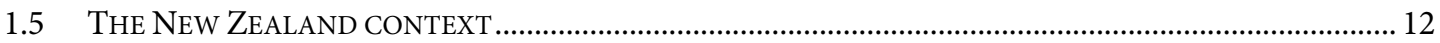

1.5.1 Legal basis for conservation and translocations in New Zealand..........................................14

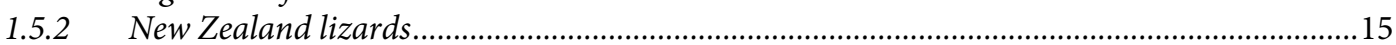

1.5.3 Translocation of lizards in New Zealand..............................................................................

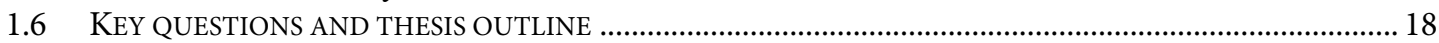

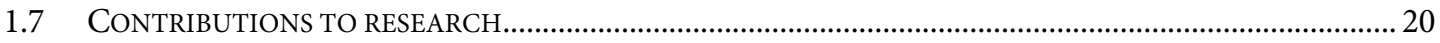

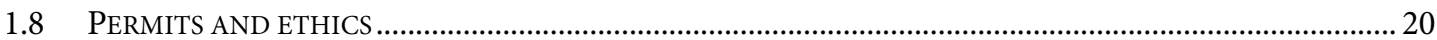

CHAPTER 2. MODELLING THREE-DIMENSIONAL REFUGE SPACE TO PREDICT ACCESSIBILITY USING VIDEO GAME SOFTWARE .......................................................................................................................................

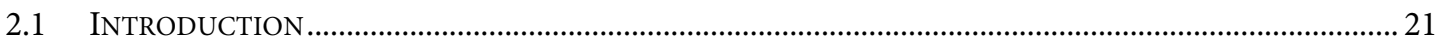

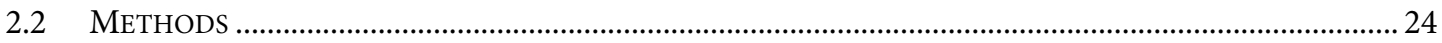

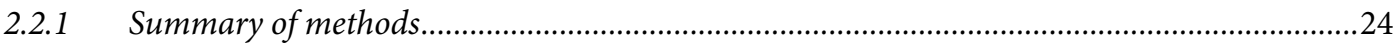

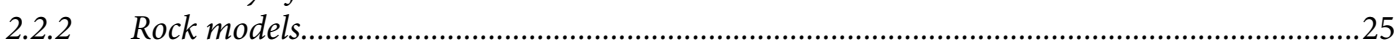

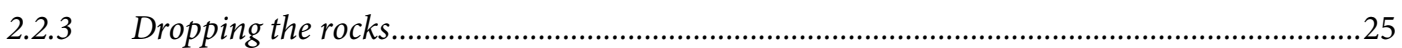

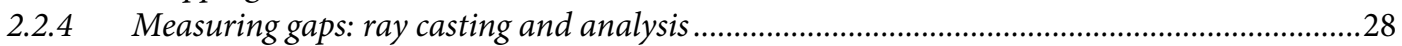

2.2.5 Classifying gaps: 'small', 'optimum', or 'large' .........................................................................29

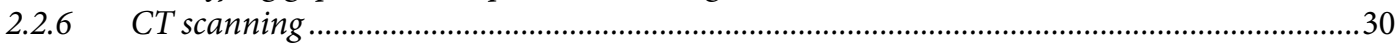

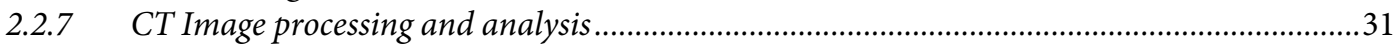

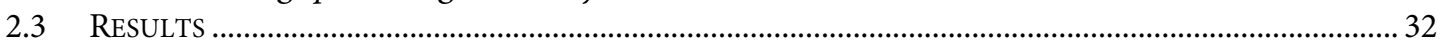

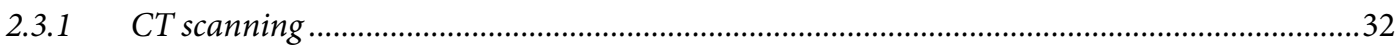

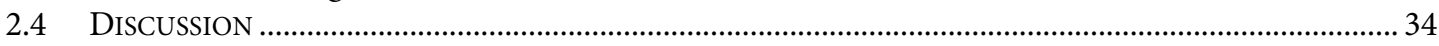

CHAPTER 3. CAN ROCK PILES BE DESIGNED TO PROTECT ENDEMIC SKINKS (SCINCIDAE) FROM INTRODUCED MICE (MUS MUSCULUS)? …………………………………………………………………….....

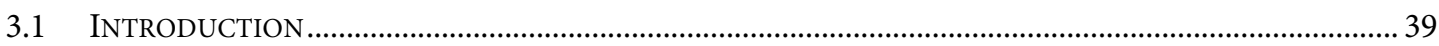

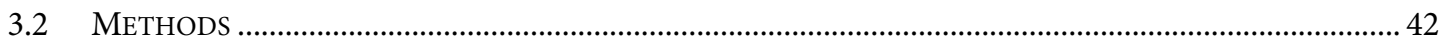

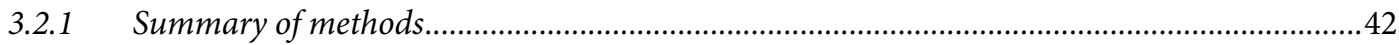

3.2.2 Study species

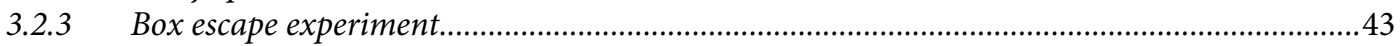

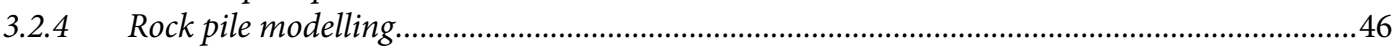

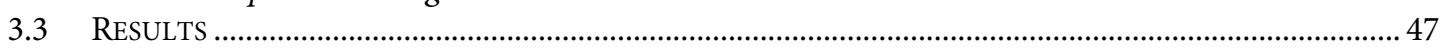

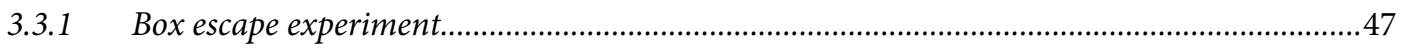

3.3.2 Rock pile modelling.....................................................................................................51

3.4 DISCUSSION …………………………………………………………………………………... 52

CHAPTER 4. CREATING ARTIFICIAL HABITAT TO PROTECT ENDEMIC SKINKS (SCINCIDAE) FROM INTRODUCED MICE (MUS MUSCULUS) FOLLOWING A MITIGATION TRANSLOCATION..................................59

$4.1 \quad$ INTRODUCTION......................................................................................................................... 59 


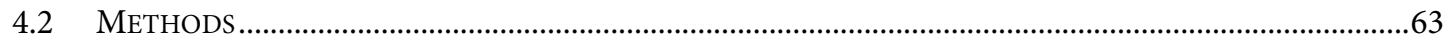

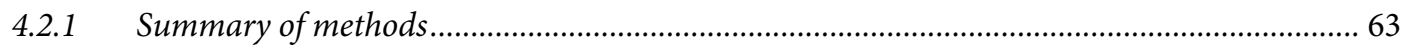

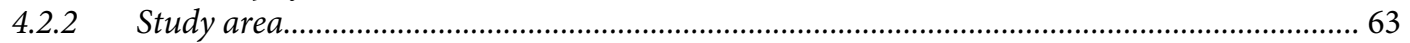

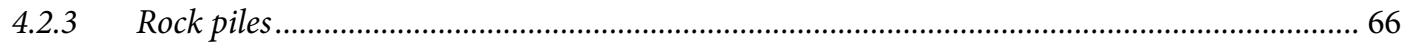

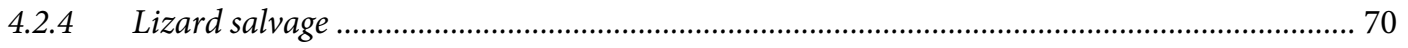

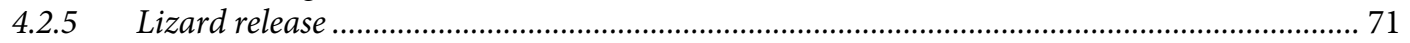

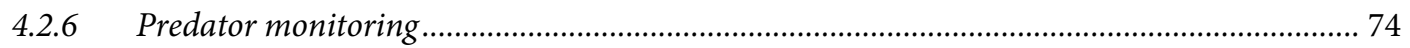

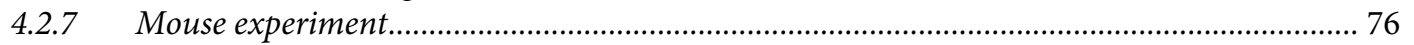

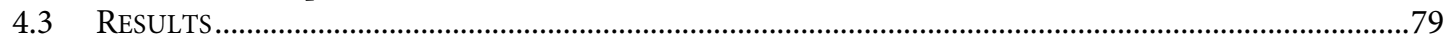

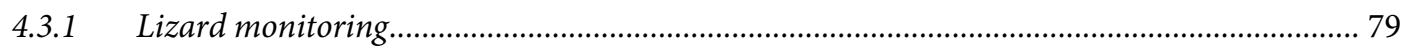

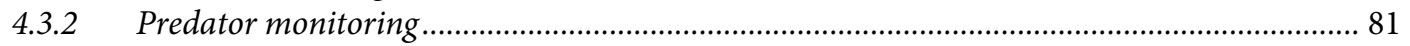

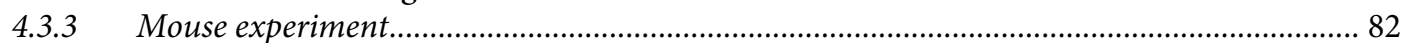

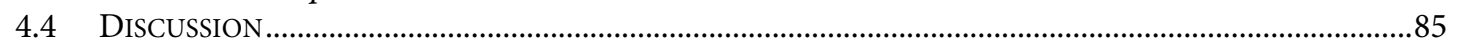

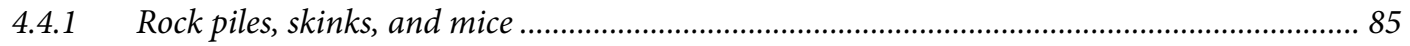

4.4.2 The effectiveness of mitigation translocations for conservation.............................................. 89

CHAPTER 5. REVISITING MITIGATION TRANSLOCATIONS OF ENDEMIC NEW ZEALAND SKINKS

(SCINCIDAE) SHOWS LOW SUCCESS RATES.................................................................................................................

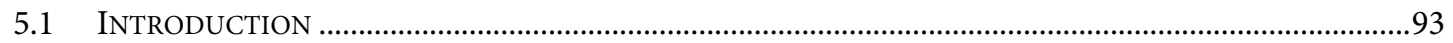

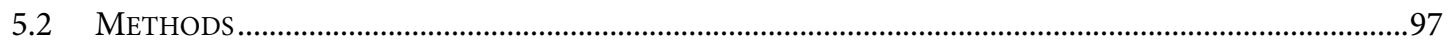

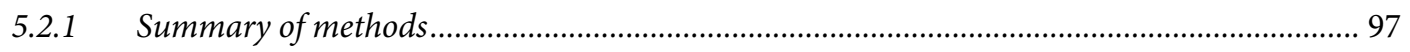

5.2.2 Translocations, previous monitoring, and revisits by site .................................................... 100

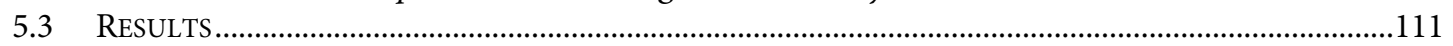

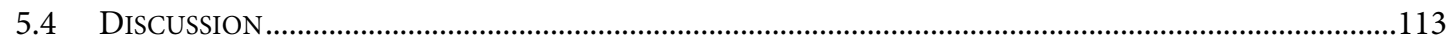

CHAPTER 6. IMPROVING MITIGATION TRANSLOCATIONS FOR CONSERVATION OF NEW ZEALAND

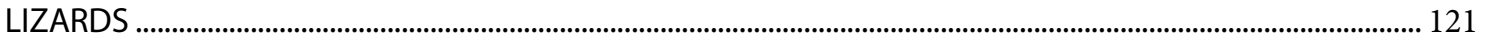

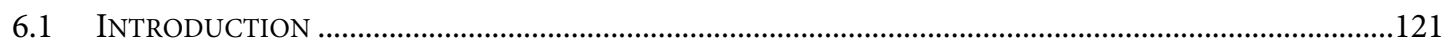

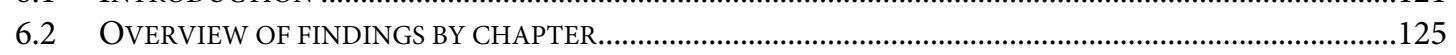

6.2.1 Chapter 2: Modelling three-dimensional refuge space to predict accessibility using video game software...................................................................................................... 125

6.2.2 Chapter 3: Can rock piles be designed to protect endemic skinks (Scincidae) from introduced mice (Mus musculus)? .................................................................................... 125

6.2.3 Chapter 4: Creating artificial habitat to protect endemic skinks (Scincidae) from introduced mice (Mus musculus) following a mitigation translocation............................... 125

6.2.4 Chapter 5: Revisiting mitigation translocations of endemic New Zealand skinks (Scincidae) shows low success rates............................................................................. 126

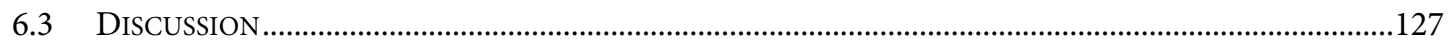

6.3.1 Are mitigation translocations meeting legal requirements?................................................ 127

6.3.2 Are mitigation translocations meeting conservation goals?................................................... 128

6.3.3 Why are mitigation translocations less successful at meeting conservation goals?............... 130

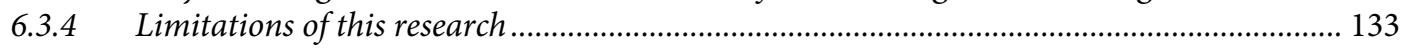

6.4 RECOMMENDATIONS FOR MITIGATION TRANSLOCATIONS ...............................................................134

6.4.1 Recommendation 1: Improve legal and regulatory structures underpinning mitigation

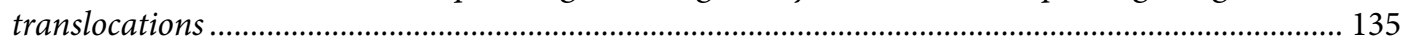

6.4.2 Recommendation 2: Mitigation translocations should be conservation translocations....... 137

6.4.3 Recommendation 3: Do not rely on mitigation translocations .............................................. 138

6.4.4 Recommendation 4: Improve mitigation translocation practices........................................... 140

6.5 FUTURE RESEARCH DIRECTIONS ....................................................................................................141

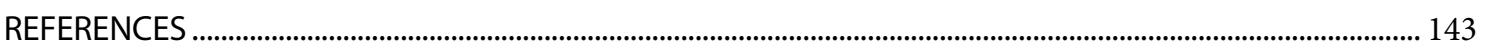

APPENDIX 1. SCRIPTS AND USER INSTRUCTIONS FOR GENERATING AND MEASURING ROCK PILES IN UNITY 


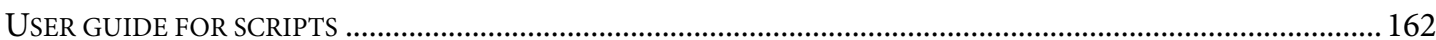

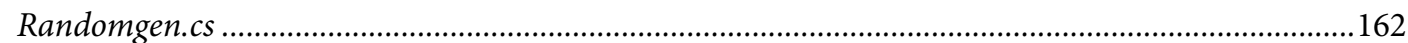

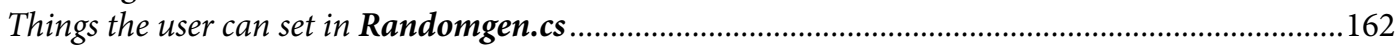

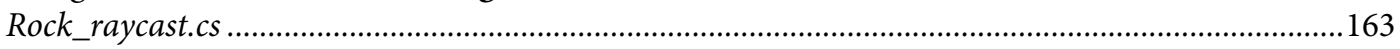

Things the user can set in Rock_raycast.cs....................................................................................164

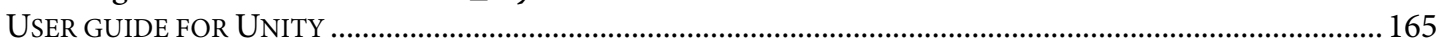

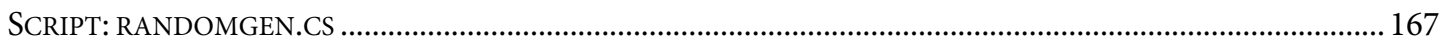

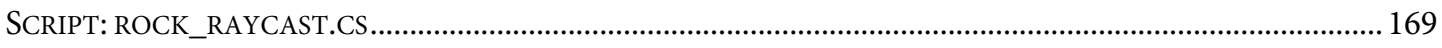

APPENDIX 2. R SCRIPT FOR PROCESSING GAP SIZE INFORMATION FROM UNITY ........................................ 173 


\section{CHAPTER 1}

\section{Mitigation translocations and their conservation context}

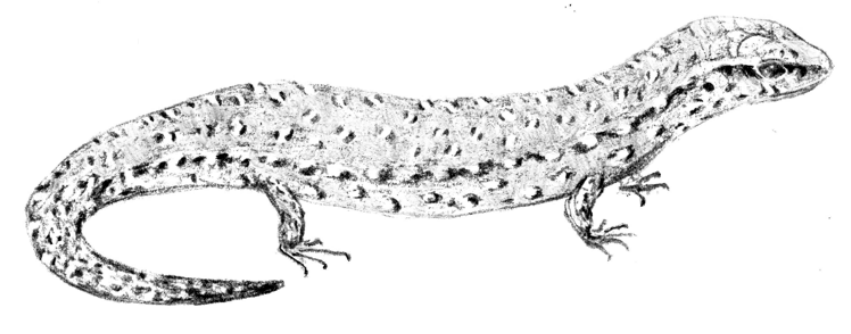

\section{$1.1 \quad$ INTRODUCTION}

As world population growth continues to accelerate, increasing and intensifying land use leads inevitably to encroachment on already diminished habitats. Where once there was little consideration for the welfare of the natural world, there is now increasing awareness of the irreversible damage already done, and the resulting worldwide effects (Seddon et al. 2007). There is growing public and political desire to find a balance between the two sides; the demand for more land-consuming developments, and the desire to limit the damage this causes to ecosystems and the environment (Craig et al. 2000). One increasingly common strategy for reducing damage is the use of mitigation translocations (Seddon et al. 2007; Miller et al. 2014).

Mitigation translocations are the movement of organisms from a future development site to another location in an effort to mitigate damage caused (International Union for the Conservation of Nature/Species Survival Commission 
[IUCN/SSC] 2013). Although this strategy is intended to reduce harm, there are currently inconsistencies and gaps in the theoretical underpinnings, scientific understanding, and implementation of the technique (Dodd \& Seigel 1991; Seddon et al. 2007; Germano et al. 2015). In many countries, mitigation translocations are both more numerous and better funded than conservation- or research-focused translocation programmes (Germano et al. 2015). However, mitigation translocations are less likely to be adequately monitored or reported on, with one review finding only $10 \%$ of mitigation translocations in New Zealand were published in the scientific literature (Miller et al. 2014). As mitigation translocations grow in number and scope, there are calls for the improvement of outcomes via the development of and adherence to effective protocols (Fischer \& Lindenmayer 2000; Edgar et al. 2005; Seddon et al. 2007; Massei et al. 2010; Ewen et al. 2014; Germano et al. 2015; Sullivan et al. 2015).

\subsection{WHAT MAKES A GOOD TRANSLOCATION?}

\subsubsection{Different kinds of translocations have different goals}

Translocation is the human mediated movement of organisms from one area to another for release (IUCN/SSC 2013). Within this overarching term, there are more precise categories to describe different kinds of translocations. Broadly, translocations can be defined based on their primary motivation; this may be conservation, research, or mitigation. A final category is commercial or recreational translocations, which differ from the other three types of translocations as they are driven by human interests rather than being for the benefit of the translocated species.

Conservation translocations are intended to yield conservation benefit at the population, ecosystem, or species level, not merely at the level of individuals (IUCN/SSC 2013). These can range from the intensive management of the critically endangered kākāpō (Strigops habroptilus), moving individuals between populations to improve breeding prospects (Elliott et al. 2007), to the harvest and release of thousands of eggs of the threatened whitefish powan (Coregonus clupeoides; Maitland \& Lyle 1992). The establishment of a viable, self-sustaining population, or improvement of conservation status of a species locally or globally, is generally considered to be an appropriate end 
goal for conservation translocations (Dodd \& Seigel 1991; Germano \& Bishop 2009; IUCN/SSC 2013; Ewen et al. 2014; Miller et al. 2014).

Research translocations employ an experimental approach to test hypotheses about the translocation process (Seddon et al. 2007). 'Least concern' species may be used as experimental surrogates to determine the best management strategy for threatened species; as in a study using the common raven (Corvus corax) as a stand-in for the endangered Hawaiian crow (C. hawaiiensis) and Mariana crow (C. kubaryi) (Valutis \& Marzluff 1999). Research translocations generally have different goals depending on their hypotheses, although they may also incorporate a conservation goal or goals (Seddon et al. 2007).

Mitigation translocations are intended to mitigate damage caused by human activities such as land development, and are generally undertaken to fulfil legal or regulatory obligations (Germano et al. 2015). Mitigation translocations may also be motivated by a desire to reduce human-wildlife conflict, for instance by removing an animal causing a nuisance in an urban environment (Massei et al. 2010). Because goals for mitigation translocations are determined based on regulatory processes as well as other factors such as ecological and logistical considerations, goals of mitigation translocations are generally more variable compared with the other two categories of translocations. Goals may be presented in terms such as observed reproduction (Kyek et al. 2007) or simple counts of adults at receptor sites (Edgar et al. 2005). As mitigation translocations are generally undertaken due to legislation, their primary goal can be inferred to be to fulfil legal requirements. In some instances, the goal may be merely to prevent deaths of animals near human developments, without regard to the continued health of the individual, population, species, or ecosystem (Platenberg \& Griffiths 1999; Massei et al. 2010; Germano et al. 2015).

Translocations can be further classified based on the type of release site. Firstly, species can either be translocated within their indigenous range, known as population restoration, or outside of their indigenous range, known as conservation introduction (IUCN/SSC 2013). There are further divisions within these broader categories. Within population restorations, translocations can be reintroduction, the release of an organism 
into an area from which it has been extirpated, or reinforcement (aka supplementation), the release of an organism into an existing population of conspecifics (IUCN/SSC 2013). Within conservation introductions, translocations can be assisted colonisation, where organisms are released outside of their indigenous range to prevent species extinction, or ecological replacement, where organisms are released outside of their range to perform a specific ecosystem function (IUCN/SSC 2013). Seddon (2010) also described a third category within assisted colonisation: community construction, or the development of designed, novel ecosystems with a conservation purpose.

While translocations can be defined based on their main motivation and methods, in reality many translocations overlap the various categories. A conservation or mitigation translocation may include an experimental research component (Ebrahimi \& Bull 2014; McCoy et al. 2014), or retrospective analysis (van Heezik et al. 2009). Various types of release sites may be used in the same project (Kyek et al. 2007). The use of adaptive management techniques may mean that goals or techniques evolve as a project progresses (Miller et al. 2014). The establishment of a viable population, or improvement of conservation status of a species locally or globally, represents a successful conservation outcome, whether it occurs as a result of a conservation, research, or mitigation translocation (IUCN/SSC 2013; Miller et al. 2014).

\subsubsection{Translocation best practices}

The particulars of translocation methods will vary with different factors, including the motivation for translocation and the species, populations, and locations involved. However, some aspects are common to successful translocations. Guidelines published by the IUCN detail general principles of best practice for conservation translocations (IUCN/SSC 2013). The guidelines emphasize the need to consider the alternatives to translocation, and to plan translocations carefully, incorporating exit strategies and adaptive management (IUCN/SSC 2013). Tactics from the IUCN guidelines were further developed by Batson et al. (2015).

In order for a translocation to succeed, one of the most important factors is identifying the agent of decline and controlling or eradicating it at the release site to 
ensure the health of the translocated population (Dodd \& Seigel 1991). Careful selection of the founder populations to have appropriate size, demographics, and genetic makeup is also important for translocation success (Griffith et al. 1989; Dodd \& Seigel 1991; Sullivan et al. 2015). Selection of the release site is also important, and interactions with resident communities as well as the availability of habitat for the released population into the future must be considered, including suitability for different life stages and for seasonal habitat use (Armstrong \& McLean 1995; IUCN/SSC 2013). Habitat enhancement is sometimes used at release sites to improve survival, health, or recruitment of the translocated population, and may also be used in the case of mitigation translocations to compensate for habitat destroyed during development (Armstrong \& McLean 1995; Kyek et al. 2007). Understanding the ecology of the species involved in the translocation is important, and techniques should be adjusted for different situations; for instance, translocations of reptile species which have a tendency to disperse after release may benefit from a 'soft release' strategy, restricting the movement of the translocated animals at the release site for a time (Knox \& Monks 2014).

Despite the existence of numerous guides in the literature outlining best practices for translocations (e.g. Armstrong \& McLean 1995; IUCN/SSC 2013; Batson et al. 2015), most translocation projects do not address all the criteria recommended to ensure success (Pérez et al. 2012). Failed translocations can have negative impacts beyond simply wasted effort and resources. They can also reduce viability of the source population through removal of individuals, or cause negative effects at the release site, for instance through transmission of diseases, outbreeding depression, overcrowding, or other unintended ecological impacts on resident communities (Pérez et al. 2012; Sullivan et al. 2015).

\subsubsection{Evaluating translocation success, monitoring, and reporting}

In order to evaluate the success of translocations, the goals of the translocation and indicators of success must be identified, defined, and measured, beginning at the planning stage. These goals and indicators will vary depending on the type of 
translocation being undertaken. Post-release monitoring is important both for determining translocation success and for managing populations after release to improve outcomes. Monitoring data can be used to adjust objectives, inform adaptive management, and determine when to activate exit strategies (IUCN/SSC 2013; Germano et al. 2014). Reporting results of monitoring is crucial to informing and improving future projects (IUCN/SSC 2013; Miller et al. 2014; Germano et al. 2015).

There are currently no broadly-accepted standard success indicators for translocations (Fischer \& Lindenmayer 2000; Sutherland et al. 2010; Robert et al. 2015). Lack of common standards makes assessment of translocation success, and comparison between translocations, more difficult and less clear (Sutherland et al. 2010). Reviews of translocation success tend to use success indicators that relate to the common conservation objective of the establishment of a viable population (Fischer \& Lindenmayer 2000; Griffiths \& Pavajeau 2008; Germano \& Bishop 2009; Ewen et al. 2014; Miller et al. 2014); however, reports on individual translocations may use a variety of different indicators (Ewen et al. 2014). Use of inappropriate success indicators may artificially inflate success rates (Gregory et al. 2012; Ewen et al. 2014). To aid translocation managers in identifying objectives and success indicators, the use of a formal structured decision-making process has been recommended (Sutherland et al. 2010; IUCN/SSC 2013; Ewen et al. 2014).

Translocation success is liable to change over time post release, and assessments of success can only be considered accurate for the time at which the assessment was made (Wolf et al. 1996; Seddon 1999). A review found that, when reassessed after six years, $38 \%$ of translocations had a different outcome than was initially reported (Wolf et al. 1996). These changes in reported outcomes may be because factors associated with low rates of early translocation failure are different from factors associated with longerterm persistence (Robert et al. 2015). These differences may have important implications for management; in a translocation of the critically endangered kaki (Himantopus novaezelandiae), long-term monitoring led to different, more accurate conclusions and management recommendations than would have been produced had only short-term monitoring taken place (van Heezik et al. 2009). Monitoring must 
therefore occur over both the short and long terms; short-term monitoring allows for adaptive management and provides a snapshot view of the success of a project, while long-term monitoring is needed to determine ultimate success or failure (Germano \& Bishop 2009; IUCN/SSC 2013). It is generally accepted that post-release monitoring must continue for an appropriate length of time based on life history traits; this may mean decades of monitoring for long-lived species (Dodd \& Seigel 1991; IUCN/SSC 2013; Robert et al. 2015). Miller et al. (2014) recommend the use of definitions of success standardised by the time elapsed since translocation. This would allow for reassessment of success using changing criteria as populations change following translocation. Evidence also suggests that such an approach can account for publication bias (Miller et al. 2014).

Translocation science cannot improve without documentation and publication of translocation projects. Unsuccessful, as well as successful, translocations need to be published in order for the field to move forward and learn from mistakes (Dodd \& Seigel 1991; Germano \& Bishop 2009; IUCN/SSC 2013; Miller et al. 2014). Both the IUCN/SSC (2013) guidelines and more in-depth policy standards suggested by Sutherland et al. (2010) recommend that reporting and dissemination of information should begin with the intention to translocate and continue throughout the process. Bajomi et al. (2010) suggest that a way to improve publication rates would be for funding bodies to require publishing as a condition of funding.

\subsection{THE SCOPE OF TRANSLOCATIONS WORLDWIDE}

\subsubsection{Numbers of translocations}

Scientific publications of translocations were scarce prior to 1960, but since then there has been an increase both in the number of translocations published and the size of the operations (Wolf et al. 1996; Seddon et al. 2007; Bajomi et al. 2010; IUCN/SSC 2013; Miller et al. 2014). It is difficult, however, to determine exactly how many translocations are occurring worldwide. Although several investigations have examined trends in translocations, these are generally restricted to scientific literature and/or survey responses; they often cannot thoroughly capture data from grey literature (Fischer \& 
Lindenmayer 2000; Griffiths \& Pavajeau 2008; Germano \& Bishop 2009; Ewen et al. 2014; Miller et al. 2014). Lack of access to grey literature and unpublished reports prevents conservation scientists from gaining a more comprehensive overview of translocation numbers and practices (Miller et al. 2014).

Griffith et al. (1989) estimated that 700 translocations were occurring per year in the late 1980s across the United States, Canada, Australia and New Zealand. Estimates for New Zealand include over 400 conservation translocations in New Zealand up to 1995 (Armstrong \& McLean 1995), and 1,100 conservation translocations of birds between 1863 and 2012 (Miskelly \& Powlesland 2013). There may be many more mitigation translocations being undertaken than this, as mitigation translocations have been increasing in scope since the 1980s and now exceed conservation translocations for many taxa (Miller et al. 2014). In England, a single species (great crested newt, Triturus cristatus) was involved in over 80 mitigation translocations in 2000, up from fewer than 10 per year in the early 1990s (Edgar et al. 2005). There are many examples of mitigation translocations which have moved thousands, or tens of thousands, of individuals (Edgar et al. 2005; Kyek et al. 2007; McCoy et al. 2014; Germano et al. 2015).

There are taxonomic biases within the translocation field; vertebrates are overrepresented compared with invertebrates, and birds and mammals are heavily overrepresented within the vertebrates, although reptiles and amphibians are generally in proportion to their prevalence in nature (Fischer \& Lindenmayer 2000; Seddon et al. 2005; Bajomi et al. 2010). This is due both to the selection of species for translocations and publication biases (Bajomi et al. 2010). There is also a bias towards regions with the most expertise and money, rather than those with the greatest biodiversity (Fischer \& Lindenmayer 2000; Griffiths \& Pavajeau 2008). Bias is more pronounced in grey literature than in scientific literature, adding to the advantages of scientific publishing (Bajomi et al. 2010).

\subsubsection{Rates of translocation success}

Inconsistent standards used to evaluate success in translocations, and the fact that many translocation outcomes are never published, means that assessments of overall success 
of translocations are imprecise. Reviews of translocation success in vertebrates often focus on either birds and mammals or herpetofauna (e.g. Griffith et al. 1989; Dodd \& Seigel 1991; Germano \& Bishop 2009; Miskelly \& Powlesland 2013). Generally, the reported success of translocations of birds and mammals is higher than that of herpetofauna (Dodd \& Seigel 1991), and there has been a trend of increasing success in translocations over time (Germano \& Bishop 2009).

A large-scale review of the success of published translocations from 1980 to 2000 found a success rate of $26 \%$ and a failure rate of $27 \%$ (Fischer \& Lindenmayer 2000). The authors considered that this was likely an overly optimistic result, due to the likelihood of publication bias (Fischer \& Lindenmayer 2000). Reviews of translocation success found success rates of $44 \%$ in birds and mammals across five nations (Griffith et al. 1989), and also of $44 \%$ in New Zealand birds particularly (Miskelly \& Powlesland 2013). Although the success rate of herpetofauna translocations $c .1990$ was half that of bird and mammal translocations (19\% for herpetofauna; Dodd \& Seigel 1991), two decades later another review found that the success rate of herpetofauna translocations had doubled to $41 \%$ (Germano \& Bishop 2009). Reviews of translocation success conducted via surveys sent to practitioners found higher success rates; for mammals and birds 67\% (Wolf et al. 1996), and for amphibians and reptiles $43 \%$ and 60\% respectively (Ewen et al. 2014). However, Ewen et al. (2014) considered results gained from surveys were likely to be overconfident, as there was a tendency for practitioners to class translocations as successful based on 'means' indicators rather than more rigorous fundamental objectives.

Results reported in the literature can also be inaccurate due to publication biases (Fischer \& Lindenmayer 2000). A review of published and unpublished herpetofauna translocations in New Zealand found that there was a large overestimate of success rates in published studies ( $41.7 \%$ success rate in published studies versus $8.1 \%$ success rate overall; Miller et al. 2014). There was a bias against publishing uncertain outcomes, but not against publishing failed translocations (Miller et al. 2014). 


\subsubsection{Cost and funding}

Translocations are often complex operations and can span decades. The level of funding required to run such projects can be high, and must cover many operational costs including personnel, equipment, and overheads (Massei et al. 2010). It is currently impossible to determine how much is spent globally on translocations, as very few publications ( 3\%) discuss costs and many translocations are unpublished (Fischer \& Lindenmayer 2000). However, Germano et al. (2015) contend that funding of mitigation translocations dwarfs that of conservation translocations; the cost of mitigation translocations of single species can be in the order of tens of millions of US dollars.

The costs of translocations vary according to factors including location, the number of animals to be translocated, and the species involved; some species require much more intensive management than others. A review found that the cost of reintroducing golden lion tamarins (Leontopithecus rosalia) to a reserve in Brazil in a 1980 s reintroduction programme was US $\$ 22,000$ per surviving animal (Kleinman et al. 1991). For endemic New Zealand frogs, a translocation of Hochstetter's frogs (Leiopelma hochstetteri) to Orokonui Ecosanctuary and a translocation of Archey's frog (L. archeyi) to an offshore island had budgets of $\mathrm{NZ} \$ 33,700$ and $\mathrm{NZ} \$ 17,500$ respectively, not including other costs such as captive breeding facilities and monitoring (Bishop n.d.). In England, $£ 1.5$ million was spent on mitigation translocations of a single species, the great crested newt, in 2000 (Edgar et al. 2005).

\subsection{PROBLEMS WITH MITIGATION TRANSLOCATIONS}

Mitigation translocations differ from conservation or research translocations in that they are implemented to fulfil legal requirements as mitigation for damage caused by development projects. Generally, an organisation wishing to develop land will contract ecologists to fulfil statutory requirements. In addition to the difficulties of, and problems with, translocations in general, mitigation translocations present unique concerns.

Mitigation translocations may meet their goal of fulfilling legal obligations without meeting conservation goals. Governmental frameworks which require 
translocations are generally intended to promote conservation. However, this intention can be lost in translation due to the nature of mitigation translocations. For instance, a mitigation translocation of slow-worms (Anguis fragilis) from a housing development site met its statutory obligation to avoid deaths of individuals, however provided no conservation benefit as the animals are likely to have died without reproducing at their new site (Platenberg \& Griffiths 1999). The difference between benefit to individual animals and benefit to a species or ecosystem may not be obvious to laypeople, or not be explicitly laid out in legislation, and can result in the failure of mitigation translocations to meet ultimate conservation goals (Miller et al. 2014).

Mitigation translocations are less likely to follow ecological best practices than other types of translocation, and are less likely to meet conservation goals (Dodd \& Seigel 1991; Germano \& Bishop 2009). In translocations of lizards in New Zealand, conservation translocations were more likely to control predators (a main agent of decline) than were mitigation translocations (Romijn \& Hartley 2016). Mitigation translocations of herpetofauna often fail to address ecological concerns such as postrelease movement of animals, and have lower success rates than other types of translocation (Sullivan et al. 2015). Developments incorporating mitigation translocations can contribute to a net loss of habitat, even when compensatory habitat is created, and this can have negative conservation implications (Edgar et al. 2005).

Mitigation translocations are less likely to be monitored than other kinds of translocations (Miller et al. 2014; Germano et al. 2015). In a review of herpetofauna translocations in New Zealand, 38 out of 49 conservation translocations (78\%) and 4 out of 5 research translocations (80\%) were monitored, compared with 8 out of 20 mitigation translocations (40\%) (Miller et al. 2014). In a study of great crested newt translocations in England, 36\% of mitigation translocations were not monitored at all; of those that were, most were monitored for two years or less (Edgar et al. 2005). Where monitoring is carried out, requirements may arbitrarily be set for only a few years without reflecting the life histories of species (Ewen et al. 2014; Germano et al. 2015). Long-term monitoring may be difficult to mandate from developers whose goals are to meet regulatory requirements, not to ensure the health of a population in perpetuity. 
Reporting success or failure of translocations is crucial for informing conservation science, as well as for accountability (Dodd \& Seigel 1991; IUCN/SSC 2013; Miller et al. 2014). However, mitigation translocations are often poorly documented (Sherley et al. 2010; Germano et al. 2015). Even when there is a requirement to report, this may not be enforced; by some estimates more than half of mitigation translocations required to report their results do not (Edgar et al. 2005; Germano et al. 2015). When there is no requirement to publish, publication rates can be as low as $10 \%$ (Miller et al. 2014). This lack of publishing is likely due at least in part to the fact that mitigation translocations are performed by managers employed as contract ecologists, not as scientists. Because of this they are rarely provided with time, funding, or support to publish the results of translocations carried out by their agencies (Miller et al. 2014). Another suggested cause of low publication rates is fear of negative publicity (Edgar et al. 2005; Teixeira et al. 2007). There are numerous publication biases in the translocation literature, including a bias against publication of mitigation translocations (Miller et al. 2014). Biases and low publication rates make it more difficult to clearly assess the state of mitigation translocations and improve practices.

\subsection{THE NEW ZeALAND CONTEXT}

New Zealand's terrestrial fauna comprises mainly endemic birds, reptiles, and invertebrates, with no endemic terrestrial mammals save three species of bat (one now extinct). There are three main islands, with another 273 islands exceeding 5 ha and more than 700 islands larger than 1 ha (Craig et al. 2000). Many islands have high levels of endemism, while others with low endemism have been used as refugia for species threatened on the mainland (Daugherty et al. 1990; Bellingham et al. 2010). The lack of mammals, and distance from other land masses, has meant that New Zealand's endemic taxa have evolved along unusual lines, some losing defences against mammals or occupying typically mammalian niches (Diamond 1990). Unfortunately, this evolutionary naivety also makes New Zealand's endemic species vulnerable to introduced mammalian predators and competitors. 
New Zealand has a relatively short history of human occupation; Māori arrived c. 1280 , followed by Europeans in the late $18^{\text {th }}$ century (Wilmshurt et al. 2008). Since the arrival of people, land-use, hunting, and introduced species have caused significant declines in biodiversity. Strains on New Zealand's ecosystems began with hunting, the use of fire to clear forests, and the introduction of kiore (Pacific rat, Rattus exulans) and dogs (Canis familiaris) by Māori (Bellingham et al. 2010). Traditional Māori tikanga (customs) and māutauranga (knowledge) established methods for ensuring sustainable harvest of some native animals such as kererū (New Zealand wood pigeon, Hemiphaga novaseelandiae; Lyver et al. 2009) and tītī (sooty shearwater, Puffinus griseus; Moller et al. 2009). Despite this, many species became extinct following the arrival of Māori, including the Haast's eagle (Harpagornis moorei) and all moa (order Dinornithiformes); many others species declined including birds, reptiles, invertebrates, and marine mammals (Diamond 1990; Craig et al. 2000). European colonists brought to New Zealand vast numbers of exotic organisms, including many mammal species. These, combined with extensive harvesting and land development, led to the rapid extinction of a further 16 birds, a bat, and a fish, as well as invertebrate and plant species (Craig et al. 2000). Many species which escaped extinction entered decline, with extirpations common (Craig et al. 2000). There are now, according to the New Zealand Threat Classification System, 887 vertebrate taxa that live or have lived in the wild in New Zealand, with 65 extinct, 142 threatened, and 191 at risk taxa, and 201 non-resident native and 63 introduced and naturalised taxa (Hitchmough et al. 2016a; Robertson et al. 2017; Burns et al. 2018; Duffy et al. 2018; Dunn et al. 2018; O’Donnell et al. 2018; Baker et al. 2019).

New Zealand conservationists have been the pioneers of several major contributions to international conservation biology: the use of offshore islands as refuges for species threatened on the mainland; translocations of threatened species; control and eradication of introduced pests; and intensive management of critically endangered species (Diamond 1990). The first known conservation translocations in New Zealand were attempts by Richard Henry in the 1890s to establish kākāpō and kiwi (Apteryx spp.) on islands in Dusky Sound, although these efforts eventually failed in the 
face of stoat (Mustela erminea) incursions (Bellingham et al. 2010). In the 1960s to 1980s, eradication of introduced pests allowed the translocation of species threatened on the mainland to islands for conservation (Towns \& Broome 2003; Bellingham et al. 2010). These developments led to New Zealand being recognised as a global leader in island conservation by the late 1980s (Bellingham et al. 2010). The preponderance of islands suitable as reserves, the development of techniques allowing eradication of introduced species from relatively large areas, and the use of predator-exclusion fencing to create fenced mainland sanctuaries, mean that in New Zealand translocation is a relatively common conservation technique compared with other countries (Armstrong \& McLean 1995; Nelson et al. 2016). Indeed, since 1863, 61\% of New Zealand's shorebird, waterfowl, and land bird species have been translocated for conservation purposes (Miskelly \& Powlesland 2013).

\subsubsection{Legal basis for conservation and translocations in New Zealand}

In 1953 the Wildlife Act was enacted in New Zealand, providing blanket protection to all terrestrial vertebrates, as well as some other species, unless they are specifically listed as unprotected (Wildlife Act 1953). This differs from some overseas jurisdictions where the default status for wildlife is unprotected, and protection is granted through species being added to a list (e.g. the USA’s Endangered Species Act 1973; 16 U.S.C. $\$ 1531$ et seq.). Following the Wildlife Act, the Conservation Act was enacted in 1987, which concerns the conservation of indigenous biodiversity (Conservation Act 1987). The Act was built on the overriding principle of protection and established the Department of Conservation (DOC), giving it responsibility for managing the nation's biological, historic, and prehistoric heritage. The Act also gave DOC a mandate for active intervention and advocacy and included provision for the rights of Māori. In 1991 the Resource Management Act (RMA) was enacted in order to "promote the sustainable management of natural and physical resources", including the principle of "avoiding, remedying, or mitigating any adverse effects of activities on the environment" (Resource Management Act 1991). The central principle of sustainable management contrasts with the principle of protection set out in the Conservation Act 1987. 
Of these three acts, the Wildlife Act and the RMA have been the two applied to mitigation translocations in New Zealand. The Wildlife Act requires that individual animals are not disturbed, injured, or killed, whereas the RMA requires identification of short- and long-term ecological effects and, if the effects are more than minor, the avoidance, remedy, or mitigation of adverse ecological effects. The Wildlife Act therefore acts at the level of the individual, while the RMA protects habitats and biodiversity, and so functions at the population level and above.

\subsubsection{New Zealand lizards}

New Zealand is home to a large diversity of endemic lizards, with 43 gecko (Diplodactylidae) and 63 skink (Scincidae) species (described and undescribed; van Winkel et al. 2018). All except one of New Zealand's reptile species are lizards, the exception being the tuatara (Sphenodon punctatus), the sole surviving member of the order Rhynchocephalia. Historically, the number of native lizard species was similar to the number of native terrestrial and freshwater bird species, and lizards played an important role in Māori worldviews (Towns et al. 2016). However, following European colonisation, lizards were generally underappreciated (Towns et al. 2016). Lizards were originally listed as unprotected under the Wildlife Act 1953 (Miskelly 2014), but when they were included in the Act in the 1980s, interest grew in identifying and conserving species (Towns et al. 2016).

New Zealand's lizard assemblage is highly diverse, significantly more so than other temperate regions of the world (Daugherty et al. 1990), and with an unusually high level of sympatric species diversity for a temperate region (Towns \& Daugherty 1994). There are few habitat generalists ( 7\%), with most species specializing in habitat ranging from coastal beaches to alpine scrub and scree (Hare et al. 2016). Many species live in relatively cool environments compared with species from other regions (Hare \& Cree 2016), and many species show strong site fidelity (Hare et al. 2016). Their cryptic natures and small body sizes (generally 50-110 $\mathrm{mm}$ snout-vent lengths in both families) make them difficult to detect and monitor (Cree \& Hare 2016). Endemic New Zealand lizards are generally characterised by slow life histories compared with lizard 
species from other regions (Cree \& Hare 2016). All but one species give birth to live young (Cree \& Hare 2016), compared with only 19\% of lizard species worldwide (Stewart \& Blackburn 2015); possibly as a result of adaptation to cold climates (Cree \& Hare 2016). Clutch size is typically one to two in geckos and three to five in skinks, with reproduction typically occurring annually or less than annually (Cree \& Hare 2016). Geckos generally mature in two to eight years, and the longest lived species (e.g. Duvaucel's gecko Hoplodactylus duvaucelii, Waitaha gecko Woodworthia cf. brunnea) can live upwards of 50 years (Cree \& Hare 2016). Small-bodied Oligosoma skinks generally mature in two to four years and live up to 8 years in wild, while larger bodied species (e.g. grand skink O. grande and Otago skink O. otagense) mature in three to six years and can live more than 20 years in the wild (Cree \& Hare 2016).

Of the 106 endemic New Zealand lizard taxa, 88 (83\%) are classified as Threatened or At Risk under the New Zealand Threat Classification System (Hitchmough et al. 2016a). Worldwide, the IUCN Red List includes 7,199 reptile species, of which $10.2 \%$ are categorised as Endangered or Critically Endangered, and $12.7 \%$ as Vulnerable or Near Threatened, with the majority (60.3\%) being of Least Concern (IUCN 2019). In New Zealand, the major agents of decline are habitat destruction and predation by a suite of introduced mammals, to which New Zealand's lizards are vulnerable due to evolutionary naivety (Hitchmough et al. 2016b). New Zealand is unusual not only in its lack of native mammals, but also as one of the few regions in the world without snakes (either native or introduced; Worthy 2016); these two clades are often important predators of lizards in other regions. The natural predators of New Zealand lizards are mainly birds and other reptiles (e.g. tuatara) (Hare et al., 2016). The general predator defense mechanisms are crypsis, flight, aggression, and, as a last resort, caudal autotomy (Hare et al. 2016).

\subsubsection{Translocation of lizards in New Zealand}

Success rates for herpetofauna translocations internationally have been recorded as ranging from 19\% (Dodd \& Seigel 1991) to 41\% (Germano \& Bishop 2009).

Conservation is the most common motivation for herpetofauna translocations, and also 
results in the highest success rate (Germano \& Bishop 2009). Worldwide, translocations motivated by mitigation or human-wildlife conflict had the lowest success rates (Germano \& Bishop 2009). Low success rates in herpetofauna translocations have been attributed to the large-scale movement of individuals following translocation (Germano \& Bishop 2009; Sullivan et al. 2015). Homing or dispersal following translocations have been observed in several endemic New Zealand gecko species, although some species show no apparent homing ability (Hare et al. 2016). Homing of New Zealand skinks has been less studied, although a study of grand skinks (Oligosoma grande) found they displayed homing ability up to a limit of about 60-70 m (Stanley 1998).

The identification of rats (Rattus spp.) as a leading agent of lizard decline (Whitaker 1973), and the development of technology allowing the eradication of rats from islands (Towns \& Broome 2003), paved the way for lizard translocations in New Zealand. The first documented translocation of a New Zealand lizard species was the conservation translocation of Whitaker's skink (O. whitakeri) in 1988 to Koropuki Island, from which kiore had been eradicated (Towns 1994). In a summary of New Zealand translocations compiled by DOC there were 58 lizard translocations between 1988 and 2008 (Sherley et al. 2010). Mitigation translocations of New Zealand lizards began in 2003, primarily motivated by land development (Miller et al. 2014), and between 2003 and 2013 represented half of lizard translocations (Romijn \& Hartley 2016). In a comprehensive review of lizard translocations in New Zealand, most conservation translocations (91\%) were to sites free of introduced mammalian predators (mostly island sanctuaries), whereas all mitigation translocations had at least some introduced mammalian predators present at the release site (generally unfenced mainland sites) (Romijn \& Hartley 2016). The presence of introduced mammalian predators at release sites endangers translocated lizards; to date there has been only one predator control regime at a mainland unfenced site allowing resident lizard populations to recover, which was intensive and targeted multiple species (Reardon et al. 2012). Predator control such as this must be maintained in perpetuity to keep mammalian predators suppressed and protect lizards. 
Techniques for mitigation translocations of New Zealand lizards include habitat enhancement and the creation of refuges to protect translocated populations (Anderson et al. 2012). I use the term refuge (plural refuges) and refugium (plural refugia) sensu Keppel et al. (2012); refuges are microhabitats which provide either protection (spatial or temporal) from disturbance or a biotic advantage (e.g. a space under a rock providing protection from predation). Refugia are geographic areas where species can retreat and survive periods of unfavourable conditions such as glaciation. Optimal foraging theory predicts that predation depends on the cost-benefit ratio involved in acquiring and consuming prey (Pyke et al. 1977); the addition of refuges may increase the cost of predation for predators and therefore reduce its occurrence (Whitlow et al. 2003). The creation of refuges to benefit vulnerable species has been used for the conservation of aquatic and terrestrial vertebrates and invertebrates (Belthoff \& Smith 2003; Green 2005; London Convention and Protocol/UNEP 2009; Rouco et al. 2011; Croak et al. 2013). In New Zealand, an example of habitat enhancing refuges is rocky habitats created for translocated rock-dwelling lizards (Anderson et al. 2012). However, the composition and design of these rocky habitats is largely ad hoc and untested.

Only $32 \%$ of mitigation translocations of New Zealand lizards surveyed by Romijn and Hartley (2016) were monitored; of these, 89\% were monitored for four years or less. In the review by Sherley et al. (2010), 89\% of mitigation translocations (24 out of 27) of endemic New Zealand lizards had an 'unknown' outcome, compared with $21 \%$ of lizard translocations for other purposes (9 out of 42 ). However, both Miller et al. (2014) and Romijn \& Hartley (2016) found no overall difference in known outcomes between conservation and mitigation translocations of New Zealand lizards. The lack of long-term data for mitigation translocations makes comparison with conservation translocations difficult, and Romijn \& Hartley (2016) recommended that older translocations where data is lacking be revisited to determine their outcomes.

\subsection{KEY QUESTIONS AND THESIS OUTLINE}

My thesis uses endemic New Zealand lizards as a study system to examine mitigation translocations and their effectiveness for achieving conservation outcomes. I investigate 
whether mitigation translocations are meeting their stated goals, how current mitigation translocation practices in New Zealand relate to conservation goals, and examine how mitigation translocation practices might be improved to achieve better conservation outcomes.

I address the following questions:

1. Are mitigation translocation practices meeting legal requirements?

2. Are mitigation translocations meeting conservation goals?

3. How can mitigation translocation practices be improved to better meet conservation goals?

This thesis is structured as a series of stand-alone manuscripts formatted for publication in peer-reviewed journals. This structure necessarily involves some repetition, particularly in the introductory sections, however it also expediates publication and allows each chapter to be placed in a wider context.

In Chapter 2, I develop a novel use of video games physics software to characterise the three-dimensional interstitial spaces in rock pile habitats. Such habitats are constructed as habitat enhancement measures in mitigation translocations of New Zealand skinks, but the geometry of their interior spaces and implications for ecology of lizards are poorly understood. In Chapter 3, I use the modelling technique developed in Chapter 2 to hypothesise a design for a rock pile which aims to protect translocated skinks from mice (Mus musculus), an introduced mammalian predator. The protection is achieved by selecting the rocks to optimise the sizes of interstitial spaces to allow skinks to move and find refuges within the rock pile, but reduce accessibility for the larger mice. In Chapter 4, I collaborate on a mitigation translocation of lizards at the roading construction site at Transmission Gully near Wellington, New Zealand. I test the rock pile design hypothesised in Chapter 3, and use this mitigation translocation as a case study of the challenges facing mitigation translocations and the barriers to conservation success. In Chapter 5, I revisit nine historical mitigation translocations of New Zealand skinks to assess their mid- to long-term success, and investigate factors that may affect their success rates compared with other types of translocation. In 
Chapter 6, I synthesize my main findings to address my three thesis questions, and discuss the state of mitigation translocations and potential opportunities to improve their conservation outcomes.

\subsection{CONTRIBUTIONS TO RESEARCH}

All study designs, data collection, analysis, and writing were conducted by Ox Lennon with advice from supervisors Nicola Nelson and Heiko Wittmer. I acknowledge the following contributions to this thesis:

Practical assistance. I had the help of field assistants in some of the installation of equipment and lizard monitoring. Nicola Moffatt from Massey University performed the CT scanning for Chapter 2. Labourers from Transmission Gully built the rock piles for Chapter 4. David Craddock installed pitfall traps at Shakespear Open Sanctuary in Chapter 5 and provided me with data about their locations, previous use and capture data. Kezia Fairbrother created figure 3.1 and illustrations of skinks throughout the thesis.

Data collection. Marieke Lettink and I collaborated on capturing and measuring skinks in Christchurch, New Zealand, for Chapter 3. Staff from Boffa Miskell Limited (BML) and $\mathrm{CPB} / \mathrm{HEB}$ contractors monitored predators and lizards (BML only) at Transmission Gully, and provided me with their data which I analysed along with data I collected for Chapter 4. Chris Wedding and Simon Chapman also shared data which I included, along with my own data, in my analysis in Chapter 5.

Statistical advice. Lisa Woods from Victoria University of Wellington provided advice on design and statistical analysis of the mouse experiment in Chapter 4.

\subsection{PERMITS AND ETHICS}

This research was carried out with approval from the Animal Ethics Committee of Victoria University of Wellington (permits AEC26705 and AEC22347) and the Department of Conservation (permits 63394-FAU, 50490-FAU, and 50568-FAU). 


\section{CHAPTER 2}

\section{Modelling three-dimensional refuge space to predict accessibility using video game software}

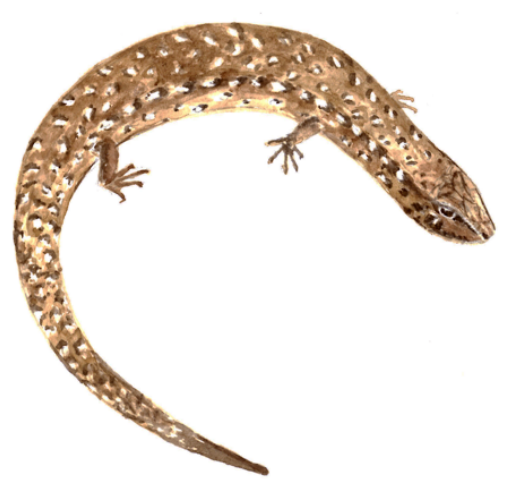

\section{$2.1 \quad$ INTRODUCTION}

Understanding relationships between organisms and physical environments is a cornerstone of ecology. The environment has profound effects on practically every aspect of an organism's biology and life history. Physical environments are often incredibly complex, and in order to study them it is common to use simplified measurements that are relatively easy to obtain and provide useful results; e.g. describing spider burrows using depth and diameter (Milne \& Bull 2000). However, some environmental factors are more difficult to measure than others. This can lead to an inability to characterise them, or a focus on less useful but more easily-measured aspects; for instance, studies of rock-dwelling lizards focussed on attributes of the overlying rock rather than the shape of the underlying crevice, which is important for 
retreat selection but hard to measure (Croak et al. 2008). Three-dimensional spaces are often significant for animals as refuges, but are difficult to measure and describe due to complexities of shape and orientation, and difficulties in delineating where one space ends and another begins.

Three-dimensional aspects of refuges can influence behaviours such as predatorprey interactions (Hesterberg et al. 2017), intra-specific interactions (Milne \& Bull 2000), and foraging (Toscano \& Griffen 2013). Previous research has examined a range of factors relating to aspects of three-dimensional refuges, including effects on retreat site selection by snakes and geckos (Croak et al. 2008, 2012), predation ability of crabs (Hesterberg et al. 2017), and abundance of prey insect species (Flecker \& Allan 1984). The sizes of predators and refuges can interact to influence predation rate (Toscano \& Griffen 2013), and the presence of predators can influence refuge selection by prey (Pike et al. 2010).

Approaches to characterising refuge space have generally fallen into three categories. The first is direct physical measurement of refuges in situ, for instance: using probes to measure the length of lizard burrows (Milne \& Bull 2000); expanding foam casts to measure spaces under rocks (Croak et al. 2008); or grids of gauges to measure reef topography (Alexander 2013). This approach allows researchers to characterise real refuges in the field, and can be useful for correlative investigations of refuge use. However, physically measuring three-dimensional space can be difficult, and only works when the refuges are either sufficiently simple (e.g. the space under a single rock, a cylindrical burrow) or simplified measures are used (gauges measure reef topology from above, but cannot reach any spaces below overhangs). A second approach is to create artificial refuges, the shape and size of which can be experimentally varied, and which can be used in field or laboratory experiments (Warfe et al. 2008; Croak et al. 2010; Pike et al. 2010; Hesterberg et al. 2017). This approach gives researchers more control over variables, allowing for more rigorous experiments with replication, blocking and crossing designs, and hypothesis testing. In order to allow for clear comparisons of size and/or shape, however, these refuges tend to be simplified. Studies using this approach tend to report the effects of spaces on animals rather than describing or characterising 
naturally occurring spaces. A third approach is to characterise habitat complexity by relating the sizes of spaces in the habitat to the size of predators (Bartholomew et al. 2000). The ratio of space size to predator size is then used to predict the manoeuvrability of the predator and therefore the prey survivorship. However, the use of the average size of spaces is a major limitation of this approach, as variably arranged spaces can result in the same score despite having vastly different effects on predator manoeuvrability (Bell et al. 2003).

While all these methods are useful for achieving their particular aims, none of them is fully adequate for investigating more complex interstitial spaces. These can be too complex and inaccessible to allow for physical measurement, rendering the first approach unusable. Creating complex artificial spaces and using them in experiments can allow researchers to investigate their ecological effects, but the problem of characterising and describing the spaces themselves remains. The index-based approach, by its use of mean sizes, is not fit to describe complex spaces. In order to better characterise and understand complex three-dimensional habitats, a new approach is needed.

One such complex biological space is interstitial spaces in rock piles, which are important habitat for saxicolous species. These spaces are labyrinthine, and not easily accessible with measuring instruments. The network of gaps is too complex to use previous approaches such as expanding foam moulds (Croak et al. 2008) or straight rulers (Milne \& Bull 2000; Alexander 2013). Variation in access to these spaces can be ecologically important, as in the case of endemic New Zealand skinks seeking refuge from larger rodent predators (Towns 1996). An understanding of interstitial spaces could allow researchers not only to characterise naturally occurring refuges, but also to design refuges optimised for conservation purposes (Chapter 3).

The question of interstitial space is somewhat similar to packing problems, that is, how densely objects can fill a container, which have been of practical and theoretical interest for centuries. Similarly to the interstitial space problem, packing problems face the issue of investigating the interior of a randomly packed structure without destroying it. Packing problems can be approached using computational algorithms or 
experimental methods, and are concerned with determining values such as packing density and contacts per particle, which are not directly relatable to ecologically relevant space. Investigative approaches include computed tomography (CT) scanning, computer modelling, or coating a physical structure in paint before disassembling it (Donev et al. 2004). Of these three approaches, computer modelling is preferable as it is cheaper than CT scanning and faster than paint and disassembly. Developing a computer modelling method also results in a tool that can be of wider use, to investigate questions about inaccessible spaces in systems beyond terrestrial rock piles.

I present a novel computer-based approach for modelling ecologically relevant aspects of three-dimensional refuge space, with the aim of understanding refuges that cannot be measured using more conventional means. My method uses physics engine software designed for video games (NVIDIA Corporation 2011; Unity Technologies 2016) to predict the sizes of interstitial spaces within rock piles, but could be generalised to characterise other kinds of refuge space. I test the accuracy of my predictions using CT scanning of rock piles.

\subsection{METHODS}

\subsubsection{Summary of methods}

I performed all simulations using a Macbook Pro with a $2.4 \mathrm{GHz}$ Intel Core i7 processor, 8 GB of RAM, NVIDIA GeForce GT 650M 1024 MB graphics card, and running macOS High Sierra 10.13.6. I used the video games design program, Unity (Version 5.5.5f1, Unity Technologies 2016), and its inbuilt physics engine PhysX (Version 3.3 SDK, NVIDIA Corporation 2011) to model the behaviour of virtual rocks dropped from a height and allowed to settle into a pile. Physics engines are simulation software which model realistic movement of objects by simulating physical traits such as mass, gravity, friction, inertia, momentum, and collisions between dynamic objects. They are under constant development and improvement, owing to their application in video game development and animation. I then used a technique called ray casting, also within Unity, to measure the interstitial spaces in the simulated rock pile. I simulated rock piles of varying compositions (sizes, shapes, and combinations of rocks). I used $\mathrm{R}$ 
(R Core Team, 2016) to translate the raw data obtained from Unity into threedimensional measurements for spaces inside the simulated rock piles. I then categorised the spaces into size classes to estimate the accessibility of rock piles to animals based on a priori data of the size of spaces the animal can access. To check that the results from my modelling were accurate for real rock piles, I CT scanned rock piles and digitally measured the three-dimensional images using ImageJ (version 1.50i; Schneider et al. 2012), and compared the results with the predictions from my modelling.

\subsubsection{Rock models}

PhysX and Unity use 'rigidbodies' to simulate physical objects, in this case rocks, which are virtual three-dimensional objects that can receive forces and torque to act in a realistic way. PhysX models rigidbodies as either pre-determined simple shapes or more complex meshes. I used the software Blender (version 2.77; Blender Foundation 2016) to make meshes that were modelled after real rocks collected from a quarry (Figure 2.1). I made 20 rock meshes, and I stretched/squashed them in three dimensions to vary their sizes and shapes. Deforming the rocks' shapes allowed me to have a larger variety of individual rock models, and changing their sizes allowed me to test different grades of rock. Each mesh became a rigidbody in Unity, resulting in rock models that behaved naturally according to physical forces. PhysX does not allow individual rigidbodies to be concave; because of this I modelled the rocks as convex shapes only.

The size of each rock model is represented as a range: this is the equivalent of the grading used to measure rocks in construction (Table 2.1). The two numbers indicate the sizes of two screens that can be used to sort the rocks, e.g. a rock graded $20-40 \mathrm{~mm}$ will go through a $40 \mathrm{~mm}$ screen but not a $20 \mathrm{~mm}$ screen.

\subsubsection{Dropping the rocks}

I wrote a C\# script for Unity (Appendix 1) which simulated tipping a number of rocks from a height and allowing them to settle in a pile before they are measured using ray casts (Figure 2.1). The script allowed me to control aspects such as the rocks' sizes and 


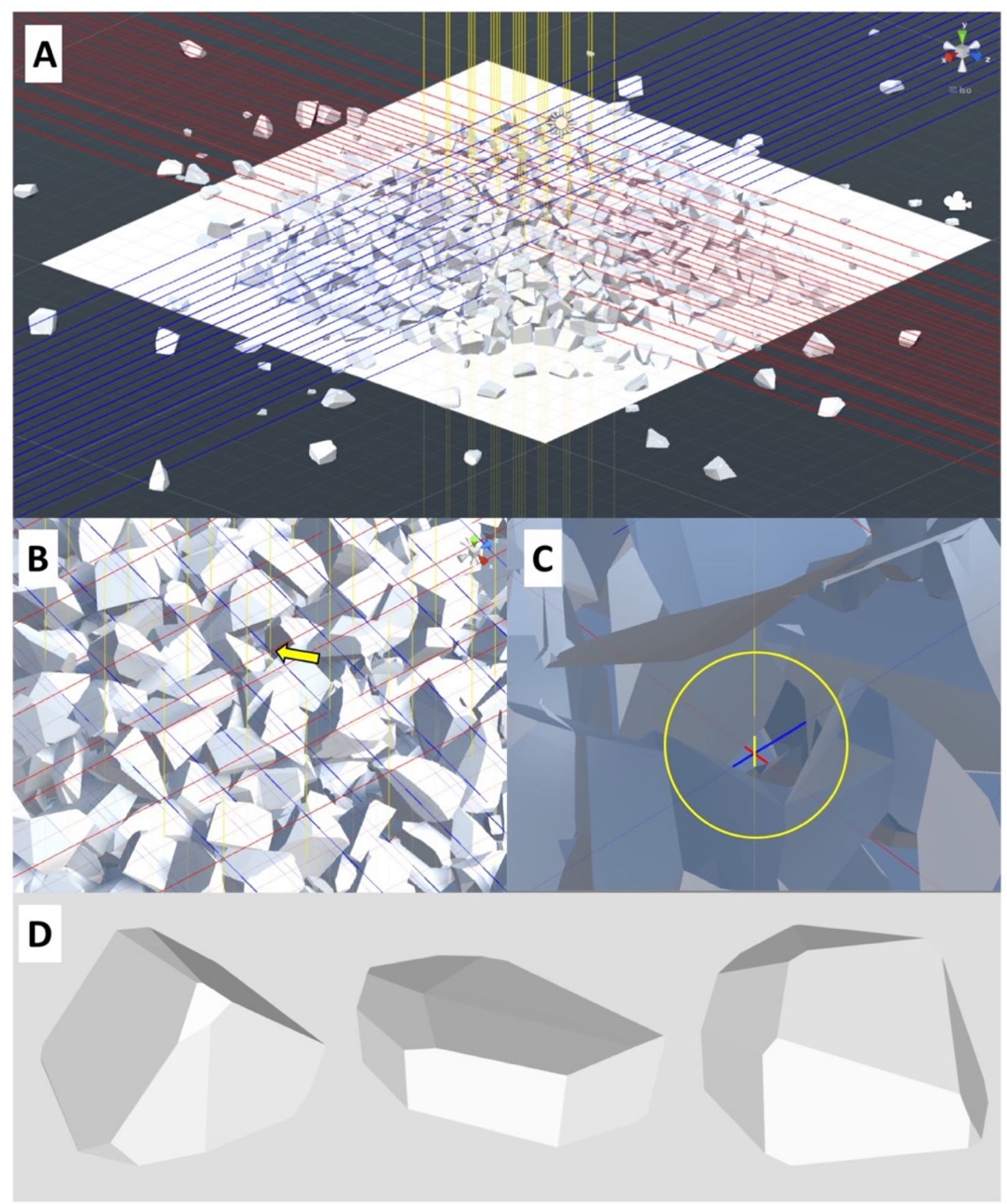

Figure 2.1. Screenshots from Unity showing simulated rock piles and ray casts. A) Three grids of ray casts travel through the rock pile in the $\mathrm{X}, \mathrm{Y}$, and $\mathrm{Z}$ directions. $\mathrm{B}$ ) The rays intersect within the rock pile in a three-dimensional grid (one point of intersection indicated by arrow). C) Where an intersection of three rays falls within an interstitial space (circled), the data obtained from ray casts (locations at which they intersect with the edges of the rocks) can be used to calculate the size of the space in three dimensions. D) Examples of rock meshes used for the simulation. NB: for clarity there are fewer rays pictured than were in the simulations. 
Table 2.1. Rock combinations tested using a Unity simulation. I modelled the 'rough' shapes after rough rocks from a quarry, and the 'smooth' shapes after oval river rocks. 'Grades' refers to the size of each rock and is represented as a range: the equivalent of the grading used to measure rocks in construction. The two numbers indicate the sizes of two screens that can be used to sort the rocks, e.g. a rock of grade $20-40 \mathrm{~mm}$ will pass through a $40 \mathrm{~mm}$ screen but not a $20 \mathrm{~mm}$ screen. Where two grades are listed, two different sizes of rocks were mixed together; 'combination' describes these mixes as a percentage of the rocks that were of the smaller grade. 'Number of rocks' is how many rocks were generated in the Unity simulation (I generated more rocks when the rocks were smaller so that the piles created were approximately equal sizes, $1-2 \mathrm{~m}$ wide and $0.5 \mathrm{~m}$ high). I generated CT comparison piles in order to compare them with CT scanned exemplar rock piles.

\begin{tabular}{|c|c|c|c|c|}
\hline Group & Shape & Grades (mm) & $\begin{array}{c}\text { Combination } \\
\text { (\% small) }\end{array}$ & $\begin{array}{l}\text { Number } \\
\text { of rocks }\end{array}$ \\
\hline \multirow{3}{*}{$\mathrm{A}$} & Rough & $11-20$ & & 6000 \\
\hline & Rough & $34-60$ & & 6000 \\
\hline & Rough & $45-80$ & & 4000 \\
\hline \multirow{4}{*}{ B } & Rough & $11-20 \& 70-100$ & $2 \%$ & 5000 \\
\hline & Rough & $11-20 \& 70-100$ & $6 \%$ & 5000 \\
\hline & Rough & $11-20 \& 70-100$ & $10 \%$ & 5000 \\
\hline & Rough & $11-20 \& 70-100$ & $20 \%$ & 5000 \\
\hline \multirow{6}{*}{$\mathrm{C}$} & Rough & $20-40$ & & 3500 \\
\hline & Rough & $10-14 \& 20-40$ & $11 \%$ & 6000 \\
\hline & Rough & $10-14 \& 20-40$ & $20 \%$ & 6000 \\
\hline & Rough & $10-14 \& 20-40$ & $33 \%$ & 6000 \\
\hline & Rough & $10-14 \& 20-40$ & $50 \%$ & 6000 \\
\hline & Rough & $10-14$ & & 6000 \\
\hline \multirow{3}{*}{$\begin{array}{c}\text { CT } \\
\text { comparison }\end{array}$} & Smooth & $45-75$ & & 6000 \\
\hline & Rough & $10-30 \& 50-80$ & $50 \%$ & 6000 \\
\hline & Rough & $50-80$ & & 4000 \\
\hline
\end{tabular}

shapes, the number of rocks, the combination of different types of rocks, and the height from which they are dropped.

I tested 14 different rock compositions (Table 2.1). The number of rocks per pile varied from 3500 to 6000 depending on their sizes; I generated more rocks when the 
rocks were smaller in order to make piles of approximately the same size. The piles I generated were $\sim 1-2 \mathrm{~m}$ in diameter and $0.5 \mathrm{~m}$ high. I ran the program 35 times for each composition, generating and measuring 35 rock piles with the same types of rocks. This was because by 35 simulations the means of gap sizes had reached an asymptote.

Following an exploratory assessment of various sizes and shapes of rocks, I performed a more exhaustive qualitative assessment of three different scenarios: A) rock piles comprised entirely of one grade of rock; B) rocks of grades 11-20 mm and 70-100 mm in combinations of different proportions; and C) rocks of grades 10-14 mm and 20-40 $\mathrm{mm}$ in combinations of different proportions (Table 2.1). I also tested three combinations in order to compare them with CT scanned exemplar rock piles (Table 2.1).

\subsubsection{Measuring gaps: ray casting and analysis}

I wrote a C\# script for Unity which uses ray casts to measure gaps within the pile in three dimensions (Appendix 1). Ray casts are virtual rays that have a defined point of origin, direction, and length. Each ray cast records the position of every point along its length at which it intersects the edge of an object. The script generates three groups of ray casts which penetrate the virtual rock pile in three orthogonal directions: an X group, a Y group, and a Z group. Each group's rays' points of origin lie on a twodimensional grid oriented perpendicular to the direction the rays are travelling in. This arrangement results in a three-dimensional grid of points within the rock pile at which rays from all three directions intersect (Figure 2.1). Some points fall within interstitial spaces and some inside rocks; I used R to discriminate between these so I only analysed points that fell within interstitial spaces. This ray casting method means that individual interstitial spaces may be sampled more than once, and larger interstitial spaces are more likely to be sampled and to be sampled more times. The data output from this script is a group of files with co-ordinates of every point where a ray cast intersected the edge of a rock ('hit locations'). I used R ( $\mathrm{R}$ Core Team 2016) to extract the X, Y, and Z sizes of all sampled gaps from this data (Appendix 2). Briefly, the R script does the following. First, it arranges the hit locations using the coordinate information so that all 
hit locations for each single ray are arranged in order. It then pairs hit locations that bound gaps along each ray to get locations and one-dimensional sizes for each gap along each ray. It then compares the location data from the $\mathrm{X}, \mathrm{Y}$, and $\mathrm{Z}$ rays to match the three one-dimensional size measurements of each sampled gap. The results are X, Y, and Z size measurements for the space around each point from the sampling grid that fell within an interstitial space.

For each pile generated, I used ray casts to sample 4000 points spaced in a grid. The grid was arranged so there were $50 \mathrm{~mm}$ spaces between each point. The grid started $10 \mathrm{~mm}$ off the ground and was $500 \mathrm{~mm}$ high and $1 \mathrm{~m}$ in width and depth, and was positioned approximately around the centre of the rock pile. I chose this spacing to ensure that it was spread throughout the entire pile so that the sampling was not biased (spaces in the centre may be different from those at the edges or top), and to create a moderate amount of data to work with in $\mathrm{R}$ (larger datasets increase the analysis time).

\subsubsection{Classifying gaps: 'small', 'optimum', or 'large'}

For any animal, access to a space will be constrained by the animal's size. Therefore, there is a minimum gap size below which the animal will be unable to access a space. Sometimes the accessibility of two or more different size classes can be ecologically important: for instance in a predator-prey system (e.g. smaller prey able to escape larger predators; Chapter 3); in cases of sexual dimorphism (e.g. smaller females able to access spaces larger males cannot; Green et al. 2019); or where there are differences between juveniles and adults (e.g. smaller/younger individuals have different burrow preferences than older/larger individuals; Milne \& Bull 2000). For demonstration purposes I used $a$ priori measurements from the predator-prey system of protected New Zealand skinks (Oligosoma spp.) and their introduced predator, house mice (Mus musculus) (Chapter 3). These species fall into two size classes, as skinks are capable of entering smaller gaps than mice (Chapter 3). Where there are two size classes, gaps can be either too small for either animal to access, large enough for the smaller animal but too small for the larger animal, or large enough for either animal to access. I named these categories small, optimal, and large respectively (optimal here refers to access for skinks, as conservation 
managers aim to protect them from mice; Chapter 3). Classifying gaps into these three categories enables an understanding of their accessibility for each animal. I classified each measured gap into one of these three categories using R (Appendix 2). A priori knowledge of gap sizes accessible to each animal is needed to define the bounds of each category (two-dimensional information is sufficient).

For demonstration purposes, I used a priori knowledge for skinks and mice (Chapter 3), to define the three size categories as follows: small, any dimension $\leq 3 \mathrm{~mm}$; optimal, all dimensions $>3 \mathrm{~mm}$, at least one dimension $<10 \mathrm{~mm}$; large, all dimensions $\geq 10 \mathrm{~mm}$. I obtained proportions of 'small', 'optimal', and 'large' gap space for each rock pile simulation using R (Appendix 2). I calculated the mean proportions of 'small', 'optimal', and 'large' gaps for each rock pile composition, and calculated 95\% confidence intervals using the percentile method.

\subsubsection{CT scanning}

In order to compare the predictions from my modelling experiment with physical measurements, I used CT scanning to measure the interstitial spaces of real rock piles. I tipped rocks into $550 \times 260 \times 410 \mathrm{~mm}$ bins which were scanned at Massey University's Veterinary Teaching Hospital using a Phillips Brilliance 16P CT scanner. The bins were necessary to allow the rocks to be stacked into a pile but still fit through the scanner's $700 \mathrm{~mm}$ diameter gantry (Figure 2.2 insert). I was limited to testing three different compositions due to the expense of hiring the CT scanner.

The three compositions I tested were as follows. 1) Rough rocks collected from a quarry, sorted by hand using screens, with a combination of $50 \%$ (by volume) rocks graded $10-30 \mathrm{~mm}$, and $50 \%$ rocks graded $50-80 \mathrm{~mm}$. 2) Rough rocks collected from a quarry, sorted by hand and using screens, graded $\sim 50-80 \mathrm{~mm}$. This was chosen to investigate whether the predictions from the computer modelling would be accurate when rocks (and gaps) are larger. 3) Smooth flat oval river stones purchased from a landscaping supplier ('beach flats, medium' purchased from The Goods Shed, Wellington). The rocks' three dimensions were $\sim 10-20 \mathrm{~mm}, \sim 45-75 \mathrm{~mm}$, and $\sim 50-100$ $\mathrm{mm}$ (i.e. approximately in the size range of other rocks tested but with a more flattened, 
round shape). I used these to investigate whether there were any adverse effects from modelling the rocks as entirely convex shapes (round rocks are entirely convex, unlike the jagged rocks which generally have some concavities).

I scanned each rock composition twice, using the same rocks and thoroughly mixing them between scans. The scans had a resolution of $1 \mathrm{~mm}$. The outputs were DICOM images, a medical imaging file format containing stacked slices of a threedimensional image.

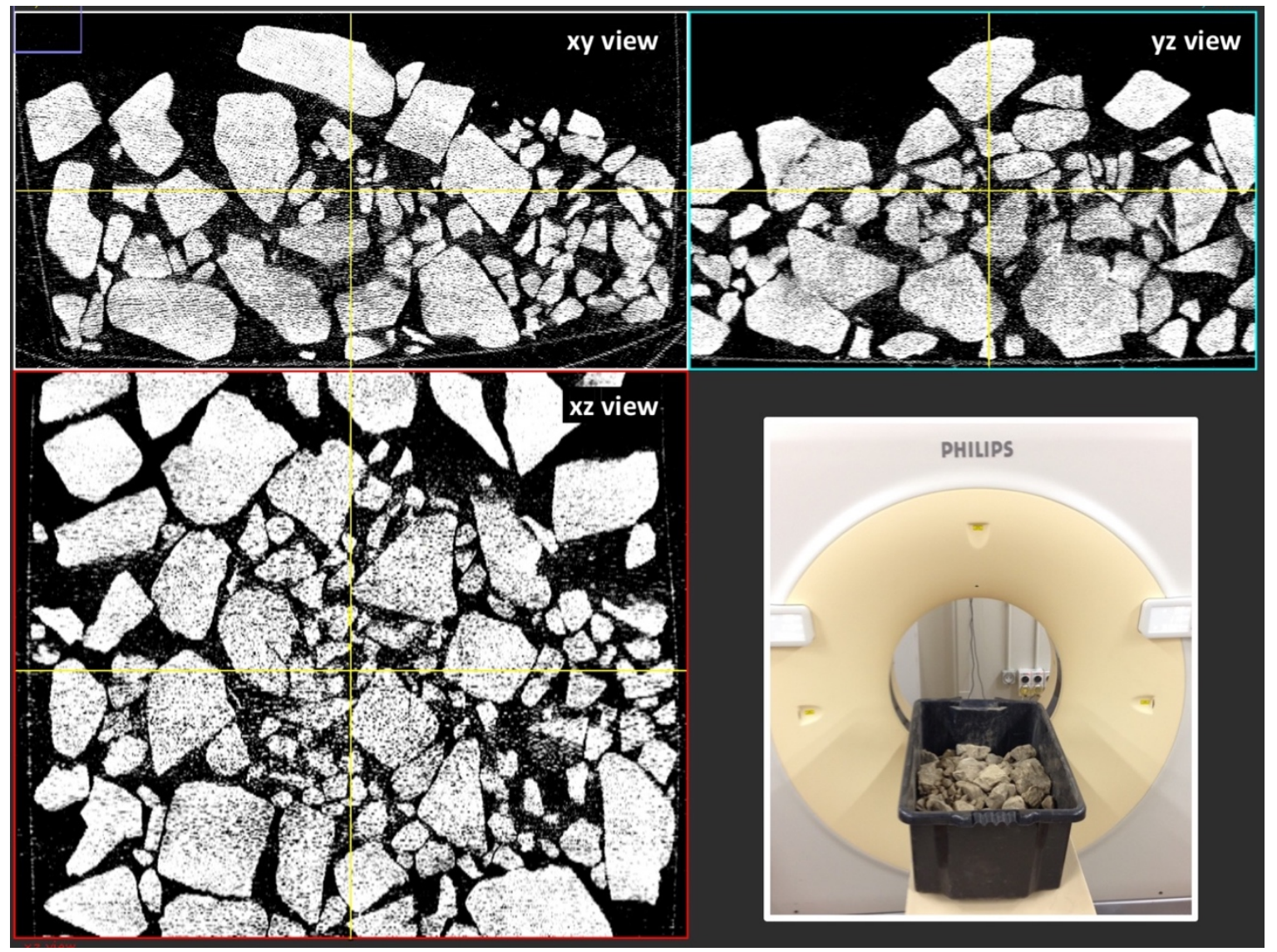

Figure 2.2. Screen capture from ImageJ (Schneider et al. 2012). Images from a CT scan representing the three dimensions of a rock pile. A cursor (yellow lines) is calibrated between the three windows and used to measurement interstitial spaces at a pre-determined grid of sampling points. Insert bottom right: rocks stacked and ready to enter the CT scanner's gantry.

\subsubsection{CT Image processing and analysis}

I used ImageJ (Schneider et al. 2012) to measure gaps in the CT images. I trimmed the images to include the entire width $(410 \mathrm{~mm})$ and height $(260 \mathrm{~mm})$ of the pile, but cut 
$\sim 40 \%$ of the length (leaving $\sim 300 \mathrm{~mm}$ ), to make processing less compute- and labourintensive. To make the measurements comparable to those obtained from the Unity simulation, I wrote a macro which displayed the DICOM images in three axes (XY, XZ, \& YZ) simultaneously and calibrated a cursor to match within all three images (Figure 2.2). A second macro placed a three-dimensional sampling grid of points within the images at $50 \mathrm{~mm}$ spacings. For each point that fell within an interstitial space, I used ImageJ's measuring tool to measure the $\mathrm{X}, \mathrm{Y}$, and $\mathrm{Z}$ dimensions of the space from that point. I measured gaps at 500-600 points within each pile. If several points fell within the same gap, I sampled the gap at each point. I used the same methods in R as I used on the data from Unity to categorise the gaps as 'small', 'optimal', or 'large'.

\subsection{RESULTS}

The computer modelling technique allowed me to obtain estimates for the sizes of interstitial spaces within a variety of rock piles, and to detect differences in gap sizes among different rock piles (Figure 2.3). The proportions of gaps varied with the rock pile composition and followed linear trends. For piles composed of just one size of rock, there was a trend for smaller rocks to produce more small and optimal gaps and fewer large gaps, and for larger rocks to produce more large gaps and fewer small and optimal gaps (e.g. 45-80 mm rocks produced 2\% small, 13\% optimal, and 85\% large gaps, whereas 11-20 mm rocks produced 25\% small, 64\% optimal, and 9\% large gaps; Figure $2.3, \mathrm{~A})$. For piles composed of mixes of two rock grades, there was a linear trend of the proportion of optimal gaps and small gaps increasing, and the proportion of large gaps decreasing, as the proportion of small rocks in the mix increased (e.g. $20-40 \mathrm{~mm}$ rocks produced $52 \%$ large, $41 \%$ optimal, and $7 \%$ small gaps whereas $10-14 \mathrm{~mm}$ graded rocks produced 6\% large, 66\% optimal, and 28\% small gaps; Figure 2.3, B \& C).

\subsubsection{CT scanning}

The observed proportions from the CT scans followed the same pattern as I predicted using the modelling method (Figure 2.4). The observed values fell within the predicted $95 \%$ confidence interval for the $10-30 \mathrm{~mm}+50-80 \mathrm{~mm}$ composition. For the pile with 


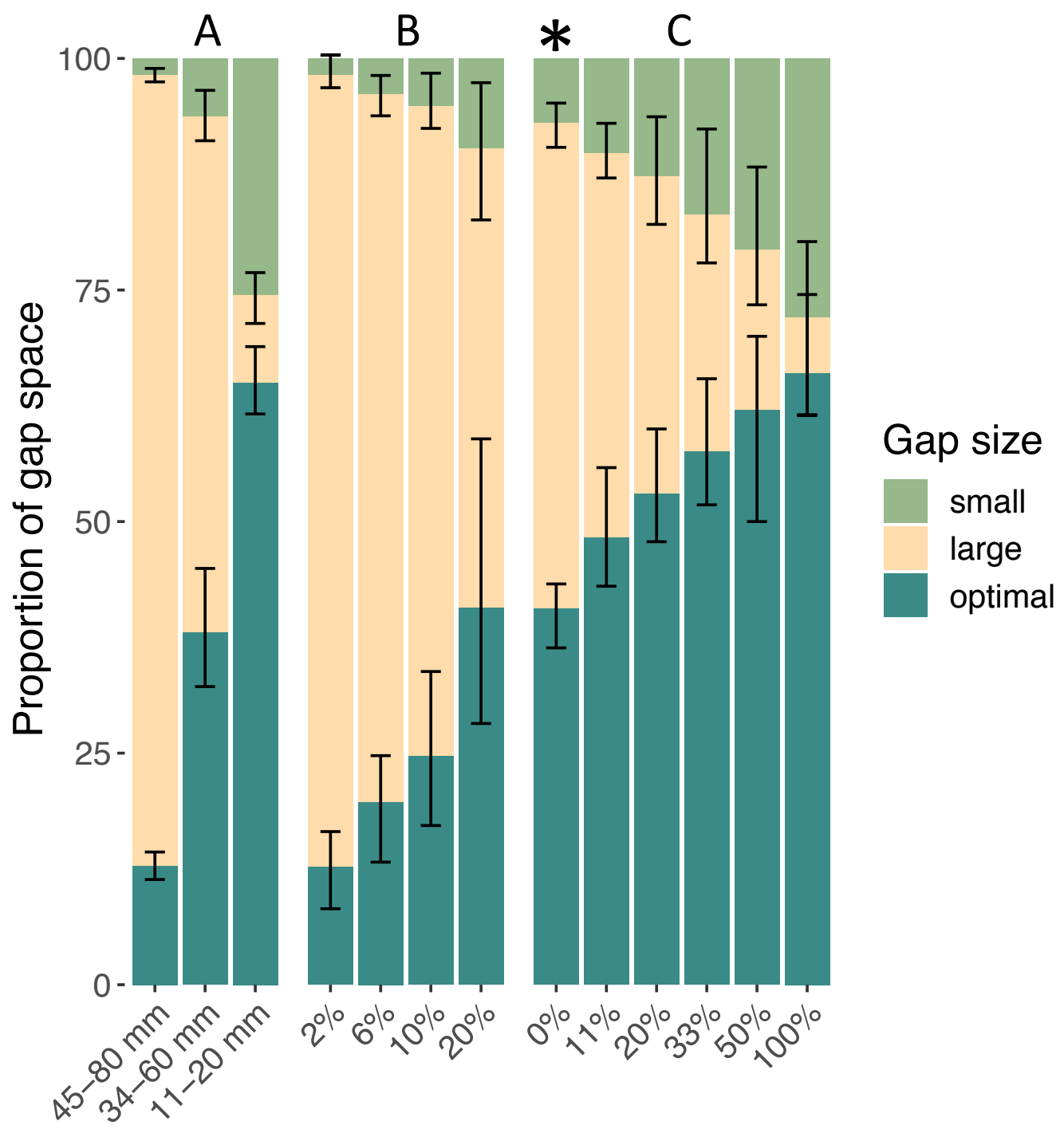

\section{Composition of rock pile}

Figure 2.3. Proportion of measured gap space that is 'small', 'large', and 'optimal' in rock piles simulated using PhysX and Unity. A) Rock piles are composed of a single grade of rock only and the rock size is represented as a range: the equivalent of the grading used to measure rocks in construction. The two numbers indicate the sizes of two screens used to sort the rocks, i.e. the rock will not pass through a screen of the smaller size but will pass through a screen of the larger size. Rock piles in B) and C) are composed of two grades of rock mixed together: percentages represent how much of the mix is rocks of the smaller grade. Rock grades in B) are 11-20 mm and 70-100 $\mathrm{mm}$, rock grades in C) are 10-14 mm and 20-40 mm. See Table 2.1 for more details of compositions. Error bars are $95 \%$ confidence interval. $\mathrm{N}=35$ simulations per composition. Asterisk indicates hypothesized best design for skink refuges. 


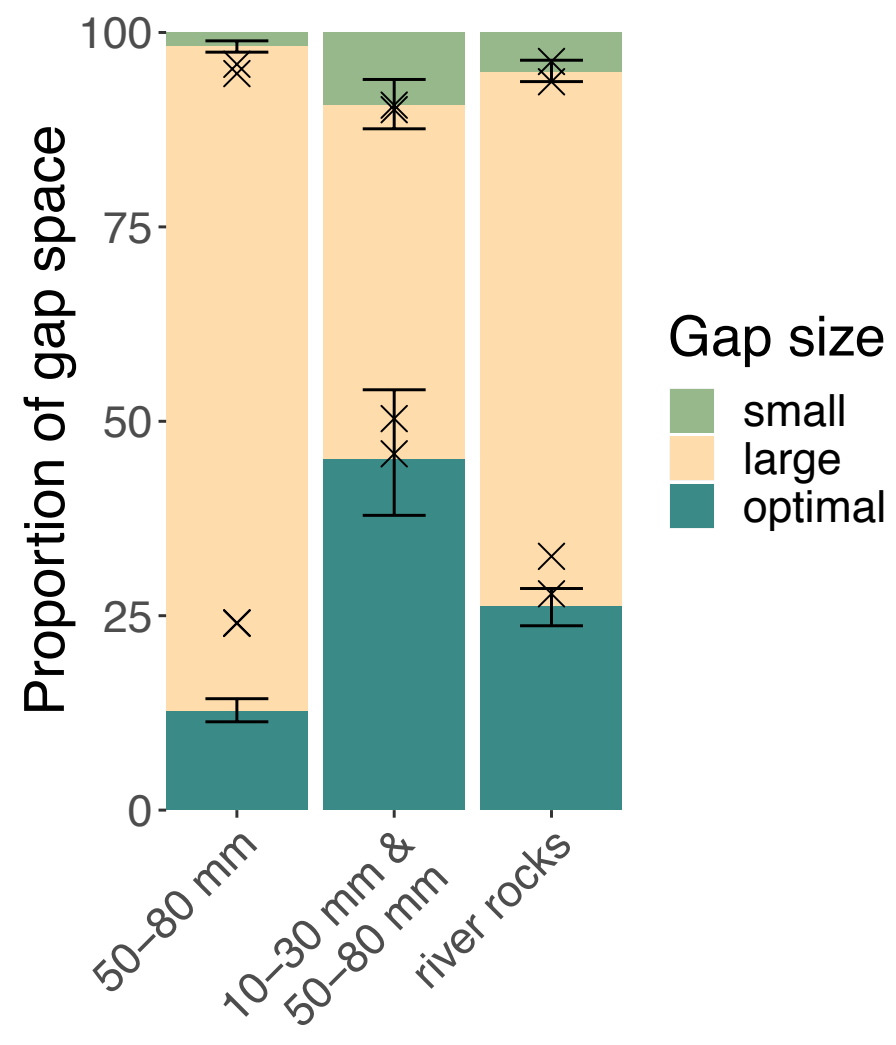

\section{Composition of rock pile}

Figure 2.4. Proportions of 'optimal', 'small', and 'large' spaces inside rock piles measured from CT scans. Columns are values predicted from a virtual modelling technique, with error bars for $95 \%$ confidence interval ( $\mathrm{N}=35$ per composition). Crosses are the proportions observed in $\mathrm{CT}$ scans $(\mathrm{N}$ $=2$ per composition).

round rocks, the observed proportions of small gaps fell within the predicted 95\% confidence interval, however only one of the observed values for proportion of optimal gaps fell within the predicted $95 \%$ confidence interval. The observed values for the 50 $80 \mathrm{~mm}$ composition fell outside of the $95 \%$ confidence value, by $2-3 \%$ for the proportion of small gaps and $\sim 10 \%$ for the proportion of optimal gaps.

\subsection{DISCUSSION}

The modelling technique I have developed gives estimates for the sizes of interstitial spaces within complex rock piles, which, when used in combination with information about space use by animals, can predict accessibility and usability of rock piles by 
different species or size classes. NVIDA PhysX has been previously used to design haptic feedback models for training medical professionals (Ricardez et al. 2018) and to simulate the interaction of ships and ice sheets (Lubbad \& Løset 2011). The current study represents a novel use of this technology for ecological purposes.

In order to have example a priori data to demonstrate this technique, I used measurements from the predator-prey system of mice and endemic New Zealand skinks (Chapter 3). Results from the modelling show that it is possible to use this technique to predict the sizes of interstitial spaces within rock piles, and to observe changes in the sizes of interstitial spaces as the rock pile compositions vary. An understanding of the unobservable interstitial spaces within these rock piles could inform conservation management of saxicolous species (Chapter 3).

CT scanning the rocks was the only way to obtain measurements of the rock piles deeper than the surface level. Due to the expense of scanning, I scanned each rock composition only twice. Because of this there are no means or standard errors for the CT scan measurements, however the data from the scans provides an indication of the accuracy of the predicted values. The observed proportions of gap sizes obtained from the CT scans followed the same pattern that I predicted using the virtual rock pile method. These results indicate that computer modelling can be used to predict the true proportions of gaps, however the real proportions may be more variable than predicted. The computer modelling method also appears to have a tendency towards underestimating the number of small and optimal gaps, and overestimating the number of large gaps. The difference in error between the large composition and the mixed/round compositions indicates that predictions may be more accurate for smaller rocks than for larger rocks.

As it is impossible to delineate discrete gaps within the network of interstitial space, and as a contiguous space will vary in its dimensions depending on the point at which it is measured, I took an approach that estimated overall proportions of gap space of different sizes rather than attempting to count individual spaces. Obtaining three measurements $(\mathrm{X}, \mathrm{Y}$, and $\mathrm{Z}$ ) provides an approximate size for the gap around each sampled point. This method could be used to generate a complete list of gap sizes and 
locations. In order to turn this raw information into useful data, a priori information about the size of gaps accessible by one or more target species can be employed. Where spaces that afford smaller animals refuge from larger animals are of interest, a category of optimal space can be defined and measured. This method could be easily adjusted to characterise the accessibility of space for a single size class of animal, or three or more. By classifying the measured spaces into categories, the data is simplified while still retaining the key information needed for understanding the ecologically relevant factor: accessibility.

This approach does not directly provide information about the connectivity of the gaps. Even a large gap could be completely cut off and inaccessible. Rock-dwelling animals are often highly flexible, and can bend around corners within piles easily; modelling this movement is more challenging than measuring gap sizes. There is therefore an underlying assumption to this model that the proportion of theoretically accessible space corresponds to the proportion of actually accessible space.

The use of rock models gives a more accurate estimate of the physics of real rocks than would be obtained using simpler shapes such as cubes. However, this also makes the simulation computationally intensive as it means modelling a large number of polygons and their interactions. A limitation of Unity is that it is unable to model concave rigidbodies. This can be overcome by modelling a single concave shape as multiple convex shapes joined together, however this greatly increases the computational intensity and difficulty of modelling. All the rock models were therefore convex, although real rocks often have some concavities. My predictions approximately matched the gaps present in real CT-scanned rock piles (with rocks containing concavities). Additionally, I CT-scanned entirely convex river rocks; if failing to model concavities has an impact on the accuracy of the prediction, there would be a difference between the accuracy of the prediction for the river rocks and the other compositions. The accuracy of predictions for the river rock and the mixed compositions are fairly similar, suggesting that modelling the rocks as convex does not have a substantial influence on the accuracy of the prediction. 
This technique could also be used to characterise interstitial spaces in areas other than terrestrial rock piles. In aquatic environments, habitat complexity is an important influence on ecological communities. The size and makeup of particulate substrate and arrangements of fractal habitat elements are just two aspects contributing to aquatic habitat complexity (Tokeshi \& Arakaki 2012). These factors influence interstitial space availability, which is currently measured using tools such as bent wires, profile gauges, or rubber fish models (McCormick 1994; Tokeshi \& Arakaki 2012; Rogers et al. 2017). Interstitial space is often acknowledged as important, but may be measured only as mean volume; for instance, in a study investigating the use of oyster shells to restore reefs (Levine et al. 2017). Measurements using physical instruments provide some information around interstitial space but can be limited in their reach, missing underhangs or only able to be used in areas a human can reach (McCormick 1994; Tokeshi \& Arakaki 2012; Rogers et al. 2017). Furthermore, measuring marine environments by hand is highly labour-intensive. These types of studies could benefit from the virtual technique I designed here, which would enable easier, more informative characterisation of interstitial spaces and contribute to understanding of habitat complexity.

The approach I developed could be used to describe interstitial spaces in habitats as they naturally occur, or it could be applied to design habitats to benefit certain species. Habitat creation and enhancement are management techniques employed in conservation, both in terrestrial (Chapter 3) and aquatic systems (Levine et al. 2017). Natural rocks are sometimes used in the creation of artificial reefs, and guidelines suggest designing interstitial spaces specifically for target species (London Convention and Protocol/UNEP 2009). The techniques outlined here could be used to design these structures to optimise interstitial space to benefit species or groups targeted for conservation. 


\section{CHAPTER 3}

\section{Can rock piles be designed to protect endemic skinks (Scincidae) from introduced mice (Mus musculus)?}

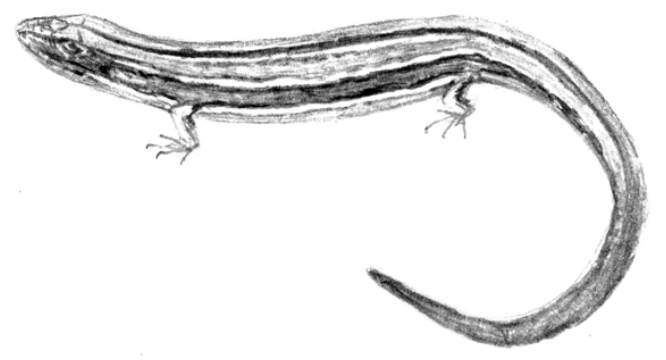

\subsection{INTRODUCTION}

The protection of endemic species from introduced predators is a challenge for wildlife managers. Introduced species can have detrimental effects on endemics, causing extirpation or extinction in many cases (Clavero \& García-Berthou 2005). Introduced predators can be extremely difficult to control or eradicate, meaning that managers must look to other strategies in order to reduce their impacts on threatened prey species (Hulme 2006). The presence of refuges can reduce the negative impacts of predators, including introduced predators, on prey (Stuart-Smith et al. 2007). Prey species may adjust their behaviour and habitat use in the presence of introduced predators to take advantage of the protection afforded by refuges (Whitlow et al. 2003; Sowersby et al. 2016). Creation of refuges via habitat manipulation represents an opportunity for conservationists seeking to protect threatened species from introduced predators (Sinclair et al. 1998). 
Optimal foraging theory predicts that predation depends on the cost-benefit ratio involved in acquiring and consuming prey (Pyke et al. 1977). The addition of refuges may increase the cost of predation for predators and therefore reduce its occurrence (Whitlow et al. 2003). The creation of artificial refuges in natural environments to benefit vulnerable species has been used for the conservation of many taxa including reptiles (Croak et al. 2013), mammals (Rouco et al. 2011), birds (Belthoff \& Smith 2003), invertebrates (Green 2005), and aquatic species (London Convention and Protocol/UNEP 2009). The ecology of predators and prey should be considered in the design of artificial refuges in order to ensure their effectiveness.

New Zealand is home to a large diversity of endemic lizards, with 43 gecko (Diplodactylidae) and 63 skink (Scincidae) species (some undescribed; van Winkel et al. 2018). Of these 106 taxa, 81 are classified as Threatened or At Risk by the New Zealand Threat Classification System (Hitchmough et al. 2016a). New Zealand skinks evolved in the presence of avian predators, and are vulnerable to predation by introduced mammals (Hitchmough et al. 2016b). House mice (Mus musculus) are an introduced predator of skinks in New Zealand, and are capable of attacking and killing juveniles and adults (Burt 1927; Newman 1988; Ainsworth et al. 1991; Newman 1994; Hoare et al. 2007; Wedding 2007; Norbury et al. 2013; Norbury et al. 2014). A mouse population explosion on Mana Island was considered a major, if not sole, cause of a decline in the McGregor's skink (Oligosoma macgregori) population, as well as a dramatic decline in the northern grass skink (O. polychroma) population and a decline in the copper skink (O. aeneum) population (Newman 1994). A dramatic decline in shore skink (O. smithi) capture rates in Tāwharanui Regional Park was also correlated with a substantial increase in mice (Ussher 2006 as reported in Wedding 2007). Mice are harder to control than larger introduced mammals and are therefore seldom targeted in mammal control operations (Innes et al. 2012; Hitchmough et al. 2016b). When only larger mammals are controlled, there can be detrimental effects on skink populations due to mesopredator, or competitive, release of mice (Newman 1994; Hoare et al. 2007; Ruscoe et al. 2011; Norbury et al. 2013). Mouse populations also boom periodically in New Zealand due to mast seasons (years with a glut of fruit and seed production; Murphy 1992). 
Many endemic New Zealand skink species live in complex three-dimensional rocky habitats, where they bask on exposed surfaces and shelter in interstitial spaces (Towns 1991, 1996; Towns \& Ferreira 2001; Hoare et al. 2007; Adams 2009). Rocky habitats are, in some cases, home to the last remaining fragments of nearly extirpated populations, such as the last mainland population of Whitaker's skink (O. whitakeri) (Hoare et al. 2007). A population of shore skinks, which formerly occupied only areas with small stones, expanded to occupy areas with larger rocks and boulders following eradication of kiore (Pacific rats; Rattus exulans; Towns 1996). This was likely due to the rats' ability to access the larger interstitial spaces among larger rocks, and inability to access interstitial spaces within habitat comprised of smaller stones (Towns 1996). Skinks' natural predator avoidance behaviour of sheltering inside rock piles can allow them to escape avian predation and larger mammals such as cats (Felis catus) or rats; however, it may do little to protect them from mice, which are small enough to enter many of the same interstitial spaces as skinks. Mice may also actively choose the same rock piles as skinks, as they are afforded protection from mutual predators, as well as access to skinks and invertebrates as prey. Mice have been directly observed to attack skinks basking near rock refuges (Norbury et al. 2014). Mouse gut content analyses from two populations indicated that mice only ate lizards from February (late summer) to June (autumn), and that lizards can comprise up to $25 \%$ of mouse diet during these months (Pickard 1984; Wedding 2007). The increase in lizard predation by mice occurs during and after the skink birthing period, and corresponds with a drop in the percentage of seeds in the mouse diet (Pickard 1984; Wedding 2007). The increase in skink predation may be due to the increased availability of neonate and juvenile skinks at this time, which increases the efficacy of density dependent predation factors such as search images (Wedding 2007).

Management of skinks in New Zealand sometimes involves building new rock pile habitat (Anderson et al. 2012). This is commonly done during mitigation translocations. Mitigation translocations are the movement of living organisms from a future development site to another location in an effort to mitigate damage caused (International Union for the Conservation of Nature/Species Survival Commission 
[IUCN/SSC] 2013) and are often implemented to fulfil legal requirements in New Zealand (Wildlife Act 1953, Resource Management Act 1991). Currently, creation of new habitat is ad hoc and based on best guesses by managers, with no formal scientific testing of rock pile composition. The characteristics of refuges in the new rock pile habitat may affect skink/mouse interactions and skink survival. It is also possible that favourable habitat is created not only for skinks, but for mice as well.

In Chapter 2, I developed a novel technique for characterising the sizes of interstitial spaces within rock piles by modelling them using the computer games programs Unity (Unity Technologies 2016) and PhysX (NVIDIA Corporation 2011). The predicted sizes of interstitial spaces can be compared with data for gap sizes accessible to animals, to predict their ability to access spaces inside the rock piles. In the current chapter, my aim was to use this technique to predict how rock piles might be used to protect skinks from mouse predation. As mice are slightly larger than many New Zealand skink species, I aimed to determine the best shapes and sizes of rocks to use to create rock piles which would optimise interstitial spaces that are big enough for skinks to access but too small for mice. This would provide natural protection for skinks from mice in two ways. Firstly, it would ensure that rock piles contain refuges that allow skinks to avoid mice; there is evidence that lizard species tend to choose the smallest refuges they can fit (Schlesinger \& Shine 1994; Milne \& Bull 2000; Webb \& Shine 2000; Shah et al. 2004), to the point of preferring smaller refuges with predator scent over larger refuges with no scent (Bourke et al. 2017). Secondly, the movement and occupancy of mice within the pile would be hindered. I aimed to design a rock pile which can be used to increase the cost-benefit ratio of mouse predation on skinks, reducing opportunistic predation by mice, and increasing skink survival, recruitment, and population viability.

\subsection{METHODS}

\subsubsection{Summary of methods}

In order to assess the accessibility of rock piles I needed information about the sizes of gaps that skinks and mice can enter. Information for mice was available from published 
experiments for designing predator exclusion fencing, testing the ability of mice to escape confinement through barriers of varying sizes (Day \& MacGibbon 2007). In an escape experiment, partial exclusion of adult mice began somewhere between $10 \mathrm{~mm}$ and $12 \mathrm{~mm}$, and complete exclusion somewhere between $8 \mathrm{~mm}$ and $10 \mathrm{~mm}$ (Day \& MacGibbon 2007). Comparable data for skinks were unavailable; I therefore performed an experiment to determine skinks' ability to escape a box through variably-sized holes. I modelled the accessibility of different rock piles using a computer modelling technique (Chapter 2), compared with the results of the gap entry size experiments, and hypothesised an ideal rock pile composition for protecting skinks from mice.

\subsubsection{Study species}

I used two endemic New Zealand skink species in these experiments: southern grass skinks (O. aff. polychroma, hereafter grass skinks) and copper skinks. Both species are small and slender (grass skink snout-vent length [SVL] 60-70 mm, copper skink 55$67 \mathrm{~mm}$; Jewel 2008). Both are listed as Not Threatened in the New Zealand Threat Classification System (Hitchmough et al. 2016a). Both are relatively common species, and (like all endemic New Zealand lizards) are protected by law (Wildlife Act 1953), and are therefore frequently subject to mitigation translocations. They are also vulnerable to mouse predation (Newman 1994).

\subsubsection{Box escape experiment}

I tested skinks to determine the smallest holes they were able to pass through. I based the experiment on an experiment measuring skink crevice accessibility by Schwarzkopf et al. (2010) and modified it to provide data comparable to that available for mice (Day \& MacGibbon 2007).

Grass skinks $(\mathrm{N}=64)$ salvaged during a mitigation translocation (construction of the Christchurch Southern Motorway in the South Island, New Zealand) were measured and used in the escape experiment on 14-17 February 2017 (late summer) prior to release. They were caught using artificial cover objects (ACOs), baited pitfall traps or funnel traps, were held in individual cotton bags, and used for this experiment 
and released within five hours of capture. Copper skinks $(\mathrm{N}=8)$ salvaged from a future roading construction site near Wellington, New Zealand, were held in approximately 1 $\mathrm{m}^{3}$ open air cages containing natural rock/leaf substrate, various refuges (bark, logs, bamboo hides) and 4 to 12 skinks. The copper skinks were used for this experiment when they were being located within their cages during a routine census of the captive population on 1 December 2016 (early summer). No pregnant females were used.

The box was a $150 \mathrm{~mm}$ x $150 \mathrm{~mm}$ x $150 \mathrm{~mm}$ acrylic container with $3 \mathrm{~mm}$ thick walls and an open top (Figure 3.1). One wall had an opening, and a slot to hold a barrier with a hole for the skink to escape through. Different barriers with varying hole sizes and shapes could be inserted. The barriers were made of $3 \mathrm{~mm}$ thick clear acrylic. The holes were of two types: square, with a range of sizes 3-15 $\mathrm{mm}$ in $1 \mathrm{~mm}$ increments; and rectangular, $30 \mathrm{~mm}$ wide with heights $3-15 \mathrm{~mm}$ in $1 \mathrm{~mm}$ increments. The box was housed within a larger plastic box to contain the skink when it escaped the small box. The bottom of the small box was filled with gravel to give the skink grip and to elevate it to eye level with the hole. Either wooden blocks or bark/wood taken from the surroundings were placed outside the hole to entice the skink to exit and to provide purchase.

I placed a skink in the box and used a paintbrush to touch the skink and rattle the gravel to encourage escape through the hole. I started with a large hole and repeated the experiment, reducing the hole size by $1 \mathrm{~mm}$ each time, until the skink would no longer exit. I repeated the experiment with a smaller hole immediately upon the skink exiting the previous hole, unless the skink showed signs of stress (i.e. floppiness/ stiffness/failing to attempt to evade capture). If the lizard showed signs of stress I placed it in a box with a lid and some damp leaf litter until it was behaving normally (usually one to three minutes) before continuing the experiment. I stopped the experiment when the skink either put its snout into the hole but would not exit, or was judged to have spent substantial time ( $\sim 30$ seconds or more) near enough the hole to see it but would not exit. 


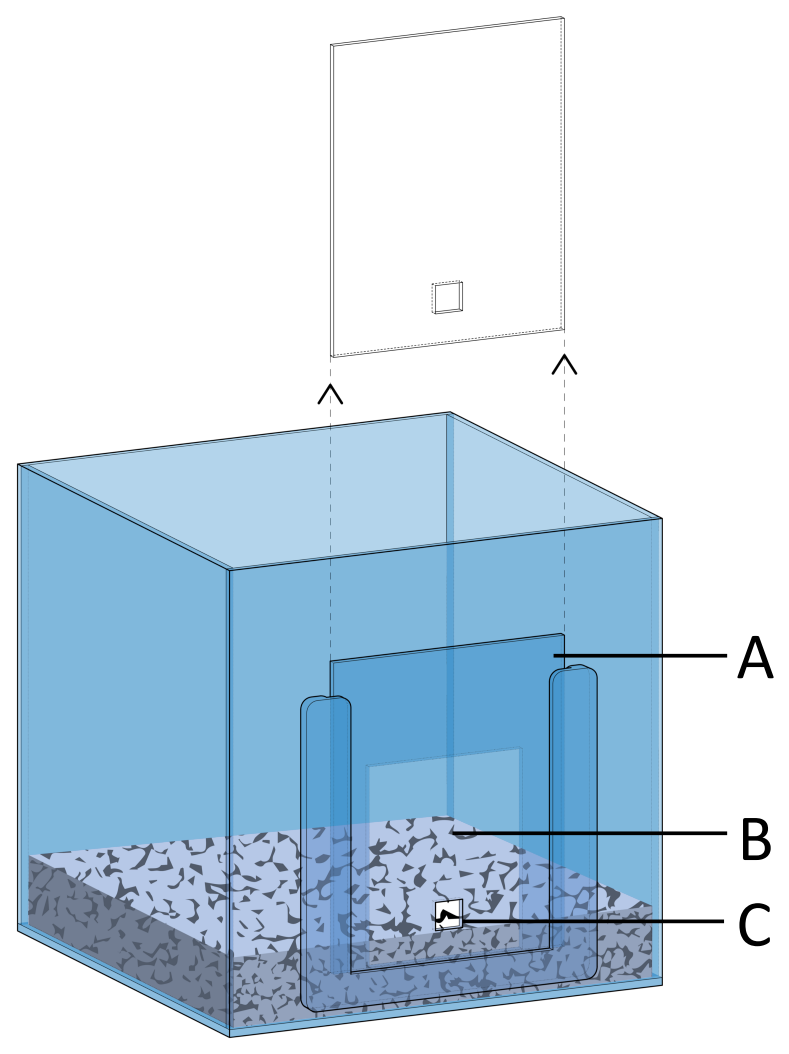

Figure 3.1. Experimental box used to test size of holes that skinks can fit through. A) Barrier can be slotted in and out. B) Rocks in bottom of container to provide purchase. C) Hole for skink to escape through. (C) Kezia Fairbrother.

If the skink appeared to have difficulty exiting through a hole (e.g. large amount of wriggling, taking a long time) then that size was considered the smallest size for that skink and smaller sizes were not tested. Following testing I measured the skink for SVL and total length, and weighed and sexed it (only grass skinks were sexed as no-one present at the testing of the copper skinks was proficient in reliably sexing skinks). The minimum escape sizes were measured once for each skink.

I performed all statistical analysis using R (R Core Team 2016). I analysed the data separately for each species. I used linear models to test for the effects of both SVL and sex (grass skinks only) on minimum gap exit size, as well as for interaction effects. Since I found no significant interaction between sex and SVL, I separated the data by sex 
and fit simple linear regressions. I used a likelihood ratio test to compare the quality among models. I calculated 95\% prediction intervals for each linear model. I calculated prediction intervals for the smallest gap size accessible by the largest possible skink (79 mm SVL for grass skinks, $62 \mathrm{~mm}$ for copper skinks; Jewel 2008) of each sex of each species.

\subsubsection{Rock pile modelling}

In Chapter 2, I designed a modelling technique which uses computer games software (Unity; Unity Technologies 2016) and a physics engine (PhysX; NVIDIA Corporation 2011) to create realistic virtual models of rock piles and provide information about the accessibility of their interstitial spaces. The output from the modelling is an estimate of the proportion of different sized spaces within the rock piles: 'optimal' (in this case, spaces that skinks can fit into but mice cannot), 'large' (either mice or skinks could fit into), or 'small' (too small for either skinks or mice to enter). By examining the proportions of optimal, large, and small gaps, the ability of each species to access the piles can be estimated. In order for the model to categorise the gaps inside the piles, data for the size of gaps accessible to each species is required. Having obtained gap accessibility measurements for skinks (box escape experiment) and mice (Day \& MacGibbon 2007), I determined the bounds for the different categories of gap sizes.

In Chapter 2, I modelled several types of rock piles as an exploratory study of the different types of interstitial spaces produced. For the current chapter, I built on this analysis and further investigated one set of these modelled rock piles to consider their potential application for skink conservation. The set comprised six rock pile compositions with different combinations of two standard rock grades available from landscaping suppliers. I chose these because for mitigation translocations it is likely that the most practical approach will be to use rocks of standard sizes easily available from landscaping suppliers. The two grades were 10-14 mm (smaller grade) and 20-40 mm (larger grade). The two numbers of each grade indicate the sizes of two screens that can be used to sort the rocks, e.g. a rock graded $20-40 \mathrm{~mm}$ will go through a $40 \mathrm{~mm}$ screen but not a $20 \mathrm{~mm}$ screen. I modelled rock piles in the following combinations: $100 \%$ 
smaller grade; $11 \%$ smaller grade $+89 \%$ larger grade; $20 \%$ smaller grade $+80 \%$ larger grade; $33 \%$ smaller grade $+67 \%$ larger grade; $50 \%$ smaller grade $+50 \%$ larger grade; $100 \%$ larger grade. I modelled the virtual rocks after real rocks available from landscaping suppliers (Chapter 2).

\subsection{RESULTS}

\subsubsection{Box escape experiment}

The minimum hole size that allowed escape ranged from $3 \mathrm{~mm}$ to $9 \mathrm{~mm}$ for grass skinks (Figure 3.2) and $4 \mathrm{~mm}$ to $8 \mathrm{~mm}$ for copper skinks (Figure 3.3). Skink size (SVL) and sex both had an effect, with larger skinks requiring larger gaps and male grass skinks requiring larger gaps than non-pregnant females. All individuals were able to fit through smaller rectangular gaps than square gaps (when heights of gaps are compared, e.g. an $8 \mathrm{~mm} \times 30 \mathrm{~mm}$ hole was easier to fit through than an $8 \mathrm{~mm} \times 8 \mathrm{~mm}$ hole).

All skinks were able to get through square and rectangular gaps smaller than $10 \mathrm{~mm}$ (Figures $3.2 \& 3.3$ ). The largest rectangular gap required by a grass skink was $6 \mathrm{~mm}$, and the largest square gap required was $9 \mathrm{~mm}$. The largest rectangular gap required by a copper skink was $5 \mathrm{~mm}$, and the largest square gap required was $8 \mathrm{~mm}$. For grass skinks, I analysed the adults separately from juveniles in order to understand the effects of sex (juveniles cannot be sexed). The linear models with interaction terms for both square and rectangular minimum accessible gap size for adult grass skinks showed no significant interaction of SVL and sex. The likelihood ratio tests for both square and rectangular models showed there was no difference in fit between the model with interaction effect or the model without interaction effect (square models, $\mathrm{F}=0.403$, $p=0.528, \mathrm{df}=1$; rectangular models, $\mathrm{F}=0.074, p=0.787, \mathrm{df}=1)$. I therefore removed the interaction effect and used additive linear models as they were the most parsimonious (Table 3.1). The additive models showed that both SVL and sex had significant effects on minimum accessible gap size. The minimum accessible gap size increased, per millimetre of SVL, by $0.09 \mathrm{~mm}(\mathrm{SE} \pm 0.01 \mathrm{~mm})$ for square gaps and by $0.07 \mathrm{~mm}$ (SE $\pm 0.01 \mathrm{~mm}$ ) for rectangular gaps. Male skinks required bigger gaps than 

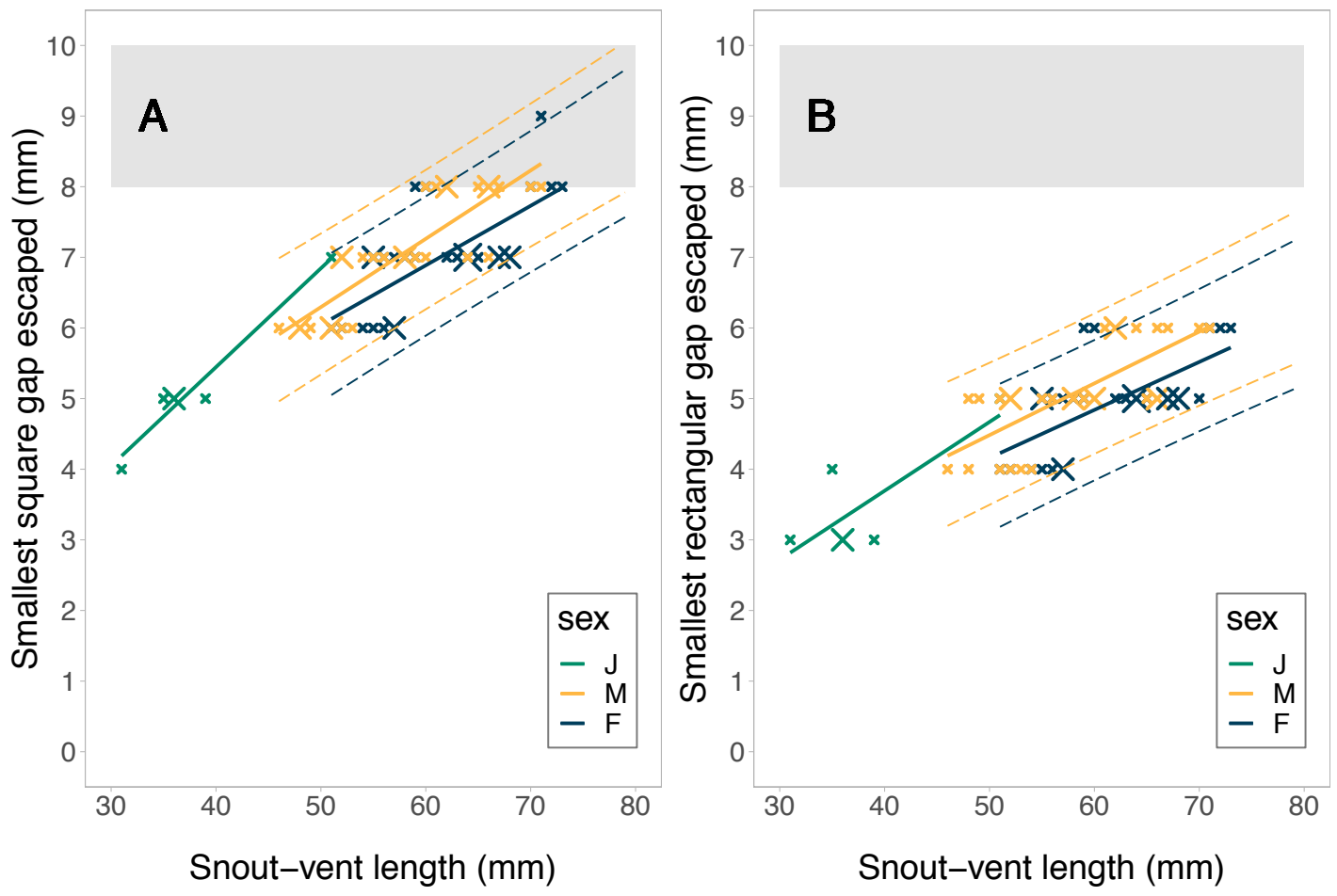

Figure 3.2. Minimum square (A) and rectangular (B) gap sizes grass skinks were able to go through in a box escape experiment. Larger points indicate multiple overlapping data points. Trend lines are linear models calculated separately for each sex/gap shape. Dashed lines are the $95 \%$ prediction intervals calculated separately for each sex/gap shape, and extending to the largest known SVL for grass skinks (79 mm SVL; Jewell 2008). Shaded region indicates the size of hole at which mouse access begins to be limited; given 24 hours, $71 \%$ of adult mice are able to exit $10 \mathrm{~mm}$ holes and none are able to exit $8 \mathrm{~mm}$ holes (Day \& MacGibbon 2007).

non-pregnant females of the same length, by $0.38 \mathrm{~mm}(\mathrm{SE} \pm 0.13 \mathrm{~mm})$ for both square and rectangular gaps. For juvenile grass skinks the linear models for minimum accessible square gap size showed that SVL had a significant effect (Table 3.1). For rectangular gap size the effect of SVL was near significant (Table 3.1). The minimum accessible gap size for juvenile grass skinks increased, per millimetre of SVL, by $0.1 \mathrm{~mm}$ $(\mathrm{SE} \pm 0.02 \mathrm{~mm})$ for square gaps and $0.1 \mathrm{~mm}(\mathrm{SE} \pm 0.04 \mathrm{~mm})$ for rectangular gaps.

For copper skinks, the linear models for minimum accessible size of both square and rectangular gaps showed that SVL had a significant effect (Table 3.1). The minimum accessible gap size increased, per millimetre of SVL, by $0.1 \mathrm{~mm}$ (SE \pm 0.01 $\mathrm{mm}$ ) for square gaps and $0.05 \mathrm{~mm}(\mathrm{SE} \pm 0.01 \mathrm{~mm})$ for rectangular gaps. 


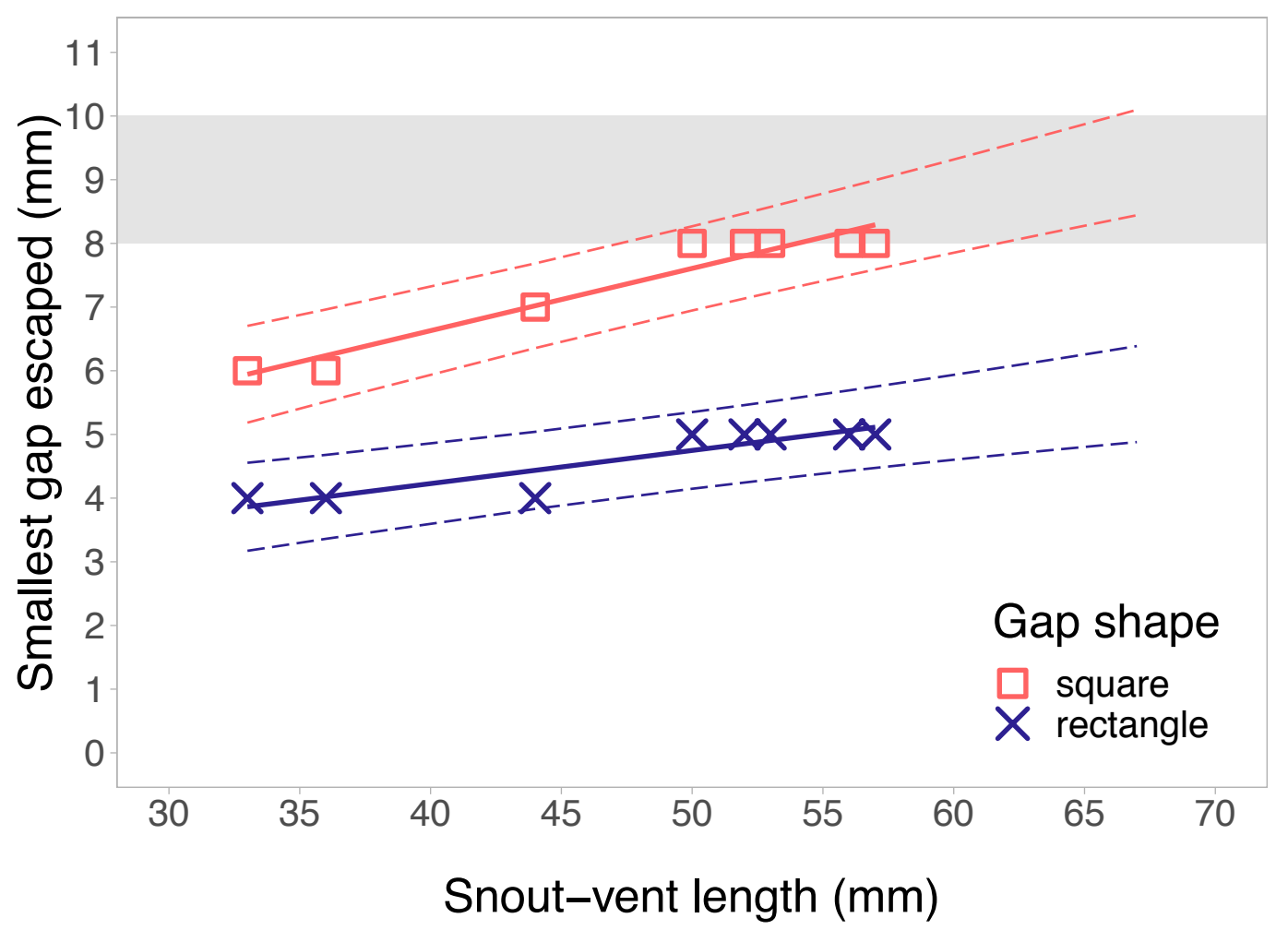

Figure 3.3. Minimum square (squares) and rectangular (Xs) gap sizes copper skinks (males, females, and juveniles) were able to go through in a box escape experiment. Trend lines are linear models calculated separately for each gap shape. Dashed lines are the $95 \%$ prediction intervals calculated separately for each gap shape, and extending to the largest known SVL for copper skinks (67 mm; Jewell 2008). Shaded region indicates the size of hole at which mice begin to be limited; given 24 hours $71 \%$ of adult mice are able to exit $10 \mathrm{~mm}$ holes and none are able to exit $8 \mathrm{~mm}$ holes (Day \& MacGibbon 2007).

The 95\% prediction intervals for the smallest gap size accessible by the largest possible grass skinks (79 mm SVL; Jewel 2008) predicted that 95\% of the largest individuals would be able to access rectangular gaps $\leq 7.6 \mathrm{~mm}$ high (Table 3.2). Of the largest females, $95 \%$ are predicted to be able to access square gaps $\leq 9.7 \mathrm{~mm}$, however for males the upper bound of the $95 \%$ prediction interval for square gaps was $10.1 \mathrm{~mm}$. A 92\% prediction interval of the smallest square gap size accessible to male grass skinks with an SVL of $79 \mathrm{~mm}$ had an upper bound of $9.9 \mathrm{~mm}$ (lower $=8.0 \mathrm{~mm}$, fit $=9.0 \mathrm{~mm}$ ). I therefore predict that $92 \%$ of the largest male grass skinks are able to enter square gaps $<10 \mathrm{~mm}$. 
Table 3.1. Results of linear model testing for effects of snout-vent length (SVL) and sex on gap escape size in grass and copper skinks. 'Square' and 'rectangular' as response variables are the minimum size of square or rectangular gap required for the skink to escape a box in an experiment.

\begin{tabular}{|c|c|c|c|c|c|}
\hline $\begin{array}{l}\text { Species } \\
\text { (life stage) }\end{array}$ & Model & Factor & Estimate $\pm \mathrm{SE}$ & $t$ & $p$ \\
\hline \multirow{4}{*}{$\begin{array}{l}\text { Grass } \\
\text { (adult) }\end{array}$} & \multirow{4}{*}{ Square $\sim \mathrm{SVL}^{*}$ sex } & Intercept & $1.826 \pm 0.898$ & 2.033 & 0.047 \\
\hline & & SVL & $0.0843 \pm 0.015$ & 5.788 & $<0.001$ \\
\hline & & SexM & $-0.368 \pm 1.175$ & -0.313 & 0.756 \\
\hline & & SVL: SexM & $0.012 \pm 0.020$ & 0.635 & 0.528 \\
\hline \multirow{4}{*}{$\begin{array}{l}\text { Grass } \\
\text { (adult) }\end{array}$} & \multirow{4}{*}{ Rectangular $\sim \mathrm{SVL}^{\star}$ sex } & Intercept & $0.765 \pm 0.908$ & 0.843 & 0.403 \\
\hline & & SVL & $0.068 \pm 0.015$ & 4.614 & $<0.001$ \\
\hline & & SexM & $0.055 \pm 1.187$ & 0.046 & 0.963 \\
\hline & & SVL: SexM & $0.005 \pm 0.020$ & 0.271 & 0.787 \\
\hline \multirow{3}{*}{$\begin{array}{l}\text { Grass } \\
\text { (adult) }\end{array}$} & \multirow{3}{*}{ Square $\sim$ SVL + sex } & Intercept & $1.402 \pm 0.598$ & 2.345 & 0.023 \\
\hline & & SVL & $0.091 \pm 0.010$ & 9.469 & $<0.001$ \\
\hline & & Sex & $0.375 \pm 0.131$ & 2.855 & 0.006 \\
\hline \multirow{3}{*}{$\begin{array}{l}\text { Grass } \\
\text { (adult) }\end{array}$} & \multirow{3}{*}{ Rectangular $\sim \mathrm{SVL}+$ sex } & Intercept & $0.582 \pm 0.602$ & 0.967 & 0.338 \\
\hline & & SVL & $0.071 \pm 0.001$ & 7.305 & $<0.001$ \\
\hline & & Sex & $0.375 \pm 0.132$ & 2.841 & 0.006 \\
\hline \multirow{2}{*}{$\begin{array}{c}\text { Grass } \\
\text { (juvenile) }\end{array}$} & \multirow{2}{*}{ Square $\sim \mathrm{SVL}$} & Intercept & $-0.147 \pm 0.587$ & -0.250 & 0.814 \\
\hline & & SVL & $0.140 \pm 0.02$ & 9.182 & $<0.001$ \\
\hline \multirow{2}{*}{$\begin{array}{c}\text { Grass } \\
\text { (juvenile) }\end{array}$} & \multirow{2}{*}{ Rectangular $\sim$ SVL } & Intercept & $-0.203 \pm 1.406$ & -0.145 & 0.892 \\
\hline & & SVL & $0.097 \pm 0.037$ & 2.669 & 0.056 \\
\hline \multirow{2}{*}{$\begin{array}{l}\text { Copper } \\
\text { (all) }\end{array}$} & \multirow{2}{*}{ Square $\sim$ SVL } & Intercept & $2.71 \pm 0.512$ & 5.306 & 0.002 \\
\hline & & SVL & $0.098 \pm 0.010$ & 9.237 & $<0.001$ \\
\hline \multirow{2}{*}{$\begin{array}{l}\text { Copper } \\
\text { (all) }\end{array}$} & \multirow{2}{*}{ Rectangular $\sim$ SVL } & Intercept & $2.146 \pm 0.466$ & 4.603 & 0.003 \\
\hline & & SVL & $0.052 \pm 0.010$ & 5.402 & 0.002 \\
\hline
\end{tabular}

The 95\% prediction intervals for the smallest gap size accessible by the largest possible copper skinks (67 mm SVL; Jewel 2008) predict that 95\% of the largest adults would be able to enter square gaps $\leq 10.1 \mathrm{~mm}$ and rectangular gaps $\leq 6.4 \mathrm{~mm}$ (Table 
3.2). A $90 \%$ prediction interval of the smallest square gap size accessible to copper skinks with an SVL of $67 \mathrm{~mm}$ had an upper bound of $9.9 \mathrm{~mm}$ (lower $=8.6 \mathrm{~mm}$, fit $=$ $9.3 \mathrm{~mm}$ ). I therefore predict that $90 \%$ of the largest copper skinks are able to enter square gaps $<10 \mathrm{~mm}$.

\subsubsection{Rock pile modelling}

Based on my findings from the box escape experiment and data from Day and MacGibbon (2007), I determined the bounds for the different categories as follows (see discussion section of this chapter for in-depth rationale).

Optimal gaps All dimensions $>3 \mathrm{~mm}$, at least one dimension $<10 \mathrm{~mm}$.

Small gaps Any dimension $\leq 3 \mathrm{~mm}$.

Large gaps All dimensions $\geq 10 \mathrm{~mm}$.

As the proportions of smaller rocks increased, the numbers of optimal and small gaps increased, and the number of large gaps decreased (Figure 3.4). For rock piles composed entirely of rocks of the larger grade, $41 \%$ (95\% CI: 36-43\%) of gaps measured were optimal, 52\% (95\% CI: 48-65\%) large and 7\% (95\% CI: 4-9\%) small. For rock piles composed entirely of rocks of the smaller grade, $66 \%$ (95\% CI: $62 \%-75 \%)$ of gaps measured were optimal, 6\% (95\% CI: 0-13\%) large and 28\% (95\% CI: 17-36\%) small.

Table 3.2. The 95\% prediction intervals for the smallest gap size accessible by the largest possible skinks in a box escape experiment. Maximum skink sizes from Jewel, 2008.

\begin{tabular}{ccccccc}
\hline Species & Sex & SVL $(\mathbf{m m})$ & Gap shape & Fit $(\mathbf{m m})$ & Lower $(\mathbf{m m})$ & Upper $(\mathbf{m m})$ \\
\hline Grass & Male & 79 & Rectangular & 6.6 & 5.5 & 7.6 \\
Grass & Male & 79 & Square & 9.0 & 7.9 & 10.1 \\
Grass & Female & 79 & Rectangular & 6.2 & 5.1 & 7.2 \\
Grass & Female & 79 & Square & 8.6 & 7.6 & 9.7 \\
Copper & - & 67 & Rectangular & 5.6 & 4.9 & 6.4 \\
Copper & - & 67 & Square & 9.3 & 8.4 & 10.1 \\
\hline
\end{tabular}




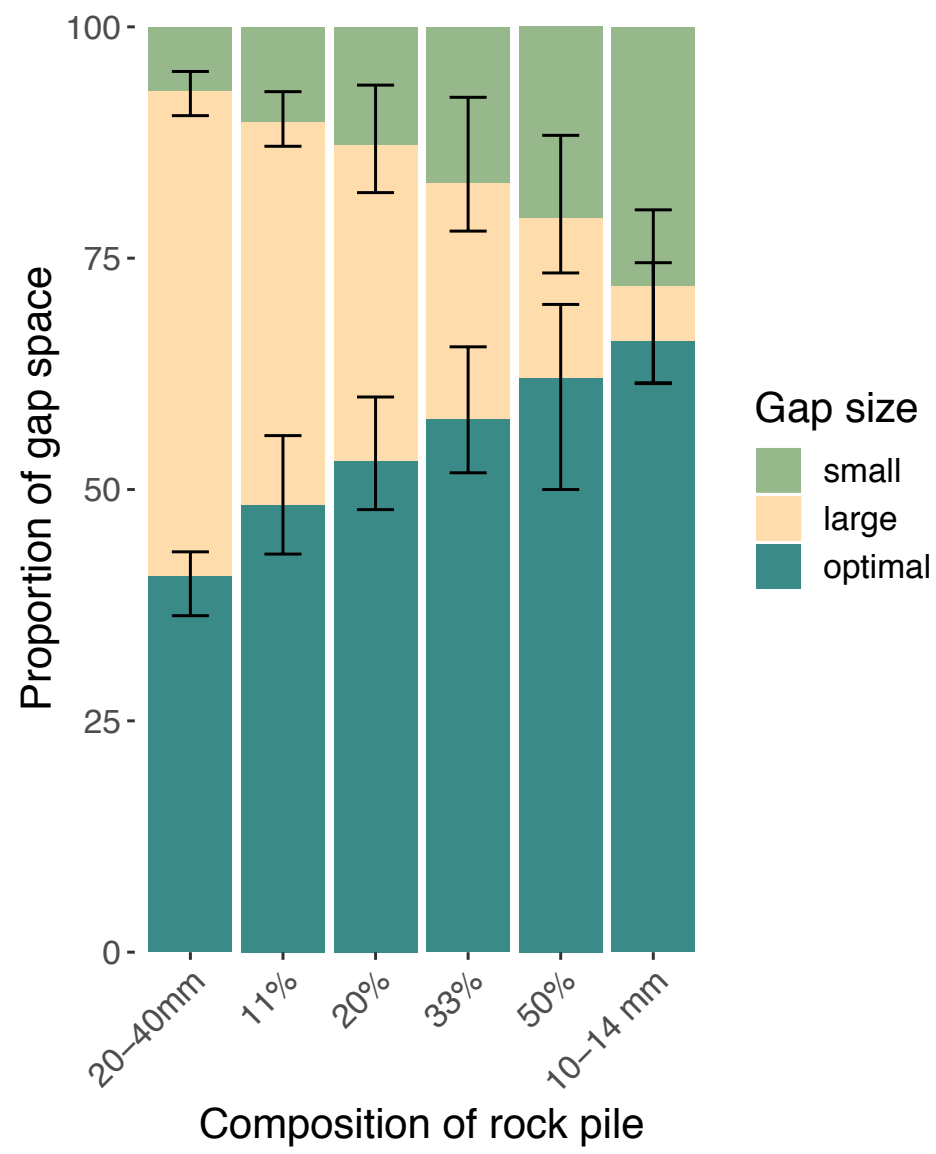

Figure 3.4. Proportion of measured gap space that is 'small', 'large', and 'optimal' in computersimulated rock piles. The piles are composed of different proportions of rocks of grades 10-14 mm and $20-40 \mathrm{~mm}$. The two numbers of the grades indicate the sizes of two screens used to sort the rocks; i.e. the rock will not go through a screen of the smaller size but will go through a screen of the larger size. Two compositions were composed of only one grade of rocks. For the rock piles represented by a percentage, the percentage represents how much of the mix is rocks of the smaller grade. Error bars are 95\% confidence intervals calculated using the percentile method. $\mathrm{N}=35$ per composition.

\subsection{DISCUSSION}

In order to estimate the accessibility of different rock piles to skinks and mice, I obtained information on the size of gaps that these species can access. I used results from a box escape experiment on skinks, with comparison to published mouse data (Day \& MacGibbon 2007), to determine the bounds of 'small', 'optimal', and 'large' gaps for a mouse-skink predator-prey system. Understanding the sizes of gaps accessible to skinks and mice allowed me to use the computer modelling method from Chapter 2 to 
predict the accessibility of different rock pile designs. These predictions can be used to protect endemic New Zealand skinks from mice by providing rock piles with interstitial spaces that are optimised for skinks to use as refuges and restrict mouse access.

The method I used to model interstitial spaces in rock piles categorises spaces as either small, optimal, or large (Chapter 2). Large spaces are accessible to mice or skinks, optimal spaces only to skinks, and small spaces are inaccessible to both. I used $10 \mathrm{~mm}$ as the upper bound for my definition of optimal gaps for several reasons. I compared the results from the box escape experiment with data for mice from the literature (Day \& MacGibbon 2007). The methods used in this mouse escape experiment differed from my skink escape experiment in that the mice were given up to 24 hours to get through the holes, and food, water, and shelter were accessible only through the barrier (Day \& MacGibbon 2007). The results therefore represent close to the physical limits of mice, and are not necessarily the same gap sizes they will be willing to pass through when their motivation is less extreme. Mice may 'give up' on accessing difficult gaps when there are other easier sources of food or shelter, as predicted by optimal foraging theory (Pyke et al. 1977). Mice may be opportunistic predators of lizards, preying on lizards only when the cost-benefit ratio swings in their favour during periods of vulnerability (e.g. when there is an abundance of neonate lizards) so increasing the cost of predation may reduce its occurrence (Wedding 2007). One of the largest skinks I measured was only able to go through a $9 \mathrm{~mm}$ square hole, although all others were able to go through square holes between $4-8 \mathrm{~mm}$, and all were able to go through rectangular holes 3-6 $\mathrm{mm}$ high. The upper bounds of the $95 \%$ prediction intervals for gap access by the largest possible skinks were below $8 \mathrm{~mm}$ for rectangular gaps for both species and sexes. However, the upper bound for square gaps for copper skinks and male grass skinks was $10.1 \mathrm{~mm}$. A $<10 \mathrm{~mm}$ square gap therefore might be good for most skinks although too small for the very largest skinks, and a $<8 \mathrm{~mm}$ tall rectangular gap is likely good for all skinks. This overlap of the largest skinks with the $8-10 \mathrm{~mm}$ restriction band for mice, as well as a desire to err on the permissive side to allow extra space for pregnant and larger skinks, were further reasons to set $10 \mathrm{~mm}$ as the upper limit for optimal gap size. I used $3 \mathrm{~mm}$ 
as the lower bound for optimal gaps because $3 \mathrm{~mm}$ rectangular gaps were the smallest gap that any skinks were able to pass through.

Since this method of protecting prey from predators relies on exploiting a size difference, it is important to consider how the largest skinks will be affected. This includes both pregnant females and large adults. Predation rates may be different for individuals of different sizes. Mean SVL was found to increase when rodents were removed in populations of McGregor's skinks (Newman 1994) and shore skinks (Towns 1991), and male SVL increased in a copper skink population when mice were removed (Nelson et al. 2016), suggesting that larger adults are more vulnerable to predation. This was attributed to the idea that smaller lizards are better able to avoid predation in refuges inaccessible to rodents (Towns 1991). If this is correct, then creating rock piles with optimised interstitial spaces may mean a greater number of spaces sized for larger adults to evade predators, reducing the impact on larger adults. It also means that this approach may be particularly useful for increasing skink recruitment, as juveniles are able to make use of small interstitial spaces to evade predators. Another study found that higher numbers of mice were correlated with fewer juvenile skinks, indicating a suppression of recruitment (Wedding 2007). In this case, it was suggested that there were periods when neonates/juveniles were particularly abundant and vulnerable, making development of a search image by mice easier and more rewarding (Wedding 2007). This study was undertaken in a dune system rather than a rocky habitat; therefore it is possible that the presence of rock piles with appropriately sized interstitial spaces might make it harder for mice to prey on neonates and reduce their likelihood of forming a search image during periods of neonate abundance.

Pregnant skinks, being larger, likely need larger retreats than non-pregnant skinks, although viviparous species may have an advantage as their extra mass is more malleable than the rigid eggs of oviparous species (Schwarzkopf et al. 2010). New Zealand's skinks are unusual in that all species except the egg-laying skink (O. suteri) are viviparous (Cree \& Hare 2016). In viviparous Australian skinks, pregnant females may gain up to $46 \%$ of their body mass in clutch weight, increasing their predation risk, partially due to the physical burden reducing their ability to flee (Shine 1980). Pregnant 
skinks were not tested in this experiment. If the optimised interstitial spaces are not large enough to protect pregnant skinks, this could make them more vulnerable to predation and reduce recruitment. Recruitment may also be affected by the size of individuals within the population; larger females produce larger clutches (Cree \& Hare 2016). These factors need to be taken into consideration when designing rock piles, and for this reason it may be prudent to ensure the presence of some larger gaps within the pile rather than seeking to include only optimally sized gaps.

For some species, predation is influenced less by the absolute size of a crevice relative to the size of the predator, and more by ability of the prey to wedge itself tightly and fully into a gap, preventing its removal (Schwarzkopf et al. 2010). However, as mice are gnawing animals that do not need to remove their entire prey in order to eat it, and are known to be capable of eating even large, live animals if they cannot escape (e.g. albatross chicks; Wanless et al. 2007), it is likely that in the case of skinks and mice the important factor is the exclusion of the mouse from the space.

When suggesting the best composition for rock pile enhancements, we should maximise the proportion of optimal spaces in piles. Aside from this, we can also aim either to maximise small spaces and minimise large spaces, or maximise large spaces and minimise small spaces. Maximising the proportion of large gaps as well as optimal gaps will maximise accessibility for skinks, reducing the likelihood of excluding pregnant and larger skinks. I posit that maximising the proportion of large spaces and minimising the amount of small spaces (while also maximising optimal spaces) is the best approach, as a rock pile that is largely inaccessible to skinks is much less useful than one that is largely accessible to skinks with some areas that are inaccessible to mice. Erring on the side of providing habitat for pregnant and large skinks is also advisable because survival of pregnant skinks is necessary for population survival, and an inadvertent increase of predation pressure on large individuals may have unintended evolutionary consequences. Some Oligosoma species are known to be aggressive and territorial (van Winkel et al. 2018), so a large number of optimal gaps is necessary to sustain a large population. Although large gaps may still form a sizable proportion of the rock pile, having more optimal gaps reduces the size of the large gaps compared with 
piles of larger rocks, so there will be fewer spaces large enough for mice to build nests (i.e. an $11 \mathrm{~mm}$ gap is preferable to a $60 \mathrm{~mm}$ gap).

Within the modelled rock piles, as optimal space increases, small space also increases at approximately the same rate. This makes it difficult to maximise optimal gaps while minimising small gaps, as all the mixes are compromises with no clear best ratio. However, I hypothesise that a rock pile composed of entirely larger rocks (20-40 $\mathrm{mm}$ ) will be best as it has the lowest proportion of small gaps and is therefore likely to be the most accessible to skinks, and still has a reasonable proportion of optimal spaces (41\%). This design should be tested in experiments with skinks and mice.

The species I tested are relatively small for New Zealand skinks. Comparing size of species and clades listed by van Winkel et al. (2018) with sizes of copper and grass skinks, seven have smaller SVLs, 14 are within the same range, and 36 are larger (excluding other grass skink clades). In addition to SVL, the morphology of individual species (e.g. slender versus fat or robust body type) could affect the gaps they are able to fit into. Also, New Zealand geckos are generally heavier and more robust than New Zealand skinks and likely require larger refuge spaces. Therefore, the rocks I recommend should be deployed with caution depending on the species that may be available to colonise them. These experiments could be repeated with different predator and prey species to hypothesise protective rock piles for other systems.

As these findings indicate a narrow range of gap sizes that benefit skinks, an alternative approach could be to create an artificial structure with precisely-sized gaps. A benefit of the rock pile approach I recommend in this chapter is that there is a diversity and complexity of gaps which can encourage diversity of invertebrates (a food source) by providing variable habitat (Tokeshi \& Arakaki 2012). Additionally, artificial rocks which mimic natural rock attributes (cavity geometry, thermal properties) appear to be preferable retreats for reptiles and invertebrates than simple concrete pavers (Webb \& Shine 2000; Croak et al. 2010). However, the alternative approach allows for precise control of the size of gaps, which could be an improvement over juggling ratios in rock piles. These two approaches could be compared experimentally. 
The predicted rock pile designs outlined here could inform not only mitigation translocations, but also conservation efforts for non-translocated lizard populations; for instance, in backyard conservation (Department of Conservation 2009). Terrestrial habitat enhancement for other species could also be aided by designing habitats using this technique. In the current study, the skinks used were relatively small, allowing the size difference between the skinks and mice to be exploited. This approach can be generalised to systems where there is a size difference between predator and prey that can be exploited. 
ChAPTER 3. DeSIGNING ROCK PILES 


\section{CHAPTER 4}

\section{Creating artificial habitat to protect endemic skinks (Scincidae) from introduced mice (Mus musculus) following a mitigation translocation}

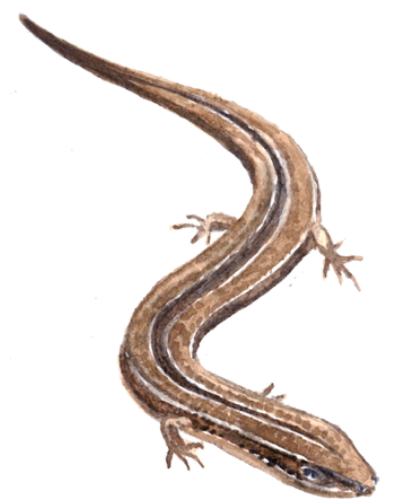

\subsection{INTRODUCTION}

Introduced predators can have detrimental effects on evolutionarily naive prey species (Salo et al. 2007). This is a challenge in the conservation of protected species, particularly when introduced predators cannot be eradicated (Hulme 2006). The vulnerability of prey to predators can be affected by aspects of habitat such as complexity or the presence of refuges (Persson \& Eklöv 1995; Hesterberg et al. 2017). Refuges can attenuate the impacts of introduced predators on prey (Stuart-Smith et al. 2007), and prey species may behave differently in the presence of introduced predators to make use of the protection of refuges (Whitlow et al. 2003; Sowersby et al. 2016). Creation of refuges via habitat manipulation is a strategy that could be employed to protect threatened species from introduced predators (Sinclair et al. 1998; Chapter 3). 
Introduced predators have become established in many areas where eradication is impossible using currently available technology (e.g. brown tree snakes Boiga irregularis in Guam, Fritts \& Rodda 1998; cats Felis catus and red foxes Vulpes vulpes in Australia, Smith \& Quin 1996; Rodentia species in many areas worldwide, Doherty et al. 2016). Predator exclusion fencing can be used to eradicate predators from small to medium areas (e.g. up to 3,336 ha at Maungatautari Ecological Island, Connolly et al. 2009), however this is expensive and must be maintained indefinitely. Fences can cause population fragmentation, and may also compound the problem of prey naivety; in the absence of predators (or of particular predator species), prey may lose anti-predator defences and recognition abilities, either ontogenetically or evolutionarily (Moseby et al. 2016; Muralidhar et al. 2019). Other common management approaches are the suppression or control of introduced predators using trapping, poisoning, or shooting; these can have varying efficacy depending on technique, species and environment (Moseby et al. 2015).

In New Zealand, Predator Free 2050 is a government initiative which aims to eradicate possums (Trichosurus vulpecula), rats (Rattus spp.), and mustelids (Mustela spp.) (New Zealand Cabinet 2016). However, other introduced predators, including mice (Mus musculus), are not targeted by Predator Free 2050. Controlling some predators and not others can cause mesopredator or competitive release; these have previously led to irruptions of mouse populations in New Zealand (Ruscoe et al. 2011; Norbury et al. 2013). Mice can negatively impact native species via competition (Huyser et al. 2000), as well as via direct predation on vertebrates and invertebrates, including animals significantly larger than themselves (e.g. widespread predation on Tristan albatross chicks Diomedea dabbenena following mesopredator/competitive release; Wanless et al. 2007). In situations where control, eradication, or exclusion of introduced predators is problematic, the conservation of vulnerable prey species could benefit from the incorporation of other complementary approaches.

New Zealand's endemic lizard fauna is both highly diverse and threatened, with 43 gecko (Diplodactylidae) and 63 skink (Scincidae) species (van Winkel et al. 2018). Of these 106 species, 81 are classified as Threatened or At Risk by the New Zealand Threat 
Classification System (NZTCS; Hitchmough et al. 2016a). The major agents of decline are habitat destruction and predation by a suite of introduced mammals, to which New Zealand's lizards are vulnerable due to evolutionary naivety (Hitchmough et al. 2016b). Many endemic New Zealand lizard species live in rocky habitats, where they bask on exposed surfaces and use interstitial spaces as refuges (Towns 1991, 1996; Towns \& Ferreira 2001; Hoare et al. 2007; Adams 2009). Rocky habitats can also be important refugia for the last remaining fragments of nearly extirpated populations, such as the last mainland population of Whitaker's skink (Oligosoma whitakeri; Hoare et al. 2007).

Mice are an introduced predator of skinks in New Zealand, and are capable of attacking and killing juveniles and adults (Burt 1927; Newman 1988; Ainsworth et al. 1991; Newman 1994; Hoare et al. 2007; Wedding 2007; Norbury et al. 2013; Norbury et al. 2014). Mice have been responsible for declines (some dramatic) in populations of McGregor's skinks (Oligosoma macgregori), northern grass skinks (O. polychroma, hereafter grass skinks), copper skinks (O. aeneum), and shore skinks (O. smithi) (Newman 1994; Ussher 2006 as reported in Wedding 2007). Mice are harder to control than larger introduced mammals and are therefore often not targeted in mammal control operations (e.g. Predator Free 2050; Innes et al. 2012; Hitchmough et al. 2016b). Mice, like skinks, may live in and build nests in rocky habitats, and have been directly observed to attack skinks basking near rock refuges (Norbury et al. 2014).

Mitigation translocations are the movement of living organisms from a future development site to another location in an effort to mitigate damage caused (International Union for the Conservation of Nature/Species Survival Commission [IUCN/SSC] 2013) and are usually undertaken to fulfil legal or regulatory requirements to mitigate negative effects on wildlife (in New Zealand, the Wildlife Act 1953, and the Resource Management Act 1991). Mitigation translocations are intended to prevent or reduce harm caused to animals as a result of construction, although their effectiveness has been questioned (Germano et al. 2015). Translocations are generally technically challenging (Germano et al. 2014), and mitigation translocations can be especially so due to both the need to work around construction, and goals being to meet legal requirements rather than purely to provide conservation benefit (Chapter 5). Mitigation 
translocations represent both an opportunity to test techniques for aiding the persistence of populations of endemic prey species and a situation where the application of such techniques could enhance conservation outcomes.

In 2014, construction began on the Transmission Gully Motorway, a $27 \mathrm{~km}$ four-lane motorway in Wellington, New Zealand. A requirement of this project was the mitigation translocation of lizards salvaged from the road footprint. The lizard management plan required the construction of replacement habitat at the release sites, a technique that is common in mitigation translocations of lizards in New Zealand. The lizard management plan also identified a lack of scientific evidence informing the design of constructed habitats, which led to an agreement between the New Zealand Transport Agency (NZTA), the Department of Conservation (DOC), the construction company $(\mathrm{CPB} / \mathrm{HEB})$, and ecological consultants hired to undertake the salvage and translocation (Boffa Miskell Limited; BML) to support research with the aim of refining habitat design and increasing the likelihood of successful conservation outcomes. This led to my involvement in the project, undertaking research in collaboration with staff from BML and $\mathrm{CPB} / \mathrm{HEB}$.

In Chapter 3, I hypothesised designs for rock piles which aim to provide protection for skinks from mice by optimising the size of interstitial spaces within the rock pile to allow skinks to enter and use refuges but restrict access by mice. I hypothesised that a pile constructed of $20-40 \mathrm{~mm}$ grade rocks would create refuges for skinks that are inaccessible to mice, and increase the cost-benefit ratio of predation on skinks by mice, thereby reducing predation (Chapter 3). This hypothesised design would benefit translocated skinks even in the presence of predators, as predator control is not always implemented effectively in mitigation translocations, and very rarely over the long term (Chapter 5).

My first aim was to test rock piles of the previously hypothesised design (from Chapter 3) for their effectiveness at protecting endemic New Zealand skinks from mouse predation. I investigated this using a field experiment looking at skinks and predators at the installed rock piles at Transmission Gully, and a lab experiment looking at the ability of mice to penetrate rock piles. I also aimed to use Transmission Gully as a 
case study to evaluate the effectiveness of mitigation translocations for the conservation of endemic lizards. I did this by investigating the number of lizards salvaged and translocated compared to the salvage effort; their survivorship, health, and dispersal post-translocation; and by looking at the challenges faced in implementing the translocation.

\subsection{METHODS}

\subsubsection{Summary of methods}

At Transmission Gully, I installed rock piles of the hypothesised best design (20-40 mm grade rocks; Chapter 3) as well as an alternative design (a mix of 20-40 mm and 10-14 $\mathrm{mm}$ grade rocks) and control piles ( 100-400 mm rocks) for comparison. I monitored lizards at the release sites before and after release. I also performed a lab experiment placing mice in cages with rocks either of the hypothesised best design (20-40 mm grade rocks) or larger control rocks $(70-150 \mathrm{~mm})$ to test for a difference in the ability of mice to penetrate piles of rocks of different sizes. I used data provided by CPB/HEB and BML for salvage effort and numbers of lizards salvaged to assess the effectiveness of the salvage and release.

\subsubsection{Study area}

The study area was Transmission Gully, a construction site for a $27 \mathrm{~km}$ motorway in the lower North Island of New Zealand. The skink release sites were four separate sites at the north end of Transmission Gully, near -40.985, 174.966 (Figure 4.1).

Within the road alignment at Transmission Gully (199 ha), most habitat was assessed as poor or marginal quality for endemic New Zealand lizards, although there were some fragments of higher quality (Leighton HEB Joint Venture 2015) (Table 4.1). The only habitats assessed as high quality were boulderfields, which varied from low quality (e.g. scattered rock with no cavities, no native species found during preliminary surveys, historically heavily grazed) to high quality (e.g. stacked boulderfields with abundant cavities and areas of low shrubs) and in total covered only about 0.5 ha. A preliminary lizard survey undertaken by BML in 2010 indicated only low numbers of 


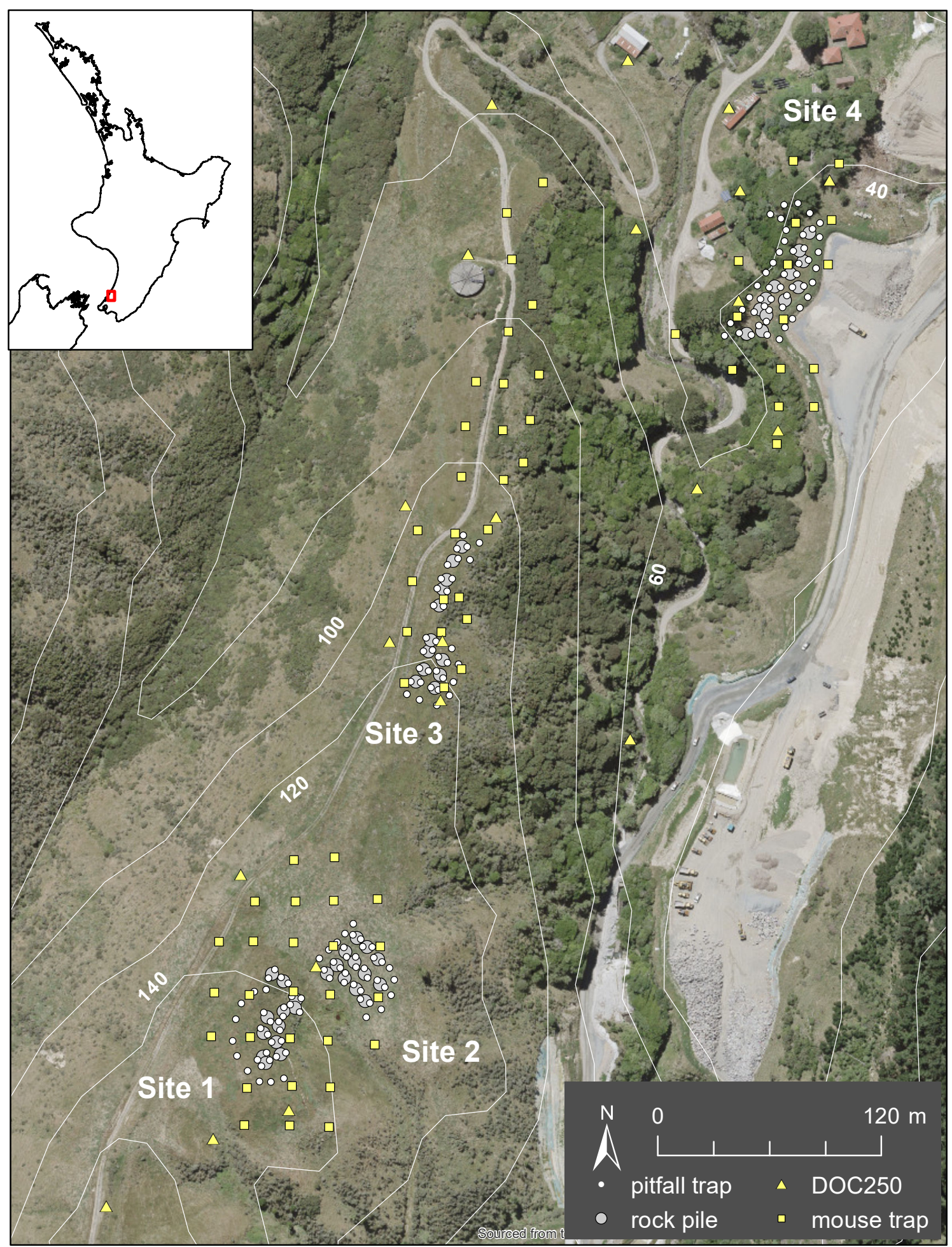

Figure 4.1. Sites for release, and rock piles and traps installed at Transmission Gully as part of a mitigation translocation of lizards. White lines are topographical lines, with the numbers indicating metres above sea level. Insert shows larger map's location on New Zealand's North Island, Te Ika-aMāui. 
Table 4.1. Habitat types within the Transmission Gully designation (data from Leighton HEB Joint Venture 2015). Species here include kanuka Kunzea ericoides ornate skink O. ornatum, brown skink O. zelandicum, barking gecko Naultinus punctatus, and forest gecko Mokopirirakau granulatus.

\begin{tabular}{|c|c|c|}
\hline Description & $\begin{array}{c}\text { Area (ha) } \\
\text { (\% of total } \\
\text { designation) }\end{array}$ & Quality and suitability of habitat to lizards \\
\hline Improved pasture & $78(39 \%)$ & Poor \\
\hline $\begin{array}{l}\text { Exotic vegetation \& } \\
\text { plantation pine }\end{array}$ & $45(23 \%)$ & Poor \\
\hline Cropland & $3(2 \%)$ & Poor \\
\hline $\begin{array}{l}\text { Rough pasture, } \\
\text { pioneer shrublands } \\
\text { and low scrub }\end{array}$ & $16(8 \%)$ & $\begin{array}{l}\text { May be suitable for grass skink, copper skink, } \\
\text { ornate skink, brown skink }\end{array}$ \\
\hline Wetland & $2(1 \%)$ & $\begin{array}{c}\text { May be suitable for grass skink, copper skink, } \\
\text { ornate skink, brown skink }\end{array}$ \\
\hline $\begin{array}{l}\text { Indigenous } \\
\text { shrubland and scrub }\end{array}$ & $16(8 \%)$ & $\begin{array}{l}\text { May be suitable for barking gecko and forest } \\
\text { gecko }\end{array}$ \\
\hline $\begin{array}{c}\text { Regenerating } \\
\text { kānuka scrub \& } \\
\text { forest }\end{array}$ & $4(2 \%)$ & $\begin{array}{l}\text { May be suitable for barking gecko and forest } \\
\text { gecko }\end{array}$ \\
\hline $\begin{array}{l}\text { Regenerating } \\
\text { broadleaved scrub } \\
\text { and forest }\end{array}$ & $12(6 \%)$ & $\begin{array}{l}\text { May be suitable for barking gecko and forest } \\
\text { gecko }\end{array}$ \\
\hline $\begin{array}{l}\text { Mature or maturing } \\
\text { indigenous forest }\end{array}$ & $6(3 \%)$ & $\begin{array}{l}\text { May be suitable for barking gecko, forest } \\
\text { gecko, ornate skink, brown skink }\end{array}$ \\
\hline $\begin{array}{l}\text { Built-up area, roads } \\
\text { and margins }\end{array}$ & $17(9 \%)$ & $\begin{array}{l}\text { Houses and gardens may provide moderate to } \\
\text { good quality habitat for terrestrial skinks. Road } \\
\text { verges may provide limited moderate quality } \\
\text { habitat for terrestrial skinks }\end{array}$ \\
\hline Boulderfields & $0.5(<1 \%)$ & $\begin{array}{l}\text { Some are high quality habitat suitable for } \\
\text { terrestrial skinks and geckos }\end{array}$ \\
\hline
\end{tabular}

lizards (grass skinks; copper skinks; and raukawa gecko Woodworthia maculata) present across the designation, although this survey was low effort with only 64 artificial cover object (ACO) checks and 20 hours of hand searching (Boffa Miskell Limited 2011). A detailed lizard management plan was prepared by BML and CPB/HEB, which acknowledged that salvage is a high-effort activity with a low return (Leighton HEB 
Joint Venture 2015). The lizard management plan therefore included predator control, the construction of new boulderfields, and enhancement of existing habitats as additional mitigation strategies (Leighton HEB Joint Venture 2015).

The four release sites were chosen to be outside of the construction zone in a mitigation planting area with ongoing protection, to have good drainage, to have a sunny aspect, and to be accessible once construction is complete. The release sites were all located within $\sim 1 \mathrm{~km}$ of each other, outside the road designation, and within $\sim 2 \mathrm{~km}$ of where most (55 out of 80 ) salvaged lizards were found. All release sites were sloping hillsides covered with rank grass ( $\sim 200 \mathrm{~mm}$ to $1 \mathrm{~m}$ long) and had sparse coverings of weeds (e.g. thistles and daisies of the Asteraceae family, gorse Ulex europaeus) and native species (e.g. Muehlenbeckia spp., kānuka Kunzea ericoides, tauhinu Ozothamnus leptophyllus). Sites 1, 2, and 3 were located on the top of a ridgeline on sloping hillsides from $\sim 100-140 \mathrm{~m}$ above sea level (Figure 4.1). Site 4 was located $\sim 40 \mathrm{~m}$ above sea level and was bordered by a fringe of Cupressus macrocarpa and native trees (e.g. rewarewa Knightia excelsa, kānuka, Pittosporaceae species) and a steep drop-off on one side, and weeds (mainly tradescantia Tradescantia fluminensis and inkweed Phytolacca octandra) on the other (Figure 4.1).

\subsubsection{Rockpiles}

Rock piles were constructed from December 2017 to January 2018; 12 piles were constructed at each of the four release sites (Figure 4.2). There were three different rock pile types, with the general construction remaining consistent but the sizes of the rocks varying. The general design was a roughly round pile of rocks $\sim 2 \mathrm{~m}$ in diameter and $0.5 \mathrm{~m}$ in height; underneath the rocks there was a shallow sloping hole for drainage and a $0.5 \mathrm{~m}$ layer of organic debris (i.e. mulch, leaf litter, log rounds) to provide substrate for invertebrates (Figure 4.3). Native plants (i.e. matagouri Discaria toumatou, pohuehue Muehlenbeckia complexa, flax Phormium spp., mingimingi Coprosma propinqua, thickleaved mahoe Melicytus crassifolius) were planted around the edges of the rock piles, however due to construction delays this did not occur until May 2018, after the lizard release. Grass seed was scattered around the edges of the constructed rock piles after 
construction to increase vegetation cover at the edges, and the rock piles were seeded 10 days prior to lizard release with leaf litter containing invertebrates collected from local reserves, which was sprinkled on the piles and inserted into some gaps. There were at least five metres separating adjacent rock piles.

I chose the rocks for the piles based on hypothesised best designs developed from previous research, using computer modelling to predict the sizes of interstitial spaces in rock piles and estimate accessibility for skinks and mice (Chapter 3). I designed control piles based on the original lizard management plan design, i.e. what would have been constructed if the mitigation had taken place without this experiment. Graded rocks were purchased from wholesalers and rocks for the control piles were salvaged from the construction site.

The three designs were as follows:

Single grade: 20-40 mm graded rocks (hypothesised best design from Chapter 3; Figure 4.3)

Mixed grade: $10-14 \mathrm{~mm} \& 20-40 \mathrm{~mm}$ graded rocks in a 1:1 ratio (alternative design from Chapter 3)

Control: $~ 100-400 \mathrm{~mm}$ diameter rocks (Figure 4.3)

At sites 1 and 4, half the piles were the single grade design and half were control piles, arranged using a stratified randomised design (Figure 4.2). Sites 1 and 4 were where captive lizards were released, and I aimed to test the differences between only the hypothesised best design and the control. I aimed to investigate differences in movement of released lizards and colonisation by resident lizards. At sites 2 and 3 there were four piles each of the control, single grade, and mixed grade designs, arranged using a stratified randomised design. No lizards were released at sites 2 and 3, so I aimed to test the difference in colonisation by resident lizards between the three different rock pile types. Stratification was designed based on the shape of the release sites; I stratified the pile locations into pairs (sites 1 and 4 ) or groups of three (sites 2 and 3 ) and randomised within each stratum to avoid grouping piles of one type at one end of a site and the possibility of spatially confounding factors (e.g. slope, vegetation, aspect). 

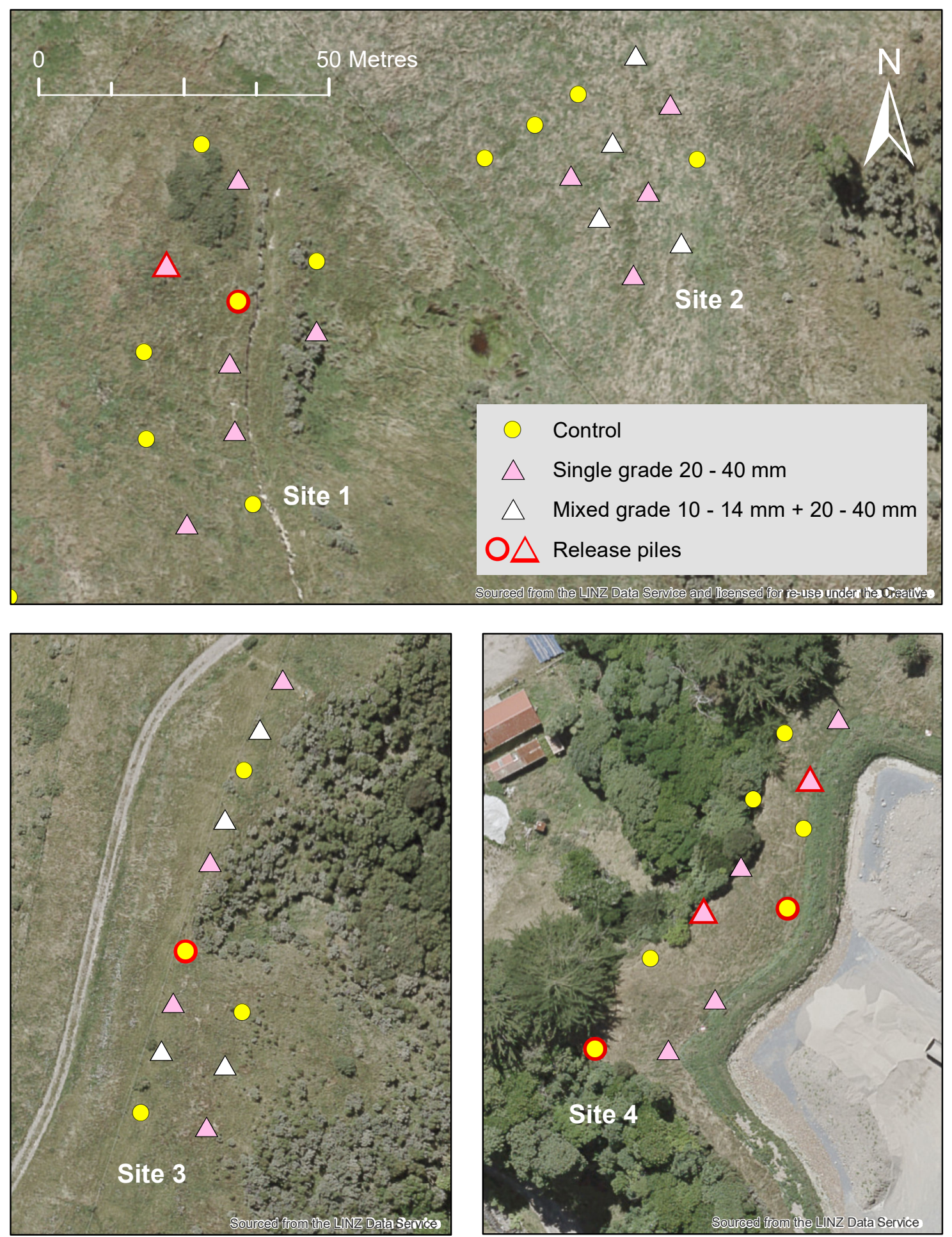

Figure 4.2. Details of rock piles installed at lizard mitigation release sites at Transmission Gully. 


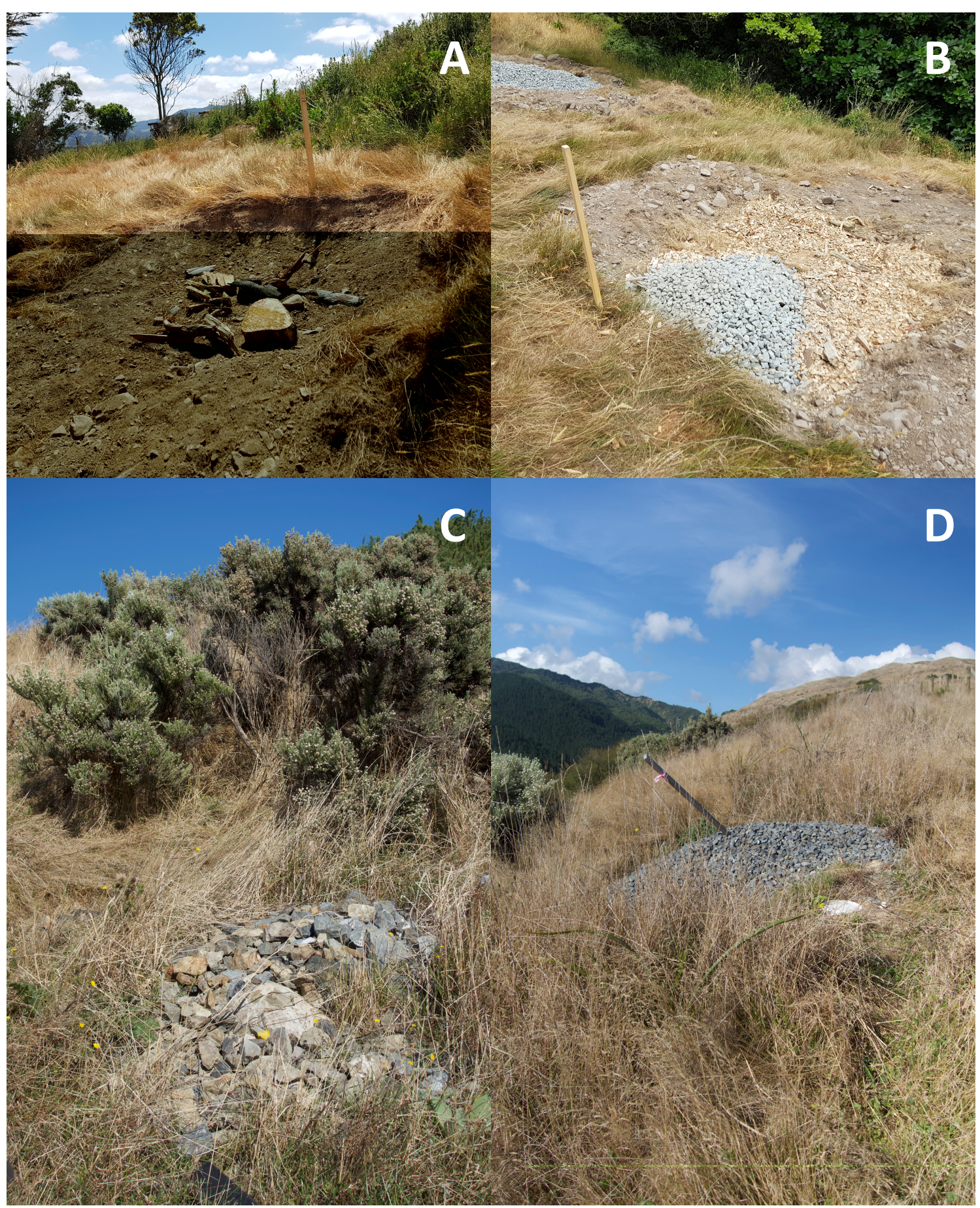

Figure 4.3. Rock piles installed as a habitat enhancement at the release sites of a mitigation

translocation for lizards at Transmission Gully. A and B: rock piles under construction. C: a control pile ( 100-400 mm diameter rocks) at site 1 . D: a single grade (20-40 mm graded rocks) at site 3 . The top of a pitfall trap can be seen (white bucket lid). 


\subsubsection{Lizard salvage}

Lizards were salvaged from habitat across the length of Transmission Gully as part of the mitigation translocation. Salvage was organised and conducted by staff from BML with assistance from CPB staff for boulderfield dismantling, and occurred from April 2015 to June 2017 through a regime of ACOs, pitfall trapping, and hand searching.

Both pitfall traps and ACOs were used for lizard salvage. The ACOs were $400 \mathrm{x}$ $400 \mathrm{~mm}$ Onduline ${ }^{\mathrm{TM}}$ sheets; these are pieces of corrugated bitumen roofing material either used as lids on pitfall traps or stacked on the ground in layers of two with a $10 \mathrm{~mm}$ spacer between. ACOs were installed at least one month in advance of monitoring to allow a 'bedding in' period. The pitfall traps were four litre plastic buckets, buried so the mouth was flush with the ground and lidded with an ACO. The base of each trap contained sheltering chicken wire, some vegetation as cover, a small damp sponge and a small piece of tinned pear as bait. Pitfall traps were checked every day when open, and the bait replaced every $24-48$ hours depending on its degradation. ACOs were checked in the morning on warm/sunny days, according to convenience but not more than once a day.

In May 2015, 16 boulderfields at the north end of the designation were dismantled by hand over 230 person-hours and lizards captured. Additionally, between April 2015 and June 2017, ACOs (14,509 ACO checks) and pitfall traps (637 trap days) were installed and checked across the road designation (habitat types: gorse and kānuka scrub, pampas grass Cortaderia selloana, native shrubland, rank grassland, mature broadleaf/kohekohe (Dysoxylum spectabile) forest, boulderfields, seral scrub/forest, road verges), and a further seven person-hours of hand searching undertaken (dismantling of additional boulderfields and searching through pampas grass).

The majority of salvaged lizards were captured in May 2015; lizards salvaged over this period were 46 copper skinks, 6 raukawa geckos, and 4 brown skinks. The remaining lizards were captured between April 2015 and June 2017. In total 50 copper skinks, 17 grass skinks, 8 raukawa geckos, and 5 brown skinks were salvaged. 
All lizards were held between salvage and release at Ngā Manu Nature Reserve in $\sim 1 \mathrm{~m}^{3}$ outdoor cages containing natural rock/leaf substrate, various refuges (bark, logs, bamboo hides), honey/jam water and fly larvae ad libitum, and four to twelve lizards. The cage groups were designed to include lizards salvaged at the same location and avoided housing multiple adult males, but included mixed-sex groups to encourage mating in captivity. Sizes of individuals housed together were chosen carefully to avoid aggressive interactions. Two cages included more than one species (one with brown skinks and a copper skink and one with grass skinks and a copper skink). The lizards were held in the cages from capture until their release in April 2018.

\subsubsection{Lizard release}

On 18 April 2018, all lizards were removed from their enclosures, measured, weighed, and sexed. Note that the lizard populations present at the end of the captive period was not the same as those salvaged, due to births and deaths in captivity. Skinks were toe clipped with individual codes. All lizards were kept overnight in individual plastic containers with moistened peat moss. On 18 April 2018 the total captive population comprised 20 copper skinks (NZTCS status not threatened), 14 grass skinks (not threatened), 4 brown skinks (at risk, declining), and nine raukawa geckos (not threatened; Hitchmough et al. 2016a) (Table 4.2).

On 19 April 2018, all captive lizards were released into rock piles at Transmission Gully. Each skink was assigned to one of six release groups (Table 4.2). The groups were chosen with the aim of creating the most suitable founder groups comprised of single species, with adult males and females, and with individuals from the same capture location and cage in the same release group. All geckos comprised one group. Each group was released in a different rock pile. Due to the small number of skinks available for release it was decided to release in only two of the four available sites; this was intended to maximise the number of skinks at each release location but avoid the risk of having all skinks at the same site. Four groups of skinks were released at site 4 and two groups of skinks at site 1; I randomly assigned half the groups at each 
site to control piles and half to single grade piles (Figure 4.2). Geckos were released in a control pile at site 3 .

Table 4.2. Lizards released at Transmission Gully as part of a mitigation translocation. Juveniles were born in captivity.

\begin{tabular}{|c|c|c|c|}
\hline Release group & Species & Individuals & Release site \\
\hline $\mathrm{a}$ & Grass skink & $\begin{array}{c}5 \text { females } \\
3 \text { males }\end{array}$ & 1 \\
\hline $\mathrm{b}$ & Grass skink & $\begin{array}{c}1 \text { female } \\
2 \text { males } \\
3 \text { juveniles }\end{array}$ & 1 \\
\hline c & Copper skink & $\begin{array}{c}4 \text { females } \\
2 \text { males }\end{array}$ & 4 \\
\hline $\mathrm{d}$ & Brown skink & 4 females & 4 \\
\hline e & Copper skink & $\begin{array}{c}1 \text { female } \\
2 \text { males } \\
4 \text { juveniles }\end{array}$ & 4 \\
\hline $\mathrm{f}$ & Copper skink & $\begin{array}{c}4 \text { females } \\
2 \text { males } \\
1 \text { juvenile }\end{array}$ & 4 \\
\hline $\mathrm{g}$ & $\begin{array}{c}\text { Raukawa } \\
\text { gecko }\end{array}$ & $\begin{array}{c}4 \text { females } \\
3 \text { males } \\
2 \text { juveniles }\end{array}$ & 3 \\
\hline
\end{tabular}

I monitored lizards via pitfall traps and visual searching, with the help of field assistants. I performed visual searches by using binoculars to systematically scan the surface of a rock pile in the mid-morning during sunny weather for one minute. I approached quietly, stood at least five metres away while searching, and avoided my shadow touching the pile so as not to disturb any basking lizards. After scanning the surface with binoculars, I approached the pile and watched for any movement. Some of the visual searches were undertaken by field assistants.

I did not use ACOs to monitor rock piles in order to avoid potential confounding effects of installing additional refuges next to rock piles. Instead of lidding 
pitfall traps with ACOs I used the bucket lid pegged above the trap leaving a $\sim 20 \mathrm{~mm}$ opening. I installed two pitfall traps at each rock pile, located on opposite sides and as close to the edge of the pile as possible (Figure 4.1). Additionally, I installed arrays of pitfall traps around the edges of each of the four sites (approximately five metres away from rock piles), with five metre spacing between the traps (Figure 4.1). At sites 1, 2, and 3, there were 10 traps in each array, and at site 4 there were 25 traps. I installed 10 traps in each array at the sites on top of the ridge $(1,2$, and 3$)$ with the intention of analysing them as a block of 30 compared with the block of 25 at site 4 (below the ridge). I checked all 151 traps daily when they were open, and closed them by sealing the lids when rain was forecast.

Prior to releasing the lizards, I monitored the pitfall traps for a total of 899 trap days (20 March-6 April 2018; traps open on six calendar days) (Table 4.3). I performed visual searches of all rock piles twice ( 4 April, $21^{\circ} \mathrm{C} ; 5$ April, $20^{\circ} \mathrm{C}$ ). Bad weather over this period prevented further monitoring. Immediately following release, I monitored the pitfall traps for a total of 1200 trap days (19 April-4 May 2018; traps open on eight calendar days). I performed visual searches of all rock piles three times ( $23 \mathrm{April}, 16^{\circ} \mathrm{C}$; 1 May, $20^{\circ} \mathrm{C} ; 2 \mathrm{May}, 17^{\circ} \mathrm{C}$ ). In 2019 , I monitored the pitfall traps for a total of 1056 trap days (19 February-12 March; traps open on eight calendar days), and performed visual searches of all rock piles three times $\left(20 \mathrm{March}, 19^{\circ} \mathrm{C} ; 21 \mathrm{March}, 19^{\circ} \mathrm{C} ; 22 \mathrm{March} 19^{\circ} \mathrm{C}\right)$ (Table 4.3).

In addition to my monitoring, some monitoring was conducted by BML to fulfil conditions of consents and to comply with permits issued by DOC. For this, the pitfall traps next to rock piles were lidded with ACOs rather than bucket lids, and one additional double-layered ACO was installed within one metre of each rock pile. Only the pitfall traps next to the piles, and not the ones in arrays at each site, were active for these monitoring sessions. All ACOs and pitfall traps were checked over four days between 10-14 December 2018 (192 ACO checks and 384 pitfall trap days) and over six days between 8-18 April 2019 (288 ACO days and 576 pitfall trap days) (Table 4.3).

I used a generalised linear mixed-effects model and an analysis of deviance in $\mathrm{R}$ (R Core Team 2016) to compare the numbers of skinks found at each rock pile type, 
with number of skinks per pile as the response variable, site and pile as random effects (pile nested within site), and pile type and monitoring method as fixed effects. I pooled the data from all monitoring sessions for this analysis, and assumed a Poisson distribution of errors. I did not include visual searching data in the model as I found no lizards using that method. Due to the low number of lizards found overall I could not assess detection probability.

\subsubsection{Predator monitoring}

On 11 December 2017, 30 DOC 250 traps (which trap rats, mustelids, and hedgehogs Erinaceus europaeus) were installed across the field site by contractors hired by $\mathrm{CPB} / \mathrm{HEB}$. At site 1 there were two traps, at site 2 there was one, at site 3 there were three, and at site 4 there were three (Figure 4.1). The remaining 21 traps were located around the study area but not within the release sites. They were baited with dried fish pellets or eggs and checked every two to three days (trapping is ongoing). On 13 March 2018, 70 mouse snap traps within bait station boxes were installed in and around the release sites (Figure 4.1). There were approximately $25 \mathrm{~m}$ between adjacent traps. These were baited with dried pellet bait or peanut butter and checked every two to three days (trapping is ongoing).

Tracking tunnels were also used to monitor mammals and lizards; these were made of black corflute plastic $500 \mathrm{~mm}$ long and $100 \mathrm{~mm}$ wide and tall, and installed by BML at least one month before monitoring to allow a bedding in period. One was placed within $0.5-1 \mathrm{~m}$ of each rock pile. For monitoring, pre-inked tracking cards with a piece of tinned pear in the middle were put inside the tunnels. There were two monitoring periods; four nights from 10-14 December 2018 (early summer, 192 tracking nights) and 11 nights from 8-18 April 2019 (autumn, 528 tracking nights). The cards were checked only at the end of each monitoring period. 


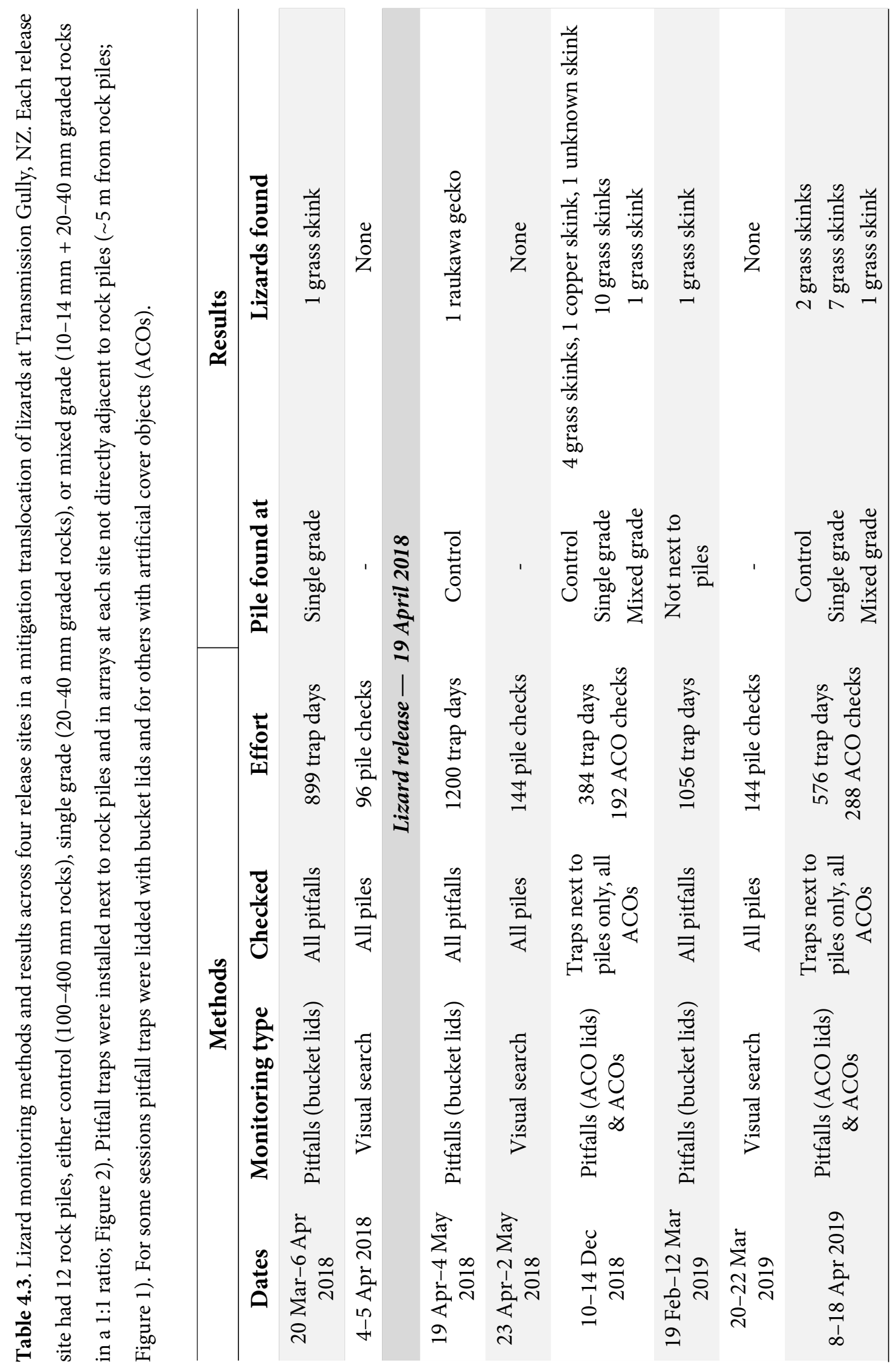




\subsubsection{Mouse experiment}

I tested lab mice for their ability to enter spaces in rock piles. I dusted the mice with fluorescent powder and housed them in cages containing rocks and with sunflower seeds scattered throughout to encourage the mice to explore the interstitial spaces. After four days I removed the mice and systematically dismantled the rocks, taking photographs of each layer under ultraviolet (UV) light to assess the amount of fluorescent powder deposited.

The mice were 18 male and 18 female wildtype adult lab mice, in 12 single-sex littermate groups of three. To check the palatability of sunflower seeds and to expose the mice to this novel food item, prior to the experiment the mice were given a small amount of sunflower seeds, which they ate readily, preferring them to their usual pellet food. The cages were rat cages comprised of two parts: a lower $120 \times 250 \times 410 \mathrm{~mm}$ rectangular plastic box with an open top, and an upper $80 \times 230 \times 260 \mathrm{~mm}$ metal-barred cage (Figure 4.4 ). Each cage was filled with $\sim 10 \mathrm{~L}$ of rocks (to approximately fill the lower part of the cage but allow space for the mice to move around and access food and water). The rocks were either design (20-40 $\mathrm{mm}$ grade, purchased from a landscaping supplier; the equivalent of the single grade rocks at Transmission Gully) or control ( 70-150 mm grade, purchased from a landscaping supplier). I tipped the rocks randomly into the containers in batches, pausing several times to scatter shelled sunflower seeds liberally throughout. The rocks were $\sim 120 \mathrm{~mm}$ deep throughout most of the cage but were lower at one end $(\sim 70 \mathrm{~mm})$ to allow space for a water bottle and food hopper. Pellet food and water was provided ad libitum, and a plastic tube was placed on top of the rocks for the mice to rest in. The cages and rocks were not reused between groups.

I coated each mouse in non-toxic Day Glo ${ }^{\mathrm{TM}}$ Corona Magenta ZQ-21 fluorescent powder by hand using a soft brush, avoiding the head and face $(\sim 50 \mathrm{mg}$ applied per mouse). Fluorescent pigments have been previously used to track the movements of small mammals (Lemen \& Freeman 1985) and amphibians (Ramírez et al. 2017). I put one litter group of three into each cage (for each sex, three groups were in control rocks and three in design rocks). Male groups were all completed before the female groups 
began, to avoid female scent influencing male behaviour (males may exhibit aggression towards cage mates in the presence of females or female scent, however male scent does not induce aggression in females; Clipperton Allen et al. 2010). I left the cages on a bench in a quiet, undisturbed lab for four days, visually checking the mice once a day to ensure their welfare. After four days, I removed the mice without disturbing the rocks.

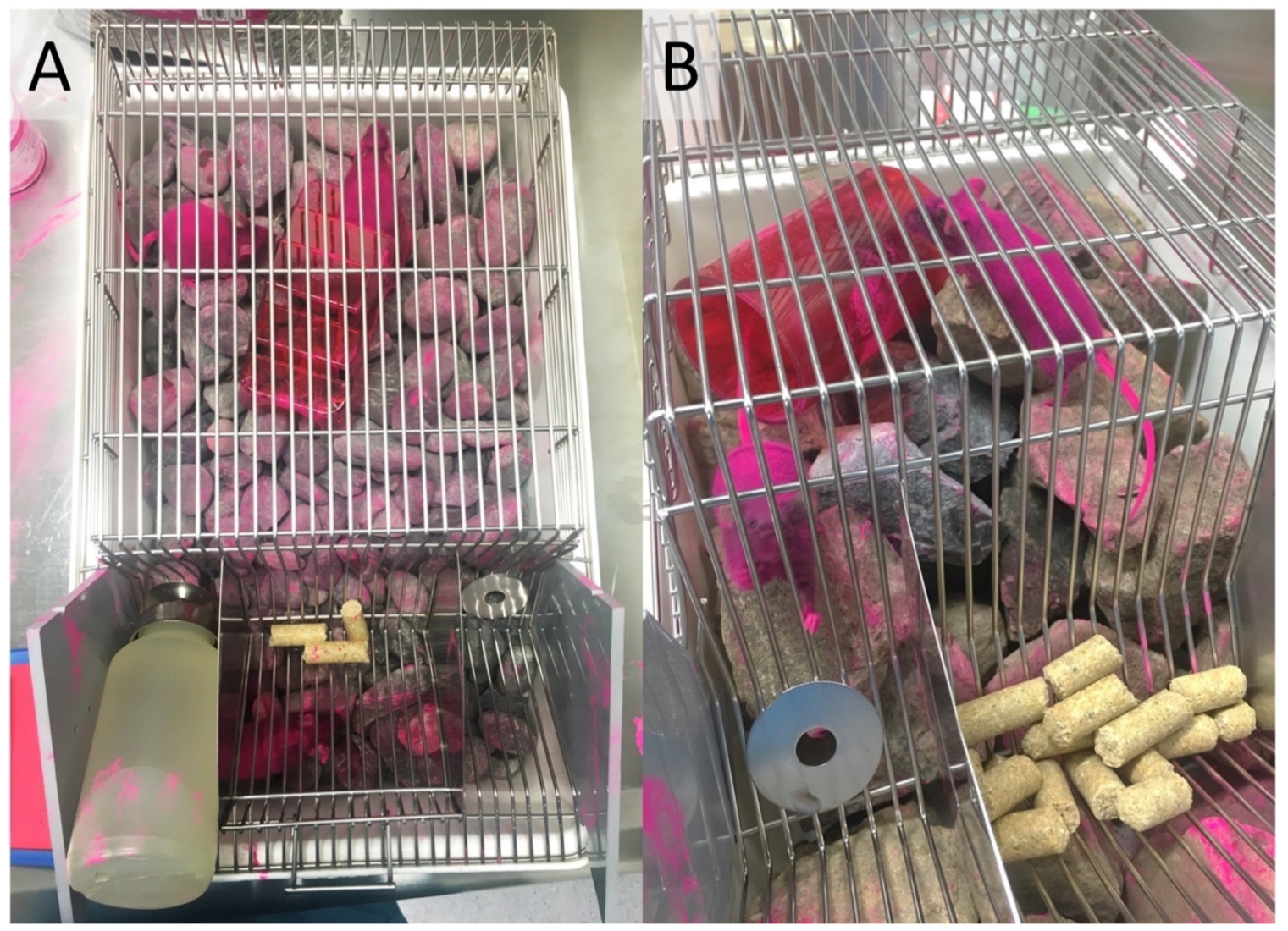

Figure 4.4. Mice coated in fluorescent powder for an experiment investigating the ability of mice to enter interstitial spaces between rocks. A: mice in design rocks, B: mice in control rocks.

I photographed the rocks in each container both under normal visual-spectrum light and using UV torches (model MTE® U301, UV wavelength $365 \mathrm{~nm}$ ). I suspended two torches $\sim 2 \mathrm{~m}$ above the rocks for even lighting and took photos from directly above using a Sony RX100 camera (f-number: 3.5; shutter speed: 0.1 seconds; ISO: 1600; Figure 4.5). I then marked all the rocks on the top layer with a paint pen before removing all marked rocks. I took photos of each rock layer until I had removed all the 
rocks in each container. I used ImageJ (Schneider et al. 2012) to analyse the fluorescence. I converted the photographs taken under fluorescent light to TIFF format, cropped them to contain only the rocks, and used ImageJ's measure tool to measure the mean grey value (indicating the intensity of the fluorescence and therefore how much powder was distributed on each layer). I analysed the fluorescence data using analysis of variance (ANOVA) (mean grey value as response variable, depth and type of rocks as predictor variables) and linear regressions in R (R Core Team 2016).

The mice were euthanised using $\mathrm{CO}_{2}$ following the experiment by a trained lab member (as required by my animal ethics permit), after which I measured their lengths and weighed them. I obtained size measurements (weight, head-body length, total length) for wild mice in New Zealand from Murphy and Pickard (1990) in the form of means for 14 different populations and plotted these against the sizes of the lab mice.

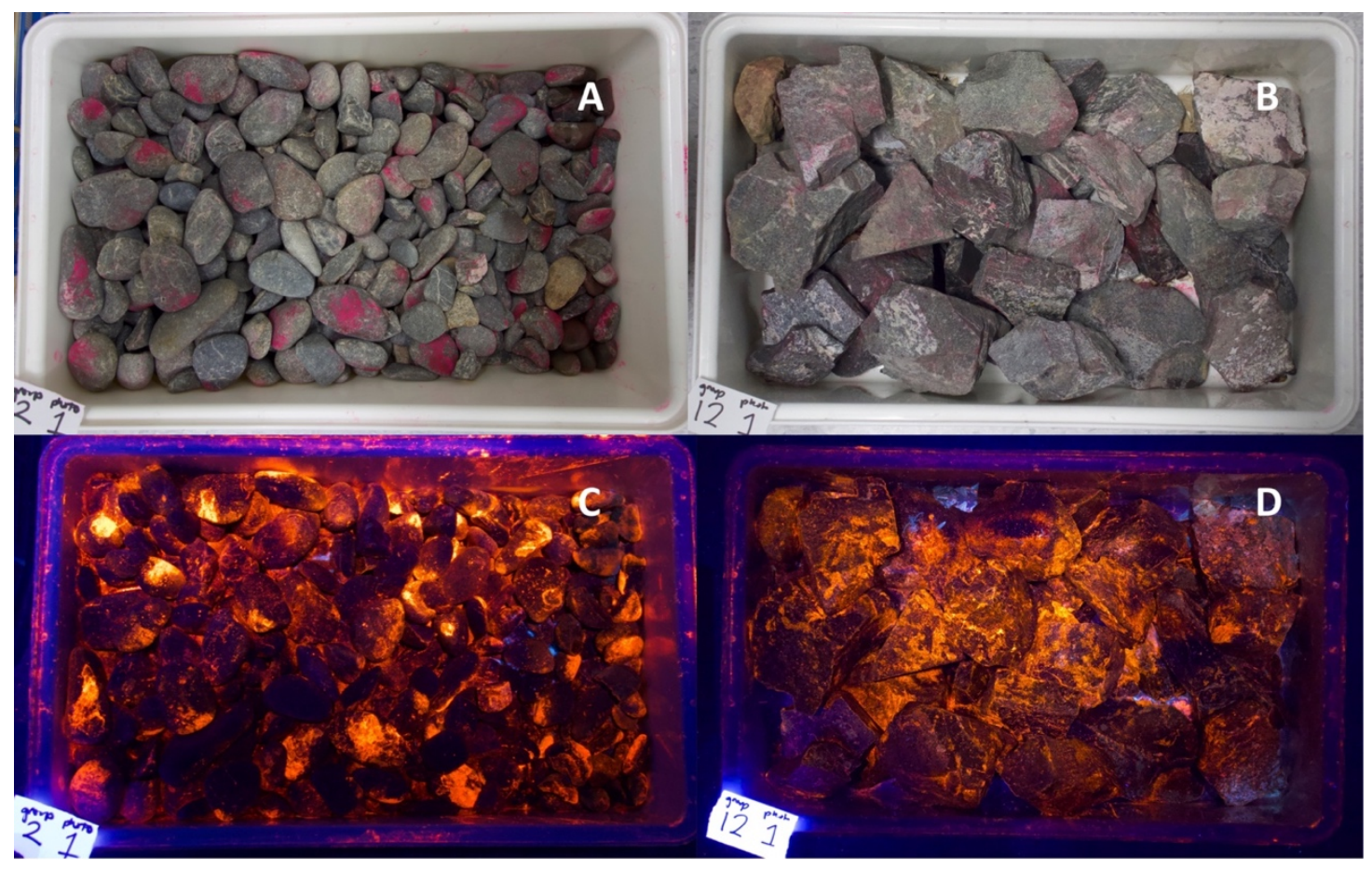

Figure 4.5. Rocks coated in fluorescent powder deposited by mice during a laboratory experiment. A and $\mathrm{C}$ are photos of the same $20-40 \mathrm{~mm}$ graded rocks (design), with $\mathrm{A}$ under normal visualspectrum lights and C under ultraviolet light. B and D are photos of the same $\sim 70-150 \mathrm{~mm}$ graded rocks (control), with B under normal visual-spectrum lights and D under fluorescent lights. 


\subsection{RESULTS}

\subsubsection{Lizard monitoring}

Pre-release, I found one adult female grass skink in a pitfall trap next to a single grade pile at site 1. Post release in the 2018 monitoring session, I found one raukawa gecko (identified as not being one of the released animals based on colour and patterning) in a pitfall trap next to a control pile at site 3 (Table 4.4). In the 2019 monitoring session, I found one adult female grass skink (no toe clips) at site 4 in a pitfall trap that was not next to a pile. I never observed any lizards during visual searches, although I was easily able to see small invertebrates on the surface of the rock piles, indicating that I would have been able to see lizards had they been there (Table 4.3; Table 4.4).

In the monitoring conducted by BML, 1 copper skink, 25 grass skinks, and 1 unidentified skink were found over all post-release monitoring sessions (Table 4.3; Table 4.4; Figure 4.6). Of all skinks found, 18 could be checked for toe clips (the others were seen but not caught); none of the checked skinks were toe clipped.

Table 4.4. Catch per unit effort for salvage and post-release monitoring stages of a mitigation translocation of endemic New Zealand lizards at Transmission Gully. ACOs are artificial cover objects. ${ }^{1}$ Effort is person-hours for hand searching, number of ACO checks for ACOs, number of trap days for pitfall traps, and number of pile searches for visual searching. ${ }^{2}$ Catch per unit effort is total lizards caught per person-hour for hand searching, per 100 ACO checks for ACOs, per 100 trap days for pitfall traps, and per 100 piles searches for visual search.

\begin{tabular}{cccccc}
\hline Stage & Search type & Effort $^{\mathbf{1}}$ & $\begin{array}{c}\text { N skinks } \\
\text { found }\end{array}$ & $\begin{array}{c}\text { N geckos } \\
\text { found }\end{array}$ & $\begin{array}{c}\text { Catch per } \\
\text { unit }^{\text {effort }}{ }^{2}\end{array}$ \\
\hline \multirow{3}{*}{ Salvage } & $\begin{array}{c}\text { Hand search } \\
\text { ACOs }\end{array}$ & 237 & 52 & 7 & 0.25 \\
& $\begin{array}{c}\text { Pitfall traps } \\
\text { (ACO lids) }\end{array}$ & 637 & 8 & 0 & 0.01 \\
& $\begin{array}{c}\text { Pitfall traps } \\
\text { (bucket lids) }\end{array}$ & 2,256 & 0 & 1 & 1.26 \\
Post release & $\begin{array}{c}\text { Pitfall traps } \\
\text { (ACO lids) }\end{array}$ & 960 & 14 & 0 & 0.04 \\
& $\begin{array}{c}\text { ACOs } \\
\text { Aisual search }\end{array}$ & 480 & 13 & 0 & 1.46 \\
& 288 & 0 & 0 & 2.71 \\
\hline
\end{tabular}



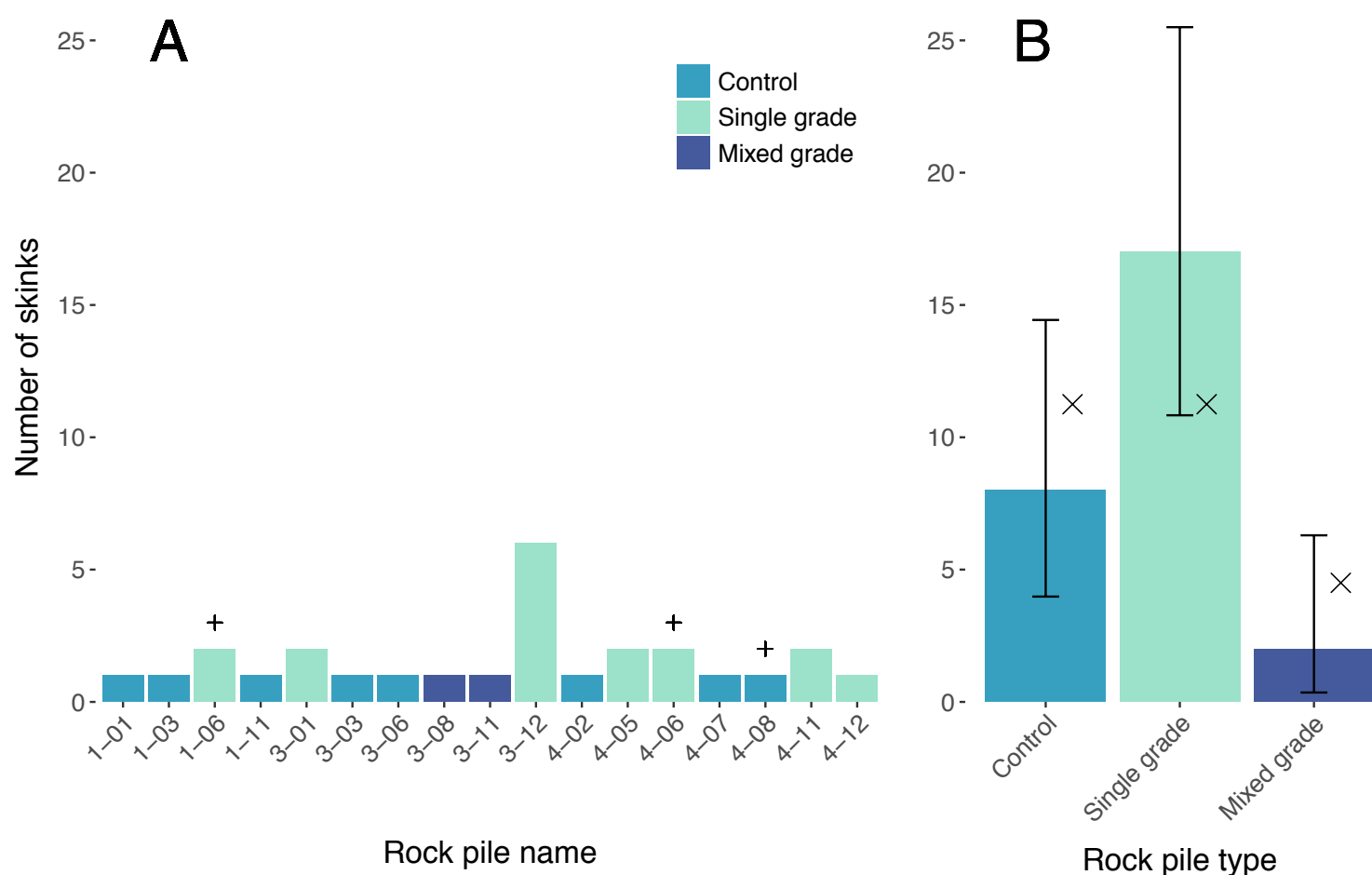

Figure 4.6. Skinks found in habitat enhancement rock piles at Transmission Gully mitigation translocation release sites. A is the number of skinks found in individual rock piles, with +'s representing piles in which skinks were released. The first digit of each rock pile name is the number of the site it is located at and the second part is a number for each pile within each site. B is the aggregate counts of skinks for different rock pile types, with error bars representing the $90 \%$ confidence interval (calculated using the Poisson distribution). X's represent the expected counts if there was no effect of pile type, based on the numbers of rock piles present at the site.

The analysis of deviance of the generalised linear mixed-effects model showed no overall effect of rock pile type on numbers of lizards found at piles $\left(p=0.2, \chi^{2}=3.34\right.$, $\mathrm{df}=2$ ). However, the direct comparison between the single grade and control designs in the linear model was suggestive of a trend. Although the $p$ value was $>0.05(0.769 \pm$ $0.517, p=0.14, Z=1.49$; Table 4.5 ), the effect size was potentially substantial, with more than twice as many skinks found per pile at single grade piles (1 skink per 10 piles) compared with control piles (0.4 skinks per 10 piles).

The analysis of deviance of the generalised linear mixed-effects model showed an effect of monitoring method $\left(p=0.03, \chi^{2}=6.83, \mathrm{df}=2\right)$. As this analysis was on pooled 
data, there was no correction for different effort for the different monitoring methods; therefore this analysis is comparing between 2,256 trap days of pitfall traps (bucket lids), 960 days of pitfall traps (ACO lids), and 480 trap checks for ACOs (Table 4.4; Table 4.5). The number of skinks caught in pitfall traps with bucket lids was significantly lower than those caught in pitfall traps with ACO lids or under ACOs.

Table 4.5. Results of fixed effects in a generalised linear mixed-effects model modelling the numbers of skinks found at rock piles of different types in a field experiment using multiple capture methods. The reference level for rock pile type is control rock piles, and the reference level for monitoring method is artificial cover objects (ACOs).

\begin{tabular}{ccccc}
\hline Variable & Covariate & Estimate $\pm \mathbf{S E}$ & $\mathrm{Z}$ & $\boldsymbol{p}$ \\
\hline- & Intercept & $-2.189 \pm 0.647$ & -3.383 & $<\mathbf{0 . 0 1}$ \\
Rock pile & Single grade & $0.769 \pm 0.517$ & 1.489 & 0.14 \\
type & Mixed grade & $-0.440 \pm 0.934$ & -0.471 & 0.64 \\
$\begin{array}{c}\text { Monitoring } \\
\text { method }\end{array}$ & Pitfall (bucket lid) & $-1.872 \pm 0.759$ & -2.465 & $\mathbf{0 . 0 1}$ \\
\hline
\end{tabular}

\subsubsection{Predator monitoring}

The DOC 250 and mouse snap traps caught a variety of predators: mice, rats, hedgehogs, possums, rabbits (Oryctolagus cuniculus), stoats (Mustela erminea), and blackbirds (Turdus merula) (Figure 4.7). Mouse capture rates peaked in March/April 2018 (early autumn). In September 2018, a mouse was seen on a control pile at site 4; it ran into the pile when startled. In early summer (December 2018) the tracking tunnels showed mouse footprints on half of the tunnels at site 4, but no mice at the other sites (Table 4.6). In autumn (April 2019) there were mouse footprints in all tracking tunnels at all sites. 


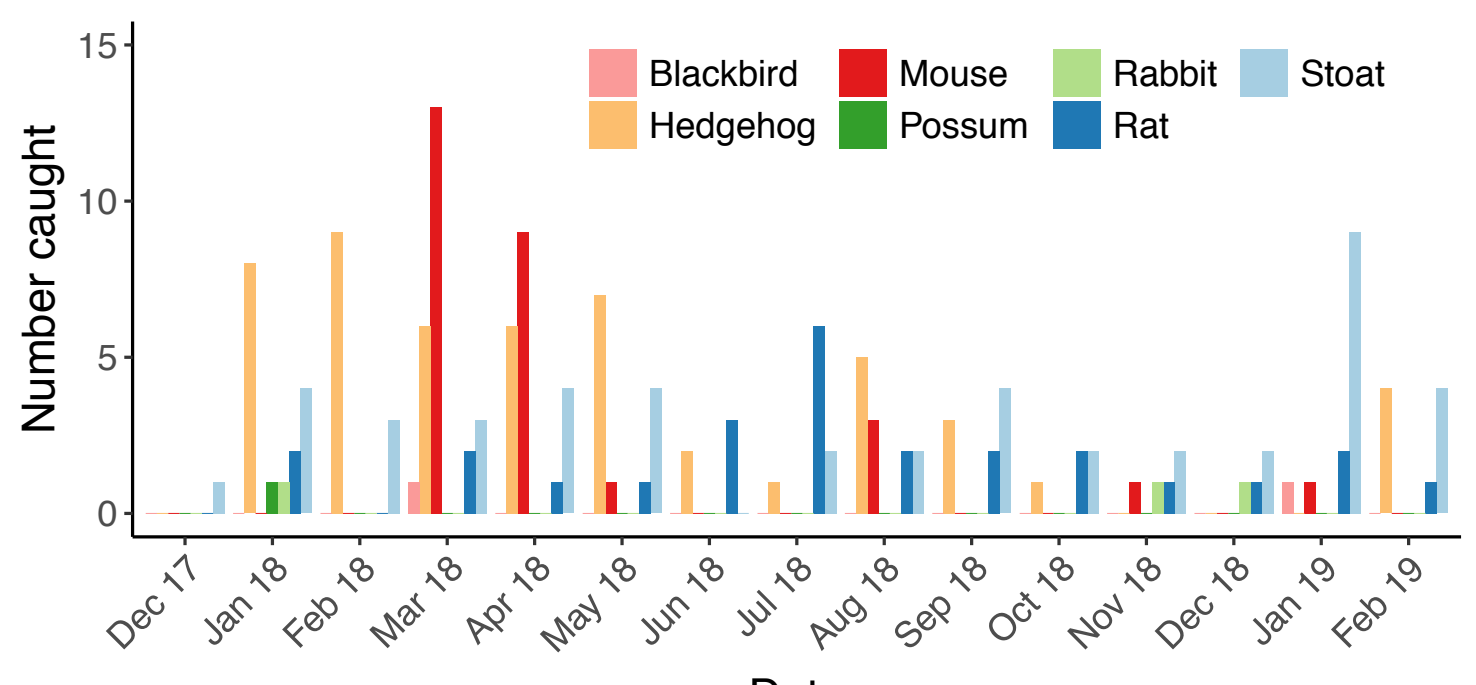

Date

Figure 4.7. Animals caught in DOC 250 and mouse snap traps at Transmission Gully lizard mitigation release sites.

Table 4.6. Footprints observed using tracking tunnels (12 per site) at Transmission Gully lizard mitigation release sites.

\begin{tabular}{cccc}
\hline Session & Site & Species & $\begin{array}{c}\text { \% of traps with } \\
\text { footprints }\end{array}$ \\
\hline Dec 2018 & 1 & Skink & $8 \%$ \\
Dec 2018 & 2 & - & $0 \%$ \\
Dec 2018 & 3 & Gecko & $8 \%$ \\
& & Mouse & $50 \%$ \\
Dec 2018 & 4 & Rat & $16 \%$ \\
& & Mustelid & $8 \%$ \\
April 2019 & 1 & Mkink & $8 \%$ \\
April 2019 & 2 & Mouse & $100 \%$ \\
April 2019 & 3 & Mouse & $100 \%$ \\
April 2019 & 4 & Mouse & $100 \%$ \\
\hline
\end{tabular}

\subsubsection{Mouse experiment}

For both the control and the design conditions, the amount of fluorescent powder decreased with depth into the pile (Figure 4.8). The trends were linear and the data 
approximately normally distributed, so I fit linear regression models. The results of the ANOVA indicated an effect on fluorescence of depth (less fluorescence as depth increases; sum of squares $=53504189, \mathrm{~F}=20.93, p<0.001$ ), and type of rocks (control rocks having more fluorescence than design rocks; sum of squares $=17935191, \mathrm{~F}=7.02$, $p=0.01$ ), but no interaction between depth and type of rocks (sum of squares $=923961$, $\mathrm{F}=0.36, p=0.55)$. These results indicate that there is no difference in accessibility between the control and the design rock piles.

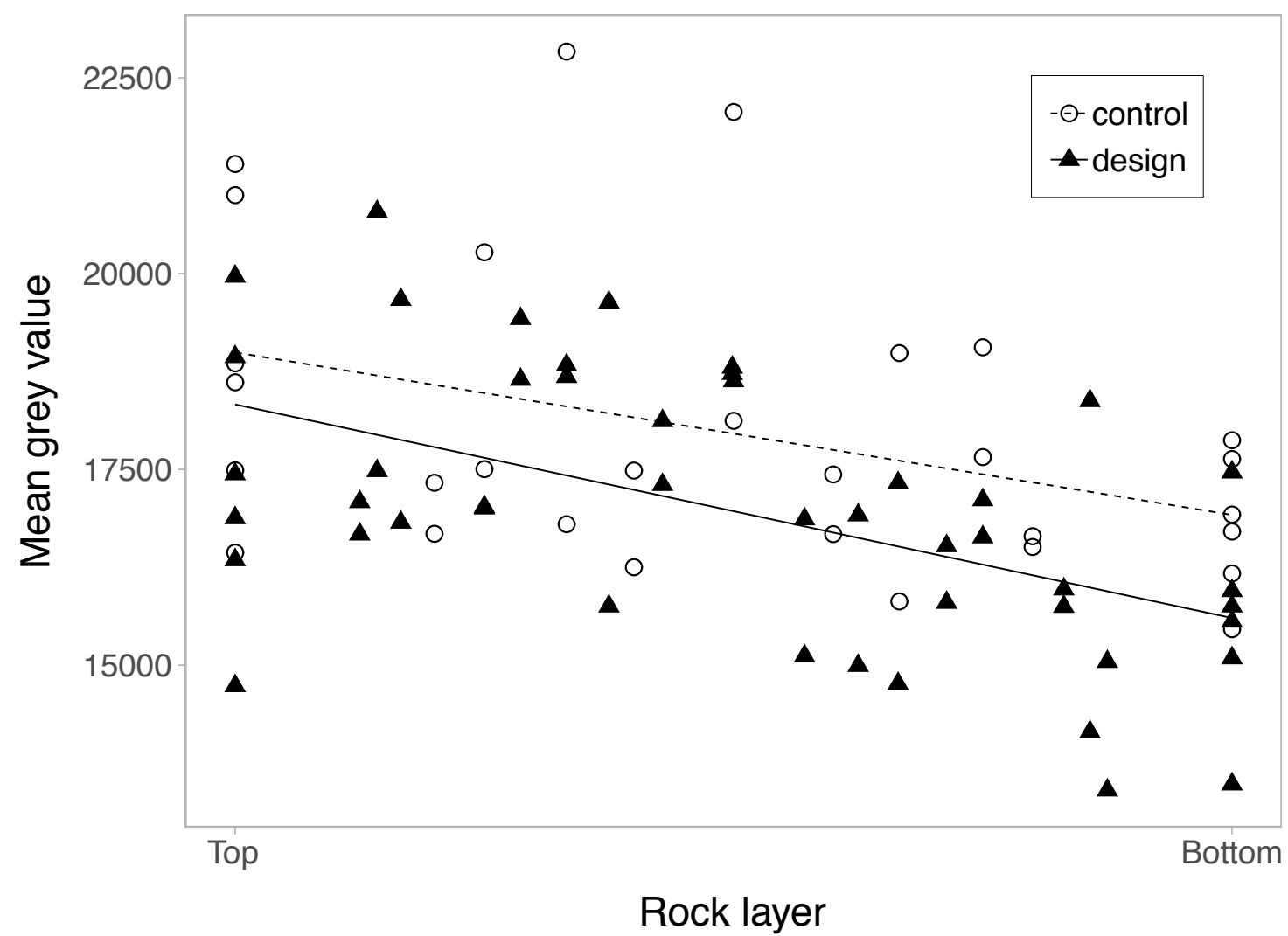

Figure 4.8. The amount of fluorescent powder deposited by mice in rocks of two compositions in a laboratory experiment. Mean grey value corresponds to the amount of fluorescence powder (higher mean grey value $=$ more fluorescent powder) and is the mean grey value of all the pixels of a photograph of the pile taken under fluorescent light. Design rocks were 20-40 $\mathrm{mm}$ grade, and control rocks were $\sim 70-150 \mathrm{~mm}$ grade. Trendlines are the linear regressions for design rocks (solid line) and control rocks (dashed line). 
Behaviourally, the mice in the design condition were only observed on top of the rocks, and were easy to remove at the end of the experiment as they stayed on the surface. Conversely, mice in the control condition were often lower in the rocks and could not be seen, and were difficult to remove as they quickly hid under rocks when I tried to catch them. The lab mice weights were similar to the means for the heaviest wild populations, and the head-body lengths and total lengths of lab mice fell within the range of wild populations (Figure 4.9).
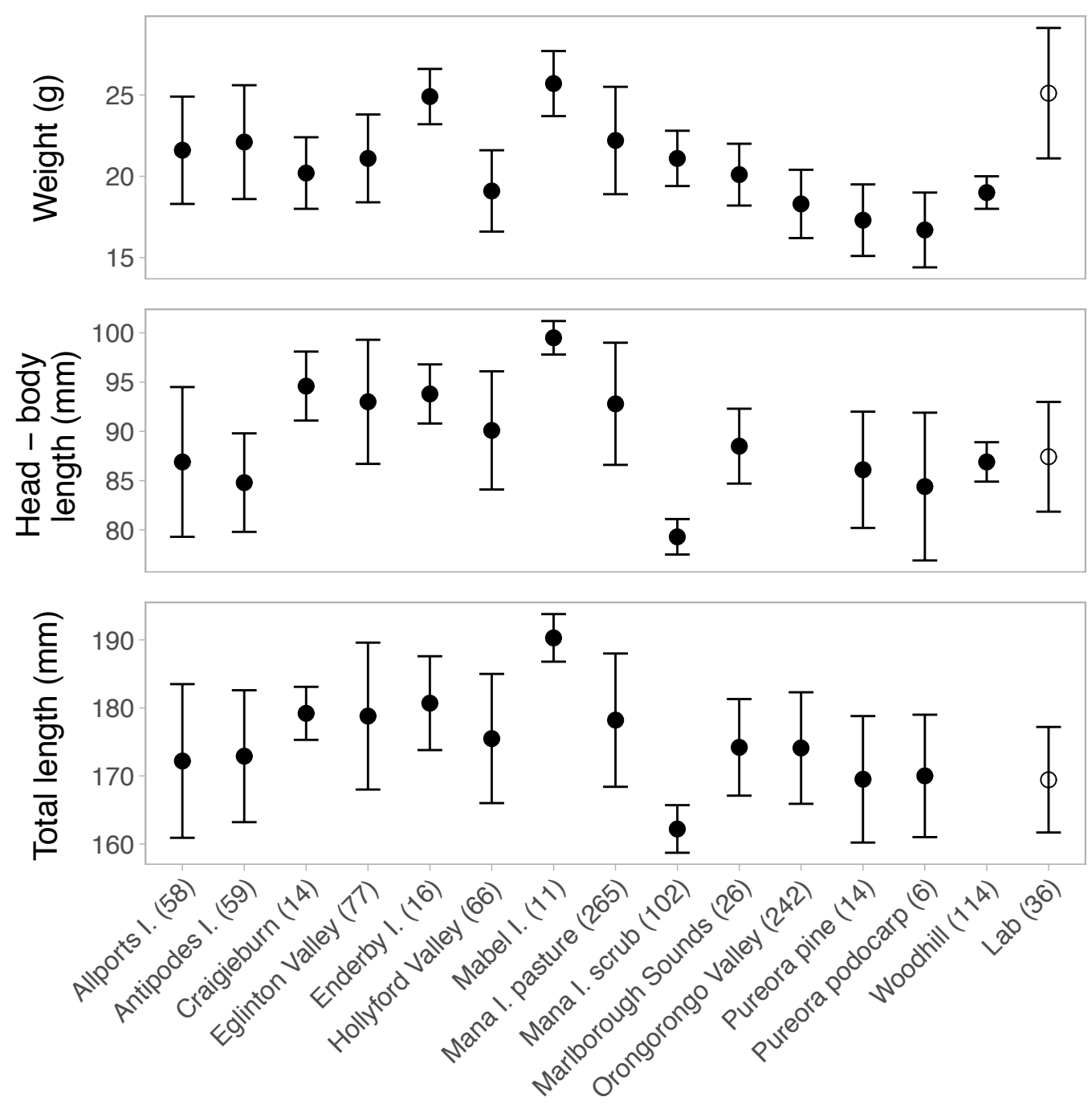

Population

Figure 4.9. The sizes of mice used in a lab experiment (unfilled circles) testing ability of mice to enter spaces between rocks compared with sizes of wild mice (filled circles) in New Zealand. Numbers in parentheses are sample sizes for each population. Wild mouse sizes are from Murphy and Pickard (1990). 


\subsection{DISCUSSION}

A large amount of effort was put into the salvage of lizards for mitigation translocation at Transmission Gully, however relatively few lizards were released. Released lizards were not recaptured, so their survival and health post release are not known. There is some indication that the single grade design rock piles are occupied by more skinks than are control piles or piles of smaller rocks, although this was inconclusive. Rock piles of the single grade design should be further tested as they may be able to be used to protect lizards, and other small endemic species, in the presence of introduced predators. The mitigation translocation at Transmission Gully is a case study of some of the challenges in using mitigation translocations to achieve positive conservation outcomes.

\subsubsection{Rock piles, skinks, and mice}

During the monitoring of the constructed rock piles, it was impossible to monitor lizards inside the rock piles; the closest option was to use pitfall traps at the edges and visual searches on the surfaces. There may be lizards which do not venture out into vegetation, preferring to live entirely within and on the surface of rock piles. Copper skinks in particular seldom emerge from cover (van Winkel et al. 2018). When designing monitoring for the rock piles, I deliberately avoided using ACOs, as I wanted to avoid the potentially confounding effects of installing additional refuges. However, BML used ACOs in their monitoring. In the monitoring sessions I conducted without ACOs, I found very few lizards, compared with higher numbers found in the sessions using ACOs (Table 4.3; Table 4.4). I also never saw any lizards during visual monitoring. Although the presence of ACOs may attract more lizards by providing additional retreat sites, this effect is likely equal across rock pile types as each pile had one adjacent ACO. It appears that lidding pitfall traps with ACOs rather than bucket lids increases capture rates; this could be taken into account when skink monitoring and salvage methods are designed. As I had very few skink captures from the monitoring sessions without ACOs for analysis, I included the data from the monitoring using ACOs in my analysis, with the caveat that the numbers of lizards present may be higher than would be found in piles without adjacent ACOs. 
There was a trend for more skinks to be found at single grade rock piles (the hypothesised best design from Chapter 3) compared with control or mixed grade, although the comparison between single grade and control in the generalised linear mixed-effects model had a $p$ value of 0.14 . This is above the typical $p$ value cut-off in ecology of 0.05 , however there have been criticisms of the arbitrariness of this level (e.g. Murtaugh 2014). A $p$ value of 0.14 is not strong evidence, however it could be considered suggestive of a trend. The low numbers of skinks caught likely contributed to the high $p$ value observed. The effect size is potentially substantial; with approximately twice as many skinks found at single grade piles compared with control piles. There was also a trend for fewer skinks to be found at mixed grade piles than control piles; this may indicate that there is a too-high proportion of inaccessible spaces inside the mixed grade piles, resulting in an interior that is largely inaccessible to skinks. There was one single grade pile (site 3, pile 12) which had more skinks (six) than any other pile (zero to two). This pile was the southern-most single grade pile at site 3 (Figure 4.2). The high number of skinks found at this pile could have been influenced by its position on the edge of a site, potentially meaning it was colonised more than piles with more adjacent piles. The overall observed pattern of occupancy follows the hypothesised pattern (i.e. more skinks at single grade than control or mixed grade piles), and more monitoring is worth pursuing as it would likely clarify the veracity and size of this trend. More monitoring may also reveal if this possible trend is due to the skinks being more attracted to the single grade piles, or if they have higher survival rates when they use single grade piles. When ecologists construct rock pile habitat for lizards, they typically design piles in an ad hoc manner based on best guesses and experience. While this design needs further testing, I have found no evidence that it is worse than an ad hoc rock pile for endemic skinks, and it is potentially better. Those undertaking habitat enhancement for similarly-sized skinks should consider installing piles of this design and comparing them with other designs, to contribute to understanding of habitat use by skinks and the potential of these rock piles to enhance survival of skinks in the presence of predators. 
The lizards found during monitoring were present at the release sites, or areas adjacent to the site, before habitat enhancement took place, and have since colonised the release sites and the rock piles. The colonisation process could have begun before rock piles were constructed, as the cessation of farming at the construction site has likely made the release sites more hospitable to lizards due to vegetation growth. However, it cannot be determined whether habitat enhancement increased population size or viability of existing lizards at the release sites, as there were no surveys taken before rock pile construction. In a study of mouse exclusion in a fenced mainland sanctuary, ornate skink (O. ornatum) catch ranged from 0 per 100 pitfall trap days shortly after construction of a mouse-excluding fence in 2006 to 13 per 100 trap days in 2015 (Nelson et al. 2016). On Korapuki island, lizard captures ranged from $\sim 5$ per 100 pitfall trap days when rodents were present to $\sim 25$ per 100 trap days following rodent eradication (Towns 1991). In comparison, in post-release monitoring at Transmission Gully capture rates ranged from 0 per 100 trap days to 1.5 per 100 trap days (or 2.7 per 100 ACO checks) (Table 4.4). The numbers of skinks found near rock piles at Transmission Gully are at the lower end of what might be expected for a mainland population of New Zealand skinks, possibly because they are being suppressed by mammalian predation. The number of skinks found near the rock piles may be set to rise due to continuing colonisation from surrounding habitat, augmentation from the released lizards, populations becoming established in the new rock piles, continuing vegetation growth, and any success of the rock piles in protecting skinks from predators.

The lab experiment with mice did not show any statistically significant difference in terms of fluorescent powder deposited between the control condition and the design rocks. However, the observational evidence of the mice in the control rocks being able to hide among the rocks, and the mice in the design conditions only being seen on the surface, suggests that there was in fact a difference of accessibility. It is possible that the fluorescent powder, rather than being deposited directly from the fur of the mice onto the rocks, mostly fell through the rocks or was moved around by air currents (an extractor fan was operating in the room). The mice appeared visually (under visual-spectrum light) to have groomed the majority of the fluorescent powder 
off their fur by the second day of the experiment. The lab mice were equivalent in weight to some of the heavier wild populations, and their overall lengths were in the middle of the range for wild populations (Figure 4.9), meaning that their exclusion from rocks may be greater than some populations with lighter individuals. At Transmission Gully, mice were present throughout the year, but there appeared to be particular spikes in capture/detection around in early autumn (Figure 4.7; Table 4.6). The observation of a mouse entering a control pile at Transmission Gully is evidence of mice using rock piles with large gaps as refuges. These findings, together with the possible trend of elevated numbers of skinks found at single grade rock piles, support the hypothesis that mice may be entering control piles and possibly attacking skinks, and that mice may be excluded from single grade piles, allowing skinks to inhabit these piles in greater numbers.

Installing naturalistic rock piles to provide skinks protection from mice may have several advantages over techniques using pest exclusion fences or other barriers or equipment that can degrade over time. Barriers must be maintained in order to work, and a barrier with a breach can become useless (Long \& Robley 2004). Indefinite maintenance of habitat enhancements or predator control cannot be guaranteed, particularly in mitigation translocations (Chapter 5). A rock pile which, by the nature of its constituent rocks, provides appropriate refuges is less likely to degrade over time without maintenance; although there is a risk of degradation caused by vegetation filling interstitial spaces, which was implicated in the dramatic decline of Whitaker's and copper skinks at Pukerua Bay (Hoare et al. 2007). There is evidence that habitat restoration that mimics natural rocks is beneficial for reptiles. In a study of velvet geckos (Oedura lesueurii), deploying artificial rocks increased the overall numbers of geckos detected and juvenile survival rates (Croak et al. 2013). Artificial rocks which mimic natural rock attributes (cavity geometry, thermal properties) also appear to be preferable retreats for a variety of reptile and invertebrate species than simple concrete pavers (Webb \& Shine 2000; Croak et al. 2010).

There is a need for novel techniques that can aid the survival of threatened prey species, short of full predator eradication. The rock pile design I have suggested, if it is 
shown to be effective, could be used when predator eradication is impractical, and allow some exposure to predators to maintain anti-predator behaviours. This technique could be particularly beneficial for protecting species where there is a danger of negative impacts from mesopredator or competitive release, for instance as a result of Predator Free 2050 (New Zealand Cabinet 2016). Rock piles could also potentially be used to protect other New Zealand lizard species, or rock-dwelling species other than lizards, for instance endemic New Zealand frogs (Leiopelma spp.) (Gill \& Whitaker 1996), or in aquatic systems (Levine et al. 2017).

\subsubsection{The effectiveness of mitigation translocations for conservation}

In the Transmission Gully mitigation translocation a total of 72 skinks were salvaged, but only 38 (53\%) were released. The differences between release and capture numbers were due to mortality in captivity; the majority of the lizards were held for almost three years. This extended time in captivity was due to delays in construction timelines pushing back the release date. The most marked difference in numbers between salvage and release was in copper skinks, where 50 were salvaged but only 20 released (40\%). Some individuals would likely have died during this period had they not been captured; the longevity of copper skinks is unknown, however small-bodied Oligosoma species generally mature in two to four years and live up to eight years in the wild (Cree \& Hare 2016). Copper skinks can be difficult to keep in captivity and can have high mortality in the early stages of captivity, due in part to stress, aggressive interactions and insufficiently cool and damp environments (Andrew Blayney, pers. comm.). Additional factors that may have contributed to the high mortality in this case were the time of capture (during colder months, possibly making adapting to captivity more difficult), the positioning of the enclosures (insufficient sunlight), escape through small gaps in the enclosures, and/or failure to recover all lizards from the cages (some juveniles may have hidden inside complex bark hides) (Scott Pearson, pers. comm.). Additionally, four skinks in one enclosure died within a short time of one another, the suspected cause is a pathogen in the substrate (Scott Pearson, pers. comm.). The original Lizard Management Plan detailed lizards being held in captivity for up to two years (Leighton 
HEB Joint Venture 2015). None of the translocated lizards were seen again; it is therefore impossible to determine their survivorship, health, or movements post release.

A substantial amount of effort was put into salvaging lizards for this translocation, using techniques generally accepted as good practice for salvage of $\mathrm{New}$ Zealand lizards, however the catch per unit effort was modest (0.01-1.26 per 100 trap/ACO checks; Table 4.4), and only common species were found. The high mortality of captive lizards further reduced the effectiveness of the translocation. For comparison, a mitigation translocation at Cobham Drive in Wellington salvaged 380 lizards at a rate of 19 per 100 trap days (Chris Woolley, pers. comm.; Iles 2019). Another salvage which was undertaken near Transmission Gully salvaged approximately 2,500 endemic skinks from a 0.8 ha area (Trent Bell, unpub. data June 2019). The differences between the numbers of lizards salvaged in these translocations is likely due to the population sizes and densities at these sites rather than a difference in the effectiveness of the techniques or the salvage efforts employed. At Transmission Gully, using hand-dismantling of boulderfields (where the majority of lizards were captured) as an example for search effort, it took four person-hours to salvage one lizard. As there were only half as many lizards released as were captured, this could be considered eight person-hours per lizard released, plus the resources put into housing each lizard for three years.

The outcomes for the released lizards are unclear. However, there were identified populations of grass and copper skinks and raukawa geckos present at the release site, with similar catches per unit effort to the salvaged lizards. Both habitat enhancement and predator control were implemented at the lizard release sites; it is possible that these strategies could be providing at least as much, if not more, conservation benefit compared to salvage efforts. Eradication of mammalian predators is a relatively reliable conservation strategy for New Zealand lizards (e.g. Towns 1991; Newman 1994; Towns 1996; Reardon et al. 2012; Nelson et al. 2016) and other taxa (e.g. Moorehouse et al. 2003; Elliott et al. 2007; Watts et al. 2011). However, it is not clear what level of predator control is necessary to support lizard populations; there has so far only been one successful predator control regime at a non-fenced mainland site that 
allowed the recovery of a lizard population (Reardon et al. 2012). Predator control may not be effective if it is only implemented for a short time or with insufficient intensity.

When aiming to minimise or mitigate damage done to the environment in the course of construction, choosing the best strategies to use can be a complex issue. There are advantages and drawbacks to different strategies such as predator control, habitat enhancement, and mitigation translocation, and they can be employed in different combinations. For mitigation translocations there can be large variations in the number of individuals salvaged; Transmission Gully is an example of a large translocation operation resulting in a relatively small number of lizards released. When mitigation translocations are legally required, salvage operations go ahead, even when it is apparent that capture rates are low. Requiring salvage as a mitigation measure may therefore have variable conservation impact. However, this is complicated by the fact that it can be difficult to predict how many individuals will be salvaged, or whether rare or threatened species might be found, before the salvage operation begins. The requirements for mitigation of environmental impacts should be designed, and mitigation actions chosen, with the aim of maximising conservation outcomes. 
92 CHAPTER 4. ROCK PILES IN A MITIGATION TRANSLOCATION 


\section{CHAPTER 5}

\section{Revisiting mitigation translocations of endemic New Zealand skinks (Scincidae) shows low success rates}

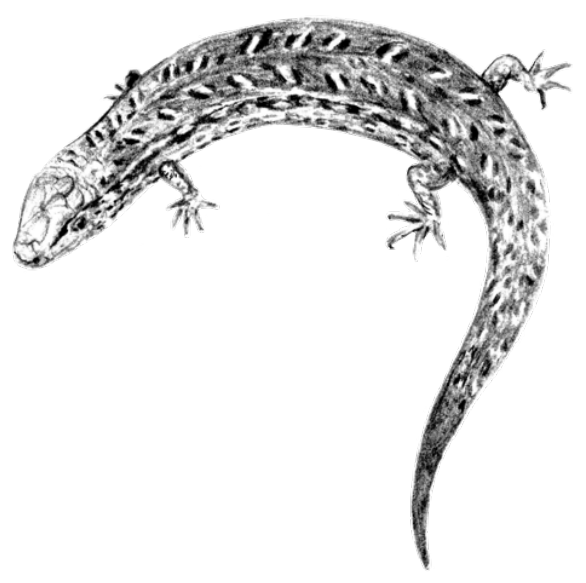

\section{$5.1 \quad$ INTRODUCTION}

Expansion and intensification of land-use by humans is causing the modification and destruction of vast amounts of natural habitat worldwide. For wildlife, these activities can result in harm, extirpation, or even extinction (Vié et al. 2009). As concern for affected species has grown, there have been attempts to mitigate or counteract negative anthropogenic effects. One approach is mitigation translocation.

Mitigation translocations (also known as salvage translocations or fauna relocation) are the human-mediated movement of living organisms from a future development site to another location in an effort to mitigate damage caused (International Union for the Conservation of Nature/Species Survival Commission [IUCN/SSC] 2013). They are usually implemented as a tool to meet legal or regulatory 
requirements to mitigate damage to wildlife; in New Zealand the Wildlife Act 1953 and the Resource Management Act 1991 (RMA) both require mitigation action and influence its implementation (Resource Management Act 1991, Wildlife Act 1953). Translocations have become increasingly common since the early 2000s (Seddon et al. 2007), with a growing uptake in the use of this tool for mitigation purposes (Miller et al. 2014; Germano et al. 2015; Sullivan et al. 2015). Although lack of reporting makes it difficult to determine exact numbers, there is evidence that in many regions mitigation translocations vastly outnumber other types of translocation in both frequency and allocated funding (Miller et al. 2014; Germano et al. 2015). Mitigation translocations have been criticised, notably characterised as 'a misguided conservation strategy' by Germano et al. (2015) due to their poor implementation and monitoring.

Mitigation translocations differ from the other two main types of translocation, research and conservation translocations, in terms of their goals. Specifically, the primary goal of mitigation translocations is to meet legislative or regulatory requirements (Germano et al. 2015), whereas research translocations aim to test hypotheses (Seddon et al. 2007), and conservation translocations to provide conservation benefit (IUCN/SSC 2013). The goals of mitigation translocations are set through regulatory processes (in New Zealand, as consent conditions in RMA consents), and their grounding in biology can thus be variable. Specified goals may be related to ecology, from colonisation of new habitat (Kyek et al. 2007) to observation of translocated individuals post release (Edgar et al. 2005). In cases where the main goal is to meet regulatory requirements, this may mean only prevention of unlawful deaths of animals near human developments, without regard to the continued persistence of the individual, population, species, or ecosystem (Platenberg \& Griffiths 1999; Massei et al. 2010; Germano et al. 2015).

Post-release monitoring is vital for determining translocation outcomes. Translocation success is liable to change over time post release, and assessments of success can only be considered accurate for the time at which the assessment was made (Wolf et al. 1996; Seddon 1999). Short-term monitoring (e.g. over a time period allowing assessment of founder survival) can be used to provide a snapshot view of 
success and inform adaptive management; long-term monitoring (e.g. over a time period allowing assessment of population establishment) is necessary to determine the ultimate success or failure of translocations (Seddon 1999; IUCN/SSC 2013; Germano et al. 2014). In a translocation of the critically endangered kakī (Himantopus novaezelandiae), long-term monitoring led to different, more accurate conclusions and management recommendations than would have been achieved using only short-term monitoring (van Heezik et al. 2009). Monitoring must therefore occur over both the short and long terms, for an appropriate length of time based on life history traits; this may mean decades of monitoring for long-lived species (Dodd \& Seigel 1991; Germano \& Bishop 2009; IUCN/SSC 2013).

Mitigation translocations are less likely to be monitored than other kinds of translocations. In a review of herpetofauna translocations in New Zealand, 78\% of conservation translocations (38 out of 49 ) and $80 \%$ of research translocations (4 out of 5) were monitored, compared with $40 \%$ of mitigation translocations (8 out of 20 ) (Miller et al. 2014). In a summary of New Zealand lizard translocations compiled by the Department of Conservation (DOC), 89\% of mitigation translocations (24 out of 27) had an 'unknown' outcome compared with $21 \%$ of translocations for other purposes (9 out of 42) (Sherley et al. 2010). In a study of great crested newt (Triturus cristatus) translocations in England, 36\% of mitigation translocations were not monitored at all; of those that were, most were monitored for two years or less (Edgar et al. 2005). The apparent worldwide lack of adequate monitoring and reporting (Miller et al. 2014; Germano et al. 2015) could partially be due to fear of negative publicity (Edgar et al. 2005; Teixeira et al. 2007). Where monitoring is carried out, requirements may be arbitrarily set for only a few years, without reflecting the life histories of species (Ewen et al. 2014; Germano et al. 2015). Long-term monitoring may be difficult to mandate from developers whose goals are to meet regulatory requirements, not to ensure the health of a population in perpetuity.

With the aim of encouraging monitoring and reporting and reducing the effects of publication biases, Miller et al. (2014) developed standardised definitions of translocation success which take into account time elapsed since translocation and 
species life history. Using this framework, a translocation can be assessed against a continuum with milestones to provide snapshots of its success from short term to long term. Success is recognised as a state that may change over time. The early stages of this framework correspond to common regulatory requirements for both conservation and mitigation translocations (e.g. survival of founders). The ultimate success according to this framework is the establishment of a self-sustaining population. This would generally be considered the ultimate goal of conservation translocations, and would indicate a successful conservation outcome (IUCN/SSC 2013). These standards were further developed by Romijn and Hartley (2016), who suggested a typical timeframe for each stage based on expected outcomes for some of New Zealand's slowest reproducing lizard taxa.

New Zealand's endemic lizards are increasingly subject to mitigation translocations. New Zealand is home to a large diversity of endemic lizards, with 43 gecko (Diplodactylidae) and 63 skink (Scincidae) species (van Winkel et al. 2018), generally characterised by long lifespans and low reproductive output (Cree \& Hare 2016). Of these 106 taxa, 88 are classified as Threatened or At Risk by the New Zealand Threat Classification system (Hitchmough et al. 2016a). The major agents of decline are habitat destruction and predation by a suite of introduced mammals, to which New Zealand's lizards are vulnerable due to evolutionary naivety (Hitchmough et al. 2016b). Mitigation translocations have been increasingly applied to endemic lizards since 2003, and between 2003 and 2013 represented half of all lizard translocations (Romijn \& Hartley 2016). Most of these projects did not feature sufficient monitoring to enable assessment of their success in achieving conservation goals.

I revisited nine historical mitigation translocations of endemic New Zealand skinks which were no longer being monitored in order to collect information about their long-term success. I took one-off surveys of the populations and assessed translocation success using the standards developed by Miller et al. (2014). Using these standards meant I was evaluating success in terms of conservation outcomes rather than the legal or regulatory goals of the mitigation translocations (although these may overlap, e.g. survival of founders is often a mitigation goal). My aims were to find out if 
mitigation translocations result in conservation gains over the long term and to compare their outcomes with other types of translocations, in order to assess their usefulness as a conservation strategy.

\subsection{METHODS}

\subsubsection{Summary of methods}

I identified historical mitigation translocations of endemic New Zealand skinks based on the following criteria: the translocation occurred at least five years previously; there were pre- and/or post-release data for comparison; there were no plans for future monitoring; and the site was accessible for monitoring. I identified suitable sites by reviewing published literature and contacting translocation practitioners. I identified six translocation operations, three of which translocated two species simultaneously (Figure 5.1, Table 5.1). Considering the translocation of each species separately, I effectively assessed nine translocations.

I revisited each translocation site and conducted surveys of the skink populations over one-off monitoring periods in Austral summer, either in February 2018 or January 2019. The weather over the monitoring period in 2018 ranged from daily highs of $22-28^{\circ} \mathrm{C}$ to lows of $15-22^{\circ} \mathrm{C}$, and in 2019 from daily highs of $23-24^{\circ} \mathrm{C}$ to lows of $15-19^{\circ} \mathrm{C}$. I designed the monitoring regimes to provide data comparable to previous monitoring sessions, either repeating the same techniques or modifying them to adjust to new conditions (e.g. increased vegetation cover, high temperatures). I then assessed each translocation's success according to the standards developed by Miller et al. (2014) and the timeline for endemic New Zealand lizards from Romijn and Hartley (2016).

For pitfall trapping I used four-litre plastic buckets, installed so the mouth was flush with the ground and the lid pegged above leaving a $20 \mathrm{~mm}$ opening. Each trap contained sheltering chicken wire and some vegetation as cover in the base, a small damp sponge, and small piece of tinned pear as bait. I checked the traps daily when open and replaced the bait every $24-48$ hours depending on its degradation. I installed 


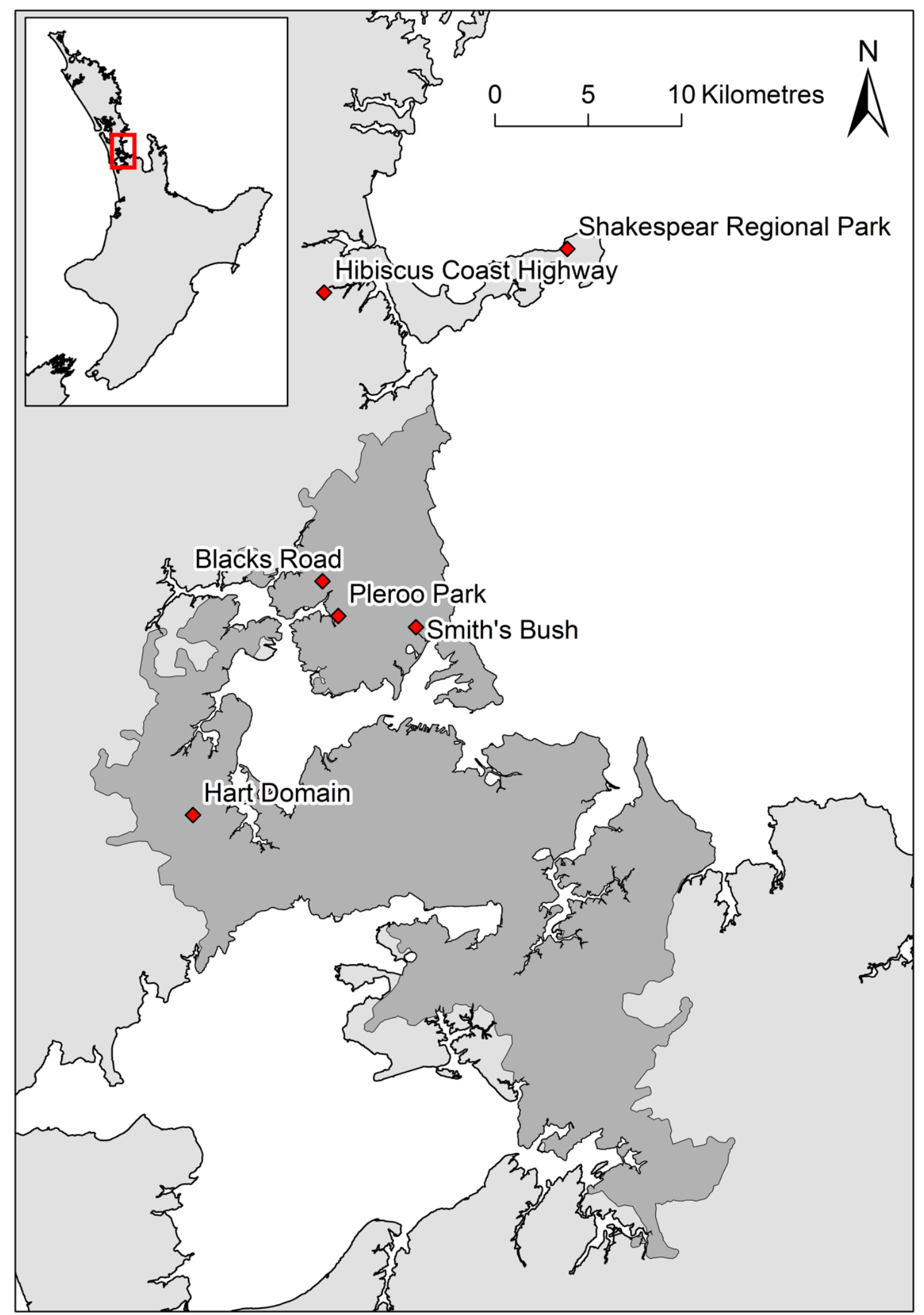

Figure 5.1. Locations of field sites in Auckland, NZ. Darker region is the Auckland urban core (Woolley et al. 2019). White regions are water. Insert of North Island of New Zealand shows location of larger map. Map data from Land Information New Zealand. 


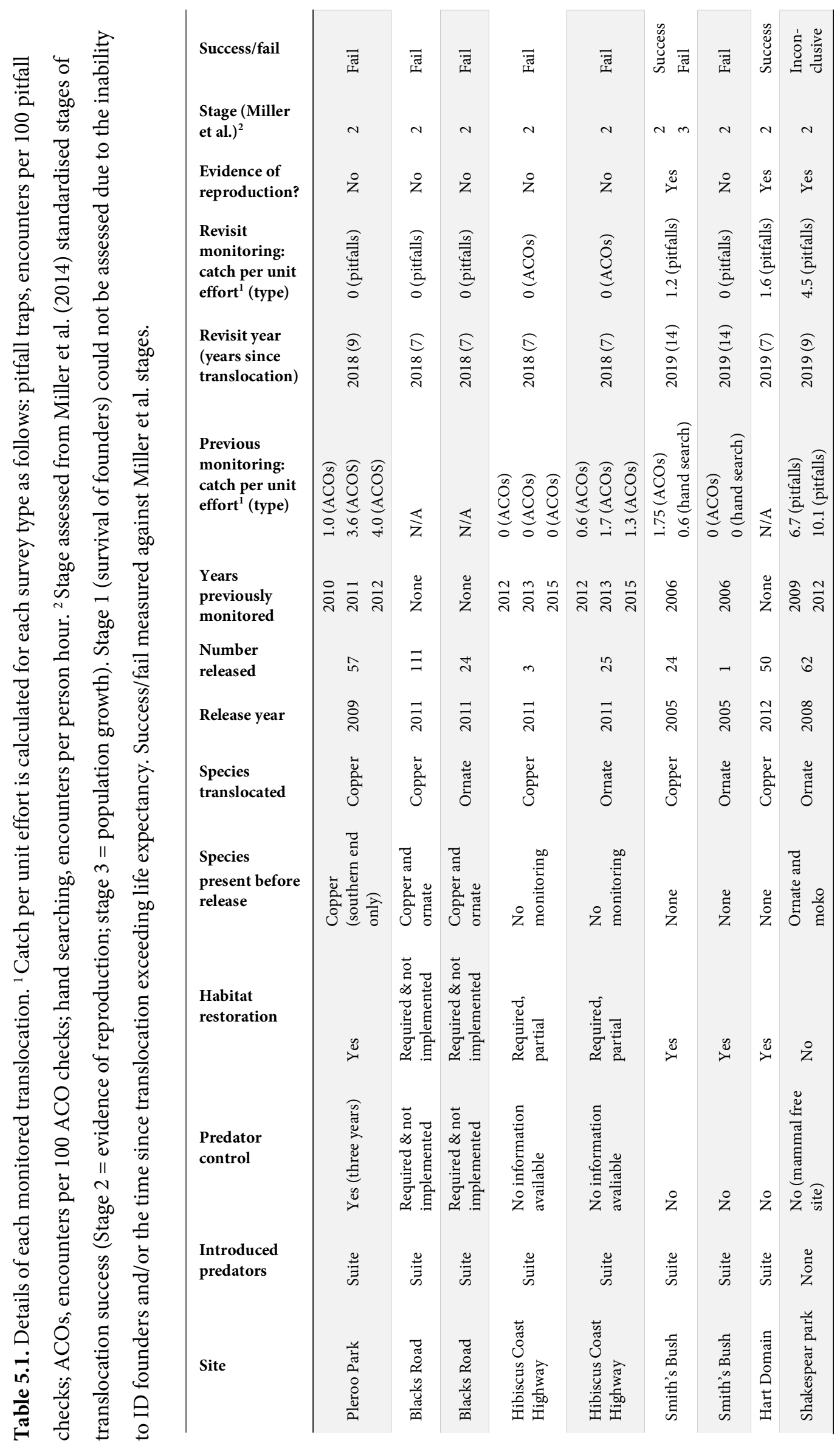


20-25 pitfall traps at each site with approximately $5 \mathrm{~m}$ spacing between traps. The artificial cover objects (ACOs) I used were $500 \times 500 \mathrm{~mm}$ Onduline $\mathrm{e}^{\mathrm{TM}}$ sheets; these are pieces of corrugated bitumen roofing material laid flat on the ground in a single layer (i.e. not stacked), installed at least one month in advance of monitoring to allow a 'bedding in' period. I checked ACOs in mid-to-late mornings with fine weather, leaving at least 48 hours between checks.

\subsubsection{Translocations, previous monitoring, and revisits by site}

Pleroo Park, Glenfield $(-36.786,174.708)$, a bush remnant located in suburban Auckland (Figure 5.2).

Between August and December 2009, 57 copper skinks (Oligosoma aeneum; NZ threat classification Not Threatened; Hitchmough et al. 2015) were salvaged from a subdivision development and released into a bush covenant area at the same site (Bioresearches 2011a; Table 5.1). Copper skinks were known to be present in the southern, established area of the bush covenant area before release, but not in the northern, formerly weed-dominated area. Thirty of the skinks were released into the bush covenant immediately after capture. The remaining 27 skinks were held in captivity while weed removal and infill planting (species chosen as lizard habitat including grasses, flax Phormium spp., Coprosma spp., Muehlenbeckia spp. etc.) were undertaken in the bush covenant, and released when the planting was completed in November 2010. Predator control (15 rodent bait stations) commenced December 2009 and ceased in early 2013 with a report indicating very low activity at bait stations.

As part of the translocation, post-release monitoring was undertaken over three years using ACOs (Bioresearches 2011a, b, 2013a). Copper skinks were found to be increasing in abundance over the three years, and a juvenile ornate skink (O. ornatum; NZ threat classification At Risk Declining; Hitchmough et al. 2015) was found in the last year of monitoring (2012/2013 summer). The encounter rates were low (1-4 skinks per 100 ACO checks; Table 5.1), which was put down to the use of ACOs under cover (Chris Wedding, pers. comm.), as ACOs have reduced effectiveness in shaded conditions (Lettink 2012). The monitoring results suggested that pest control and 


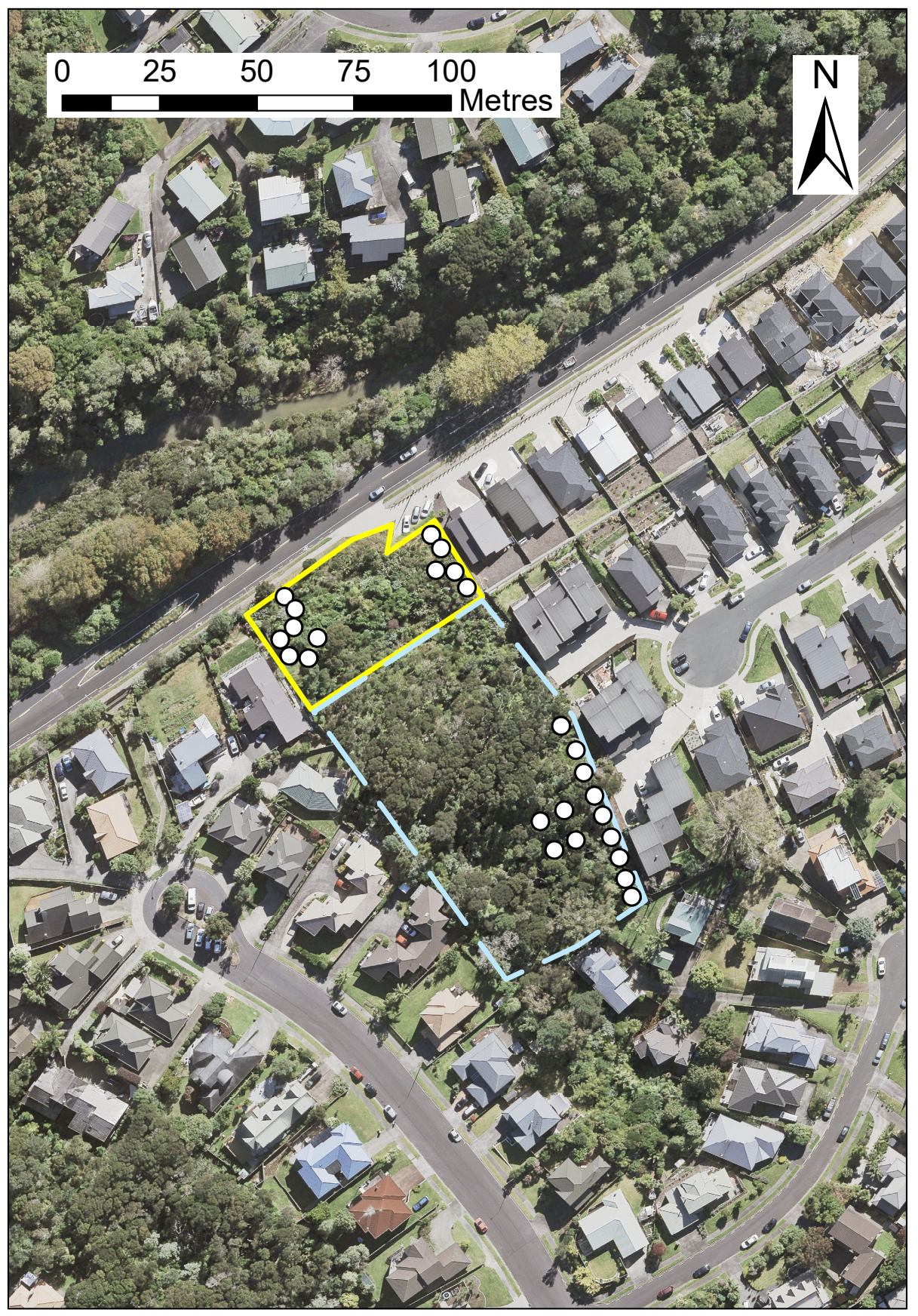

Figure 5.2. Pitfall traps locations (white dots) at Pleroo Park, Glenfield. The solid yellow border encompasses the formerly weed-dominated area; the broken blue border encompasses the area of established vegetation. Arial photograph from Land Information New Zealand.

vegetation growth had benefited the lizard populations. Five years of monitoring and pest control had been recommended, but the developer successfully applied to the council for a variation to the consent to reduce the requirement to three years (North Shore City Council 2009). 
I revisited Pleroo Park in February 2018. The vegetation at the site was substantially taller and denser than the last time it was monitored in 2012 (based on photographs; approximately ankle to hip height in 2012 and above head height in 2018). For the 2017/2018 monitoring season I therefore used pitfall traps rather than ACOs due to their greater effectiveness in shaded environments (Lettink 2012).

I installed 25 pitfall traps, 13 in the southern bush covenant and 12 in the northern bush covenant, placed in rows and clusters as close as possible to the locations of ACOs in previous years, with five metre spacing between traps (Figure 5.2). I checked the traps daily over an 11-day period from 12-23 February 2018 for 229 trap days.

Blacks Road, Greenhithe $(-36.767,174.696)$, a bush remnant in a recently urbanised, previously semi-rural area of Auckland (Figure 5.3).

In 2011, 111 copper and 24 ornate skinks were salvaged from a housing development site and released into a bush covenant at the same site (Table 5.1) (Bioresearches 2012a). The capture site was contiguous with the release site (protected riparian bush) where copper and ornate skinks were found from opportunistic searches. Photographs were taken of all released animals with the intention of identifying founders in subsequent monitoring. However, none of the anticipated plantings were completed (this is apparent when looking at the site) and no monitoring or pest control took place (there are no council records of completion). These appear to be breaches of the resource consent conditions (resource consent SA3022537). The surrounding land was cleared in 2012, and houses built from 2014 onwards.

In February 2018 I installed 25 pitfall traps from the edges of the habitat to $\sim 40$ m into the habitat, with $\sim 8 \mathrm{~m}$ gaps between traps (spaces between traps were slightly larger here in an attempt to cover a wider range of habitat from edge to deeper bush; Figure 5.3). I placed 13 traps in lizard release areas, and 12 in non-release areas, with the intention of investigating if founders had left their release area using the ID photos. I checked the traps daily over an 11-day period from 12-23 February 2018 for 209 trap days. 


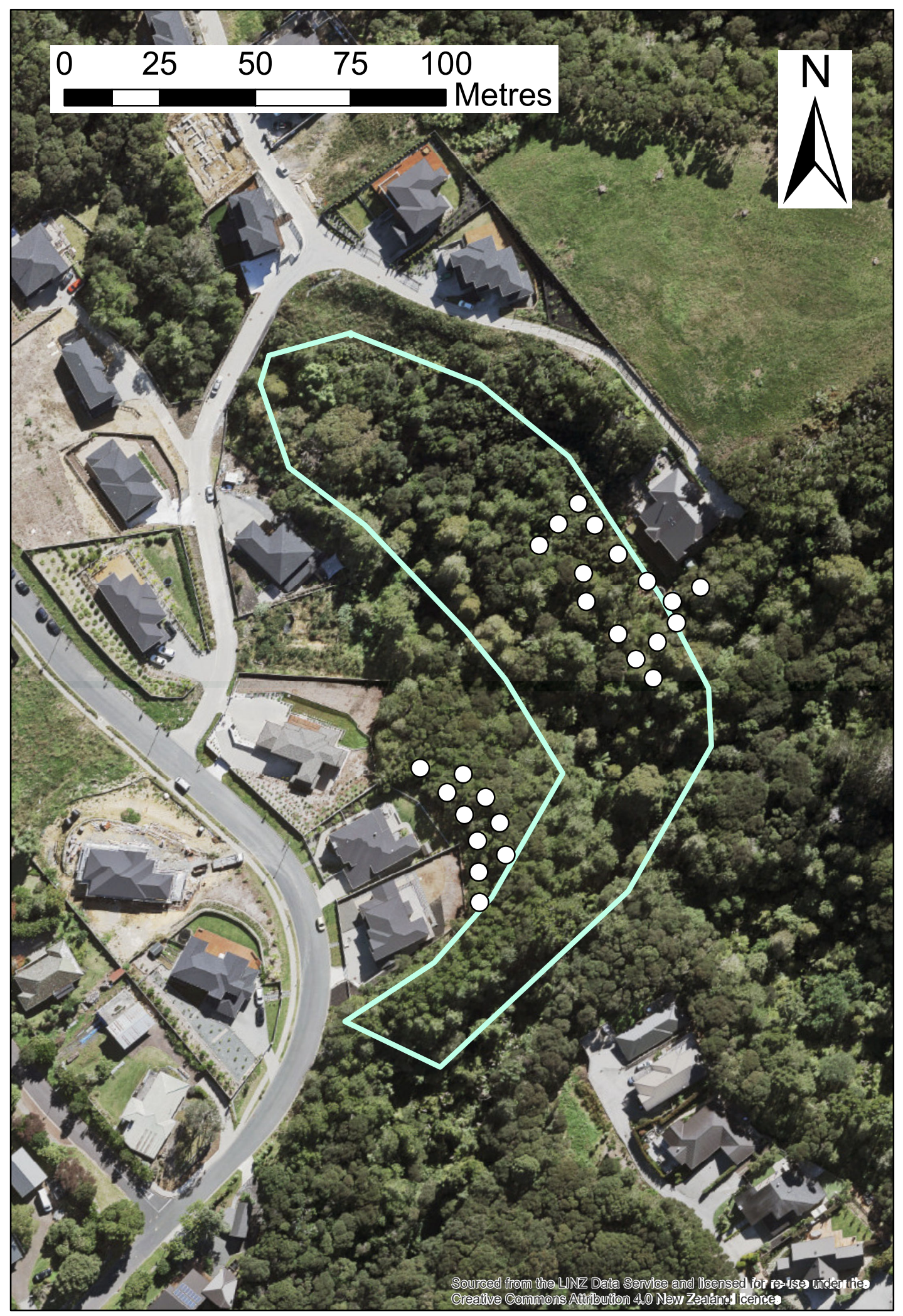

Figure 5.3. Pitfall trap locations (white dots) at Blacks Road, Greenhithe. The bordered region is the area where skinks were released in 2011. Arial photograph from Land Information New Zealand. 
Hibiscus Coast Highway, Silverdale (-36.620, 174.674), a supermarket and petrol station in semi-rural Silverdale, north of Auckland (Figure 5.4).

In early 2011, 25 ornate skinks and 3 copper skinks were translocated from the intended building site for the supermarket complex into the adjacent Weiti River riparian strip (Table 5.1) (Bioresearches 2011c). Pre-release monitoring was not undertaken at the release site.

While a buffer with appropriate lizard habitat plantings (i.e. native plants providing ground cover) between the riparian strip and the supermarket was required by the lizard management plan, this was not installed until 2014, and still contained some bare areas of woodchip inappropriate for lizards at the time of the last monitoring session in 2015 (Bioresearches 2015a). No information about pest-control regimes was available. Semi-annual monitoring using ACOs was conducted until 2015 (with the exception of 2014 when no monitoring took place) (Bioresearches 2012b, 2013b, 2015a). Ten stations of four ACOs each were used: in 2012 and 2013 all within the riparian strip, and in 2015 half in the replanted area and half in the riparian strip. No endemic skinks were recorded within the replanted areas, and each year one to two endemic skinks were recorded in the riparian strip over $160 \mathrm{ACO}$ inspections (encounter rates from 0.6-1.7 per 100 ACO checks; Table 5.1).

In January 2018, I installed 40 ACOs at Hibiscus Coast Highway in 10 clusters of 4 (Figure 5.4). I placed the ACOs as close as possible to where ACOs were located in previous monitoring. I checked all ACOs on five occasions: the $16^{\text {th }}, 18^{\text {th }}, 20^{\text {th }}, 22^{\text {nd }}$, and $24^{\text {th }}$ of February 2018. 


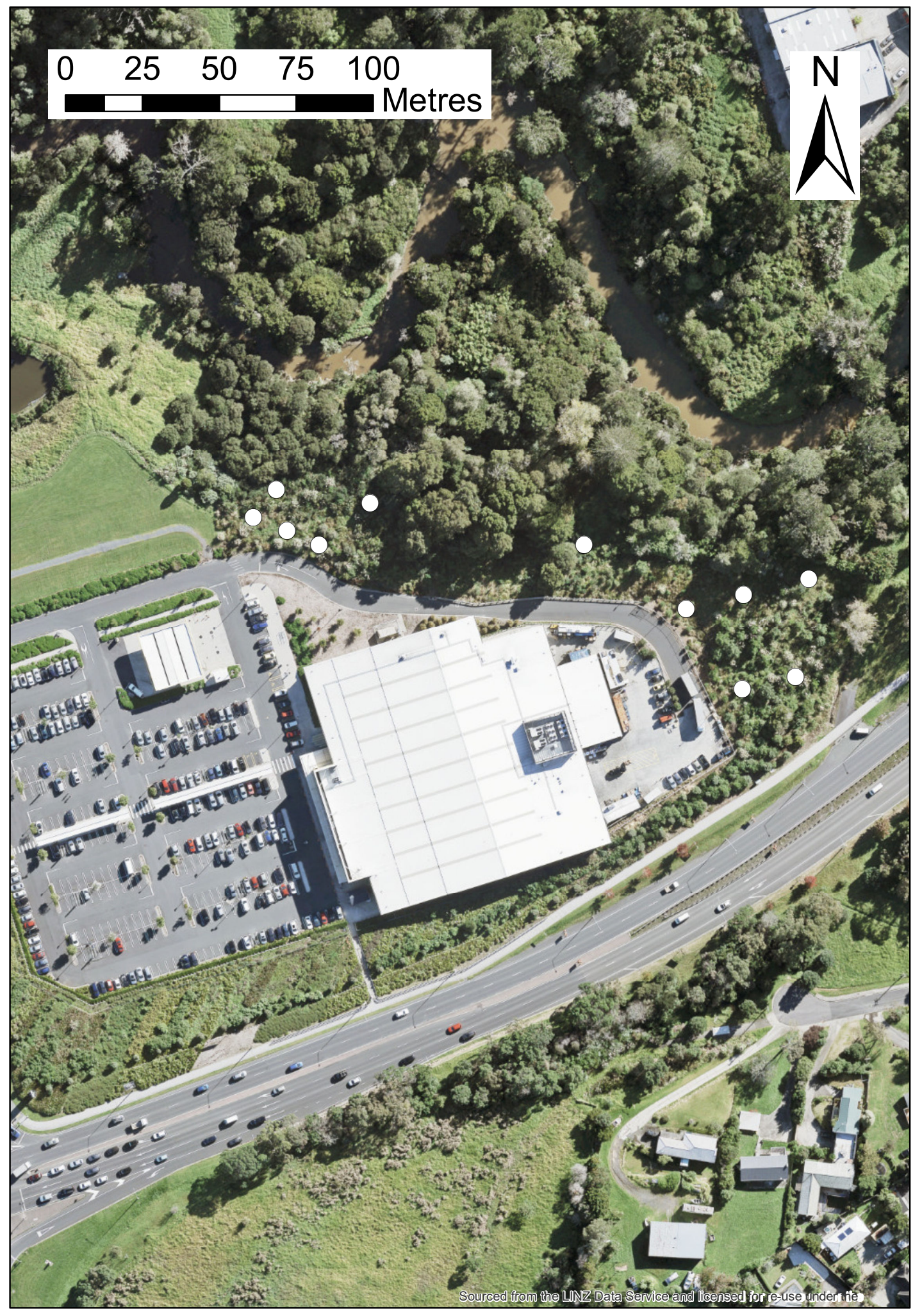

Figure 5.4. Artificial cover object (ACO) locations (white dots) at Hibiscus Coast Highway,

Silverdale. Each dot is a cluster of four single-layered 500 x 500 mm ACOs. Arial photograph from Land Information New Zealand. 
Smith's Bush, Takapuna $(-36.790,174.755)$, a scenic reserve in suburban Auckland fragmented by a motorway into two sections: the western (6.2 ha) and the eastern (1.1 ha) (Figure 5.5).

In May 2005, $900 \mathrm{~m}^{2}$ of edge habitat was cleared from the eastern section for expansion of the motorway. Twenty-four copper skinks (including three juveniles and one neonate) and one ornate skink were salvaged from the cleared area (Table 5.1). Prior to vegetation clearance, the natural debris (primarily logs and epiphyte clumps) was collected and redistributed in the remaining eastern segment to recreate the original edge habitat (Simon Chapman, pers. comm.). The captured skinks were released into this area. No predator control was implemented.

The ecologist who undertook this translocation was confident that there were no skinks present in Smith's bush in the period between salvage and release, based on the concentration of the skinks in the edge habitat and the subsequent destruction of the edge habitat (Simon Chapman, pers. comm.). In October 2006, a follow-up survey was conducted using hand searching and ACOs. Forty ACOs were used and checked once. A total of 16 skinks were found: nine copper skinks over 15.25 hours of hand searching (0.6 skinks/hour), and four copper skinks and three unidentified skinks using ACOs (0.175 skinks/ACO check), with two skinks appearing gravid (Table 5.1).

I revisited Smith's Bush in January 2019. Although the previous monitoring used ACOs, I used pitfall traps due to the difficulty of catching skinks by hand or under ACOs in hot weather, as well as the reduced effectiveness of ACOs under cover. I installed 25 pitfall traps along the edge habitat with at least five metre spacing between traps (Figure 5.5). I checked the traps daily over an 11-day period from 30 December 2018 to 9 January 2019 for 250 trap days. 


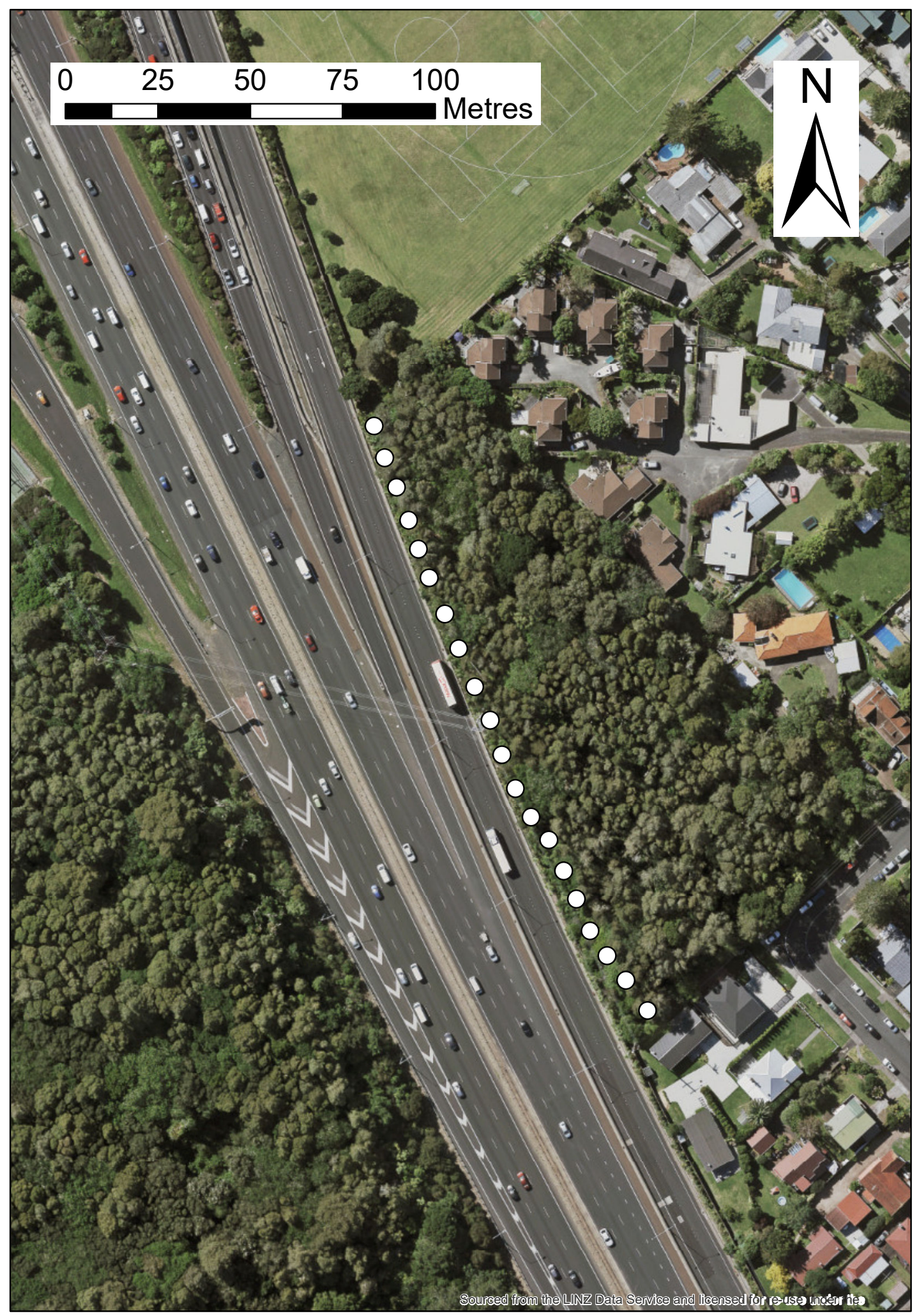

Figure 5.5. Pitfall trap locations (white dots) at Smith's Bush, Takapuna, Auckland. Arial photograph from Land Information New Zealand. 
Hart Domain, Henderson $(-36.885,174.634)$, a council reserve in suburban Auckland bordered by mown lawn (Figure 5.6).

In 2012, 50 copper skinks ( 25 from each of two sites in Henderson) were translocated to Hart Domain (Table 5.1). Low-growing native plants were planted at high density along the bush edge at the release site one to two years before the translocation (Simon Chapman, pers. comm.). The ecologist who undertook this translocation was confident that there were no native skinks in this area prior to release based on pre-release monitoring (Simon Chapman, pers. comm.). No post-release monitoring or predator control was undertaken.

In January 2019, I installed 25 pitfall traps along the western planting with at least $5 \mathrm{~m}$ spacing between traps (Figure 5.6). I checked the traps daily over an 11-day period from 29 December 2018 to 8 January 2019 for 245 trap days.

Shakespear Regional Park, Whangaparoa (-36.601, 174.817), a grassy hillside within a mammalian predator-free sanctuary in Shakespear Regional Park, protected by a predator exclusion fence (Figure 5.7).

In 2007 and 2008, ornate skinks were captured as part of the extension of nearby sewage ponds. In February 2008, 62 ornate skinks were released at the hillside, approximately 200-300 $\mathrm{m}$ from the capture site (Table 5.1). This site was known to have populations of both moko (O. moco) and ornate skinks prior to release. No additional planting or predator control was undertaken (this is a mammalian predator-free site).

In April 2009 and November 2012, the release site was monitored using 20 pitfall traps lidded with ACOs. In 2009, four ornate skinks were found over 60 trap nights (6.7 per 100 trap checks; Table 5.1). In 2012, 2 moko, 8 copper, and 11 ornate skinks were found over 109 trap nights (10.1 ornate skinks per 100 trap checks; Table 5.1).

In January 2019, I monitored 20 pitfall traps which were placed in the same locations as the previous monitoring periods (in pairs with five metre spacing between traps in each pair), and lidded with ACOs as in previous monitoring periods (Figure 5.7). I checked the traps daily over an 11-day period from 28 December 2018 to 7 January 2019 for 200 trap days. 


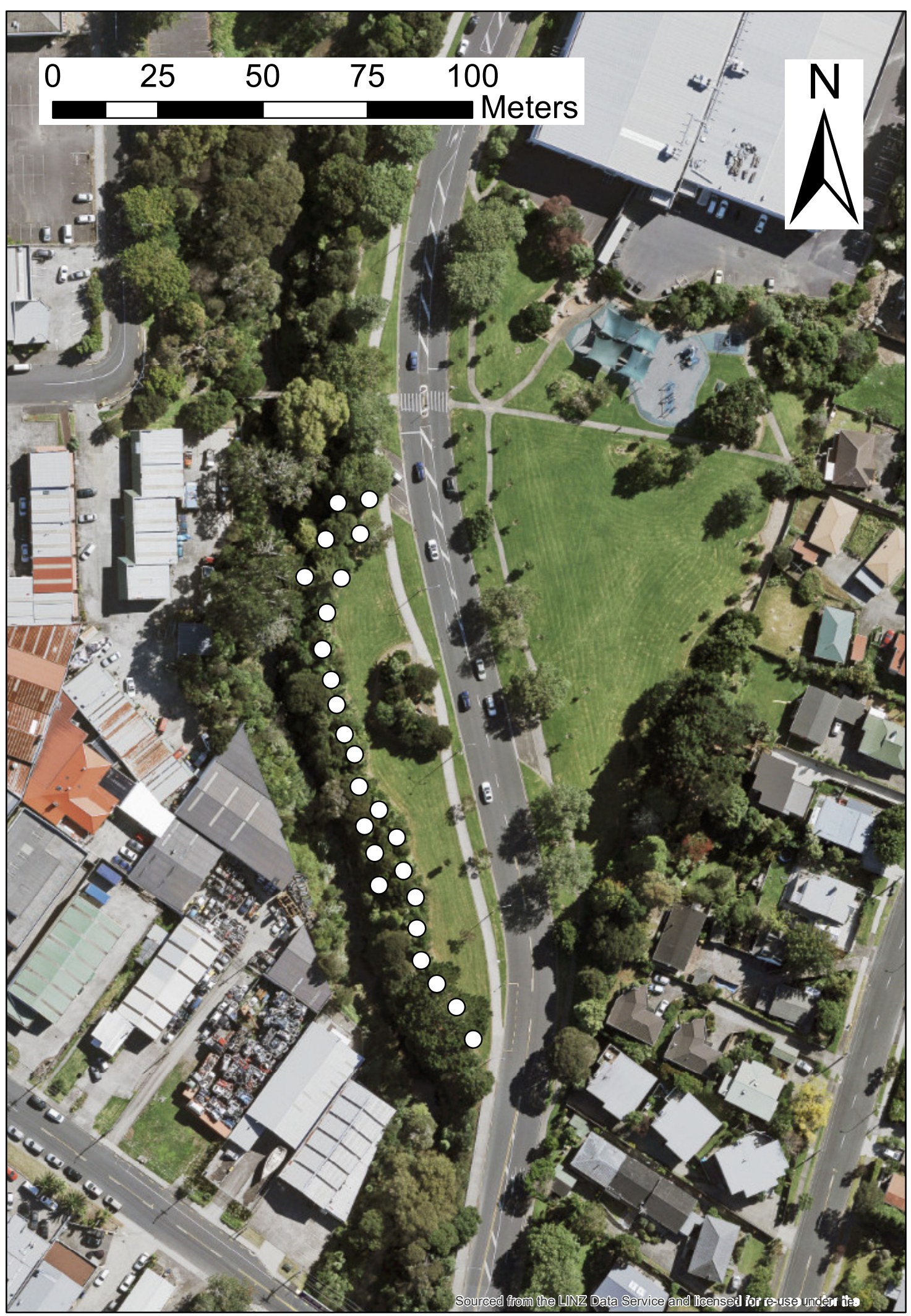

Figure 5.6. Pitfall trap locations (white dots) at Hart Domain, Henderson. Arial photograph from Land Information New Zealand. 


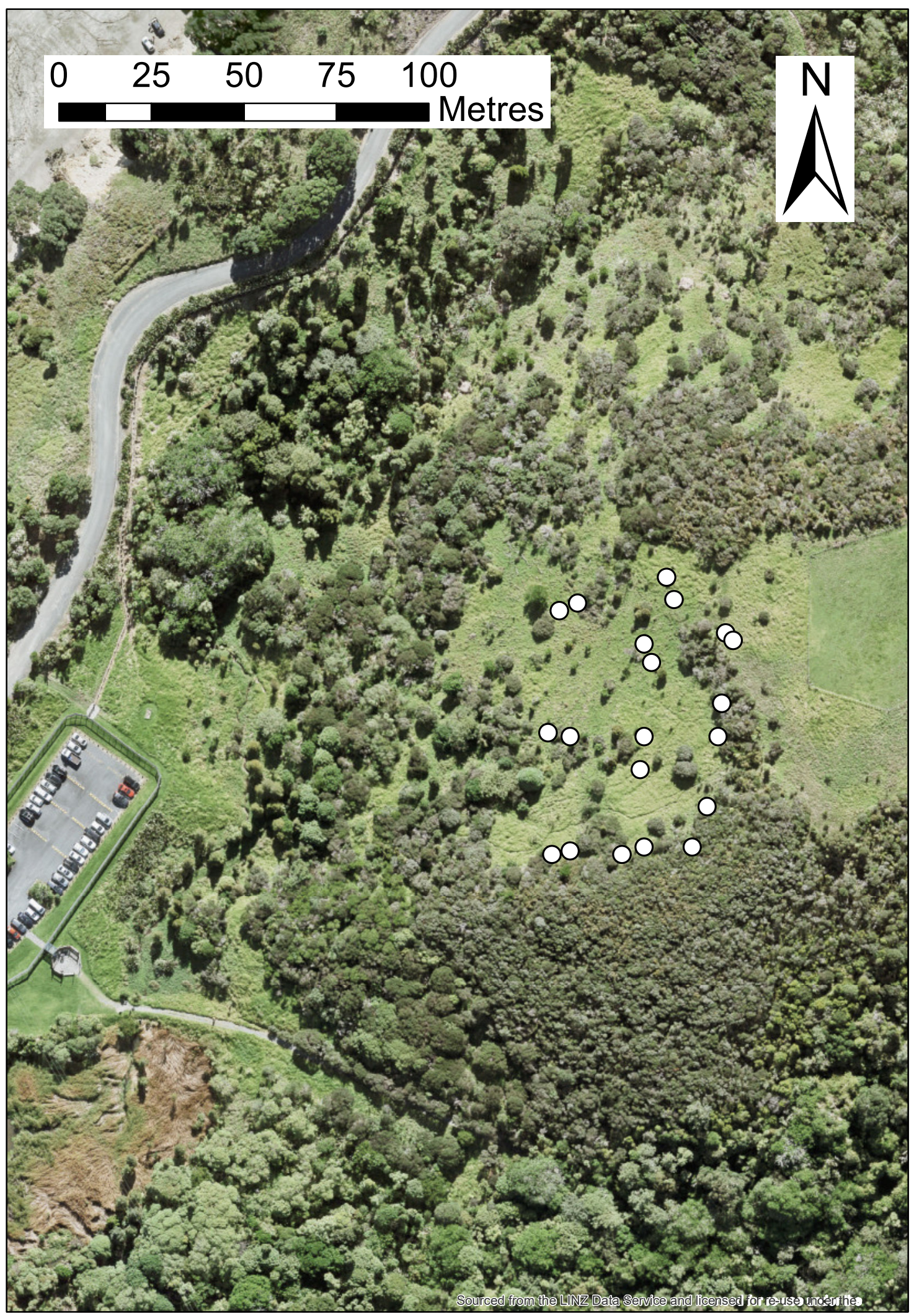

Figure 5.7. Pitfall trap locations (white dots) at Shakespear Regional Park, Whangaparaoa Peninsula. Arial photograph from Land Information New Zealand. 


\subsection{RESULTS}

Pleroo Park, Glenfield. I saw no endemic skinks over 229 trap days at Pleroo Park (Table 5.1). I caught 18 introduced rainbow skinks (Lampropholis delicata; 7.9 per 100 trap days).

Stage 1 of the Miller et al. criteria, recapture of founders, could not be assessed due to the time elapsed since translocation (nine years; small bodied Oligosoma species' general longevity is up to eight years; Cree \& Hare 2016) and the inability to identify founders. The revisit fell within the timeframe suggested by Romijn and Hartley (2016) for assessment of stage 2 (evidence of reproduction, 5-9 years). This translocation is currently a failure at stage 2 as no endemic skinks were found.

Blacks Road, Greenhithe. I saw no endemic skinks over 209 trap days at Blacks Road (Table 5.1). One property owner had built a path and planted exotic bromeliads inside the bush covenant, and aerial imagery shows incursion of house platforms and gardens into the legally protected covenanted bush.

Although photo IDs were taken of founders prior to release, no skinks were found therefore this translocation could be considered a failure at stage 1, recapture of founders. However many founders would not have survived seven years post translocation simply due to the natural lifespans of these species (Cree \& Hare 2016). This revisit fell within the timeframe suggested by Romijn and Hartley (2016) for assessment of stage 2, evidence of reproduction. This translocation is currently a failure at stage 2 as no endemic skinks were found.

Hibiscus Coast Highway, Silverdale. I saw no confirmed endemic skinks in 200 ACO checks (Table 5.1). I caught 11 rainbow skinks (5.5 per 100 ACO checks). There were a number of suspected rainbow skinks under ACOs that I was unable to catch due to their speed in the high temperatures $\left(>18^{\circ} \mathrm{C}\right)$.

Stage 1, recapture of founders, could not be assessed as the founders had not been marked and there was no way to identify them. As this revisit was seven years post translocation, it falls within the timeframe suggested for assessment of stage 2, evidence 
of reproduction. This translocation is a current failure at stage 2 as no endemic skinks were found.

Smith's Bush, Takapuna. Over 250 trap days I caught three adult copper skinks (1.2 per 100 trap days): one male and two females, with one female appearing pregnant (Table 5.1). I also caught 28 rainbow skinks (11.2 per 100 trap days).

Stage 1 could not be assessed due to the time elapsed since translocation (14 years). Although outside of the timeframe suggested for assessment of stage 2 (evidence of reproduction, 5-9 years), this translocation could be considered a success at this stage as I found a pregnant copper skink. The translocation of the single ornate skink would be considered a failure as no ornate skinks were found, however it is highly improbable for a translocation of a single individual to meet these criteria. This revisit fell within the timeframe suggested for assessment of stage 3 (population growth, $10+$ years). This translocation is currently a failure at stage 3 as fewer skinks were found than were released of both species (copper skinks 24 released, 3 found; ornate skinks 1 released, 0 found).

Hart Domain, Henderson. Over 245 trap days I caught one juvenile and three adult copper skinks (1.6 per 100 trap days; Table 5.1). Of the adults, two were female and one male. I also caught 23 rainbow skinks (9.4 per 100 trap days).

Stage 1 could not be assessed as the founders had not been marked and there was no way to identify them. As this revisit was seven years post translocation, it fell within the timeframe suggested for assessment of stage 2 (evidence of reproduction, 5-9 years). This translocation is currently a success at stage 2 due to the finding of a juvenile copper skink.

Shakespear Regional Park, Whangaparoa. Over 200 trap days I caught eight adult copper skinks (four per 100 trap days; Table 5.1). Three were male and five female, with one appearing pregnant. I also caught nine adult ornate skinks (4.5 per 100 trap days). Three were male and six female, with one appearing pregnant. I also caught 44 rainbow skinks (22 per 100 trap days). 
Stage 1 could not be assessed both due to the time elapsed since translocation (nine years) and the inability to identify founders. This translocation could be considered a success at stage 2 (evidence of reproduction) as I found pregnant copper and ornate skinks; however, as there were populations of both species here prior to translocation and the translocated individuals were not marked, this is inconclusive.

\subsection{DISCUSSION}

This study represents the first time mitigation translocations of New Zealand lizards to non-fenced sites (i.e. not sanctuaries) have been assessed more than five years post translocation, as far as we are aware. The assessment of these mitigation translocations is a step towards counteracting publication bias, which favours publication of successful translocations and also disfavours publication of mitigation translocations (Miller et al. 2014). Unsuccessful, as well as successful, translocations must be published in order to understand their outcomes and to improve practices (Dodd \& Seigel 1991; Germano \& Bishop 2009; IUCN/SSC 2013; Miller et al. 2014). Of the nine translocations I revisited, I found two to be current successes and six to be current failures at stage 2 of the criteria developed by Miller et al. (2014), with one inconclusive. I found the translocation at Smith's Bush to be a current failure at stage 3. This represents a success rate of $22 \%$ at stage 2; in comparison, conservation translocations of lizards in New Zealand monitored to the same stage showed a success rate of 88.9\% (Romijn \& Hartley 2016). My results differ from previous findings that there were no overall differences in known outcomes between conservation and mitigation translocations of New Zealand lizards (Miller et al. 2014; Romijn \& Hartley 2016), but concur with other studies that have found mitigation translocations to be generally less successful than other translocations (Germano \& Bishop 2009; Sullivan et al. 2015).

I assessed mitigation translocations as successes or failures against markers of success leading to an ultimate goal of establishment of a self-sustaining population (Miller et al. 2014). This would generally be considered the ultimate goal of conservation translocations (IUCN/SSC 2013). However, as these are mitigation translocations, their actual goals could be inferred to be the avoidance of prosecution (in 
which case all were successful) or the meeting of regulatory requirements (in which case four of six operations were successful, with the exceptions being those at Blacks Road and Hibiscus Coast Highway). In New Zealand, the Wildlife Act mandates the absolute protection of all terrestrial vertebrates unless they are specifically listed as not protected (Wildlife Act 1953). Compliance under the Wildlife Act requires only that individual animals are not disturbed, injured, or killed unlawfully. The Wildlife Act is applied to mitigation translocations in New Zealand, primarily to authorise the handling of protected wildlife so they can be translocated (Wildlife Act 1953, section 53). However, in addition to the application of the Wildlife Act, there has been a recent shift towards increased application of the Resource Management Act. The RMA requires identification of short- and long-term ecological effects that might result from activities, and the avoidance, remedy, or mitigation of the identified potential and actual adverse ecological effects, including effects on ecosystems and flora and fauna populations (RMA 1991). This is likely a positive shift as it may lead to mitigation translocations being more likely to meet, or at least set, conservation-focused goals. However, the application of the two acts is inconsistent; varying around the country, among projects, and between DOC-issued wildlife permits and council-issued resource consents (Simon Chapman, pers. comm.).

I used timeframes approximately based on the timeline from Romijn and Hartley (2016) for the assessment of the revisited mitigation translocations. Romijn and Hartley state that their proposed timeline is based on New Zealand lizard taxa with low reproductive rates, although they provided no details of the methods for determining this timeframe. Ornate skinks live for up to 13 years in captivity; the longevity of copper skinks is unknown however small-bodied Oligosoma species generally mature in two to four years and live up to eight years in the wild (Cree \& Hare 2016). Both copper and ornate skinks reproduce annually, ornate skinks producing four to six young and copper skinks one to four (van Winkel et al. 2018). This is relatively fast reproduction among New Zealand lizard species (Cree \& Hare 2016). Stage 2 from Miller et al. (evidence of reproduction), using the Romijn and Hartley timeframe of five to nine years, could therefore encompass one to four generations for these species. Given the 
uncertainty around the basis of this timeframe, its generalised nature, and the uncertainty around the life history of the species, it is not clear exactly which criteria should be evaluated. Therefore, it is appropriate to expand evaluation of stage criteria beyond the timeframe specified by Romijn and Hartley.

The first stage of the Miller et al. criteria is survival of founders (Miller et al. 2014). However, this could not be assessed for any of these translocations, as only Blacks Road had a way to identify founders, and the time elapsed since that translocation was close to the life expectancy of founders. Marking of founders is rare in mitigation translocations in New Zealand, as there is reluctance from both DOC and iwi (local indigenous peoples) to permanently mark wildlife as part of projects with no clear plan for continued monitoring which will contribute to conservation (Simon Chapman, pers. comm.). Two of nine translocations (Hart Domain and Smith's Bush) were current successes at stage 2 of the Miller et al. (2014) criteria, as I found evidence of reproduction. This criterion is a relatively low bar to clear, requiring only that pregnant/gravid females or juveniles/neonates conceived and born after translocation are found. In both cases of success at this stage, each was due to finding a single individual. It remains to be seen if either will be evaluated as successful at stage 3 (population growth), however Smith's Bush was at this time, 14 years post translocation, evaluated as a failure at stage 3 .

The low success rate of mitigation translocations of New Zealand lizards (22\%) compared with that of conservation translocations (88.9\%; Romijn \& Hartley 2016) may be partially due to the release sites. Only one conservation translocation was to an unfenced mainland site, and $91 \%$ of release sites were free of introduced mammalian predators (Romijn \& Hartley 2016), whereas all but one of the mitigation translocations revisited here were to mainland unfenced sites where mammalian predators were likely present. In a study of mouse exclusion in a fenced mainland sanctuary, ornate skink catch ranged from 0 per 100 pitfall trap nights shortly after construction of a mouseexcluding fence in 2006 to 13 per 100 pitfall trap nights in 2015 (Nelson et al. 2016). On Korapuki island, lizard captures ranged from $\sim 5$ per 100 pitfall trap nights when rodents were present to $\sim 25$ per 100 trap nights following rodent eradication (Towns 1991). 
These are examples of populations that are recovering well in the absence of predation by introduced mammals. In comparison, the general capture rates at unfenced sites within the current study are $\sim 0-2$ skinks per 100 trap nights. It is clear that even when lizards were found at these unfenced sites, their capture rates were still below the potential for a healthy population.

Confirming absence of endemic New Zealand skinks is very difficult (Hare 2012; Lettink 2012). In some cases in New Zealand, skink populations have been undetectable only to recover to detectable levels following eradication of mammalian predators (e.g. ornate skinks becoming detectable two years after mouse eradication; Nelson et al. 2016). The possibility of false negatives at the receptor sites before translocation means that some of the revisited translocations may be unrecognised reinforcements or supplementations of existing populations. Reinforcements should aim to enhance population viability via contributions to population size, genetics, or demographics (IUCN/SSC 2013). It is possible that these positive effects were occurring if these translocations were in fact reinforcements; however, I could not assess this because there was no evidence for receptor populations, no genetic data were collected, and there was no marking to allow identification of translocated individuals. In particular, the translocations of one ornate skink at Smith's Bush and of three copper skinks at Hibiscus Coast Highway would likely only result in conservation outcomes if they were reinforcements. The assessment of these translocations using the Miller et al. criteria holds merit even if these are reinforcements, as a population that is moving from undetectable levels towards a detectable self-sustaining population could reflect positive contribution from reinforcing translocations or from predator control associated with mitigation work (Miller et al. 2014).

The possibility of false negatives in my follow-up monitoring means it is possible that populations persist at Blacks Road, Pleroo Park, and Hibiscus Coast Highway in low numbers. Microhabitat, macrohabitat, and weather-related factors influence the capture rates of lizards (Phillpot 2000; Lettink \& Seddon 2007). This, combined with zero or low capture numbers, make it impossible to assess detectability at these sites. Capture rates such as 1.2 copper skinks per 100 trap nights at Smith's Bush may not in 
fact represent a significant difference in population compared with the sites with recorded zeros. The categorisation of the individual translocations as failures is therefore not absolute. However, the overall low proportion of translocations meeting success standards at this time, and the fact that those that met success standards often did so based on very few individuals, point to a pattern of mitigation translocations failing to provide conservation benefit.

Translocations are unlikely to succeed unless the agent or agents of decline are controlled (IUCN/SSC 2013). New Zealand reptiles are vulnerable to mammalian predation, particularly by rodents, and predator incursions or irruptions have been linked to reptile extirpations across the mainland and islands of New Zealand (Cree \& Butler 1993; Towns \& Daugherty 1994; Hoare et al. 2007). All release sites except Shakespear Regional Park were likely occupied by a suite of introduced mammalian predators, as they were all urban and unfenced. Predator assemblages and habitat factors can interact to cause population declines which are difficult to recognise due to their slow pace and uncertainty around carrying capacity; i.e. when carrying capacity is unknown, predator-caused suppression or slow declines can be mistaken for a low carrying capacity or rarity (Hoare et al. 2007). At Pleroo Park, the lack of endemic skinks found in 2017/2018 could potentially indicate a population crash following cessation of predator control. This pattern has been observed previously in a mitigation translocation of 258 moko skinks to Te Puia marginal strip in Whangamata in 2009, where encounters of released skinks increased over the course of monitoring until pest control was stopped, with a subsequent population crash in the final year of monitoring (Bioresearches 2015b). It is highly possible that the mammalian predator assemblages at many of the sites I revisited are responsible for lizard declines both before and after translocations.

The mean propagule size for lizard translocations in New Zealand ranges from 40-50 individuals (Romijn \& Hartley 2016; Towns et al. 2016). Of the revisited translocations, founder populations were $>30$ at three locations and in the 20-30 range at three locations. Two had exceedingly small founder population sizes; three copper skinks released at Hibiscus Coast Highway and the single ornate skink released at 
Smith's Bush (both failures at stage 2). Translocations of this size and of common species are unlikely to contribute greatly to conservation; they are likely only to meet regulatory or legislative goals (i.e. avoidance of immediate death of individuals). Given the known link between extinction risk and lack of genetic diversity within populations (Saccheri et al. 1998), translocations using small founder populations may represent a large amount of effort spent on meeting legislative goals with little conservation benefit.

Monitoring is essential for determining the success of translocations, however three of these translocations (Hibiscus Coast Highway, Blacks Road, Pleroo Park) did not fully execute the monitoring that was initially planned and required under the resource consent conditions. At Pleroo Park, if the initial monitoring requirement had been met, a decrease in population size might have been recognised earlier. However, it is unlikely that finding a decreasing population would have required further action from the developer to protect the translocated lizards, as there were no conditions in the resource consent which required action under these circumstances. Council-issued resource consent conditions must be commensurate with the scale of the effect of the land use, with the result that consent conditions are rarely enforced over longer than five years (Chris Wedding, pers. comm.). This hinders the enactment of more effective monitoring and pest control that take into account lizard life history characteristics.

A translocation that meets the goal of a self-sustaining population may be considered a positive conservation outcome (Miller et al. 2014). This is especially true when compared with a scenario of no mitigation action. However if, for instance, the source population was self-sustaining, is completely destroyed, and the only outcome is another self-sustaining population, this might be considered a neutral outcome in terms of conservation. It may even be considered a negative outcome if it is accompanied by a loss of habitat at the source site, as is generally the case in mitigation translocations. Several of the translocations revisited here were accompanied, or planned to be accompanied, by habitat enhancement (e.g. plantings) or predator control. Measures such as these could contribute to a net conservation gain. When considering the effectiveness of mitigation translocations for conservation, it is important to consider 
them as part of a wider picture of landscapes, communities, ecosystems and metapopulations, not just whether the translocated population succeeds.

Mitigation translocations are less successful than conservation translocations for reasons that are inherent to mitigation. For instance, when common species are salvaged in low numbers (e.g. three copper skinks at Hibiscus Coast Highway, one ornate skink at Smith's Bush) their translocation is unlikely to have a large impact; however, animals salvaged must be released, and so a mitigation translocation occurs even when meaningful conservation outcomes are unlikely. The obligation to avoid, mitigate, or remedy the effects of land-use in situ (Resource Management Act 1991) means receptor sites usually have mammalian predators which threaten translocation success (as was the case for all sites revisited except Shakespear). Working around construction means that salvage is often $a d$ hoc or opportunistic rather than based entirely on ecological best practice. Even when management plans are drafted following good ecological practices, non-compliance is common (e.g. Hibiscus Coast Highway, Blacks Road; Brown et al. 2013) and is rarely penalised. For these reasons, a reliance on mitigation translocation as a remedial measure for damage to native fauna is, at best, hit-and-miss. To improve conservation outcomes, mitigation translocation practices should be improved, but they should also be accompanied by actions such as predator control, habitat enhancement, and ongoing legal protection for habitat. Mitigation translocations are undertaken based on minimum legal standards; therefore, to improve conservation outcomes the legal standards and/or mechanisms must be improved. In New Zealand this could be achieved by DOC enforcing best-practice standards in Wildlife Act permits, by local and regional councils enforcing best-practice requirements based on the RMA, or ideally through cooperation and collaboration between the authorities at all stages. In any jurisdiction with legal requirements for mitigation translocations, their inherent flaws must be acknowledged when designing standards. Consideration should also be given to mandating complementary actions such as predator control, habitat protection, and habitat enhancement to ensure conservation outcomes. 


\section{CHAPTER 6}

\section{Improving mitigation translocations for conservation of New Zealand lizards}

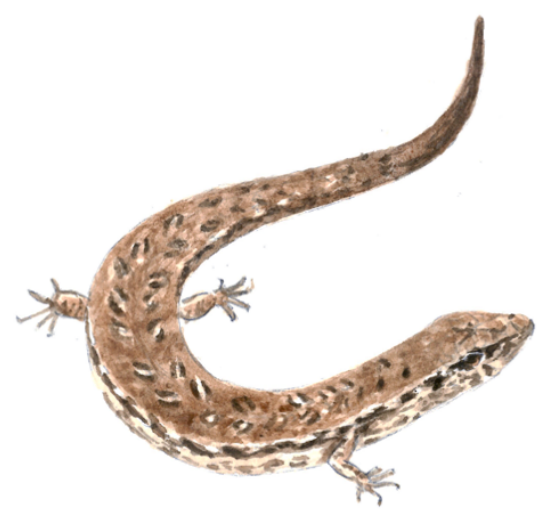

\subsection{INTRODUCTION}

Worldwide, human expansion and intensification of land-use are causing the destruction of natural habitats, and wildlife are suffering declines, extirpations, and extinctions as a result (Vié et al. 2009). One strategy to alleviate these negative effects on species is mitigation translocation, the intentional movement of organisms away from development sites (International Union for the Conservation of Nature/Species Survival Commission [IUCN/SSC] 2013). These are generally undertaken due to regulatory requirements intended to protect species, but may be poorly implemented, lack sufficient monitoring, or have uncertain conservation outcomes (Germano et al. 2015).

Mitigation translocations have become increasingly common since the early 2000s (Seddon et al. 2007; Miller et al. 2014; Sullivan et al. 2015), and in many regions vastly outnumber other types of translocation both in frequency and allocated funding 
(Miller et al. 2014; Germano et al. 2015). However, mitigation translocations have been criticised as a 'misguided conservation strategy' due to poor implementation and documentation (Germano et al. 2015). Mitigation translocations are less likely to be monitored than other types of translocations (Sherley et al. 2010; Miller et al. 2014), and this has contributed to the uncertainty surrounding their conservation outcomes (Germano \& Bishop 2009).

IUCN guidelines classify translocations based on their aims. A conservation translocation aims to provide a measurable conservation benefit (IUCN/SSC 2013), whereas the primary goal of a mitigation translocation is to meet legislative or regulatory requirements (IUCN/SSC 2013; Germano et al. 2015). According to these guidelines, a mitigation translocation might be further classed as a conservation translocation if it is undertaken following best practices for conservation, or it might be classed as an 'irresponsible release' if animals are, for instance, released into an area that is 'definitely not habitat' (IUCN/SSC 2013). There is a grey area in this definition occupied by mitigation translocations that neither strictly follow best practices, nor release animals into unsuitable areas.

A successful conservation outcome for a translocation means a measurable conservation benefit for populations, species, or ecosystems, not just for individuals (IUCN/SSC 2013). Standardised criteria can be used to assess a translocation's success state over the short to long terms, with the establishment of a self-sustaining population as an ultimate conservation goal (Seddon 1999; Miller et al. 2014). In order to achieve conservation success, a translocation must be implemented carefully from beginning to end, including aspects such as a founder population which is genetically diverse and appropriately-sourced, monitoring which informs management, and a release site which can support translocated animals post release (IUCN/SSC 2013). The degree to which mitigation translocations should follow these guidelines is unresolved. Some argue that as mitigation translocations are intended to mitigate negative ecological effects, they should be implemented as best-practice conservation translocations, although their implementation based on legal standards often falls short of this (IUCN/SSC 2013; Germano et al. 2015; Romijn \& Hartley 2016). This may be due to failures of legal 
standards, their implementation or enforcement, or a combination of these factors.

I used endemic New Zealand lizards as a study system to investigate the implementation of mitigation translocations, their conservation outcomes, and their barriers to conservation success. New Zealand is home to a large diversity of endemic lizards, with 43 gecko (Diplodactylidae) and 63 skink (Scincidae) species (described and undescribed; van Winkel et al. 2018). Of these 106 taxa, 88 are classified as Threatened or At Risk under the New Zealand Threat Classification System (Hitchmough et al. 2016a). The major agents of decline are introduced mammalian predators, to which New Zealand lizards are vulnerable due to evolutionary naivety, and habitat destruction (Hitchmough et al. 2016b). New Zealand lizards are protected under the Wildlife Act 1953, which gives absolute protection to all terrestrial vertebrates not specifically listed as unprotected, and are subject to the Resource Management Act 1991 (RMA), which requires action to avoid, remedy, or mitigate any actual or likely adverse effect on the environment. Mitigation translocations of endemic lizards have been increasing in number since 2003, and between 2003 and 2013 half of all lizard translocations in New Zealand were for mitigation purposes (Romijn \& Hartley 2016); however, most of these projects did not feature sufficient monitoring to allow assessment of their success in achieving conservation outcomes. This, combined with the vulnerable conservation status of many species, makes New Zealand lizards an ideal study system to investigate the effectiveness of mitigation translocations.

The ability of translocated populations to persist and grow at the release site is the first step in the conservation success of a translocation. With translocations of New Zealand lizards, two aspects which affect population health post release are predators and habitat characteristics. Conservation translocations of New Zealand lizards generally move animals to sites where introduced predators are either absent or controlled to levels low enough to allow translocated species to recover; however, receptor sites for mitigation translocations often have introduced predators (Romijn \& Hartley 2016). New Zealand lizards are vulnerable to a suite of introduced mammalian predators, including mice (Mus musculus) which are harder to control than larger mammals (Innes et al. 2012; Hitchmough et al. 2016b), are capable of attacking and 
killing juveniles and adults (Burt 1927; Newman 1988; Ainsworth et al. 1991; Newman 1994; Hoare et al. 2007; Wedding 2007; Norbury et al. 2013; Norbury et al. 2014), and have been connected to declines in several lizard species (Newman 1994; Hoare et al. 2007; Ussher 2006 as reported in Wedding 2007). Habitat characteristics can increase the persistence of prey species in the presence of predators, including introduced predators (Whitlow et al. 2003; Stuart-Smith et al. 2007; Sowersby et al. 2016), and habitat manipulation is a technique employed by conservationists seeking to protect threatened species from introduced predators (Armstrong \& McLean 1995; Sinclair et al. 1998).

Understanding the difficulties and outcomes of mitigation translocations is important for ensuring that the most effective actions are taken to protect vulnerable species. Where actions are mandated by legislation, their evaluation using scientific evidence is important, as misguided requirements could lead to resources being directed towards ineffective activities and away from more effective strategies.

In this thesis, I addressed the following key questions:

1. Are mitigation translocation practices meeting legal requirements?

2. Are mitigation translocations meeting conservation goals?

3. How can mitigation translocation practices be improved to better meet conservation goals?

Questions 1 and 2 were addressed in Chapters 4 and 5 by investigation into the conservation outcomes and legal basis of mitigation translocations of New Zealand lizards from the past (Chapter 5) and the present (Chapter 4). Question 3 was addressed in Chapters 2, 3, and 4 through the development and testing of a novel technique for protecting translocated skinks from mouse predation, and in Chapters 4 and 5 through the investigation of practices affecting conservation outcomes of mitigation translocations of New Zealand skinks. 


\subsection{OVERVIEW OF FINDINGS BY CHAPTER}

6.2.1 Chapter 2: Modelling three-dimensional refuge space to predict accessibility using video game software

A technique used in mitigation translocations of lizards in New Zealand is the enhancement of habitat at the receptor site, which can be achieved through the creation of rock piles. Three-dimensional interstitial spaces inside rock piles are important for rock-dwelling animals, including as refuges from predation; however, methods for measuring or characterising them are currently limited in scope. I devised a novel technique for characterising the interstitial spaces within rock piles by modelling a realistic rock pile using video game design program Unity (Unity Technologies 2016) and physics engine PhysX (NVIDIA Corporation 2011). The output from this technique is estimated proportions of spaces within the rock pile which are accessible to different size-classes of animals (e.g. mice and skinks), allowing the accessibility of rock piles to be estimated.

\subsubsection{Chapter 3: Can rock piles be designed to protect endemic skinks (Scincidae) from introduced mice (Mus musculus)?}

I used the method developed in Chapter 2 to hypothesise a design for a rock pile which could be used to protect endemic New Zealand skinks from mice. I performed an experiment in which skinks escaped a box through holes of varying sizes. I used the results from this experiment and similar data for mice from published literature (Day \& MacGibbon 2007) as data for the sizes of gaps accessible to skinks and mice. Using the gap accessibility data and the modelled rock piles, I hypothesised that a rock pile composed of 20-40 mm graded rocks would be the best option for protecting endemic skinks from mice.

\subsubsection{Chapter 4: Creating artificial habitat to protect endemic skinks (Scincidae) from introduced mice (Mus musculus) following a mitigation translocation}

The Transmission Gully motorway project is a $27 \mathrm{~km}$ four-lane motorway currently being constructed north of Wellington. I took part in a mitigation translocation of endemic lizards which was required as part of this construction and used it as a case 
study to investigate the effectiveness of mitigation translocations for conservation. At the release sites I installed rock piles of the design developed in Chapter 3, which was hypothesised as being able to provide endemic skinks protection from mice, as well as an alternative design and control piles. The salvaged lizards were released into the rock piles, but were not seen again in subsequent monitoring. There was some indication of more colonisation of local skinks into the piles of the hypothesised best design from Chapter 3. However, sample sizes were low, so this is only suggestive, not conclusive. The salvage effort was high, but only a modest number of skinks were captured, and even fewer released, especially when compared with other recent mitigation translocations in the region. One factor contributing to the low numbers released was a relatively long captive period of three years for many of the lizards, which was due to construction timelines delaying the release. This case study illustrates the variable outcomes of mitigation efforts and the difficulty in determining likely outcomes before salvage begins.

\subsubsection{Chapter 5: Revisiting mitigation translocations of endemic New Zealand skinks (Scincidae) shows low success rates}

Assessment of the effectiveness of mitigation translocations has been hampered by a lack of long-term monitoring and reporting of outcomes. I revisited nine translocations of endemic skinks in New Zealand, 7 to 14 years post translocation, to determine their success according to a standardised framework (Miller et al. 2014). Only two (22\%) met success criteria, a lower success rate than had previously been found for conservation translocations of endemic New Zealand skinks (88.9\%; Romijn \& Hartley 2016). The reduced success rate may be due to the differences in goals between mitigation and conservation translocations as well as the presence of introduced mammalian predators at release sites and small founder groups. Conservation outcomes may be improved by a shift to the application of legislation requiring protection of species and populations rather than individuals (i.e. greater application of the RMA rather than only the Wildlife Act), or the increased use of additional techniques other than translocations for mitigation purposes (e.g. predator control or habitat enhancement). 


\subsection{DISCUSSION}

\subsubsection{Are mitigation translocations meeting legal requirements?}

In New Zealand, the legislative basis for mitigation translocations comes from the Wildlife Act 1953 and the Resource Management Act 1991 (RMA). The Wildlife Act confers blanket protection to all terrestrial vertebrates (and some other species) not specifically listed as unprotected, and requires that individual animals are not disturbed, injured, or killed (Wildlife Act 1953). The RMA's more extensive requirements include identification of short- and long-term ecological effects and, if the effects are more than minor, the avoidance, remedy, or mitigation of potential and actual adverse ecological effects (Resource Management Act 1991). The RMA also gives regional councils "control of any actual or potential effects of the use, development, or protection of land, including for the purpose of the maintenance of indigenous biological diversity." (Resource Management Act 1991). Additionally, the RMA allows a resource consent applicant to propose an offset to compensate for adverse environmental effects. An offset is defined as “... a measurable conservation outcome resulting from actions designed to compensate for residual, adverse biodiversity effects arising from activities after appropriate avoidance, remediation, and mitigation measures have been applied. The goal of a biodiversity offset is to achieve no-net-loss, and preferably a net-gain, of indigenous biodiversity values." (Maseyk et al. 2018). Responsibility for enforcing the RMA lies with local government (i.e. regional councils and territorial authorities) whereas responsibility for the Wildlife Act lies with the Department of Conservation (DOC).

In the early years of mitigation translocations in New Zealand, the principle legislation applied was the Wildlife Act, and mitigation translocations were primarily conducted with the goal of preventing harm to individuals. In recent years there has been a shift towards application of the RMA in requirements for mitigation translocations, which appears to have been positive in terms of mitigations having more conservation-focused goals (i.e. protection of populations and habitat rather than simply individuals; Simon Chapman, pers. comm.). Mitigation translocations are typically implemented under the RMA as conditions of land use consents. Consent 
conditions typically require a fauna-specific management plan to be developed and the actions outlined in it undertaken, sometimes including mitigation translocation, according to standards drafted by an expert (e.g. a suitably qualified and experienced herpetologist).

Of the translocation operations I investigated, the majority (five out of seven) met their legal requirements (that is, adherence to the actions laid out in consent conditions; Chapters $4 \& 5$ ). Of those that did not, this is my judgement rather than being tested in a court of law or formally evaluated by a local council. My evaluations were based on evidence such as failure to complete required plantings, failure to complete required monitoring, or encroachment on legally covenanted habitat. Often breaches of this nature are not formally evaluated for compliance (Brown 2017; Biodiversity Collaborative Group 2018); therefore, I cannot say what enforcement action might be taken in response.

\subsubsection{Are mitigation translocations meeting conservation goals?}

Germano et al. (2015) criticised mitigation translocations as a misguided conservation strategy due to poor implementation, monitoring, and reporting of outcomes. This criticism reveals an issue at the heart of mitigation translocation practice. Namely, that mitigation translocations are not strictly implemented as a conservation strategy; rather, they are undertaken with the goal of fulfilling legal requirements. The relevant legislation was arguably written with conservation as a goal. However, the resulting regulatory requirements do not consistently mandate best practices, and successfully meeting legal requirements does not depend on delivering successful conservation outcomes.

I found that a high proportion (six out of nine) of mitigation translocations of New Zealand lizards are not meeting conservation goals, are not likely to provide significant conservation benefit, or are providing a small amount of benefit compared with what might be achieved by allocating similar levels of resources to alternative strategies (e.g. predator control, habitat enhancement, or offsetting; Chapters $4 \& 5$ ). While investigating mitigation translocations, I often found no individuals of 
translocated species at release sites following translocation (Chapters $4 \& 5$ ). Where translocated individuals die at, or move away from, release sites without reproducing, the effort put into mitigation translocations provides no conservation benefit. Although all of the translocations I examined involved salvage of small or moderate numbers of individuals, there are some instances where mitigation translocations allow the salvage of large numbers of individuals which would otherwise have died during construction, such as in the cases of two other mitigation translocations of lizards in the Wellington region (Chris Woolley, pers. comm.; Trent Bell, pers. comm.; Chapter 4). Translocations of large numbers of individuals do not necessarily lead to positive conservation outcomes, however (e.g. male desert tortoises, Gopherus agassizii, had very low fecundity following a translocation of 570 individuals; Mulder 2017).

Some mitigation translocations may provide conservation benefit as reinforcements (aka supplementations) of existing populations at receptor sites, i.e. enhancing population viability via contribution to population size, genetics, or demographics (IUCN/SSC 2013). The salvage of a few individuals from a highly endangered species could be considered a conservation success if the individuals successfully reinforce an existing population (Fischer \& Lindenmayer 2000). The outcomes of reinforcements can be subtler than translocations to sites without resident conspecifics, and harder to measure, as the impact of the translocated animals can be difficult to separate from the resident population. Genetic monitoring is one way to investigate the success of reinforcements, although it can be expensive (IUCN/SSC 2013). Mitigation translocations often occur without sufficient understanding of resident populations (e.g. the presence of conspecifics, the health of the resident population, whether the habitat is at carrying capacity) to allow assessment of whether the translocation is a reinforcement or not, let alone whether it provides conservation benefit.

Mitigation translocations are a hit-and-miss tool for conservation and are less successful over the medium to long terms than are conservation translocations (Chapter 5). Requiring a mitigation translocation as a condition of a resource consent may not result in any positive conservation outcomes, depending both on how the translocation 
is implemented and the circumstances of the local ecosystem. The likely conservation outcomes of a mitigation translocation may be apparent in its early or middle stages. For instance, it could be apparent partway through a salvage operation that very few animals will be salvaged, or the fact that few animals were salvaged could allow the prerelease prediction that they will be unlikely to contribute meaningfully to the persistence of the population. However, once the requirement for mitigation translocation is enacted it can be difficult or impossible to change tactics, both for practical and legal reasons, especially when animals are already in captivity (e.g. Chapter 4).

\subsubsection{Why are mitigation translocations less successful at meeting conservation goals?}

Mitigation translocations were less successful in meeting conservation goals than were conservation translocations. The reasons for this are complex, often intrinsic to mitigation translocations, and influenced by the divergent goals of mitigation and conservation translocations.

When a translocation is legally required, it will go ahead even when only a small number of individuals of common species are found, and therefore significant conservation outcomes are unlikely (Chapters $4 \& 5$ ). A conservation translocation under these circumstances would be less likely to continue. In conservation translocations the intended propagule size is generally determined at the beginning of the process, with the aim of balancing the ability to establish a population at the release site while limiting negative effects on the source population (Towns \& Ferreira 2001). If surveys of the intended source population do not indicate that a propagule of the target size can be obtained, the translocation will not go ahead. A conservation translocation equivalent to mitigation translocations might be a 'last ditch' translocation, carried out where a population is so imperiled at its current site that as many individuals as can be salvaged are translocated. Examples of last ditch translocations include almost the entire population of kākāpō (Strigops habroptilus) being translocated to island sanctuaries between 1974 and 1992 (Lloyd \& Powlesland 1993); as many as could be salvaged of the last mainland Whitaker's skink (Oligosoma whitakeri) population being taken into captivity between 2002 and 2010 following declines, as extirpation was expected (Lynn 
Adams, pers. comm.); and 27 cobble skinks (O. aff. infrapunctatum "cobble") being taken into captivity in 2016 ahead of a storm that killed the rest of the only remaining population (Lynn Adams, pers. comm.). However, as these translocations are generally of highly endangered species, they typically involve intensive management and monitoring before and after release, differing from mitigation translocations. 'Last ditch' translocations are performed for conservation purposes, but are often very expensive and suffer from complicating factors, including inbreeding due to small population sizes (in the case of kākāpō; White 2015) or a lack of suitable release sites (the cobble skink and Whitaker's skink populations remain in captivity).

There is an obligation under the RMA to avoid, mitigate, and remedy effects of land-use in situ (Resource Management Act 1991), and most construction occurs at mainland, often urban, sites. Consequently, receptor sites are usually close to construction sites and are host to suites of mammalian predators which threaten translocation success. In contrast, the presence of mammalian predators at release sites is rare in conservation translocations of New Zealand lizards, which are often to predator-free sanctuaries (Romijn \& Hartley 2016; Chapter 5). To ensure a successful translocation, the agent of decline must be controlled or eradicated at the release site (Fischer \& Lindenmayer 2000). For New Zealand species, the main agent of decline is often introduced predators (Hitchmough et al. 2016b). Cessation of predator control can lead to lizard population crashes that negate its initial benefit (Bioresearches 2015b). However, in consent conditions set under the RMA, predator control is generally required for periods of three to five years (Brown et al. 2014; Chapter 5) and no consent has yet required it in perpetuity (Christensen \& Baker-Galloway 2013). The difficulty of mandating long-term predator control from developers means that, even when there is initial predator control, after the mandated period is expired predator assemblages are likely to return to pre-control levels and have negative impacts on translocated populations. Aside from predator eradication using fences or islands, only a highly intensive predator control regime has been shown to support New Zealand lizard population growth (Reardon et al. 2012), so it is doubtful that short-term predator suppression will ultimately benefit lizard populations. 
The prioritisation of construction needs can interfere with mitigation translocations using ecological best practices (Chapters $4 \& 5$ ). This can be because working around construction means that salvage is ad hoc or opportunistic, or because construction timelines can delay releases (e.g. Chapter 5), shorten planning timeframes, or require actions (e.g. salvage, release, planting) to be taken in unfavourable conditions (e.g. out of season) (pers. obs.). Conservation translocations do not need to work around construction in this way, although they do need to account for other factors such as budgets, social and legal factors, and the rights of indigenous people who may have guardianship (in New Zealand, kaitiakitanga) over wildlife (IUCN/SSC 2013). Even when mitigation management plans are drafted following good ecological practices, there may be non-compliance (which often goes unpenalised; Brown et al. 2013; Brown 2017), or there may be low numbers of animals salvaged, either because they are not present in high numbers or they cannot be easily captured (Chapters $4 \& 5$ ). Compounding this is the difficulty of estimating before a salvage begins how many individuals, and of which species, will be present to translocate. The requirement to undertake a translocation can be set before it is clear whether it will be an effective strategy for achieving successful conservation outcomes. Alternatively, construction or planning may begin at sites which turn out to be heavily populated, leading mitigation translocations and subsequent construction to occur in areas with hundreds or thousands of animals present (Edgar et al. 2005; Kyek et al. 2007; McCoy et al. 2014). In some cases, councils will not impose requirements for complete faunal surveys, so there may be many instances of which we are unaware where habitats with healthy populations of native fauna were modified or destroyed with no mitigation measures taken (Lynn Adams, pers. comm.). Even when assessments are undertaken, they can be less than comprehensive, especially with regard to detecting cryptic species such as New Zealand lizards (Lynn Adams, pers. comm.). This can have particularly negative impacts on species with small home ranges (e.g. lizards) that can be contained entirely within even small building footprints. 


\subsubsection{Limitations of this research}

The use of a particular taxonomic group as a study system always imposes some limitations on the ability to generalise to other systems. New Zealand skinks often have very small home ranges (Hare et al. 2016), which means their translocations face different challenges compared to highly mobile taxa such as some bird species. The outcomes of herpetofauna translocations can be difficult to determine, in part due to the high proportion of long lived, k-selected species (Dodd \& Seigel 1991; Germano \& Bishop 2009). New Zealand lizards are generally k-selected and relatively long-lived (Cree \& Hare 2016), and this makes it hard to determine translocation success over a three-year research period, even when looking at historical translocations. Many New Zealand lizard species are also highly cryptic and too small to allow tracking or identifying devices to be used, which makes monitoring difficult and increases the likelihood of false negatives. Other taxa subject to translocations may share some combination of these complicating factors, so findings from studies of New Zealand lizards may be more or less applicable depending on similarities in their lifestyles.

I considered ways to improve mitigation translocation practices in the context of New Zealand and its legal system. As mitigation translocations are intrinsically linked to mechanisms set out in legal and regulatory requirements, the legal framework they operate in will influence their implementation and outcomes. The New Zealand system can be used as an example internationally; by understanding aspects are functioning well, and aspects that need improvement, researchers and policy makers in other jurisdictions might gain insight into their own implementation of mitigation translocations, and discover potential directions for improvement.

The low numbers of skinks captured caused limitations across several areas of this thesis. This starts with low numbers of lizards salvaged (and released) for the mitigation translocation at Transmission Gully in Chapter 4, which likely contributed to the fact that none were recaptured following release. Additionally, few resident lizards were captured at the site, especially when using the less confounding sampling method without artificial cover objects (ACOs). These low numbers hampered my ability to draw strong conclusions about the effectiveness of the rock piles, and prevented me 
from collecting any data about the movement, survival, or health of skinks post release. I also found low numbers of lizards at the revisits of mitigation translocations in Auckland in Chapter 5. Due to the low numbers, I was unable to assess detection probability in these surveys.

I was only able to test the rock piles at Transmission Gully and not at other mitigation translocations, which reduced my ability to collect enough data for a powerful analysis. I investigated the possibility of experimenting at other locations; however, I abandoned this line of research as, although there were several opportunities that I could have pursued, none were reliable enough to ensure that the operations would go to time and plan within the three-year timeframe of my research.

In revisiting past translocations, a limitation of this research was that many mitigation translocations simply could not be assessed for their long-term outcomes because there were no genetic data, methods for identifying founders, or information about populations at the site prior to release available. I identified and revisited translocations that did have available data that allowed assessment of their outcomes. Generally, this meant that there had been an assessment of no conspecifics being present at the release site. Consequently, I generally did not assess translocations that were intended to be reinforcements of existing populations. Assessing the impact of reinforcements can be difficult as the effects can be subtle. Assessment therefore would usually require more intense monitoring, and possibly comparison to reference populations or genetic assessment.

\subsection{RECOMMENDATIONS FOR MITIGATION TRANSLOCATIONS}

Mitigation translocations are currently an unreliable conservation strategy. Improvements could be made, beginning with clarifying the goals for fauna threatened by developments, and extending to the implementation of mitigation translocations following ecological best practices. The following recommendations could be considered in New Zealand's National Policy Statement on Indigenous Biodiversity, which is currently in a drafting stage and will provide national direction to councils on managing biodiversity under the RMA (Biodiversity Collaborative Group 2018). They 
could also be considered in the context of improvements to the law itself, particularly with regards to the Wildlife Act and the RMA.

\subsubsection{Recommendation 1: Improve legal and regulatory structures underpinning mitigation translocations}

Mitigation translocations in New Zealand are carried out to fulfil requirements set out in the RMA and the Wildlife Act. Applying the RMA as well as the Wildlife Act to mitigations is likely to lead to better conservation outcomes because the RMA confers responsibilities for maintaining biodiversity whereas the Wildlife Act's protection functions at the level of the individual animal. Mitigation translocations should also be considered in the light of The Treaty of Waitangi/Te Tiriti o Waitangi; protection of individual animals may not provide conservation benefit but may align with treaty obligations (acknowledged in the RMA) to protect taonga (treasures, including wildlife) and the rights of Māori to exercise kaitiakitanga (guardianship) over taonga.

The RMA sets out obligations and duties; however it does not provide clear guidelines on how to achieve its broad requirements. Deciding how to meet the RMA's requirements is instead left up to local government bodies. The result of this devolution is that actions taken to meet obligations under the Act are not standardised across New Zealand and are highly variable. Additionally, the standards laid out by ecologists for each mitigation translocation will vary due to factors such as conditions of their Wildlife Act permit (issued by DOC), variation of opinion among ecologists as to what constitutes acceptable practice, and negotiation with clients over what actions should be taken to meet the standards required for obtaining a resource consent (e.g. offsetting measures). Local government bodies have identified a need for reform of the RMA to clarify their role in maintaining biodiversity and to put in place a coherent national strategy for biodiversity management (Willis 2017). In 2012, the Auditor-General highlighted the need for DOC to partner with local authorities in a more co-ordinated and integrated way to achieve strategic goals (Provost 2012). A more integrated approach across central and local government to clarify firstly biodiversity goals, and secondly actions to be taken to meet these goals, is needed. This is a goal acknowledged in New Zealand's Biodiversity Action Plan (Department of Conservation 2016). Greater 
integration would improve not only the regulatory underpinnings of mitigation translocations, but all avoidance, remediation, mitigation, and offset measures undertaken due to obligations under the RMA.

The RMA requires that adverse effects be avoided, remedied, or mitigated. However, there is no requirement under the Act to achieve a 'no net loss' outcome in order for a resource consent to be granted; the benefits of development are weighed as well as the environmental effects (Department of Conservation 2014). This means that mitigation translocations may meet their legal requirements without achieving conservation objectives. The introduction and enforcement of a standard of no net loss of biodiversity (and preferably a net gain; Department of Conservation 2014) would likely lead to improved practices and reduce damage done to the environment. To ensure better conservation outcomes, legal requirements should be constructed so that they better match conservation goals and mandate best ecological practices. In order to meet requirements of no net loss, developers would need to ensure that mitigation translocations were undertaken in ways more likely to result in conservation outcomes, and implement thorough post-release monitoring in order to ascertain that no net loss was achieved. When considering no net loss standards, another aspect that should be taken into account is avoiding 'death by a thousand cuts'. In other words, avoiding an overall decline in habitat extent and quality through the incremental destruction of habitat, even when mitigating or offsetting actions are taken.

Regional councils and territorial authorities should be consistent, both within and among districts, in requiring assessment of endemic fauna before consents are drafted, so fauna management strategies can be put in place. This would ensure that mitigation translocations (or other avoidance, remediation, or mitigation measures) are implemented where appropriate.

Significant shortcomings in compliance, monitoring, and enforcement have been identified as a cross-cutting RMA issue, and improvement has been suggested as a national goal (Brown 2017; Biodiversity Collaborative Group 2018). In some instances negotiated conditions have not been detailed in consents, which undermines legal enforcement (Brown et al. 2014). One study looking at compliance with resource 
consent requirements relating to ecological compensation (including mitigation translocations) found that $35.2 \%$ of requirements were not met (Brown et al. 2013). In order to allow enforcement, consent conditions should be clear. Compliance, monitoring, and enforcement of consent conditions for mitigation translocations should be improved. Currently, some mitigation translocations do not adhere to their consent conditions, which goes unnoticed and without consequences or remedy (Chapter 4).

\subsubsection{Recommendation 2: Mitigation translocations should be conservation translocations}

Success for mitigation translocations is measured against meeting legal or regulatory requirements rather than conservation goals (which are the indicators of success for conservation translocations). Conservation translocations have higher success rates and generally use better ecological practices than mitigation translocations (Germano \& Bishop 2009; Sullivan et al. 2015; Chapter 5). However, by the IUCN's definitions, a mitigation translocations can also be a conservation translocation if it is undertaken using ecological best practices and aims to provide a measurable conservation benefit (IUCN/SSC 2013). Mitigation translocations should be conservation translocations, and mitigation translocations that are not conservation translocations (i.e. 'irresponsible translocations'; IUCN/SSC 2013) should not be considered to have met conservation or legal goals.

By using conservation translocations as a model for designing mitigation translocations, and by following best practice guidelines for conservation translocations (e.g. IUCN/SSC 2013), the standards of mitigation translocations could be improved. However, some of the differences between mitigation translocations and conservation translocations are more difficult to overcome. Mitigation translocations, by their nature, must occur in conjunction with land development. A conservation translocation has conservation as its highest priority. As development often has negative ecological impacts, if conservation were prioritised above development, the best choice would often simply be not to undertake development. The conflict between conservation and development means that it is not possible to always follow best practices in 
translocations. Therefore, mitigation translocations should aim to be conservation translocations, although by their nature they will sometimes fall short of this goal.

\subsubsection{Recommendation 3: Do not rely on mitigation translocations}

Mitigation translocations should be framed as a tool to be used in achieving conservation outcomes, and one that can be supplemented or replaced by another if it is not working. When designing requirements, care should be taken to ensure that the completion of a mitigation translocation is not a goal in and of itself, divorced from measurable conservation outcomes. Before a development begins, any strategies for avoidance, mitigation, and offsetting should be considered for their effectiveness, informed by scientific evidence and surveys of the proposed development site. Consideration should be given to restricting development in situations where there is not good evidence that negative environmental impacts can be properly attenuated.

Translocations, even conservation translocations, are not a reliable strategy for achieving conservation success. A review of translocations published from 1980 to 2000 found a success rate of $26 \%$ and a failure rate of $27 \%$; however, this was considered to be probably skewed towards success due to the likelihood of publication bias (Fischer \& Lindenmayer 2000). Other reviews reported rates of translocation success of $44 \%$ in birds and mammals (Griffith et al. 1989), 51\% in birds (Miskelly \& Powlesland 2013), and 19\% (Dodd \& Seigel 1991) to 41\% (Germano \& Bishop 2009) in herpetofauna. Mitigation translocations are less successful than other translocations generally, and are therefore even less reliable as a conservation strategy (Germano \& Bishop 2009; Sullivan et al. 2015; Chapter 5).

When considering implementing a mitigation translocation, comparisons should be made between mitigation translocations and alternative strategies that might be employed in their place to meet conservation and legal goals. Strategies employed in similar scenarios to mitigation translocations include pest control, habitat enhancement or restoration, covenanting of habitat, as well as more removed strategies such as funding for conservation programmes (Environmental Protection Authority 2011a). Each of these strategies has its own advantages and disadvantages, both generally and 
when applied to specific situations, and the appropriateness of their implementation has been subject to considerable ecological and judicial analysis (Christensen 2012; Christensen \& Baker-Galloway 2013; Brown et al. 2014). Therefore, no overall best approach can be recommended. Alternative approaches should be considered in the light of their likely conservation outcomes, and decisions should be informed by scientific evidence. Alternative strategies should also be compared in the light of the 'mitigation hierarchy': first, avoidance; then minimisation (mitigation translocations are primarily classed here as minimisation of deaths of animals; Germano et al. 2015); then rehabilitation/restoration (i.e. restoration of degraded habitat at the development site); and finally, offsetting (Ekstrom et al. 2013). While this approach is not explicitly mentioned in the RMA, it was noted by a Board of Inquiry into the Transmission Gully project that the mitigation hierarchy is both supported by ecological evidence and broadly consistent with the RMA (Environmental Protection Authority 2011b). A wellimplemented mitigation translocation has the advantage of protecting animals which would otherwise be killed during construction; however, it is less reliable than other strategies. Eradication of mammalian predators, for example, is a relatively reliable conservation strategy for New Zealand lizards (e.g. Towns 1991; Newman 1994; Towns 1996; Reardon et al. 2012; Nelson et al. 2016) and other taxa (e.g. Moorehouse et al. 2003; Elliott et al. 2007; Watts et al. 2011). Predator or pest control has been accepted by the Environment Court as an acceptable measure for offsetting biodiversity loss caused by construction projects in several cases (Christensen 2012). However, predator or pest control may not be effective if it is only implemented for a short time or with insufficient intensity. Indeed, there has so far only been one successful predator control regime at a non-fenced mainland site that allowed the recovery of a lizard population (Reardon et al. 2012). Any actions taken should be evaluated in terms of their actual conservation outcomes (i.e. positive outcomes at the population, species, or ecosystem level; no net loss standards) given the constraints around what can be imposed on developers under the law (e.g. timeframes for mitigation/offsetting measures).

Where mitigation translocations are undertaken, they should be assessed for their effectiveness as they progress, and alternative strategies to avoid, remedy, or 
mitigate adverse effects should be triggered if it is indicated that the mitigation translocation is unlikely to meet these obligations. IUCN translocation guidelines recommend that exit strategies should be an integral part of any translocation plan, and they should be triggered in the event of a lack of success and when further investment of resources is no longer justified (IUCN/SSC 2013). Plans should be made in advance for how to handle different salvage outcomes (e.g. alternative receptor sites to ensure enough capacity for large salvaged populations, exit strategies if very few animals are found). This would help avoid large amounts of resources being spent on actions with little conservation outcome while still allowing mitigation translocations to be used where and when they can be effective: in cases of salvage of large numbers of animals, or of rare or threatened species. In cases such as these, mitigation translocations might be a good use of resources and be more effective than alternative strategies (e.g. predator control, habitat enhancement, offsetting).

Other approaches should be taken in conjunction with mitigation translocations, even when the mitigation translocation continues. A mitigation translocation could appear to be developing well at the beginning; however, it could be subject to problems partway through, for instance through construction timelines delaying release or release habitat being unsuitable. Mitigation translocations should be employed as part of a multi-faceted approach to mitigation, remediation, and avoidance of adverse effects, so that failure in one aspect will not result in complete failure overall.

\subsubsection{Recommendation 4: Improve mitigation translocation practices}

In order to increase conservation success, mitigation translocation practices should be improved. Many aspects of best-practice for translocations have been covered in-depth in other places (e.g. Griffith et al. 1989; Dodd \& Seigel 1991; Armstrong \& McLean 1995; Sutherland et al. 2010; IUCN/SSC 2013; Germano et al. 2014; Batson et al. 2015; Sullivan et al. 2015). Despite this, most translocations, even conservation translocations, do not address all the criteria recommended to ensure success (Pérez et al. 2012). Best practices are often context-specific, including with regards to aspects of location, taxa, and populations. There are still many aspects of translocations where best practices are not 
well developed, and outcomes could be improved by an adaptive management framework (Ewen et al. 2014).

For New Zealand lizard species, many of the techniques and tools that could be useful to support successful translocations are not fully understood. Translocation success could be improved by research and development of techniques into a reliable toolkit; for instance, greater understanding of predator control regimes that can support lizard recovery.

In Chapters 2, 3, and 4, I developed a design for a rock pile habitat that is intended to protect skinks from mice (and larger predators) with the aim of creating a technique to aid the survival and persistence of endemic skinks post translocation. Although the evidence for its efficacy was inconclusive, there was a suggestive trend that indicated that the piles may be functioning as intended (although this was not statistically significant; Chapter 4). As there is nothing to indicate that these rock piles are worse than current practices (i.e. ad hoc rock piles based on best guesses of managers), this design could be incorporated into translocations of small rock-dwelling lizards with comparison to other designs to further test its efficacy.

\subsection{FUTURE RESEARCH DIRECTIONS}

1. Long-term monitoring of mitigation translocations, including developing criteria for determining failure (rather than just lack of success yet).

2. Research into tipping points for densities of introduced mammalian predators affecting lizard populations across different habitats. Identification of appropriate predator control regimes to allow lizard recovery on the mainland.

3. Research to understand carrying capacities of habitats for lizard populations and how these could be enhanced. Mapping and modelling of factors affecting lizard distributions.

4. Further development of the methods from Chapters 2-4 to improve the ability to characterise refuges and to verify the effectiveness of the hypothesised rock pile designs. 
5. Development of alternative designs based on the principle of using specifically sized refuge space to exclude predators.

6. Further collaboration between those undertaking mitigation translocations and scientists. 


\section{References}

Adams LK. 2009. Lizard action plan for Poneke Area, Wellington Conservancy. Department of Conservation, Wellington, NZ.

Ainsworth R, et al. 1991. Proceedings of the Society for Research on Amphibians and Reptiles in New Zealand. New Zealand Journal of Zoology 18:343-348.

Alexander TJ. 2013. Cryptic invertebrates on subtidal rocky reefs vary with microhabitat structure and protection from fishing. Marine Ecology Progress Series 481:93104.

Anderson P, Bell T, Chapman S, Corbett K. 2012. New Zealand lizards conservation toolkit - a resource for conservation management of the lizards of New Zealand. Society for Research on Amphibians and Reptiles of New Zealand (SRARNZ).

Armstrong DP, McLean IG. 1995. New Zealand translocations: theory and practice. Pacific Conservation Biology 2:39-54.

Bajomi B, Pullin AS, Stewart GB, Takács-Sánta A. 2010. Bias and dispersal in the animal reintroduction literature. Oryx 44:358-365.

Baker CS, Boren L, Childerhouse S, Constantine R, van Helden A, Lundquist D, Rayment W, Rolfe JR. 2019. Conservation status of New Zealand marine mammals. Department of Conservation, Wellington, NZ.

Bartholomew A, Diaz RJ, Cicchetti G. 2000. New dimensionless indices of structural habitat complexity: predicted and actual effects on a predator's foraging success. Marine Ecology Progress Series 206:45-58.

Batson WG, Gordon IJ, Fletcher DB, Manning AD, Hayward M. 2015. Translocation tactics: a framework to support the IUCN Guidelines for wildlife translocations and improve the quality of applied methods. Journal of Applied Ecology 52:1598-1607.

Bell SS, Brooks RA, Ellis WE. 2003. Structural spacing and the determination of habitat complexity: examining the Bartholomew et al. (2000) index. Marine Ecology Progress Series 248:293-295. 
Bellingham PJ, Towns DR, Cameron EK, Davis JJ, Wardle DA, Wilmshurt JM, Mulder CPH. 2010. New Zealand island restoration: seabirds, predators, and the importance of history. New Zealand Journal of Ecology 34:115-136.

Belthoff JR, Smith BW. 2003. Patterns of artificial burrow occupancy and reuse by burrowing owls in Idaho. Wildlife Society Bulletin 31:138-144.

Biodiversity Collaborative Group. 2018. Report of the Biodiversity Collaborative Group.

Biodiversity (Land and Freshwater) Stakeholder Trust, Wellington, New Zealand.

Bioresearches. 2011a. Copper skink monitoring at Pleroo Park - Year 1. Prepared by Bioresearches Group Limited for Goodland Glenfield Development Limited. Bioresearches. 2011b. Copper skink monitoring at Pleroo Park - Year 2. Prepared by Bioresearches Group Limited for Goodland Glenfield Development Limited. Bioresearches. 2011c. Herpetofaunal mitigation: summary of findings for 30 Hibiscus Coast Highway, Silverdale. Prepared by Bioresearches Group Limited for Foodstuff Limited.

Bioresearches. 2012a. Covenant Management Plan, Blacks Road. Prepared by

Bioresearches Group Limited for 21 Blacks Road Limited.

Bioresearches. 2012b. Skink monitoring at 30 Hibiscus Coast Highway, Silverdale - Year

1. Prepared by Bioresearches Group Limited for Foodstuff Limited.

Bioresearches. 2013a. Copper skink monitoring at Pleroo Park - Year 3. Prepared by

Bioresearches Group Limited for Goodland Glenfield Development Limited. Bioresearches. 2013b. Skink monitoring at 30 Hibiscus Coast Highway, Silverdale - Year

2. Prepared by Bioresearches Group Limited for Foodstuff Limited.

Bioresearches. 2015a. Skink monitoring at 30 Hibiscus Coast Highway, Silverdale - Year

4. Prepared by Bioresearches Group Limited for Foodstuff Limited.

Bioresearches. 2015b. Moko skink (Oligosoma moco) final monitor 2014-2015. Prepared by Bioresearches Group Limited for Whangamata Marina Society.

Bishop P. n.d. Frog projects. Available from www.nzfrogs.org (accessed 16 June 2019). Blender Foundation. 2016. Blender v2.77. Computer program, Blender Foundation, Amsterdam, NL. 
Boffa Miskell Limited. 2011. Transmission Gully Project technical report 7 herpetofauna and terrestrial macro-invertebrates: ecological valuation. Prepared by Boffa Miskell Ltd for New Zealand Transport Agency and Porirua City Council.

Bourke G, Matthews A, Michael D. 2017. Can protective attributes of artificial refuges offset predation risk in lizards? Austral Ecology 42:497-507.

Brown MA, Clarkson BD, Barton BJ, Joshi C. 2013. Ecological compensation: an evaluation of regulatory compliance in New Zealand. Impact Assessment and Project Appraisal 31:34-44.

Brown MA, Clarkson BD, Stephens TRT, Barton BJ. 2014. Compensating for ecological harm - the state of play in New Zealand. New Zealand Journal of Ecology 38:139-146.

Brown MA. 2017. Last line of defence: compliance, monitoring, and enforcement of New Zealand's environmental law. Environmental Defence Society Incorporated, Auckland, New Zealand.

Burns RJ, Bell BD, Haigh A, Bishop P, Easton L, Wren S, Germano J, Hitchmough RA, Rolfe JR, Makan T. 2018. Conservation status of New Zealand amphibians, 2017. Department of Conservation, Wellington, NZ.

Burt CE. 1927. A note on the mouse, Mus musculus Lnn. as an enemy to lizards. Copeia 162:15-16.

Christensen M. 2012. Biodiversity offsets - a further update on the law. Anderson Lloyd Lawyers, Auckland, NZ.

Christensen M, Baker-Galloway M. 2013. Biodiversity offsets - the latest on the law. Anderson Lloyd Lawyers, Auckland, NZ.

Clavero M, García-Berthou E. 2005. Invasive species are a leading cause of animal extinctions. Trends in Ecology and Evolution 20:110.

Clipperton Allen AE, Cragg CL, Wood AJ, Pfaff DW, Choleris E. 2010. Agonistic behavior in males and females: effects of an estrogen receptor beta agonist in gonadectomized and gonadally intact mice. Psychoneuroendocrinology 35:10081022. 
Connolly TA, Day TD, King CM. 2009. Estimating the potential for reinvasion by mammalian pests through pest-exclusion fencing. Wildlife Research 36:410-421.

Conservation Act 1987. New Zealand legislation.

Craig J, Anderson S, Clout M, Creese B, Mitchell N, Ogden J, Roberts M, Ussher G. 2000. Conservation issues in New Zealand. Annual Review of Ecology, Evolution, and Systematics 31:61-78.

Cree A, Butler D. 1993. Tuatara recovery plan (Sphenodon spp.). Department of Conservation, Wellington, NZ.

Cree A, Hare KM. 2016. Reproduction and life history of New Zealand lizards. Pages 169-207 in Chapple DG, editor. New Zealand Lizards. Springer International, Victoria, AU.

Croak BM, Pike DA, Webb JK, Shine R. 2008. Three-dimensional crevice structure affects retreat site selection by reptiles. Animal Behaviour 76:1875-1884.

Croak BM, Pike DA, Webb JK, Shine R. 2010. Using artificial rocks to restore nonrenewable shelter sites in human-degraded systems: colonisation by fauna. Restoration Ecology 18:428-438.

Croak BM, Pike DA, Webb JK, Shine R. 2012. Habitat selection in a rocky landscape: experimentally decoupling the influence of retreat site attributes from that of landscape features. PLoS One 7:e37982.

Croak BM, Webb JK, Shine R. 2013. The benefits of habitat restoration for rockdwelling velvet geckos Oedura lesueurii. Journal of Applied Ecology 50:432-439.

Daugherty CH, Towns DR, Atkinson IAE, Gibbs GW. 1990. The significance of the biological resources of New Zealand islands for ecological restoration. Pages 921 in Towns DR, Daugherty $\mathrm{CH}$, and Atkinson IAE, editors. Ecological restoration of New Zealand islands, Conservation Sciences Publication No. 2. Department of Conservation, Wellington, NZ.

Day T, MacGibbon R. 2007. Multiple-species exclusion fencing and technology for mainland sites. Managing vertebrate invasive species. USDA National Wildlife Research Center, National Wildlife Research Center, Fort Collins, Colorado, USA. 
Department of Conservation. 2009. Gardening for lizards. Department of Conservation, Wellington Hawke’s Bay Conservancy, Wellington, NZ.

Department of Conservation. 2014. Guidance on good practice biodiversity offsetting in New Zealand. New Zealand Government, Wellington, NZ.

Department of Conservation. 2016. New Zealand Biodiversity Action Plan 2016-2020. New Zealand Government, Wellington, NZ.

Diamond JM. 1990. New Zealand as an archipelago: an international perspective. Pages 3-8 in Towns DR, Daugherty CH, and Atkinson IAE, editors. Ecological restoration of New Zealand islands, Conservation Sciences Publication No. 2. Department of Conservation, Wellington, NZ.

Dodd CK, Seigel RA. 1991. Relocation, repatriation, and translocation of amphibians and reptiles: are they conservation strategies that work? Herpetologica 47:336350.

Doherty TS, Glen AS, Nimmo DG, Ritchie EG, Dickman CR. 2016. Invasive predators and global biodiversity loss. Proceedings of the National Academy of Sciences 113:11261-11265.

Donev A, Cisse I, Sachs D, Variano EA, Stillinger FH, Connelly R, Torquato S, Chaikin PM. 2004. Improving the density of jammed disordered packings using ellipsoids. Science 303:990-993.

Duffy C, Francis M, Dunn M, Finucci B, Ford R, Hitchmough RA, Rolfe JR. 2018. Conservation status of New Zealand chondrichthyans (chimaeras, sharks and rays), 2016. Department of Conservation, Wellington, NZ.

Dunn NR, et al. 2018. Conservation status of New Zealand freshwater fishes, 2017. Department of Conservation, Wellington, NZ.

Ebrahimi M, Bull CM. 2014. Resources and their distribution can influence social behaviour at translocation sites: lessons from a lizard. Applied Animal Behaviour Science 156:94-104.

Edgar PW, Griffiths RA, Foster JP. 2005. Evaluation of translocation as a tool for mitigating development threats to great crested newts (Triturus cristatus) in England, 1990-2001. Biological Conservation 122:45-52. 
Ekstrom J, Temple H, Pilgrim J. 2013. Independent report on biodiversity offsets. Prepared by The Biodiversity Consultancy for The International Council on Mining and Metals and the International Union for Conservation of Nature. Elliott GP, Merton DV, Jansen PW. 2007. Intensive management of a critically endangered species: the kakapo. Biological Conservation 99:121-133. Endangered Species Act of 1973 (ESA; 16 U.S.C. \$1531 et seq.). Legislation of the United States of America.

Environmental Protection Authority. 2011a. Final report and decision of the Board of Inquiry into the Hauauru mā Raki Wind Farm and Infrastructure Connection to Grid. Environmental Protection Authority, Wellington, NZ.

Environmental Protection Authority. 2011b. Final decision and report of the board of inquiry into the New Zealand Transport Agency Transmission Gully plan change request. Environmental Protection Authority, Wellington, NZ.

Ewen JG, Soorae PS, Canessa S. 2014. Reintroduction objectives, decisions and outcomes: global perspectives from the herpetofauna. Animal Conservation 17:74-81.

Fischer J, Lindenmayer DB. 2000. An assessment of the published results of animal relocations. Biological Conservation 96:1-11.

Flecker AS, Allan JD. 1984. The importance of predation, substrate and spatial refugia in dertermining lotic insect distributions. Oecologia 64:306-313.

Fritts TH, Rodda GH. 1998. The role of introduced species in the degredation of island ecosystems: a case history of Guam. Annual Review of Ecology and Systematics 29:113-140.

Germano JM, Bishop PJ. 2009. Suitability of amphibians and reptiles for translocation. Conservation Biology 23:7-15.

Germano JM, Ewen JG, Mushinsky H, McCoy E, Ortiz-Catedral L. 2014. Moving towards greater success in translocations: recent advances from the herpetofauna. Animal Conservation 17:1-3.

Germano JM, Field KJ, Griffiths RA, Clulow S, Foster J, Harding G, Swaisgood RR. 2015. Mitigation-driven translocations: are we moving wildlife in the right direction? Frontiers in Ecology and the Environment 13:100-105. 
Gill B, Whitaker AH. 1996. New Zealand frogs and reptiles. David Bateman Limited, Auckland, New Zealand.

Green C. 2005. Using artificial refuges to translocate and establish Auckland tree weta Hemideina thoracica on Korapuki Island, New Zealand. Conservation Evidence 2:94-95.

Green RE, Purcell KL, Thompson CM, Kelt DA, Wittmer HU. 2019. Microsites and structures used by fishers (Pekania pennanti) in the southern Sierra Nevada: A comparison of forest elements used for daily resting relative to reproduction. Forest Ecology and Management 440:131-146.

Gregory R, Failing L, Harstone M. 2012. Structured descision making: a practical guide to environmental management choices. Wiley-Blackwell, Chichester, UK.

Griffith B, Scott JM, Carpenter JW, Reed C. 1989. Translocation as a species conservation tool: status and strategy. Science Translational Medicine 245:477480.

Griffiths RA, Pavajeau L. 2008. Captive breeding, reintroduction, and the conservation of amphibians. Conservation Biology 22:852-861.

Hare KM. 2012. Herpetofauna: pitfall trapping. Inventory and monitoring toolbox: herpetofauna. Department of Conservation, Wellington, NZ.

Hare KM, Chapple DG, Towns DR, van Winkel D. 2016. The ecology of New Zealand's lizards. Pages 133-168 in Chapple DG, editor. New Zealand Lizards. Springer International, Victoria, AU.

Hare KM, Cree A. 2016. Thermal and metabolic physiology of New Zealand lizards. Pages 239-267 in Chapple DG, editor. New Zealand Lizards. Springer International, Victoria, AU.

Hesterberg SG, Duckett CC, Salewski EA, Bell SS. 2017. Three-dimensional interstitial space mediates predator foraging success in different spatial arrangements. Ecology 98:1153-1162.

Hitchmough RA, Barr B, Lettink M, Monks JM, Reardon JT, Tocher MD, van Winkel D, Rolfe J. 2016a. Conservation status of New Zealand reptiles, 2015. Department of Conservation, Wellington, NZ. 
Hitchmough RA, Adams LK, Reardon JT, Monks JM. 2016b. Current challenges and future directions in lizard conservation in New Zealand. Journal of the Royal Society of New Zealand 46:29-39.

Hoare JM, Adams LK, Bull LS, Towns DR. 2007. Attempting to manage complex predator-prey interactions fails to avert imminent extinction of a threatened New Zealand skink population. The Journal of Wildlife Management 71:15761584 .

Hulme PE. 2006. Beyond control: wider implications for the management of biological invasions. Journal of Applied Ecology 43:835-847.

Huyser O, Ryan PG, Cooper J. 2000. Changes in population size, habitat use and breeding biology of lesser sheathbills (Chionis minor) at Marion Island: impacts of cats, mice and climate change? Biological Conservation 92:299-310.

Iles J. 2019. Hundreds of native lizards being relocated for Wellington harbourside development. Stuff.co.nz, 11 January.

Innes J, Lee WG, Burns B, Campbell-Hunt C, Watts C, Phipps H, Stephens T. 2012. Role of predator-proof fences in restoring New Zealand's biodiversity: a response to Scofield et al. (2011). New Zealand Journal of Ecology 36:232-238.

IUCN. 2019. The IUCN red list of threatened species. Available from http://www.iucnredlist.org (accessed 14 June 2019).

IUCN/SSC. 2013. Guidelines for reintroductions and other conservation translocations. Version 1.0. IUCN Species Survival Commission, Gland, Switzerland. Jewell T. 2008. Reptiles and amphibians of New Zealand. New Holland, Auckland, NZ. Keppel G, Van Niel KP, Wardell-Johnson GW, Yates CJ, Byrne M, Mucina L, Schut AGT, Hopper SD, Franklin SE. 2012. Refugia: identifying and understanding safe havens for biodiversity under climate change. Global Ecology and Biogeography 21:393 - 404.

Kleinman DG, Beck BB, Dietz JM, Dietz LA. 1991. Costs of a re-introduction and criteria for success: accounting and accountability in the Golden Lion Tamarin Conservation Program. Symposia of the Zoological Society of London 62:125142. 
Knox CD, Monks JM. 2014. Penning prior to release decreases post-translocation dispersal of jewelled geckos. Animal Conservation 17:18-26.

Kyek M, Maletzky A, Achleitner S. 2007. Large scale translocation and habitat compensation of amphibian and reptile populations in the course of the redevelopment of a waste disposal site. Zeitschrift für Feldherpetologie 17:175190.

Leighton HEB Joint Venture. 2015. Transmission Gully lizard management plan TGLHJV-SUB-ALL-EN-0033 Revision 00. Prepared for Leighton HEB Joint Venture.

Lemen CA, Freeman PW. 1985. Tracking mammals with fluorescent pigments: a new technique. Journal of Mammalology 66:134-136.

Lettink M, Seddon PJ. 2007. Influence of microhabitat factors on capture rates of lizards in a coastal New Zealand environment. Journal of Herpetology 41:187-196.

Lettink M. 2012. Herpetofauna: artificial retreats. Inventory and monitoring toolbox: herpetofauna. Department of Conservation, Wellington, NZ.

Levine EA, Gosnell JS, Goetz EM, Malinowski CR. 2017. Natural cultch type influences habitat preference and predation, but not survival, in reef-associated species. Restoration Ecology 25:101-111.

Lloyd BD, Powlesland RG. 1993. The decline of kakapo Strigops habroptilus and attempts at conservation by translocation. Biological Conservation 69:75-85.

London Convention and Protocol/UNEP. 2009. Guidelines for the Placement of Artificial Reefs. United Nations Environment Programme, London, UK.

Long K, Robley A. 2004. Cost effective feral animal exclusion fencing for areas of high conservation value in Australia. Australian Government, The Department of the Environment and Heritage, Melbourne, AU.

Lubbad R, Løset S. 2011. A numerical model for real-time simulation of ship-ice interaction. Cold Regions Science and Technology 65:111-127.

Lyver POB, Jones CJ, Doherty J. 2009. Flavor or forethought: Tuhoe traditional management strategies for the conservation of Kereru (Hemiphaga novaeseelandiae novaeseelandiae) in New Zealand. Ecology and Society 14:40. 
Maitland PS, Lyle AA. 1992. Conservation of freshwater fish in the British Isles: proposals for management. Aquatic conservation: Marine and Freshwater Ecosystems 2:165-183.

Maseyk F, Ussher G, Kessels G, Christensen M, Brown MA. 2018. Biodiversity offsetting under the Resource Management Act, a guidance document. Biodiversity Working Group, Local Government New Zealand, Wellington, NZ.

Massei G, Quy RJ, Gurney J, Cowan DP. 2010. Can translocations be used to mitigate human-wildlife conflicts? Wildlife Research 37:428-439.

McCormick MI. 1994. Comparison of field methods for measuring surface topography and their associations with a tropical reef fish assemblage. Marine Ecology Progress Series 112:87-96.

McCoy ED, Osman N, Hauch B, Emerick A, Mushinsky HR. 2014. Increasing the chance of successful translocation of a threatened lizard. Animal Conservation 17:56-64.

Miller KA, Bell TP, Germano JM. 2014. Understanding publication bias in reintroduction biology by assessing translocations of New Zealand's herpetofauna. Conservation Biology 28:1045-1056.

Milne T, Bull CM. 2000. Burrow choice by individuals of different sizes in the endangered pygmy blue tongue lizard Tiliqua adelaidensis. Biological Conservation 95:295-301.

Miskelly CM, Powlesland RG. 2013. Conservation translocations of New Zealand birds, 1836 - 2012. Notornis 60:3-28.

Miskelly CM. 2014. Legal protection of New Zealand's indigenous terrestrial fauna - an historical review. Museum of New Zealand Te Papa Tongarewa, Wellington, New Zealand.

Moller H, Kitson JC, Downs TM. 2009. Knowing by doing: learning for sustainable muttonbird harvesting. New Zealand Journal of Zoology 36:243-258.

Moorehouse R, et al. 2003. Control of introduced mammalian predators improves kaka Nestor meridionalis breeding success: reversing the decline of a threatened New Zealand parrot. Biological Conservation 110:33-44. 
Moseby KE, Carthey A, Schroeder T. 2015. The influence of predators and prey naivety on reintroduction success: current and future directions. Pages 29-42 in Armstrong DP, Hayward MW, Moro D, and Seddon PJ, editors. Advances in Reintroduction Biology of Australian and New Zealand Fauna. CSIRO Publishing, Clayton South, VIC, Australia.

Moseby KE, Blumstein DT, Letnic M. 2016. Harnessing natural selection to tackle the problem of prey naïveté. Evolutionary Applications 9:334-343.

Mulder KP, Walde AD, Boarman WI, Woodman AP, Latch EK, Fleischer RC. 2017. No paternal genetic integration in desert tortoises (Gopherus agassizii) following translocation into an existing population. Biological Conservation 210:318-324. Muralidhar A, Moore FL, Easton LJ, Jamieson IG, Seddon PJ, van Heezik Y. 2019. Know your enemy? Conservation management causes loss of antipredator behaviour to novel predators in New Zealand robins. Animal Behaviour 149:135-142.

Murphy EC, Pickard CR. 1990. House mouse. Pages 225-245 in King CM, editor. The handbook of New Zealand mammals. Oxford University Press, Auckland, NZ.

Murphy EC. 1992. The effects of a natural increase in food supply on a wild population of house mice. New Zealand Journal of Ecology 16:33-40.

Murtaugh PA. 2014. In defense of $P$ values. Ecology 95:611 - 617.

Nelson NJ, Romijn RL, Dumont T, Reardon JT, Monks JM, Hitchmough RA, Empson R, Briskie JV. 2016. Lizard conservation in mainland sanctuaries. Pages 321-340 in Chapple DG, editor. New Zealand Lizards. Springer International, Victoria, AU.

New Zealand Cabinet. 2016. Accelerating Predator Free New Zealand. CAB-16-MIN0335. Cabinet Economic Growth and Infrastructure Committee.

Newman DG. 1988. Evidence of predation on a young tuatara, Sphenodon punctatus, by kiore, Rattus exulans, on Lady Alice Island. New Zealand Journal of Ecology 15:443-446.

Newman DG. 1994. Effects of a mouse, Mus musculus, eradication programme and habitat change on lizard populations of Mana Island, New Zealand, with special reference to McGregor's skink, Cyclodina macgregori. New Zealand Journal of Zoology 21:443-456. 
Norbury G, Byrom A, Pech R, Smith J, Clarke D, Anderson D, Forrester G. 2013. Invasive mammals and habitat modification interact to generate unforeseen outcomes for indigenous fauna. Ecological Applications 23:1707-1721.

Norbury G, van den Munckhof M, Neitzel S, Hutcheon A, Reardon JT, Ludwig K. 2014. Impacts of invasive house mice on post-release survival of translocated lizards. New Zealand Journal of Ecology 38:322-327.

North Shore City Council. 2009. Decision on the notified application for resource consent to subdivide land at 82-84 Kaipatiki Road, Glenfield, SA3021698.

NVIDIA Corporation. 2011. PhysX v3.3 SDK. Computer program, NVIDIA Corporation, Santa Clara, CA, USA.

O’Donnell CFJ, Borkin KM, Christie JE, Lloyd B, Parsons S, Hitchmough RA. 2018. Conservation status of New Zealand bats, 2017. Department of Conservation, Wellington, NZ.

Pérez I, Anadón JD, Díaz M, Nicola GG, Tella JL, Giménez A. 2012. What is wrong with current translocations? A review and a decision-making proposal. Frontiers in Ecology and the Environment 10:494-501.

Persson L, Eklöv P. 1995. Prey refuges affecting interactions between piscivorous perch and juvenile perch and roach. Ecology 76:70-81.

Phillpot P. 2000. The skinks of North Brother Island: abundance, habitat use, and species interactions. Master of Science thesis. Victoria University of Wellington, Wellington, NZ.

Pickard CR. 1984. The population ecology of the house mouse (Mus musculus) on Mana Island. Master of Science with honours thesis. Victoria University of Wellington, Wellington, New Zealand.

Pike DA, Croak BM, Webb JK, Shine R. 2010. Context-dependent avoidance of predatory centipedes by noctural geckos (Oedura lesueurii). Behaviour 147:397412.

Platenberg RJ, Griffiths RA. 1999. Translocation of slow-worms (Anguis fragilis) as a mitigation strategy: a case study from south-east England. Biological Conservation 90:125-132. 
Provost L. 2012. Department of Conservation: Prioritising and partnering to manage biodiversity. Office of the Auditor-General, Wellington, NZ.

Pyke GH, Pullman HR, Charnov EL. 1977. Optimal foraging: a selective review of theory and tests. The Quarterly Review of Biology 52:137 - 154.

R Core Team. 2016. R: A language and environment for statistical computing. Computer program, R Foundation for Statistical Computing, Vienna, Austria.

Ramírez PA, Bell BD, Germano JM, Bishop PJ, Nelson NJ. 2017. Tracking a small cryptic amphibian with fluorescent powders. New Zealand Journal of Ecology 41:134-138.

Reardon JT, Whitmore N, Holmes KM, Judd LM, Hutcheon AD, Norbury G, Mackenzie DI. 2012. Predator control allows critically endangered lizards to recover on mainland New Zealand. New Zealand Journal of Zoology 36:141-150.

Resource Management Act 1991. New Zealand legislation.

Ricardez E, Noguez J, Neri L, Escobar-Castillejos D, Munoz L. 2018. SutureHap: Use of a physics engine to enable force feedback generation on deformable surfaces simulations. International Journal of Advanced Robotic Systems 15:1-16.

Robert A, Colas B, Guigon I, Kerbiriou C, Mihoub JB, Saint-Jalme M, Sarrazin F. 2015. Defining reintroduction success using IUCN criteria for threatened species: a demographic assessment. Animal Conservation 18:397-406.

Robertson HA, et al. 2017. Conservation status of New Zealand birds, 2016. Department of Conservation, Wellington, NZ.

Rogers A, Blanchard JL, Mumby PJ. 2017. Fisheries productivity under progressive coral reef degradation. Journal of Applied Ecology 55:1041-1565.

Romijn RL, Hartley S. 2016. Trends in lizard translocations in New Zealand between 1988 and 2013. New Zealand Journal of Zoology 43:191-210.

Rouco C, Villafuerte R, Castro F, Ferreras P. 2011. Effect of artificial warren size on a restocked European wild rabbit population. Animal Conservation 14:117-123.

Ruscoe WA, et al. 2011. Unexpected consequences of control: competitive vs. predator release in a four-species assemblage of invasive mammals. Ecology Letters 14:1035-1042. 
Saccheri I, Kuussaari M, Kankare M, Vikman P, Fortelius W, Hanski I. 1998. Inbreeding and extinction in a butterfly metapopulation. Nature 392:491-494.

Salo P, Korpimäki E, Banks PB, Nordström M, Dickman CR. 2007. Alien predators are more dangerous than native predators to prey populations. Proceedings of the Royal Society B: Biological Sciences 274:1237-1243.

Schlesinger CA, Shine R. 1994. Selection of diurnal retreat sites by the nocturnal gekkonid lizard Oedura lesueurii. Herpetologica 50:156-163.

Schneider CA, Rasband WS, Eliceiri KW. 2012. NIH Image to ImageJ: 25 years of image analysis. Nature Methods 9:671-675.

Schwarzkopf LIN, Barnes M, Goodman B. 2010. Belly up: reduced crevice accessibility as a cost of reproduction caused by increased girth in a rock-using lizard. Austral Ecology 35:82-86.

Seddon PJ. 1999. Persistence without intervention: assessing success in wildlife reintroductions. Trends in Ecology and Evolution 14:503.

Seddon PJ, Soorae PS, Launay F. 2005. Taxonomic bias in reintroduction projects. Animal Conservation 8:51-58.

Seddon PJ, Armstrong DP, Maloney RF. 2007. Developing the science of reintroduction biology. Conservation Biology 21:303-312.

Seddon PJ. 2010. From reintroduction to assisted colonization: moving along the conservation translocation spectrum. Restoration Ecology 18:796-802.

Shah B, Shine R, Hudson S, Kearney M. 2004. Experimental analysis of retreat-site selection by thick-tailed geckos Nephrurus milii. Austral Ecology 29:547-552.

Sherley GH, Stringer IAN, Parrish GR. 2010. Summary of native bat, reptile, amphibian and terrestrial invertebrate translocations in New Zealand. Department of Conservation, Wellington, New Zealand.

Shine R. 1980. "Costs" of reproduction in reptiles. Oecologia 46:92-100.

Sinclair ARE, Pech RP, Dickman CR, Hik D, Hamon P, Newsome AE. 1998. Predicting effects of predation on conservation of endangered prey. Conservation Biology 12:564-575.

Smith AP, Quin DG. 1996. Pattern and causes of extinction and decline in Australian conilurine rodents. Biological Conservation 77:243-267. 
Sowersby W, Thompson RM, Wong BBM. 2016. Invasive predator influences habitat preferences in a freshwater fish. Environmental Biology of Fishes 99:187-193.

Stanley MC. 1998. Homing in the skink, Oligosoma grande, within a fragmented habitat. Journal of Herpetology 32:461-464.

Stewart J, Blackburn D. 2015. Viviparity and placentation in lizards. Pages 448-563 in Rheubert J, Siegel D, and Trauth S, editors. Reproductive biology and phylogeny of lizards and tuatara. CRC Press, Taylor and Francis Group, Boca Raton, FL.

Stuart-Smith RD, Stuart-Smith JF, White RWG, Barmuta LA. 2007. The impact of an introduced predator on a threatened galaxiid fish is reduced by the availability of complex habitats. Freshwater Biology 52:1555-1563.

Sullivan BK, Nowak EM, Kwiatkowski MA. 2015. Problems with mitigation translocation of herpetofauna. Conservation Biology 29:12-18.

Sutherland WJ, et al. 2010. Standards for documenting and monitoring bird reintroduction projects. Conservation Letters 3:229-235.

Teixeira CP, de Azevedo CS, Mendl M, Cipreste CF, Young RJ. 2007. Revisiting translocation and reintroduction programmes: the importance of considering stress. Animal Behaviour 73:1-13.

Tokeshi M, Arakaki S. 2012. Habitat complexity in aquatic systems: fractals and beyond. Hydrobiologia 658:27-47.

Toscano BJ, Griffen BD. 2013. Predator size interacts with habitat structure to determine the allometric scaling of the functional response. Oikos 122:454-462.

Towns DR. 1991. Response of lizard assemblages in the Mercury Islands, New Zealand, to removal of an introduced rodent: the kiore (Rattus exulans). Journal of the Royal Society of New Zealand 21:119-136.

Towns DR, Daugherty CH. 1994. Patterns of range contractions and extinctions in the New Zealand herpetofauna following human colonisation. New Zealand Journal of Zoology 21:325-329.

Towns DR. 1994. The role of ecological restoration in the conservation of Whitaker's skink (Cyclodina whitakeri), a rare New Zealand lizard (Lacertilia: Scincidae). New Zealand Journal of Ecology 21:457-471. 
Towns DR. 1996. Changes in habitat use by lizards on a New Zealand island following removal of the introduced pacific rat Rattus exulans. Pacific Conservation Biology 2:286-292.

Towns DR, Ferreira SM. 2001. Conservation of New Zealand lizards (Lacertilia: Scincidae) by translocation of small populations. Biological Conservation 98:211-222.

Towns DR, Broome KG. 2003. From small Maria to massive Campbell: forty years of rat eradications from New Zealand islands. New Zealand Journal of Ecology 30:377398.

Towns DR, Hitchmough RA, Perrott J. 2016. Conservation of New Zealand lizards: A fauna not forgotten but undervalued? Pages 293-320 in Chapple DG, editor. New Zealand Lizards. Springer International, Victoria, AU.

Unity Technologies. 2016. Unity v5.5.5f1. Computer program, Unity Technologies, San Francisco, CA, USA.

Valutis LL, Marzluff JM. 1999. The appropriateness of puppet-rearing birds for reintroduction. Conservation Biology 13:584-591.

van Heezik Y, Maloney RF, Seddon PJ. 2009. Movements of translocated captive-bred and released Critically Endangered kakī (black stilts) Himantopus novaezelandiae and the value of long-term post-release monitoring. Oryx 43:639.

van Winkel D, Baling M, Hitchmough RA. 2018. Reptiles and amphibians of New Zealand: a field guide. Auckland University Press, Auckland, NZ.

Vié JC, Hilton-Taylor C, Stuart SN. 2009. Wildlife in a changing world - an analysis of the 2008 IUCN Red List of Threatened Species ${ }^{\mathrm{ru}}$ IUCN, Gland, Switzerland.

Wanless RM, Angel A, Cuthbert RJ, Hilton GM, Ryan PG. 2007. Can predation by invasive mice drive seabird extinctions? Biology Letters 3:241-244.

Warfe DM, Barmuta LA, Wotherspoon S. 2008. Quantifying habitat structure: surface convolution and living space for species in complex environments. Oikos 117:1764-1773. 
Watts C, Armstrong DP, Innes J, Thornburrow D. 2011. Dramatic increases in weta (Orthoptera) following mammal eradication on Maungatautari - evidence from pitfalls and tracking tunnels. New Zealand Journal of Ecology 35:0-0.

Webb JK, Shine R. 2000. Paving the way for habitat restoration: can artificial rocks restore degraded habitats of endangered reptiles? Biological Conservation 92:9399.

Wedding CJ. 2007. Aspects of the impact of mouse (Mus musculus) control on skinks in Auckland, New Zealand. Master of Science thesis. Massey University, Auckland, New Zealand.

Whitaker AH. 1973. Lizard populations on islands with and without Polynesian rats, Rattus exulans (Peale). Proceedings of the New Zealand Ecological Society 20:121-130.

White KL, Eason DK, Jamieson IG, Robertson BC. 2015. Evidence of inbreeding depression in the critically endangered parrot, the kakapo. Animal Conservation 18:341-347.

Whitlow WL, Rice NA, Sweeney C. 2003. Native species vulnerability to introduced predators: testing an inducible defense and a refuge from predation. Biological Invasions 5:23-31.

Wildlife Act 1953. New Zealand legislation.

Willis G. 2017. Addressing New Zealand's biodiversity challenge: A Regional Council thinkpiece on the future of biodiversity management in New Zealand. Wellington, NZ.

Wilmshurt JM, Anderson AJ, Higham TFG, Worthy TH. 2008. Dating the late prehistoric dispersal of Polynesians to New Zealand using the commensal Pacific rat Proceedings of the National Academy of Sciences 105:7676-7680.

Wolf CM, Griffith B, Reed C, Temple SA. 1996. Avian and mammalian translocations: update and reanalysis of 1987 survey data. Conservation Biology 10:1142-1154. Woolley CK, Hartley S, Hitchmough RA, Innes JG, van Heezik Y, Wilson DJ, Nelson NJ. 2019. Reviewing the past, present and potential lizard faunas of New Zealand cities. Landscape and Urban Planning 192:103647. 
Worthy TH. 2016. A review of the fossil record of New Zealand lizards. Pages 65-86 in Chapple DG, editor. New Zealand Lizards. Springer International, Victoria, AU. 


\section{Appendix 1. Scripts and user instructions for generating and measuring rock piles in Unity}

INTRODUCTION

These are instructions, and scripts, for using Unity (v5.5.5f1; Unity Technologies 2016) to generate and measure interstitial spaces in simulated rock piles. Appendix 2 contains an R script (R Core Team, 2016) which can be used to process the measurement data produced from Unity into informative data.

There are two C\# Unity scripts, Randomgen.cs and Rock_raycast.cs. In addition, the 'scene' in Unity must be built in a particular way, and rock models need to be built in a 3D modelling program (I used Blender; Blender Foundation 2016). From Unity, you get many files with the results of the simulations. These files are then read by an R script for the final analysis (Appendix 2).

You can think of what the program and analysis do as this:

- Simulates tipping a pile of rocks out and allowing them to settle naturally.

- Samples a 3D grid of points within the rock pile.

- For points that fall within gaps, measures the size of that gap in the X, Y, and Z dimensions from that point.

- Uses the measurements to assign each gap as a 'small' 'large' or 'optimal' gap.

The proportion of 'optimal' 'small' and 'large' gaps is the proportion of grid points that fall within holes which are optimal, too small, or too large. This means it is relative to the amount of space available, not the numbers of holes present. E.g. many tiny holes that make up the same amount of space as one 'optimal' hole will not disproportionately increase the 'small' score.

The data output from this method is a folder with multiple files. There are three files for each run, one for each ray cast direction (X, Y, and Z). The first three columns 
of each file are the $\mathrm{X}, \mathrm{Y}$, and $\mathrm{Z}$ co-ordinates of each 'hit' from the ray casts. The fourth column is a letter, $\mathrm{a}$ or $\mathrm{b}$, representing the direction of the ray cast (this allows the coordinates to be sorted in R). Each row is an individual 'hit' from a ray cast.

\section{USER GUIDE FOR SCRIPTS}

\section{Randomgen.cs}

The script Randomgen.cs generates the rock pile. The script works by choosing rocks from an array (designated by the user within Unity's GUI) and generating ('spawning') them above the ground of the scene. They are spawned randomly within a set zone and in multiple batches, one after another, which recreates the effect of tipping the rocks from a height onto the ground.

Things the user can set in Randomgen.cs

public static int numruns = 5;

Here you choose how many times to generate and measure a new rock pile (called a 'run').

public static int numrocks = 5000;

Here you choose the number of rocks to spawn for each rock pile.

public static float size = 3f;

Here you set the size of the zone in which the rocks will be spawned. This is a measure of the horizontal component of the zone; it represents a horizontal square. This number is actually one half of the length of the sides of the square. For example, setting this number to $3 f$ will give you a square with sides 6 Unity units long (Unity units are controlled by changing Physics settings in Unity).

public static float bottomrange $=2.0 \mathrm{f}$;

public static float toprange $=10.0 \mathrm{f}$; 
Here you set how far above the ground the rocks are spawned. bottomrange gives you the lowest point at which rocks are spawned and toprange gives you the highest point at which rocks are spawned. These are measured in Unity units. Rocks are generated at random positions within the zone designated by bottomrange, toprange, and size.

TextWriter $f=$ new StreamWriter (@"/Users/Shared/Unity/roc k_pile_generation/hit_locations/metadata.csv"');

Sets where the metadata is saved to. This is a complete file name, not a folder.

Rock_raycast.runrays (@"/Users/Shared/Unity/rock_pile_gene ration/hit_locations/hitlocations" + addzeros + runsdone);

This is a call to run the script Rock_raycast.cs. The part within the brackets is where all ray cast data will be saved. File names are generated by adding the number of each run as well as some zeros to make sure that each number has the same number of digits. Each direction $(\mathrm{X}, \mathrm{Y}, \mathrm{Z})$ of each run has its own file. A letter to distinguish which direction the file represents, as well as the file extension (.csv) is added in Rock_raycast.cs.

Rock_raycast.cs

The script Rock_raycast.cs makes ray casts to measure the rock piles. Rock_raycast.cs is actually called from within randomgen.cs, and a path is passed to Rock_raycast.cs during the call. This path is where the output will be stored. If you wish to change the location of the output from the ray casts, you need to change this in randomgen.cs.

In order to take measurements of the gaps in the pile, this script generates three groups of 'ray casts'; an X group, a Y group, and a Z group. Ray casts are like lasers that measure the location of everything that they intersect (they are unlike lasers in that they don't stop when they hit something - they keep going through and measure everything within a certain distance). The $\mathrm{X}, \mathrm{Y}$, and $\mathrm{Z}$ ray casts measure the gaps in three dimensions. 
Because the ray casts in Unity only log a 'hit' when they enter an object, and not when they exit it, the program also generates matching rays that start at the opposite side of the pile and run back towards the 'point of origin' of the rays. Effectively this is invisible to the user and it creates the effect of rays that measure both when entering and when exiting rocks.

The output is saved as a number of files, each representing one set of ray casts (X, Y or Z) from one run. Within the file the three columns represent $\mathrm{X}, \mathrm{Y}$ and $\mathrm{Z}$ coordinates. Each row is one hit location (where a ray cast intersected with the edge of a rock).

\section{Things the user can set in Rock_raycast.cs}

The points of origin of the ray casts in each group are arranged in a grid, and the location of the bottom left corner of the grid can be set in Rock_raycast.cs.

> Vector3 startpoint_x = new Vector3 $(30,0.1 f,-1)$;

Here you set the location (in Cartesian co-ordinates) of the bottom left corner of the grid for the origins of the ray casts that run along the $\mathrm{X}$ axis.

> Vector3 startpoint_y = new Vector3 $(-1,30,-1)$;

Here you set the location (in Cartesian co-ordinates) of the bottom left corner of the grid for the origins of the ray casts that run along the $\mathrm{Y}$ axis.

$>$ Vector3 startpoint_z = new Vector3 $(-1,0.1 f, 30)$

Here you set the location (in Cartesian co-ordinates) of the bottom left corner of the grid for the origins of the ray casts that run along the $\mathrm{Z}$ axis.

Next you set the number of rays for each group. You do this by setting the number of rays along each of the two axes of the grid of origins for each group.

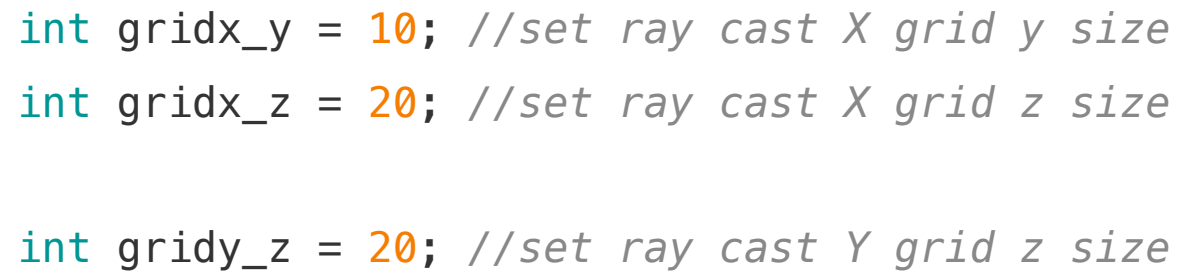




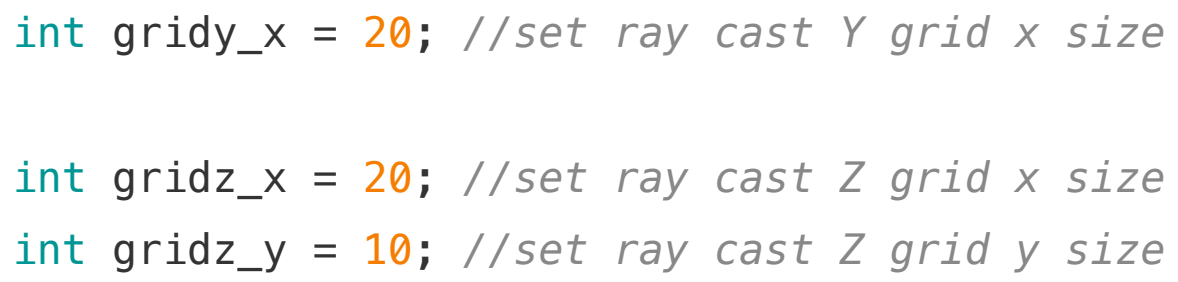

So when you set gridy_z $=20$ and gridy_x $=20$ you have 400 rays in the $\mathrm{Y}$ group.

Next you set the distance between the rays in the grids.

float sizeconvert $=0.5 f$

If you set sizeconvert to $0.5 f$ that means that the rays within each group are spaced 0.5 units apart. The units are whatever units are set to in Unity (default setting for this project should have the units as $0.1 \mathrm{~m}$, so with this setting the rays will be positioned $5 \mathrm{~cm}$ apart). The units in Unity are controlled according to the gravity setting in the physics menu (see above).

\section{USER GUIDE FOR UNITY}

Some Unity settings need to be changed.

- $\quad$ Physics - The physics setting can be used to control the size of a unit in Unity. When the gravity is set to -9.81 , one unit is one metre. Changing the gravity changes the units. For this project, set gravity to $y=-98.1$. This is 10 times normal gravity, which effectively means that the units in unity are $0.10 \mathrm{~m}(10$ $\mathrm{cm}$ ) instead of $1 \mathrm{~m}$. This makes it easier to deal with the rocks which are around 1 unit in size (instead of being around $1 / 10^{\text {th }}$ of a unit).

Edit $>$ project settings $>$ physics $>$ Gravity $\mathrm{Y}=-98.1$

Bounce threshold $=2$

Sleep threshold $=0.0005$

- $\quad$ Fixed timestep controls when physics calculations are performed. To prevent the rocks from acting strangely (shivering around) set fixed timestep to 0.002 .

Edit $>$ project settings $>$ time $>$ fixed timestep $=0.002$ 
Create a box collider that sits below ground level in the scene with its top surface at the level of the ground. Make sure that the box collider underneath is in 'ignore raycast' layer. Put a copy ground layer directly overlapping the top face of the box collider and allow this to be seen by the ray cast so that you don't miss gaps between the floor and the rocks. Make sure ray cast ignores the ground layer.

Make an empty object and add component Randomgen (Script). Set the 'size' in Randomgen (script) to the number of rocks you want in your array. When the program generates the rock pile it randomly chooses rocks from this array to spawn. The ratio of rocks in your array will approximate the ratio of rocks generated.

Put rocks as objects in the scene. These rocks will sit in the corner of the scene and not be part of the simulation. Their purpose is to be the array from which the program randomly chooses rocks to spawn. You just need one model rock for each size and shape you want to be included in the array. When you actually make the array, you can put the same size/shape of rock in multiple times to increase the proportion of rocks in the pile of that size/shape.

- Add your rock models into the scene as objects. Drag them to the corner of the scene so they won't be hit by the ray casts.

- Add a rigidbody to each rock. The rigidbody has settings that need to be specified. These are:

- Mass. Check the relative mass of the rocks. The mass should be relative to the size of the rocks. Absolute values aren't very important so long as the relative masses are correct. So if you have two types of rocks, and one is 5 times smaller than the other, it should have its mass set to $1 / 5^{\text {th }}$ of the larger rock's mass.

○ Drag -0

○ Angular drag - 0.05

○ Use gravity - ticked

- Is Kinematic - unticked

- Interpolate - none

- Collision detection - continuous dynamic 


\section{○ No constraints}

- If you're using rock models you made yourself (or those provided) they need mesh colliders. Otherwise you can use simple sphere or box colliders if you have sphere- or box-shaped models. Settings for the mesh collider:

○ Convex - ticked

○ Material - rock physic material. This is a physic material I made to make the rocks behave realistically. The settings are:

- Dynamic Friction - 0.5

- Static Friction - 0.5

- Bounciness - 0

- Friction Combine - 0

- Bounce Combine - Minimum

Drag the rocks from the hierarchy tab into the Randomgen (Script) array to populate it.

SCRIPT: RANDOMGEN.CS
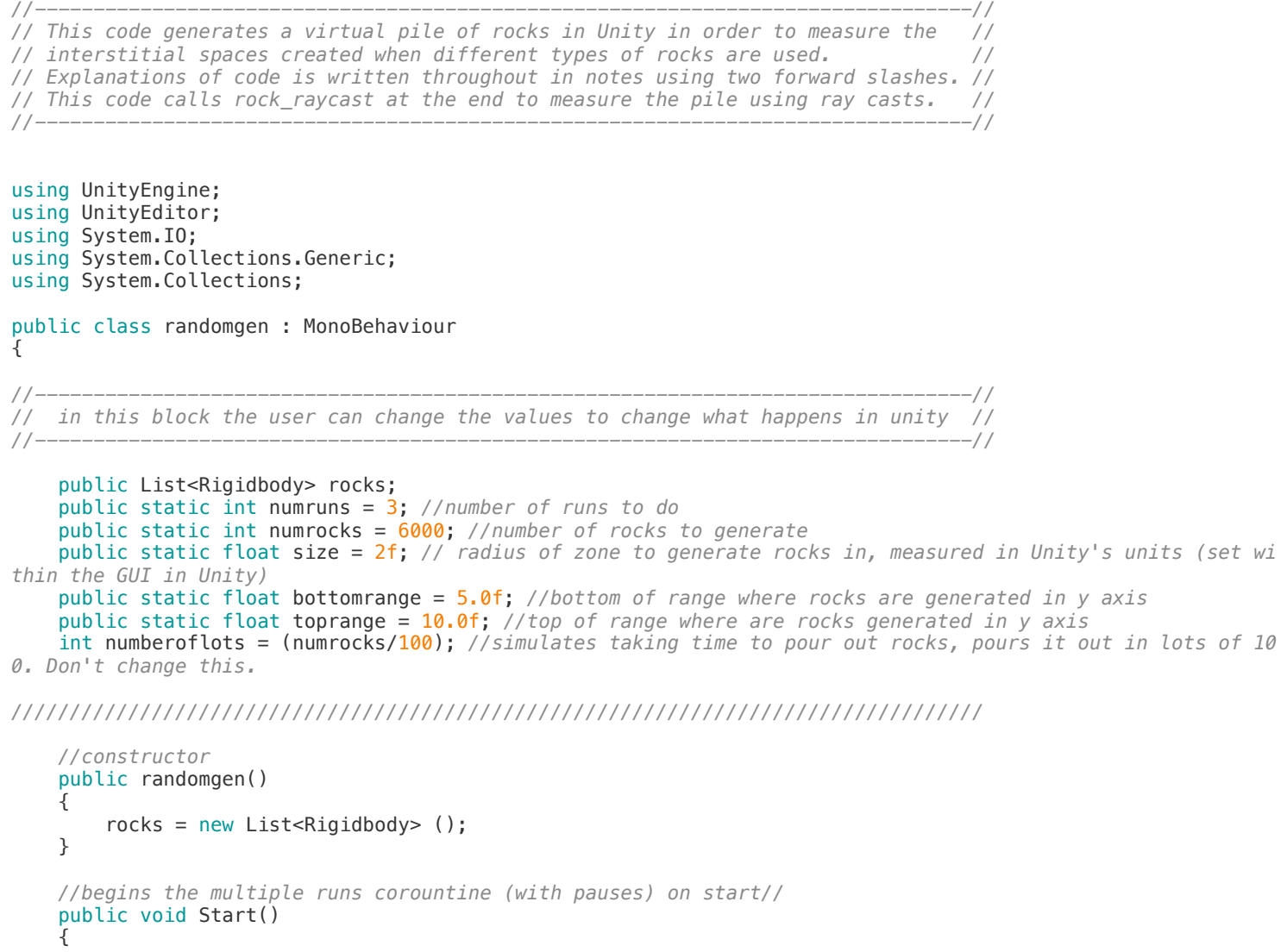
int rocksgenerated $=0$

int rocknumber $=0 ; / /$ number to name rocks

int lotsdone $=0$;

while (lotsdone < numberoflots)

int rockIndex $=$ Random. Range ( $\theta$, rocks. Count); //chose a random rock from the list Rigidbody rockinstance = Instantiate (rocks [rockIndex], new Vector3 (Random. Range ((size), size), Random.Range (bottomrange, toprange), Random.Range (-

(size), size)), Random. rotation)as Rigidbody;

rockinstance . name $=$ ("rockinstance" + rocknumber $) ; / /$ name the rocks so they can be found and

deleted later

\}

rocksgenerated++; //plus one rock generated rocknumber++

yield return new WaitForSeconds $(0.1 \mathrm{~F})$

rocksgenerated $=0$

public void metadata() //this section saves a file of metadata for the run.

//change the pathway to save the metadata to below

TextWriter $f=$ new StreamWriter (@"/Users/Shared/Unity/rock_pile_generation/hit_locations/metadata.c

sv");

f.WriteLine ("gravity" + "," + Physics.gravity.y)

f.Writeline ("fixed timestep" + "," + Time.fixedDeltaTime);

f.Writeline ("units (m)" + "," + 9.81 / Physics.gravity.y*-1)

f.Writeline ("number of rocks per pile" $+1,1+$ numrocks);

f.Writeline ("number of piles" $+1,1$ + numruns):

f.Writeline ("rocks in array for generation"):

f.Writeline ("rock \#" + ", " + "rock name" + " " + "x scale" + " " + "y scale" + " " + "z scale" + ", " + "mass" + ', + + "drag" + ', + "angular drag" + ', + + "dynamic friction" + "," + "static friction" + "," + "bounciness" + "," + "friction combine" + "," + "bounce combine");

for (int $i=0 ; i<$ rocks. Count; $i++)$ '

f.Writeline ("rock" $+i+1,1+$ rocks [i].name $+1, '+$ rocks [i].transform.lossyScale. $x+1,1+$

rocks[i].transform. lossyScale.y + ', ' + rocks[i].transform.lossyScale.z + "," + rocks [i].mass + "," + rock $s$ [i].drag + " " + rocks [i].angularDrag + " " + (rocks[i].GetComponent<Collider> ()). material.dynamicFrict ion + " " + (rocks [i].GetComponent<Collider> ()) material.staticFriction + " " + (rocks [i].GetComponent<Coll ider> (')). material. bounciness + "," + (rocks[i].GetComponent<Collider $>$ ()). material.frictionCombine $+"$ ", + ( rocks [i]. GetComponent<Collider $>$ ' ()) . material. bounceCombine);

//runs multiple runs

IEnumerator multipleruns()

int runsdone $=0$;

while (runsdone < numruns)

\{

metadata ():

StartCoroutine(droprocks ());

runsdone++;

rock pile

yield return new WaitForSeconds $((0.1 \mathrm{~F} *$ numberoflots +15$))$; //wait for 15 seconds after making

//little bit to add 0 s to the front of numbers so that they order correctly when reading into $R$ string addzeros = " $0 "$

if (runsdone $<10)\{$

\}

addzeros = "00";

else if (runsdone < 100)\{ addzeros = "0"

else\{

\}

addzeros = ""; //numbering gets messed up if you go over 999 runs.

//A call to rock_raycast.cs script. The path name is used in rock_raycast.cs as locations to sav e the output to.

rock_raycast.runrays (@"/Users/Shared/Unity/rock_pile_generation/hit_locations/hitlocations" + a ddzeros + runsdone);

for (int $i=0$; $i$ <umrocks; $i++) / /$ this for loop destroys the rocks to set up for the next run

Game0bject rock $=($ Game0bject $)$ Game0bject.Find ("rockinstance" $+\mathrm{i})$

if (rock) 


\} $\}$ \} $\quad$ G Game0bject.Destroy (rock);

\section{SCRIPT: ROCK_RAYCAST.CS}

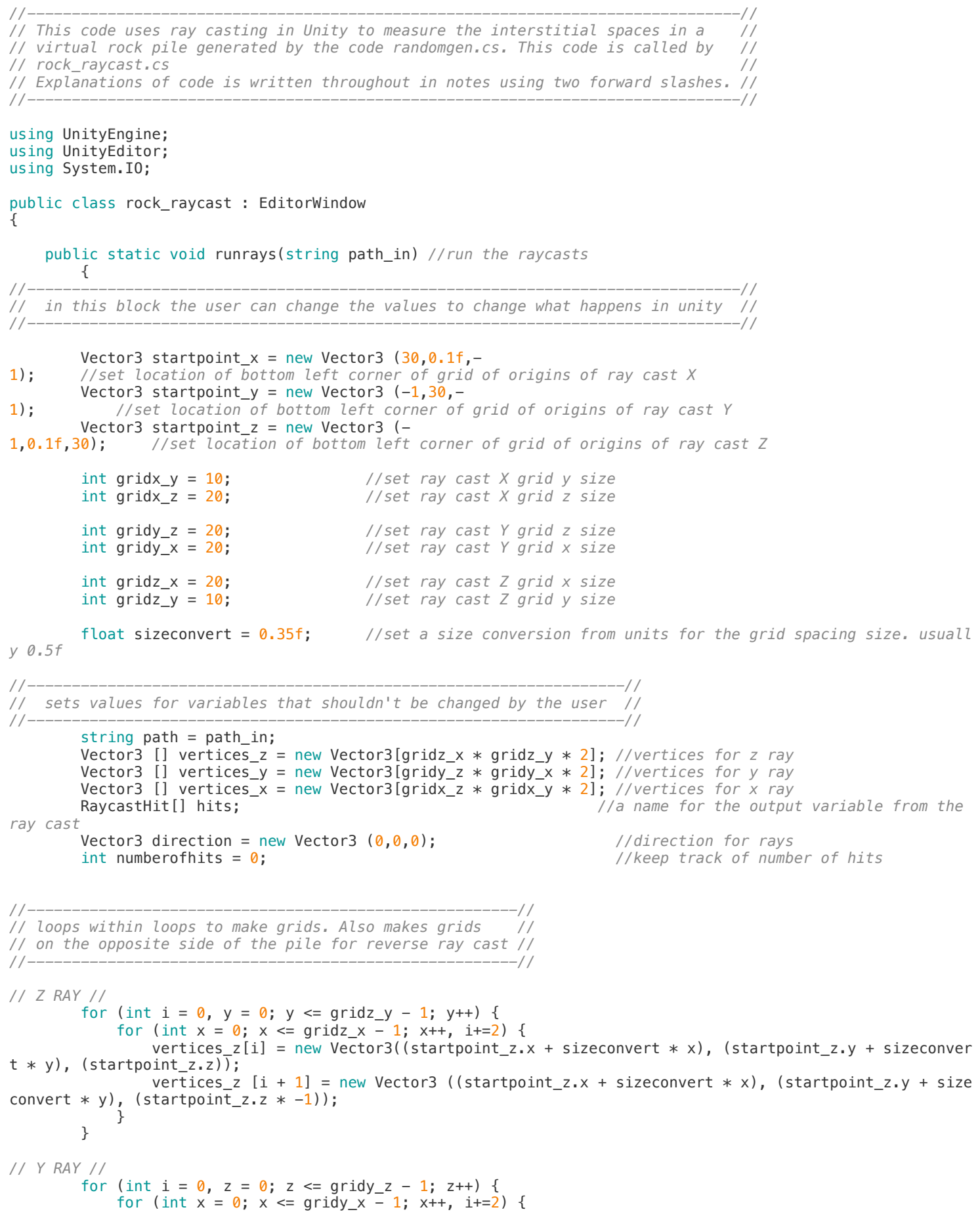




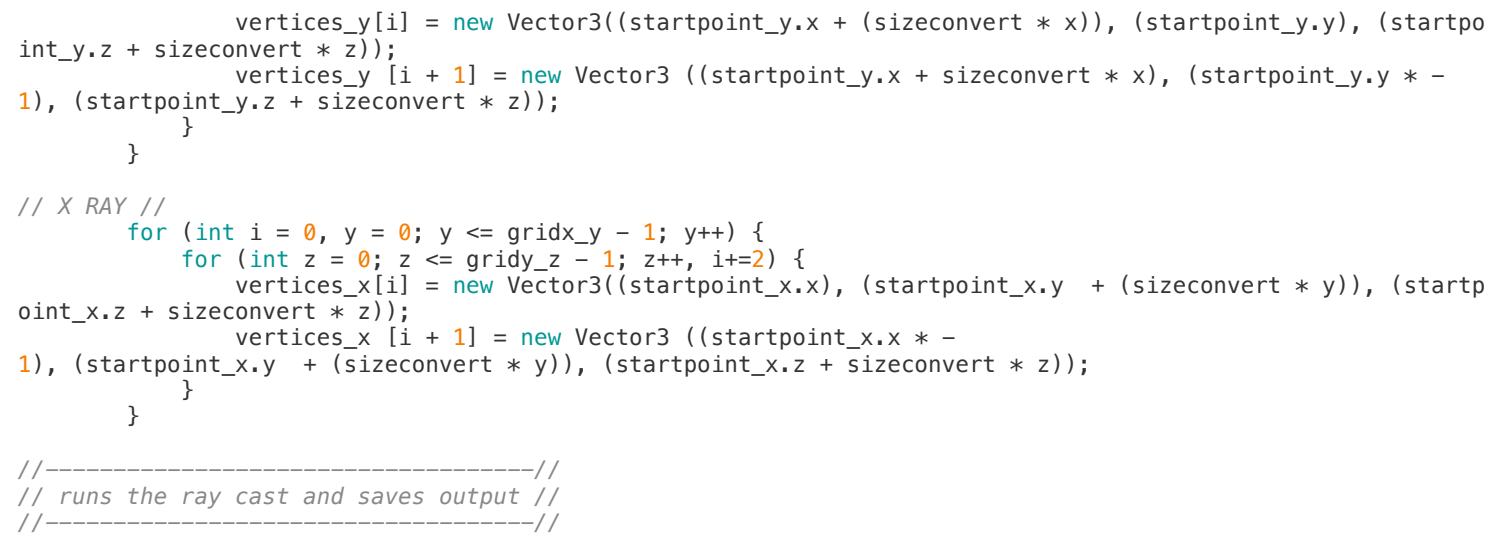

//first ray (Z RAY), static in $x$ and $y$ dimensions but varies in $z$ dimension//

TextWriter $\mathrm{fz}=$ new StreamWriter (path + 'z' + ".csv"); //to write my files to the path

char raysidez = new char(); //a character to indicate which side the ray came from to help in organi sing data later

for (int $i=0 ; i<=$ vertices z. Length $-1 ; i++$ ) \{

//this block sets the correct direction for the rays in the $z$ axis depending on ray origin

if (vertices_z[i].z>0) \{ direction $=$ new Vector3 $(0,0,-100)$;

\} raysidez $=$ ' $a$ ';

else \{

direction $=$ new Vector3 $(0,0,100)$;

\} raysidez $={ }^{\prime} b^{\prime}$;

Ray myRay = new Ray (vertices_z [i], direction); //make a ray called my ray al debugging Debug.DrawRay (myRay.origin, myRay.direction * 100, Color.red, 2.0f); //draw a red ray for visu

hits = Physics.Raycastall (myRay,100); //do the ray cast and give the output to 'hits'

foreach (RaycastHit hit in hits) \{ //run through all co-ords in 'hits' fz.Writeline (hit.point.x.ToString ("F5") + ", " + hit.point.y.ToString ("F5") + "," + hit.p oint.z.Tostring ("F5") + ', + raysidez ); // save worldspace co-ords \} numberofhits++ ; //increment number of hits saved to hitlocations.cvs

Debug.Log ("I saved " + numberofhits + " hit locations to " + path + 'z' + ". cSV");

fz.close (); //closes the text file, to stop writing more lines to the file

//second ray (Y RAY), static in $x$ and $z$ dimensions but varies in $y$ dimension//

TextWriter fy = new StreamWriter (path + "y" + ".csv"); //to write my files to the path

char raysidey = new char(); //a character to indicate which side the ray came from to help in organi sing data later

numberofhits $=0$;

for (int $\mathrm{i}=0$; $\mathrm{i}<=$ vertices_y. Length -1 ; $i++$ ) \{

//this block sets the correct direction for the rays in the $z$ axis depending on ray origin

if (vertices y [i].y $>0$ ) \{

direction $=$ new Vector3 $(0,-100,0)$;

\} raysidey $=$ ' $a$ ';

else \{

direction $=$ new Vector3 $(0,100,0)$; raysidey $={ }^{\prime} b$ ',

Ray myRay = new Ray (vertices_y [i], direction); //make a ray called my ray

Debug.DrawRay (myRay.origin, myRay.direction * 100, Color.yellow, 2.0f); //draw a yellow ray fo r visual debugging

hits = Physics. RaycastAll (myRay,100); //do the ray cast and give the output to 'hits'

foreach (RaycastHit hit in hits) \{ //run through all co-ords in 'hits'

fy.Writeline (hit.point.x.ToString ("F5") + ", " + hit.point.y.ToString ("F5") + "," + hit.p

oint.z.ToString ("F5") + ', + raysidey ); // save worldspace co-ords

numberofhits++ ; //increment number of hits saved to hitlocations.cvs
\}

\}

Debug.Log ("I saved " + numberofhits + " hit locations to " + path + "y" + ".csv");

fy.Close (); // closes the text file, to stop writing more lines to the file

//third ray ( $X$ RAY), static in $z$ and $y$ dimensions by varies in $x$ dimension//

TextWriter $\mathrm{fx}=$ new StreamWriter (path + "x" + ". csv"); //to write my files to the path sing data later

char raysidex $=$ new $\operatorname{char}() ; / /$ a character to indicate which side the ray came from to help in organi

numberofhits $=0$; 
for (int $i=0 ; i<=$ vertices_x. Length -1 ; $i++)\{$

//this block sets the correct direction for the rays in the $z$ axis depending on ray origin if (vertices_x[i].x>0) \{

direction $=$ new Vector3 $(-100,0,0)$;

else \{

raysidex $=$ ' $a$ ';

direction $=$ new Vector3 $(100,0,0)$;

\} raysidex $=$ ' $b$ ';

myay = new Ray (vertices $x$ [i], direction): //make a ray called my ray

Debug.DrawRay (myRay.origin, myRay.direction * 100, Color.blue, 2.0f); //draw a blue ray for vi sual debugging

hits = Physics. Raycastall (myRay,100); //do the ray cast and give the output to 'hits'

foreach (RaycastHit hit in hits) \{//run through all co-ords in 'hits'

fx.Writeline (hit.point.x.ToString ("F5") + ", " + hit.point.y.ToString ("F5") + "," + hit.p

oint.z.ToString ("F5") + "' + raysidex ); // save worldspace co-ords

numberofhits++ ; //increment number of hits saved to hitlocations.cvs

Debug.Log ("I saved " + numberofhits + " hit locations to " + path + "X" + ".csv");

.Close (); // closes the text file, to stop writing more lines to the file 
172 APPENDICES 


\section{Appendix 2. R script for processing gap size information from Unity}

This $\mathrm{R}$ code takes the data produced from the Unity simulation of rock piles (Appendix 1) and analyses it to produce useful data (proportions of gap sizes that are small, optimal, and large).

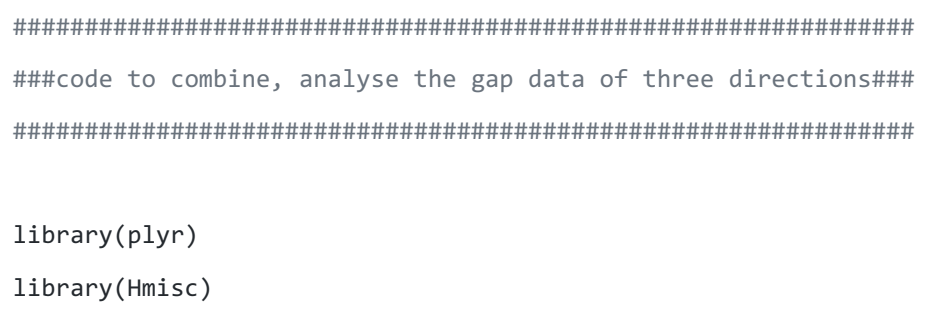




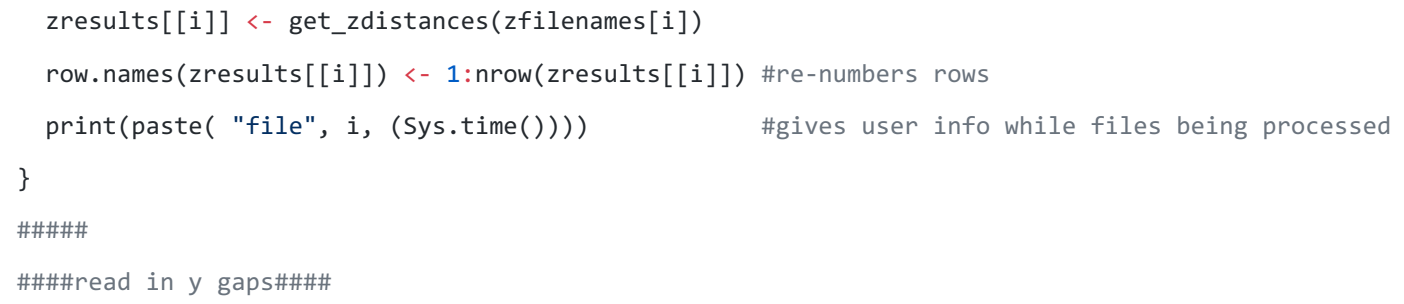


\#loop to get distances between hits (which is the size of the gaps).

$q=1$

for ( $i$ in $1:$ length(split_locations)) $\{$ \#goes through each ray

for $(j$ in $3:$ nrow(split_locations[[i]])) \{ \#within each ray, skipping number 1 (entrance to pile)

if $(j \% 2 \quad !=0)\{\quad$ \#gets only odd numbers

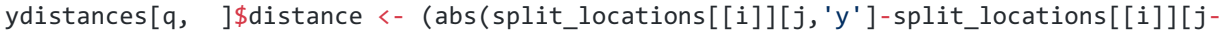

$\left.\left.\left.1, y^{\prime}\right]\right)\right)$ \#distance between entrance to a rock and previous exit from a rock

$\operatorname{ydistances}[q, \quad] \$ x \quad<-\operatorname{split} l o c a t i o n s[[i]][j, \quad$ ' $x ']$

$\operatorname{ydistances}[q, \quad] \$ z \quad<-\operatorname{split}$ locations $[[i]][j, \quad$ 'z']

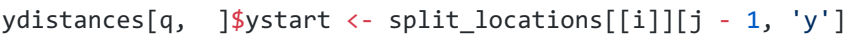

$\operatorname{ydistances}[q, \quad]$ \$yend $<-s p l i t \_l o c a t i o n s[[i]][j, \quad$ 'y']

$q<-(q+1)$

\}

\}

\}

return(ydistances)

\}

\#A loop to call the 'get_ydistances' function on each file of y ray cast co-ordinates.

yresults <- list() \#store output here

for ( $i$ in 1:length(yfilenames)) \{

yresults[[i]] <- get_ydistances(yfilenames[i])

row.names (yresults[[i]]) <- 1 :nrow(yresults[[i]])

print(paste( "file", i, (Sys.time())))

\}

\#\#\#\#\#

\#\#\#\#read in $x$ gaps\#\#\#\#

\#a function to pull out the distances between hits (size of gaps) in the $\mathrm{X}$ direction. The function is run on each $\mathrm{X}$ direction file.

get_xdistances <- function(filename) \{

xdistances $<-$ data.frame $($ distance $=$ numeric ()$, y=\operatorname{numeric}(), z=$ numeric ()$, x \operatorname{start}=$ numeric () , xend = numeric ()) \#store output here

hit_locations <- read.csv(filename, header = F) \#read in the hit data from the file to dataframe 'hit_locations'

colnames(hit_locations) <-c('x', 'y', 'z', 'direction') \#name columns

hit_locations $\$ z<-$ round(hit_locations $\$ z$, digits $=2$ ) \#rounding fixed co-ords because some are off by 0.00001 (an artefact from Unity)

hit_locations $\$ y<-$ round(hit_locations $\$ y$, digits $=2$ ) \#rounding fixed co-ords because some are off by 0.00001

hit_locations <- hit_locations[with(hit_locations, $\operatorname{order}(y, z, x)$ ), ] \#reorder by $y, z$, then $x$ 
\#all co-ords with same $z$ and $y$ represent a single ray. order them to figure out which bits are gaps

row.names(hit_locations) <- 1:nrow(hit_locations)

\#loop through, look for overlaps ( $a$ and b not alternating), mark them with ' $c$ ' for removal.

\#Tiny overlaps are an artefact from unity. Effectively the rocks are touching - so it can be treated as being no gap present (therefore remove the hits)

levels(hit_locations[,'direction']) <-c('a', 'b', 'c')

for (k in 2:(nrow(hit_locations) - 2)) \{

if ((hit_locations[k, 'direction'] == hit_locations[(k - 1), 'direction']) \& (hit_locations[(k

+1), 'direction'] == hit_locations $[(k+2)$, 'direction' $]))\{$

hit_locations[k, 'direction'] <- 'c'

hit_locations $[(k+1)$, 'direction']<- 'c'

\}

\}

hit_locations <- hit_locations[!hit_locations\$direction \%in\% c('c'), ] \#remove overlapping hits (treat them as touching)

row.names(hit_locations) <- 1:nrow(hit_locations) \#rename rows

\#split the locations so each ray is in its own group, can be accessed like: split_locations[[1]]

split_locations <- split(hit_locations, list(hit_locations\$y, hit_locations $\$ z)$ )

split_locations <- split_locations[sapply(split_locations, function(x) $\operatorname{dim}(x)[1])>1]$ \#only

dataframes largeger than 1

\#loop to get distances between hits (which is the size of the gaps).

$q=1$

for (i in 1:length(split_locations)) $\{$ \#goes through each ray

for(j in 3:nrow(split_locations[[i]]))\{ \#within each ray, skipping number 1 (entrance to pile)

if $(j \%$ 2 ! = 0$)\{$ \#gets only odd numbers

xdistances $[q, \quad]$ distance <- $($ abs(split_locations[[i]][j, 'x']-split_locations[[i]][j-1,

' $x$ '])) \#distance between entrance to a rock and previous exit from a rock

\begin{tabular}{|c|c|c|}
\hline xdistances $[q$, & ]$\$ y$ & <- split_locations[[i]][j, \\
\hline$x d i s t a n c e s[q$, & ]$\$ z$ & $<-$ split_locations $[[i]][j$, \\
\hline xdistances $[q$, & ]\$xstart & $<-$ split_locations $[[i]][j-1$, \\
\hline$x$ distances $[q$, & ]\$xend & $<-$ split_locations[[i]][j, \\
\hline
\end{tabular}

$q<-(q+1)$

\}

\}

\}

return(xdistances)

\}

xresults<-list() \#store output here 


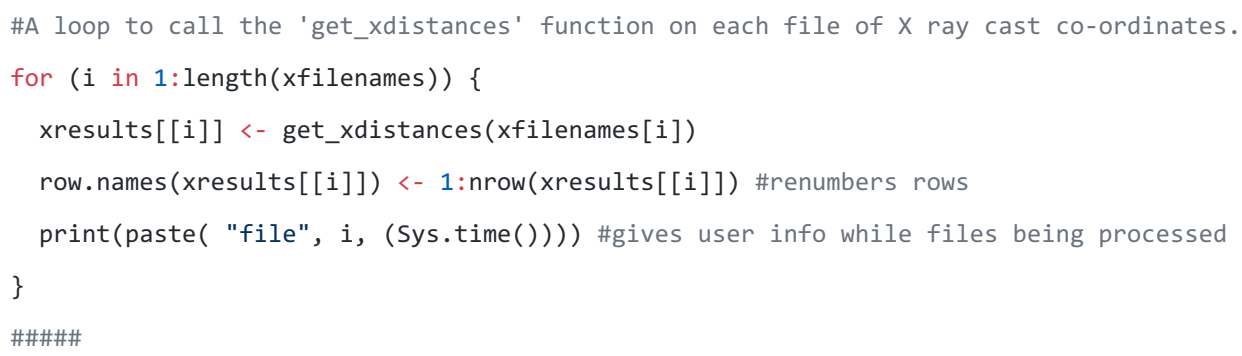




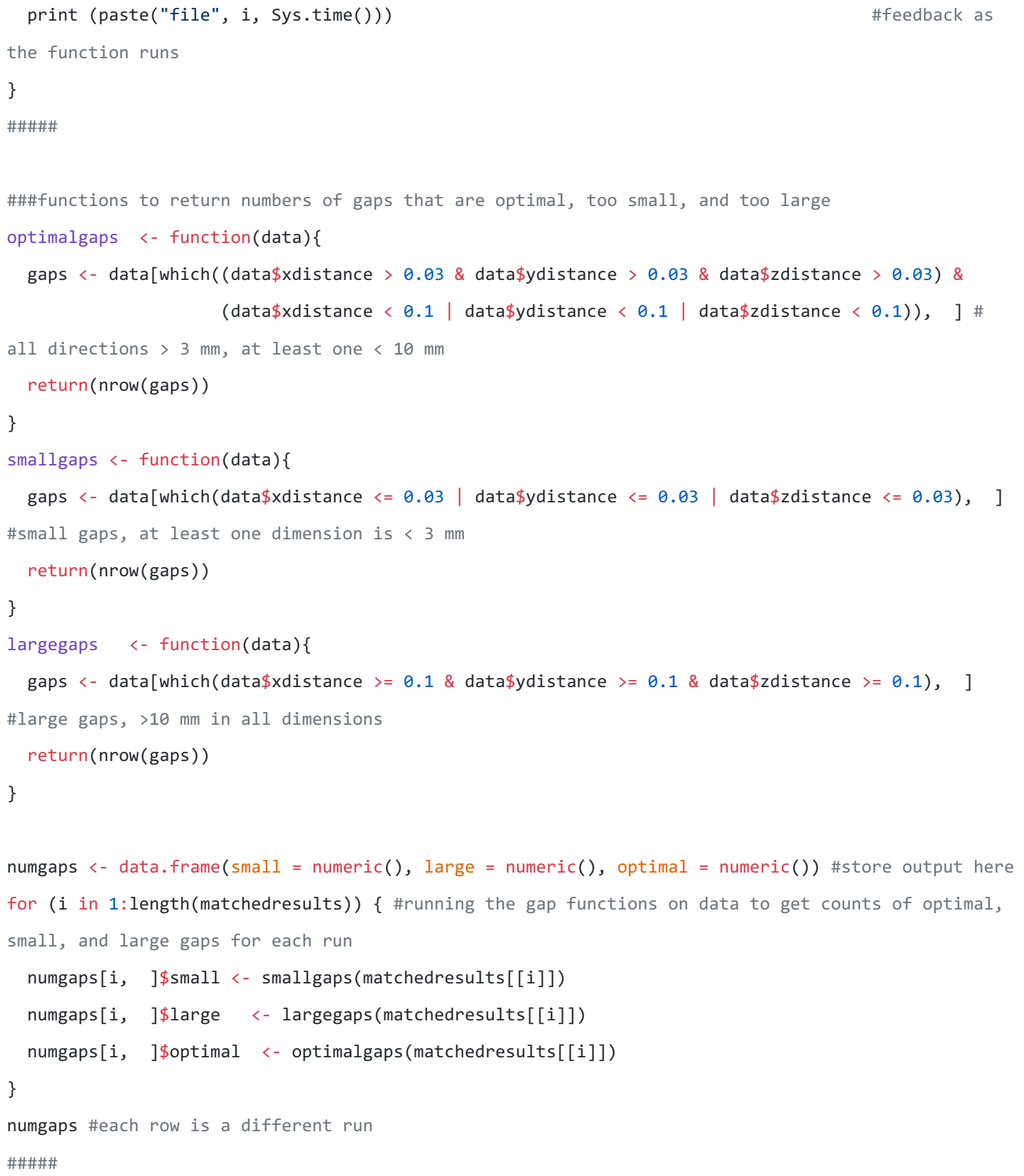

